\title{
XVIII. On the Genera of the Cossonidæ.
}

\section{By T. Vernon Wollaston, M.A., F.L.S.}

[Read 2nd June, 1873.]

Having determined during the past winter to examine critically the structural characters of the various genera of the Cossonidae (so far as accessible) which have hitherto been published, I soon perceived that a very small proportion of the numerous species which were submitted to me could by any possibility be embraced by the 29 groups which were acknowledged by Lacordaire, and which have been admitted subsequently (with two or threễ additions) into the Munich catalogue. And moreover the excessive inaccuracy of the greater number of the diagnoses, as given by Lacordaire. (-for which however he was not himself responsible, they having simply been epitomized, at times perhaps somewhat in haste, from the different authors by whom they were originally compiled), made it but too evident that, in order to define them aright, no asserted peculiarity could be trusted as necessarily true, but that every single feature would have to be collated afresh, and on an independent basis. This being the case, it will at once be seen that my object in the present memoir has not been to monograph the species; and therefore in two or three extensive and well-established genera, such as Cossonus and Rhyncolus, I have been content to select a few types, from distant parts of the world, and to treat them as representing their respective groups. Yet this very method of proceeding has involved the necessity of examining at any rate certain species with the utmost care; and as an accurate list of these will be found at the close of my paper, it follows that the members of the family which are there catalogued (amounting to 253) may be looked upon as arranged systematically in accordance with my own views.

At the same time I would not intend to imply that no other representatives of the groups which are more par-

TRANS. ENT. SOC. 1873.-PAR'T IV. (OCT.) 
ticularly extensive have been carefully overhauled,-for amongst the Cossoni, for instance, a very large number have passed under my eye ; but since I am not desirous of undertaking to determine critically their exact specific titles (which would be rather the work of a separate monograph), I have thought it safer to leave them unnoticed in my general list,-lest a possible misquotation of the names might result in confusion as regards the nomenclature.

To those Coleopterists who have granted me the loan of their specimens, in this somewhat difficult task, I would desire to return my warmest thanks. To Mr. Pascoe and Mr. Fry my acknowledgments are especially due,both of whom have, with characteristic liberality, placed their large and valuable Cossonideous collections at my entire disposal. It is indeed to the former that I am indebted for many of the most remarkable types which I have been thus enabled to examine,-his series including, in addition to some curious modifications from Australia, a large proportion of the species which were obtained by Mr. Wallace in the islands of the Malayan Archipelago; whilst the rich material of Mr. Fry in the number of its South-American forms stands probably unrivalled. To Mr. Janson also I must express my peculiar obligations, the whole of his examples having been generously entrusted to me without reserve; and my worthy friend John Gray, Esq., and Dr. Sharp have likewise afforded much valuable aid in communicating all the members of the family that they respectively possess. The former in fact owns the most complete set of European Cossonids with which I am acquainted; whilst the latter has contributed, amongst numerous other genera (many of which had been transmitted, lately, by Mr. Lawson, from New Zealand), the very rare and minute Alaocyba carinulata of Mediterranean latitudes. M. Roelofs, also, of Brussels, has had the kindness to send for inspection his unique type of the Georrhynchus Mortctii, from Monte Video; and I need not here allude again to the interesting material, amassed in Japan, of which Mr. G. Lewis has granted me the loan,--it having formed the subject for a separate enumeration in a late-Number of the Entomological Society's Transactions.

As regards the method of arrangement, it has been my endeavour to arrive, so far as is possible, at a natural one. Had I been content to adopt a purely artificial plan, the 
various generic characters might have been more easily, and completely, tabulated; but since in that case a considerable number of groups which I am satisfied have no real affinity with each other would have been brought into juxta-position, I have preferred to sacrifice even convenience in identification to the more important principle of a correct adjustment of the several types.* On this account it is, that while acknowledging the exact number of the funiculus-joints as of primary signification, I have not allowed it to over-ride (in a few exceptional instances) a combination of other features which more than counterbalance it in structural importance; and hence amongst the true Cossonides, in which that organ is essentially 7-articulate, I have admitted one genus (Tetracoptus) in which the funiculus is composed of four joints, two (Pentamimus and Tomolips) in which it is made-up of five, and one (Hexarthrum) in which it consists of six,for it would be simply preposterous to include the first of these amongst the Dryophthorides (with which in other respects it has absolutely nothing in common), and the second and third amongst the Pentarthrides, or to associate the fourth (which belongs to the sub-Hylastideous, asperated types) with the anomalous and more or less fossorial Onycholipides - in which the body is pallid and somewhat hairy, the tibial hook obsolete, and the tarsi strictly tetramerous. Moreover Lacordaire has himself acknowledged this principle by placing Hexarthrum in the same situation as I have done, namely towards the close of the subfamily Cossonides; and it is a method indeed which is acted upon, more or less, in nearly every department of the Coleoptera.

With respect to the singular cluster of forms which I have brought together under the Onycholipides, they might well be supposed, if viewed per se, to pertain to some totally distinct (and perhaps as yet undefined) family of the Rhynchophora; but they are nevertheless so unmistakeably connected on the one hand, by means of Halorhynchus and Pentatemnus, with the Pentarthrides, and on the

* Finding it next to impossible in the subfamily Cossonides to tabulate the characters of more than a small number of the very numerous genera (whilst, at the same time, adhering to what I believe to be the natural sequence of the latter), I have, instead, and as a slight assistance towards the identification, noted a few diagnostic features of each successive group; and, as a still further aid to the eye, I have cited the particular country to which the several genera are peculiar, or in which they more especially predominate. 
other, through Alaocyba, Lipommata, and Styphloderes, with the Cossonides proper, that it is well-nigh impossible to doubt (despite their subfossorial habits, 6-jointed funiculus, quadriarticulate feet, obsolete tibial hook, and other eccentricities) that the present family is their natural location.

Although dissenting from the views of Lacordaire, in recognizing no particular department which is characterized par excellence, like his Lymantides, by the shortness of the metasternum (for there is scarcely a single item of the structure which varies more, according to the exact genus, and sometimes even according to the species, than the latter), I have nevertheless not departed greatly from the method of arrangement which was adopted by him ; and if there could have been any doubt that the Dryophthorides constitute an integral portion of the family, it would be completely dispelled by the existence of such links as Charorrhinus and Pentacoptus (the former of which, indeed, although, like the latter, manifestly Pentarthrideous, has actually been cited hitherto, through an unpardonable error in its original diagnosis, as a Dryophthorid) and still more by that wonderful genus Synommatus, from Borneo, - the distinctive peculiarities of which are so evenly balanced between those of the Dryophthorides and Pentarthrides that it is by no means easy to decide into which of the two subfamilies it should be received.

There are six genera, however, of those hitherto published, which I have not been able to procure for examination; and these therefore (having convinced myself by experience that recorded characters are seldom completely to be trusted) I am compelled to leave in doubt,--merely placing their names between brackets (not altogether unaccompanied by a few remarks, gleaned from their respective diagnoses) in order to indicate the several positions which it seems to me not unlikely that they will be found to occupy. The genera to which I allude are as follows :I.ymantes (from North America), Aparoprion (from the south of Europe), Oodemas (from Tahiti), Mimus (from Southern Africa), Porthetes (likewise South-African), and Proëces (from Madagascar).

Of the twenty-nine groups acknowledged by Lacordaire, I have rejected Phanomerus,--being satisfied that it is not truly a member of the Cossonida. Its general facies and considerably developed prosternum bespeak, I cannot but think, a much nearer relationship with the Sphadas- 
mides and Mecopus; and although the breast is not channelled for the reception of the rostrum, some of the species nevertheless have a faint tendency for the slight pectoral cavity which is very appreciable in Sphadasmus, Mecopus, \&c., and which implies at all events an exceedingly different situation, in a natural system, to that which is occupied by the Cossonids. Moreover, the large and robust spine with which its intermediate tibiæ are furnished towards their external apex is quite without precedent in the present family, and I have had no hesitation therefore in expunging the genus from our list.

Glancing at the 122 genera embodied in this paper (75 of which have been treated as new), there are one or two points to which it may be worth while to draw attention. Thus, the only groups, outside the anomalous subfamilies Notiomimetides and Onycholipides, in which the tibial hook (that almost universal appendage) is obsolete, are Thaumastophasis, Aorus, Lipancylus, and Xenocnema (though in Homaloxenus it is greatly reduced in dimensions). And we might perhaps add Amorphocerus to the number, were it not that the tibir in that genus are eminently spinose at their apex; and it may be a question how far the largest of the terminal spines, although not proceeding from the outer angle, represents the tibial uncus. Another feature which might be noted, and which certainly is not in accordance with what I had originally imagined, is the excessive rarity of anything approaching to a dentate structure of the femora. The only group indeed, the truly Cossonideous affinities of which are beyond a question, in which it is, so far as I am aware, indicated, is Odontomesites; and even there the tooth is but obtuse and anguliform, and exists only in the male sex. It is however more strongly expressed in Notiomimetes, Coptorhamphus and Homaloxenus, -all of which, nevertheless, are, in other respects likewise, abnormal, their right of location in the present family being possibly open to dispute. The third peculiarity, concerning which I would say a few words, is more superficial, and yet, as a mere aid in the identification, it is practically of considerable importance : I refer to the extreme scarcity of metallic tints which is observable amongst the Cossonids. A brassy lustre, sometimes merging into green, is almost the only one of which I am cognizant, and even that is remarkably uncommon. It is conspicuous however (albeit subject to complete obliteration) in Lamprochrus and 
Acanthomerus, from St. Helena, in some of the Madeiran Caulotrupides, and in Oodemas, from the Sandwich Islands, - a genus which I have not been able to procure for inspection. We see it also, though much less powerfully indicated, in the Sericotrogus subøescens from New Zealand, and in certain of the Phloophagi,-as, for instance, the European $P$. reneopiceus; and it is about equally traceable in the Pseudophlœophagus tenax, of the Madeiran and Azorean archipelagos. Except in these particular instances I have no evidence of its existence; for in the Pachystylus dimidiatus, from Chili, as well as in two Pentarthra from the same region, it is so excessively faint as to be hardly even recognizable. But what I should regard as far more significant, in a systematic point of view, is the occasional obsoleteness, or even total absence, of the scutellum,-for in by far the greater number of the Cossonids that organ is (in proportion to their size) largely expressed. In the small subfamilies however of Notiomimetides and Dryopthorides, as well as in 13 genera of the Pentarthrides, 2 of the Onycholipides, and 10 of the true Cossonides (making 30 groups in all, out of the 122), it is either altogether untraceable, or else so far reduced in dimensions as to be detected with difficulty; and it will be seen by a reference to my tabular synopsis that I have made use of this fact in locating the particular types to which it applies.

The curious instability which is indicated amongst the representatives of the present family, in the exact number of the funiculus joints, is more than paralleled by the occasional obliteration (whether wholly or in part) of the organs of sight. The only member however of the true Cossonides in which the eyes, so far as I am aware, are absent, is the Lipommata calcaratum,-a pilose, Phloophagus-like Cossonid, of slightly burrowing propensities, which lives about the roots of sand-plants in the island of Porto Santo, of the Madeiran archipelago. But in the anomalous subfamily Onycholipides, no less than three genera (out of the four)-namely Onycholips, Raymondionymus, and Alaocyba-are totally blind; and the Australian Halorhynchus, which (although pertaining to the latter) is exactly osculant between the Onycholipides and Pentarthrides, is in a similar condition. And there are four other Pentarthrideous types-namely Pentatemnus, Pseudomesoxenus, Amaurorrhinus, and Heteropsis,-as well as the single exponent of the abnormal subfamily 
Notiomimetides, in which the visual organs are so far reduced in dimensions, and so rudimentary in character, as to be emphatically obsolete.

Into the question of the geographical distribution I need not now enter, for a glance at the systematic catalogue will suffice to shew approximately what the ranges are of the several types. It is curious however to note how large a proportion of the latter, which have hitherto been brought to light, possess insular habitats; and, if we except the great and almost cosmopolitan genus Cossonus, it would seem as if islands afforded conditions more peculiarly favourable for the modes of life of the members of the present family. And this completely accords with my own experience in the sub-African archipelagos, - no island appearing to be too minute for the modus vivendi of the Cossonids. In the Maderian and Canarian groups there is scarcely any fact more distinctly observable, - where every detached rock is tenanted by some one representative, or more, of this particular department. Nor are trees and shrubs (which seldom flourish in localities thus weather-beaten and exposed) by any means essential for their support,- the pithy stems of the ordinary plants being amply sufficient to sustain them; and I have frequently found the stalks of dead Thistles and Umbelliferce to be perforated through-and-through by their ravages. In our own country the Cossonids would seem to play a very insignificant part amongst the Coleopterous population, only nine members having hitherto been recorded; whereas at the Canaries (made ûp, as they are, of so many islands and islets) I have myself met with no less than fourteen, and at the Madeiras (which present a considerably smaller area) with nineteen; whilst even in the little island of St. Helena (the geographical base of which does not exceed that of the Isle of Wight) as many as fourteen have already been noted, and these I have good reason to suspect represent but an instalment of its whole Cossonideous fauna. The British members of our present family are as follows:-Pentarthrum Huttoni, Woll. (= Rhyncolus Hervei, Allard); Phloeophagus spadix, Hbst., and eneopiceus, Bohm.; Rhopalomesites Tardii, Curt.; Cossonus ferrugineus, Clairv.; Rhyncolus ater, Linn. (= chloropus, Fab.), cylindrirostris, Oliv. (= lignarius, Mshm.), and gracilis, Rosenh.; and Stereocorynes truncorum, Germ. 
I will merely add that in treating the subject-matter of the present memoir, it has divided itself into five parts :-

(1) A catalogue of the several groups-arranged systematically, and (so far as I have been able whilst adhering to what I believe to be their natural sequence) tabulated;

(2) full generic diagnoses, taken seriatim;

(3) observations (diagnostic and geographical) on each separate genus ;

(4) brief characters of 139 species which, so far as I am aware, have not hitherto been recorded; and

(5) a complete list of the particular members of the family (amounting, in all, to 253), the structural and specific features of which I have examined with the greatest care, and which may be regarded consequently as the material from which the paper has been compiled.

\section{Enumeratio generum Systematica. Fam. COSSONID AE.}

I. Funiculus 4-art........Notiomimetides.

(Corpus calvum, subnitidum; oculis obsoletis; coxis valde separatis; tibiis apice haud uncinatis ; tarsis pseudotetrameris.)

1. Notiomimetes

II. Funiculus 4-art. ...... Dryophthorides.

(Corpus aut lutosum aut subvelutinum, opacum, rariss. subnitidum; oculis distinctis, demissis, transversis; coxis, presertim anticis, minus separatis; tibiis apice uncinatis; tarsis conspicue 5-art.is.)
2. Psilodryophthorus ... $\quad . . \quad$.. $\quad$.. Nov. Guinea.

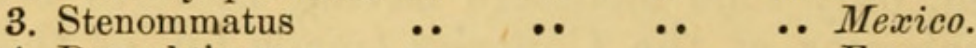
4. Dryophthorus $\quad$.. $\quad$.. $\quad$.. $\quad$.. Europa.
5. Tetratemnus .. $\quad \ldots \quad \ldots \quad \ldots \quad$.. ins. Japon.

III. Funiculus 5-art. ......Pentarthrides.

(Tibiis apice uncinatis; tarsis pseudotetrameris.)

a. Oculi distincti.

b. Corpus lutosum; scutello hàud, vel vix, observando.

6. Synommatus $\quad$.. $\quad$.. $\quad$.. $\quad$.. Borneo.

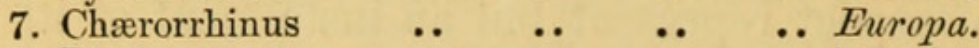

8. Pentacoptus .. $\quad \ldots \quad \ldots \quad \ldots \quad \ldots \quad$.. ins. Japon.

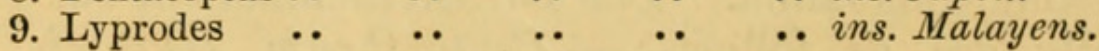

bb. Corpus (in Sericotrogo et Leptomimi parte exceptis) calvum; scutello conspicuo.

10. Phlœophagomorphus $\quad$.. $\quad$.. $\quad$.. Nov. Granada.

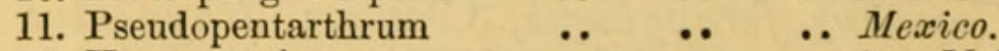

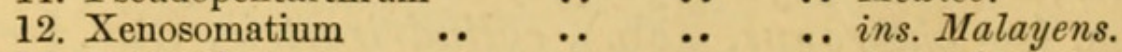

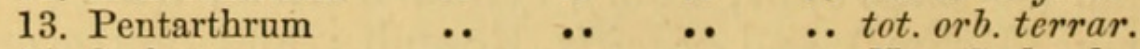

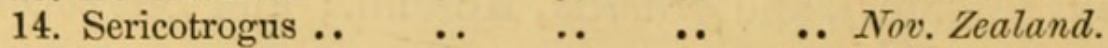

15. Stenotrupis $\quad . \quad \ldots \quad \ldots \quad \ldots \quad$.. $\quad$ ins. Malay., et Antilla. 


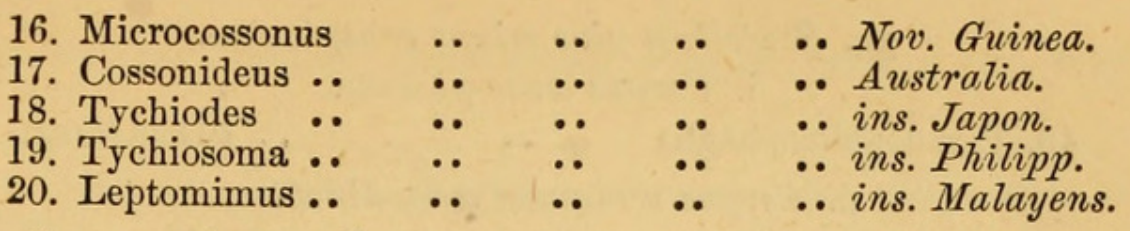

bbb. Corpus calvum, vel rarius minute pubescens; scutello obsoleto.

21. Lamprochrus

22. Acanthomerus

23. Microxylobius

24. Microtribus .

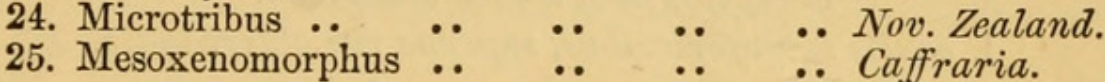

$\begin{array}{lllll}\text { morphus } & . & \text {.. } & \text {.. } & \text {.. Caffraria. }\end{array}$

aa. Oculi obsoleti.

c. Scutellum distinctum.

26. Heteropsis

cc. Scutellum obsoletum.

27. Amaurorrhinus

$\begin{array}{ccc}\ldots & \ldots & \ldots \\ \cdots & \ldots & \ldots\end{array}$

.. Nov. Zealand.

28. Pseudomesoxenus

29. Pentatemnus

aaa. Oculi nulli.

30. Halorhynchus

.. .. ..

.. St. Helena.

.. Id.

.. Id.

IV. Funiculus 6-art....... Onycholipides.

ins. Atlant., Europa.

.. St. Helena.

.. ins. Atlant.

.. Australia.

(Corpus pallidum, plus minus pilosum; metasterno brevi, interdum brevissimo; tibiis fossoriis, plus minus compressis ac ciliatis, apice haud uncinatis ; tarsis vere 4-articulatis.)

d. Oculi distincti.

31. Georrhynchus .. $\quad$.. .. .. Monte Video.

dd. Oculi nulli.

e. Rostrum breve, latum. Antenna brevissima. Scutellum distinctum. Unguiculi nulli.

32. Onycholips .. $\quad . . \quad$.. $\quad . . \quad$.. ins. Canariens.

ee. Rostrum longius, gracilius. Antenna longiores. Scutellum nullum. Unguiculi magni.

33. Raymondionymus .. $\quad$.. $\quad$.. $\quad$.. Europa.

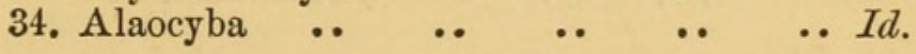

V. Funiculus 7 -art. ...... Cossonides.

In Tetracoptus (4-art.), in Pentamimus et Tomolips (5-art.), et in Hexarthrum (6-art.) exceptis.

(Tibiis apice uncinatis, raris inarmatis; tarsis pseudotetrameris.)

f. Oculi nulli.

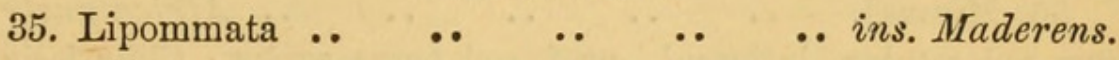

ff. Oculi distincti.

g. Scutellum aut nullum aut obsoletum.

h. Metasternum brevissimum.

36. Styphloderes.. $\quad$.. $\quad$.. $\quad$.. $\quad \ldots$ Europa, Afr. bor.

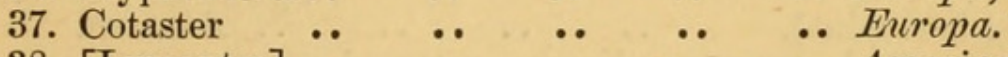

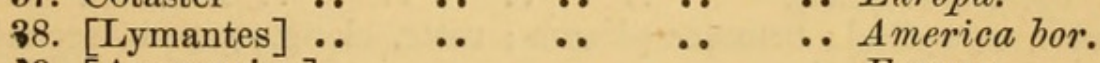

B9. [Aparoprion] $\quad$.. $\quad$.. $\quad$.. $\quad$.. Europa.

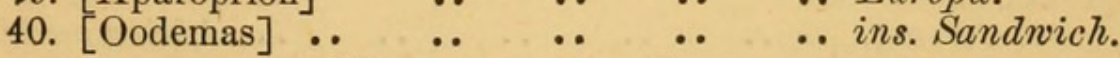

hh. Metasternum breve.

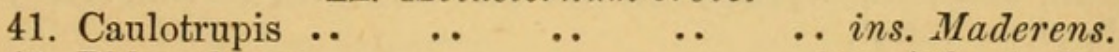

42. Phloophagus $\quad \ldots \quad \ldots \quad \quad \ldots \quad$ ins. Atlant., Europa. 
gg. Scutellum plus minus conspicuum.

i. Corpus aneo-piceum.

43. Pseudophlœophagus _.. .. ‥ ins. Atlant.

ii. Corpus nunquam aneo-tinctum.

k. unco tibiali obsoleto. (Oculi maximi.)

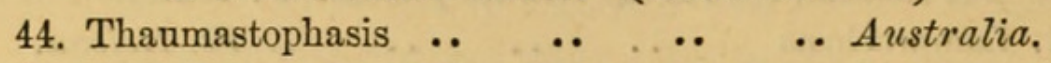

kk. unco tibiali (in Amorphocero, Lipancylo, Aoro, et Xenocnema exceptis) plus minus conspicuo.

1. oculis subinferioribris, superne vix observandis.

m. Corpus pubescens, piceum.

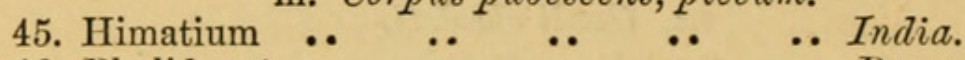

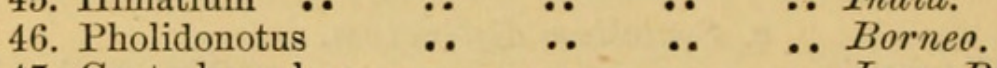

47. Coptorhamphus .... $\quad$.. $\quad$.. $\quad$.. Java, Borneo.

48. Aphanommata

11. oculis superne conspicuis (vel lateralibus, vel subapproximatis).

n. coxis anterioribus plus minus separatis.

o. scapo brevissimo. (rostro subtriangulari.)

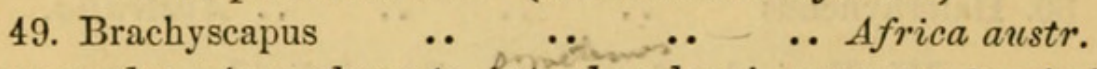
oo. scapo plus minus elongato, interdum brevi, nunquam brevissimo.

no (calvum, nitidum, sæpius atrum; rostr. interd. ante basin aut in medio subgibboso.

50. Phlœophagosoma)... $\quad$.. $\quad$.. $\quad$.. ins. Orient.

(setuloso-squamosum, angust., antice et postice acutum; oculis prominentibus.

51. Pholidoforus). $\quad$.. $\quad$.. $\quad$. $\quad$.. ins. Japon.

(lutosum, fusif.; elytris costatis, apice recte truncat.; rostr. antice subatten.; ocul. demiss.

52. Coprodema). $\quad$.. $\quad$.. $\quad$.. $\quad$.. ins. Japon.

(fere ut in Coprodema, sed magis parall.; elytr. apice integris ; tars. art. ${ }^{\circ}$ $3^{\text {tio }}$ bilobo.

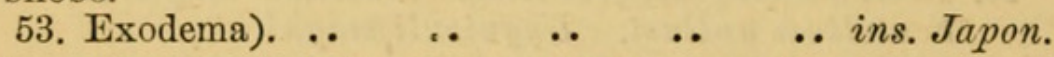

(sublutos., minutiss. sericat., opacum, densiss. sculpt., nigrum ; oculis valde prominent.

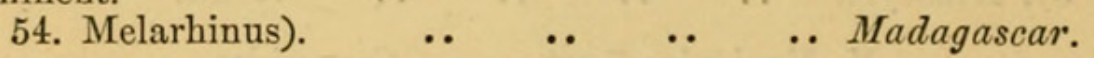

(calvum, fusif., opacum, dense punctat., nigrum ; rostr. crasso, cylindr.; elytr. sulcato-linèatis.

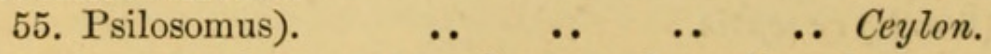

[calvum, dense sculpt.; rostr. robusto, subparall. sed post. subincrass.; elytr. sulcatis.

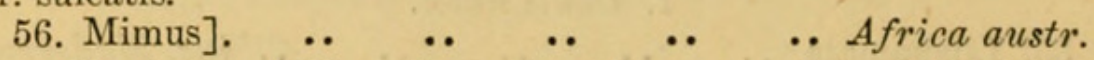

(calvum vel setulos., latiuscul., prof. sed parce sculpt.; tibiis latis, apice spinulosis.

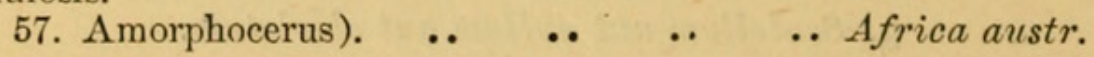

(subcalvum, nitid., nigrum ; rostr. elongat., gracill.; unco tib. obsol.; tars. art. ${ }^{\circ} 3^{\text {tio }}$ late bilobo,

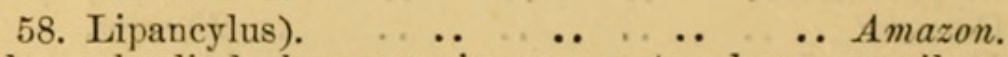

(subcalv., subcylind., brunneo-piceum ; rostr. elong., gracil., arcuat.; tib. asperat., unco obsol.

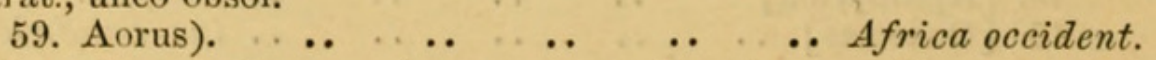

(sericat., subopac., depress., ferrug.; rostr. longiss., gracill., recto; anten. ad apicem insert.

60. Homaloxenus). . . 
(sericat., subopac., angust., pallid.; rostr. longiss., gracill.; tars. art.o $3^{\text {too }}$ late bilobo.

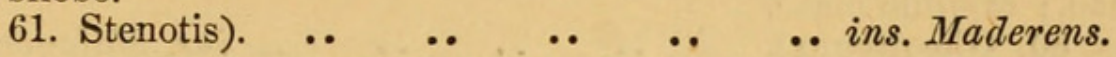

(parvum, subcalv., angust., depress., piceum; rostr. sec. sexum valde diverso.

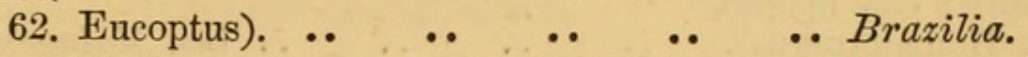

(calvum, cylindr., castaneum; antenn. et rostr. sec. sexum valde diversis.)

63. Mesites). .. $\quad$. $\quad$.. $\quad$. $\quad$.. Europa.

(fere ut in Mesites, sed sæpe sericat.; antenn. longiorib., capitul. majore ; tars. art. ${ }^{\circ} 3^{\text {tio }}$ bilobo.

64. Rhopalomesites). .. $\quad$.. Europa occident., ins. Atlant.

(magis fusif. ac depressius; in $\delta$ rostr. apice barbato et fem. subdentatis.

65. Odontomesites). $\quad . . \quad$.. $\quad . . \quad$.. ins. Atlant.

[setulos., depress., parall.; antenn. et rostr. sec. sexum divers.; tars. art. ${ }^{\circ}$ $3^{\text {tio }}$ bilobo.

66. Porthetes]. .. $\quad$. $\quad$.. $\quad$.. $\quad$.. Africa Austr.

(calvum, depress., nigrum; proth. brevi; anten. et rostr. sec. sexum diversis; capitulo max. ${ }^{\circ}$

67. Megalocorynus). $\quad$. $\quad$.. $\quad$.. $\quad$.. Mexico.

(angust., depress., sæpius piceum ; rostr. a fronte diviso, post. et ant. sublat.; tars. brev., crass.

68. Catolethrus). $\quad$.. $\quad$.. $\quad$.. $\quad$.. America.

(parv., angustiss., cylindr., nigrum ; rostr. a fronte diviso, parall.; proth. longiss.; tars. simpl.

69. Stenotribus)... $\quad$.. $\quad \ldots \quad$.. $\quad$.. Brazilia.

[fere ut Catoleth., sed parv.; rostr. gracil., parall.; funic. art. ${ }^{\circ}{ }^{\text {do }}$ sublong.; tars. simpl.

70. Proëces]. $\quad$. $\quad$.. $\quad$.. $\quad$.. $\quad$.. Madagascar.

(angust., piceum; rostro a fronte diviso, et, præsertim ant., lato; ped. crass; tars. brev., crass.

71. Phacegaster). $\quad$.. $\quad$.. $\quad$.. $\quad$.. Brazilia.

(fusif., politiss., fere esculpt., atrum sed rufo-varieg.; rostr. ant. dilatat.; tars. brev., crass.

72. Glœodema)... $\quad \ldots \quad \ldots \quad \ldots \quad \ldots$ Nov. Guinea.

(fusif., polit., leviter sculpt., atrum; rostr. lato, parall.; ped. crass., tib. ant. ad ap. int. longe spinosis.

73. Glœoxenus)... $\quad$.. $\quad \ldots \quad$. $\quad$.. Madagascar.

(cylindr., nitid., atrum sed rufo-varieg.; rostr. lato, in $\delta$ antice dilat.; tars. brev., crassis.

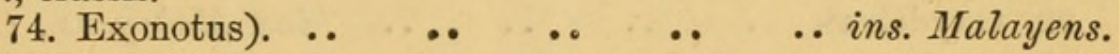

(nitid., antice levit. sculpt., atrum vel rufo-varieg.; rostr. in $\delta$ ant. sublat.; tars. brev., crass.

75. Pseudocossonus). . . $\quad \ldots . \quad \ldots \quad$.. ins. Orient.

(angust., parall., subdepress., rufo-castan.; proth. brevi; rostr. parall.; oculis prominent.

76. Catolethromorphus). ... ... .. India.

(subdepress., rufo-ferrug.; rostr. parall. ; funicul. brevi; capitulo magno; tarsis brev.

77. Brachychænus). $\quad$. $\quad$. $\quad$.. $\quad$.. Borneo.

(parv., august., parall., ferrug., sericat.; rostr. parall. ; scapo brevi ; oculis prominent.

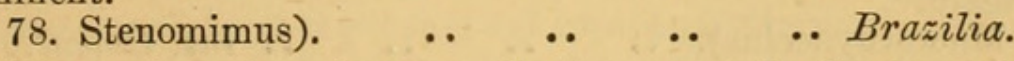

(subfusif., prof. sculpt., ferrug. vel nigrum; rostr. brevi, post. angust.; scapo brevi ; ocul. magn., demiss.

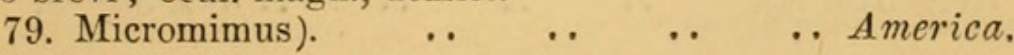


(politiss., depress., esculpt., piceo-ferrug.; capite exsert.; rostr. depress., subquad.; capitulo max ${ }^{\circ}$.

80. Glœotrogus). $\quad \ldots \quad \ldots \quad \ldots \quad \ldots \quad \ldots$ ins. Malayens.

(depress., leviss. sculpt., piceum et ferrug.; capite exsert., angust.; rostr. post. contr.; cap. magno.

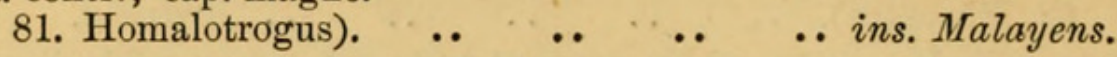

(depress., prof. sculpt., nigr. vel dilut.; capite exsert., subangust.; rostr. magis parall.; cap. magno.

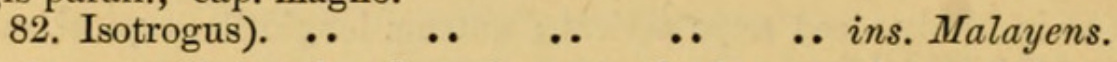

(fusif., depress., nigr. vel rufo-varieg.; proth. fere esculpt., sed in medio biseriatim punct. ${ }^{\circ}$

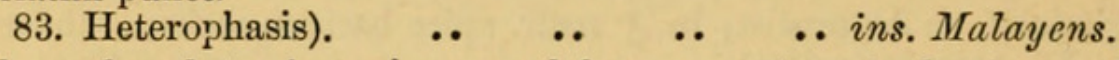

(parall., prof. sculpt., nigr., piceum, vel ferrug.; rostr. ant. pl. min. ampliat.; proth. post. impress.

84. Cossonus). $\quad$.. $\quad$. $\quad$.. $\quad$.. $\quad$.. fere tot. orb. terr.

(cylindr., opac., dense sculpt., minute pubesc., nigr.; rostr. brevi, lato, parall.; ocul. prom.

85. Hyponotus)... $\quad \ldots \quad$.. $\quad \ldots \quad$.. Singapore.

(parall., dense sculpt., nigr.; rostr. breviusc., latiusc., subparall.; oculis prominent.

86. Borophlœus). $\quad$. $\quad$. $\quad$. $\quad$. $\quad$.. Mexico.

(subcylindr., crass., grossiss. sculpt., atrum; cap. crass; rostri brevi, subtriang.; ocul. demiss.

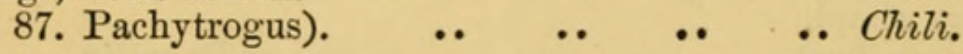

(parall.-fusif., crass., grosse sculpt., atrum; rostr. brevi; ped. crass.; tib. • ant. intus ampliat.

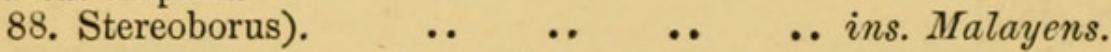

(fere ut Stereoboro, sed rostr. subtus apice barb., post. inciso, tubercul.; tib. ant. int. spinâ auctis.

89. Stereotribus). $\quad \ldots \quad$. $\quad \ldots \quad$. $\quad$ ins. Malayens., Ceylon.

(parall., nigr.; rostr. sublongior., basi angust., post. canalic.; tib. 4 post. calcari bipartitâ auct.

90. Stereomimetes). . . . $\quad \ldots \quad$.. $\quad$. $\quad \ldots$ Australia.

(cylindr., crass., levit. sculpt., nitidiss., atrum; rostr. breviss., latiss.; proth. elong.; tib. ut in Stereotribo.

91. Stereoderus). $\quad \ldots \quad \ldots \quad \ldots \quad \ldots \quad$ ins. Malayens., Fiji.

(angust., fusif., antice et post. attenuatum, nigr.; rostro subgrac., postice subangust.

92. Oxydema). .. ... ... ... . ins. Malayens., Ceylon.

(fere ut Oxydema, sed antice et post. minus attenuatum; rostr. post. minus angust.

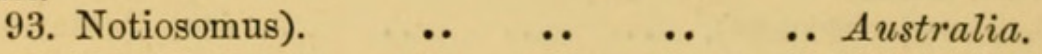

(fere ut Oxydema, sed depressius, post. minus atten.; rostr. parall.; capitul. angustiss.

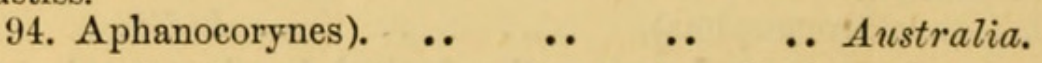

(angust., parall., depress., nigr.; proth. et elytr. basi rectiss. truncat., his apice recurvis.

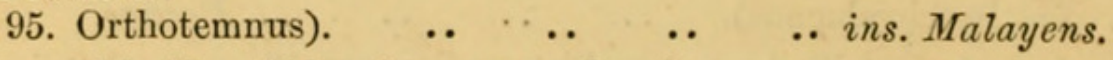

(angust., subfusif., nitid., nigr.; rostr. breviusc., robust., subparall.; ped. brev., crassiusc.

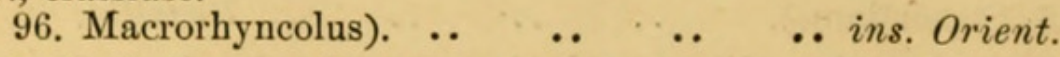

(angust., fusif., ferrug.-pictum; rostr. ant. sublat.; ped. et tarsis elongatis.

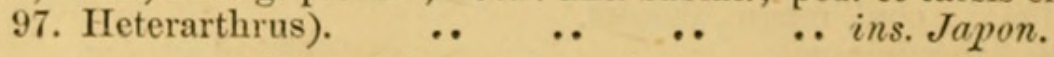


(angust., cylindr., parall., nigr.; cap. et rostr. crass., latis; ped. crass.; tars. art. ${ }^{\circ}$ ult. ${ }^{\text {mo }}$ conico.

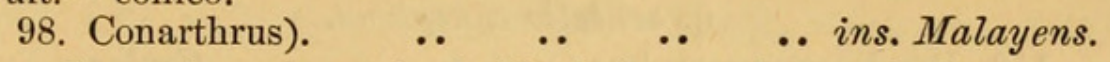

(fere ut Conarth., sed magis fusif., levius sculpt., rufo-ferrug.; rostr. minus lat.; tars. art. $^{\circ}$ ult. ${ }^{\circ}$ m. con. ${ }^{\circ}$

99. Eutornus). .. $\quad \ldots \quad \quad \ldots \quad \ldots \quad$.. ins. Orient.

(parv., parell., rufo-piceum; ocul. max., prom.; rostr. brev., lat. arcuat.; anten. vers. basin insert.

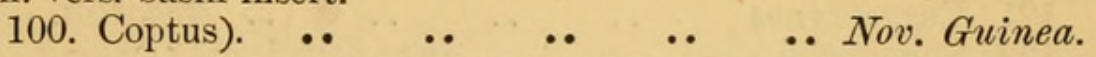

(angust., cylindr., nigr.; cap. crass.; rostr. brev., lato, arcuat.; capitulo magn., abrupto.

101. Pachyops)... $\quad$.. $\quad$. $\quad$.. $\quad$. Borneo.

(fere ut Pachyops, sed funic. 5-art. ${ }^{\circ}$; capitulo minore; scutell. minus transverso.

102. Pentamimus). $\quad$. $\quad$.. $\quad$.. $\quad$.. Australia.

(parv., angust., cylindr., nigr.; cap. crass.; rostr. breviss., latiss.; funic. 4 - $^{\text {art. }}{ }^{\circ}$; capit. $^{\circ} \max$.

103. Tetracoptus). $\quad \ldots \quad \quad \ldots \quad \quad \ldots \quad$.. Nov. Guinea.

(angust., fusif.-cylindr., nitid., antice lev. sculpt., atrum ; rostr. brev., latiss.; tars. art. ${ }^{\text {tio }}$ angust.

104. Xestoderma). $\quad \ldots \quad \ldots \quad \ldots \quad \ldots \quad \ldots$ ins. Malayens.

(fere ut Xestoderma, sed rostr. ant. late canalic.; scapo longiore ; capit. $^{\circ}$ max., nigresc., velutino.

105. Xestosoma). $\quad$. $\quad \ldots \quad \ldots \quad \ldots \quad \ldots$ ins. Malayens.

(oblong., latiusc., nigr.; rostr. breviss., latiss, post. in medio polito ; elytr. post. asperatis.

106. Lissopsis). .. $\quad$.. $\quad$.. $\quad$.. $\quad$.. Nov. Guinea.

(subcylindr., vix calv., brunn.-nigr.; rostr. breviss., canalic.; scapo elong., capit. ${ }^{\circ}$ magn., abrupt.

107. Sphærocorynes). $\quad \ldots \quad \ldots \quad \ldots \quad$.. $\quad$ ins. Japon.

(fusif., nitid., lev. sculpt., atr.; rostr. longuisc., minus crass., post. angust.; scapo elong.; cap. ${ }^{\circ}$ abrupt.

108. Xenotrupis). $\quad$.. $\quad$.. $\quad$.. $\quad$.. ins. Malayens.

(fusif., ant. subopac. post. subnit., nigr.; proth. magn.; rostr. longiusc.; ocul. prom.; scap. recto, crass.

109. Pachystylus). $\quad$.. $\quad$.. $\quad$.. $\quad$.. Chili.

(elong., angust., cylindr., nigr.; elytr. post. subpubesc., asperat. et subdivaric.; rostr. breviss., recto.

110. Xenomimetes). $\quad$. $\quad \ldots \quad \quad \ldots \quad$.. ins. Japon.

(cylindr., prof. sculpt., nigr.; rostr. breviss., latiss.; ocul. prom.; ant. crass.; funic. art. ${ }^{\circ} 2^{\text {do }}$ breviss.

111. Eremotes)... $\quad$.. $\quad$. $\quad$.. Europa, ins. Canariens.

(subovat.-cylindr., nigr. vel piceum ; antennis subcrass.; capitulo angusto.

112. Rhyncolus). $\quad . . \quad \ldots \quad \ldots$.. fere tot. orb. terr.

(cylindr., piceus ; antenn. minus incrass.; capit. ${ }^{\circ}$ majore; ocul. magn., haud late sep.

113. Caulophilus). $\quad \ldots \quad$. $\quad \ldots \quad$.. $\quad \ldots$ ins. Maderens.

(oblong., depress., piceo-ferrug.; elytr. costat. ; tib. ext. spinos., unco obsol. 114. Xenocnema). $\quad$.. $\quad$.. $\quad$.. $\quad$.. Nov. Zealand.

nn. coxis anterioribus vel fere vel omnino contiguis. (oculi demissi.)

p. rostro brevi, triangulari-cylindrico.

115. Stereocorynes $\quad$. $\quad$. $\quad$.. $\quad$.. Europa.

116. Hexarthrum $\quad \ldots \quad \quad \ldots \quad$ ins. Japon., Madera, Europa.

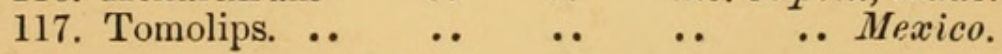


pp. rostro brevissimo, lato, crasso, triangulari. (caput crassum.)

q. scutello conspicuo.

118. Dendroctonomorphus $\quad$.. $\quad$.. $\quad$.. Ceylon.

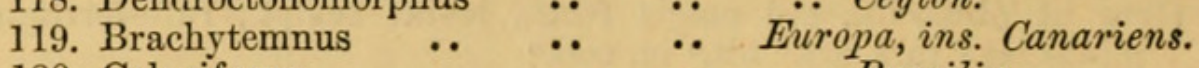

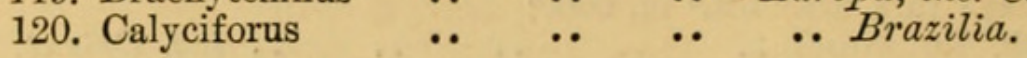

qq. scutello agre observando.

121. Eurycorynes $\quad$.. $\quad$.. $\quad$.. $\quad$.. Brazilia.

122. Stenoscelis .. $\quad \ldots \quad$.. ins. Japoñ., St. Helena, Africa.

\section{Ordo C OLE P TER A.}

Sectio RhynchopHora.

Fam. Cossonida.

I. Funiculus 4-art. ..... Subfam. Notiomimetides.

(Corpus calvum, subnitidum; oculis obsoletis; coxis valde separatis ; tibiis apice haud uncinatis ; tarsis pseudotetrameris.)

1. Corpus minutum, breviter fusiforme, parum grosse sculpturatum, piceum, subtus deplanatum; rostro subgracili, parallelo, arcuato, supra subgibboso, oculis minutissimis, obsoletis, ægerrime observandis, et lentibus perpaucis (ut in Amaurorrhino et Pentatemno) compositis; capite in prothorace profunde immerso, hôc elongato-subquadrato; longe pone apicem valde transversim constricto ; elytris haud costatis, versus apicem regulariter attenuatis (nec cariniformibus); metasterno longiusculo; abdominis segm. ${ }^{\text {tis }} 1^{\text {mo }}$ et $2^{\text {do }}$ inter se arcte connatis. Antennæ subgraciles, mox ante medium rostri insertæ; scapo longe ante apicem subito elongate clavato; funiculi (4-articulati, laxi) art. ${ }^{\circ}{ }^{\text {do }}$ sequentibus sensim longiore ; capitulo magno, abrupto, ovali. Pedes longiusculi, antici ad basin late, intermedii etiam multo latius, et postici latissime separati; femoribus subtus denticulo subobsoleto armatis; tarsis brevissimis, latis, crassis, art. ${ }^{\text {is }} 1^{\text {mo }}$ et $2^{\text {do }}$ brevibus et (præsertim hôc) transversis, $3^{\text {tio }}$ latiore et profunde bilobo (lobis tamen haud divaricatis) ult. ${ }^{\text {mo }}$ brevi, inter lobos tertii fere abscondito et unguiculis maximis, subparallelis armato.

Hab. Australiam meridionalem (juxta mare captus).Notiomimetes. 
II. Funiculus 4-art. . . . . Subfam. Dryophthorides.

(Corpus aut lutosum aut subvelutinum, opacum, rariss. subnitidum; oculis distinctis, tamen demissis, transversis; coxis, prasertim anticis, minus separatis; tibiis apice uncinatis; tarsis conspicue 5-articulatis, i. e. art. $^{\circ} 4^{\text {to }}$ distincto.)

2. Corpus fusiformi-ellipticum, grosse arguteque sculpturatum, subnitidum et fere calvum (punctis solum hine inde lutoso-repletis); rostro crasso, cylindrico, parallelo, oculis transversis, demissis; prothorace (postice elytrorum latitudine) magno, cylindrico-subquadrato, æquali (sc. antice vix constricto et haud impresso); elytris ellipticis, basi late arcuatim emarginato-truncatis, costatis, apice simplicibus (nec cariniformibus); metasterno longiusculo. Antennæ breviusculæ, crassiusculæ, pone medium rostri insertæ : funiculi (4-articulati, compacti) art. $^{\circ} 2^{\text {do }}$ sequentibus haud longiore; capitulo magno, ovali. Pedes antici ad basin parum separati, posteriores (præsertim postici) magis, sed haud valde, distantes; tibiis, præcipue versus apicem, gracilibus; tarsis gracillimis, filiformibus, art. ${ }^{\circ} 3^{\text {tio }}$ angusto, simplici, unguiculis minutissimis.

(Inter Dryophthorides valde anomalum corpore fere calvo, sc. punctis solum hinc inde lutoso-repletis, ac subnitido, nec opaco; prothorace magno, postice elytrorum latitudine, et æquali, nec antice constricto et impresso; elytris basi late emarginato-truncatis, humeris subporrectis, necnon ad apicem simplicibus, nullo modo cariniformibus.)

Hab. Nov. Guinea (ad Saylee deprehensus).-

Psilodryophthorus.

3. Corpus ellipticum, aut breviter fusiforme, grosse sculpturatum, dense sericato-velutinum; rostro elongato, gracili, arcuato, parallelo, ad apicem polito calvo et haud sculpturato; oculis angustissimis, valde transversis, demissis, subtus fere contiguis; prothorace (elytris paulo angustiore) antice constricto ; elytris costatis, postice attenuatis sed haud cariniformibus (tamen costâ $2^{\text {dâ }}$ a suturâ postice gradatim paulo magis prominente); metasterno breviusculo. Antennæ longiusculæ, longe pone medium rostri insertæ; scapo elongato; funiculi (4-articulati, compacti) art. ${ }^{\circ} 2^{\mathrm{do}}$ sequentibus paulo longiore; capitulo magno, elongato. Pedes longiusculi, subgraciles, velutini, antici ad basin parum, intermidii multo latius, et postici 
fere latissime separati; tibiis gracilibus; tarsis gracillimis, filiformibus, art. ${ }^{\circ} 3^{\text {tio }}$ angusto, simplici, unguiculis minutissimis.

(A Dryophthoro distinctum corpore minore, etiam magis elliptico, et dense velutino, nec lutoso; rostro multo longiore, graciliore, magis arcuato, et magis parallelo; oculis multo angustioribus ac magis transversis, sc. subtus etiam fere contiguis; elytris apice magis attenuatis et haud cariniformibus, sed tamen costâ $2^{\text {dầ }}$, nec $4^{\text {tâ }}$, postice paulo exstanti; antennis longioribus, scapo præcipue longiore; metasterno sub-breviore; coxisque omnibus, sed præsertim posterioribus, magis separatis.)

Hab. Americam borealem (in Mexico degens).-

Stenommatus.

4. Corpus fusiforme, grosissime sculpturatum, plus minus lutosum, necnon (oculo fortissime armato) minutissime, brevissime, parcissimeque setulosum; rostro robusto, parallelo sed mox ante antennarum insertionem paululum ampliato, valde rugoso; oculis transversis, demissis; prothorace (elytris angustiore) antice profunde constricto ; elytris costatis, utrinque versus apicem cariniformibus (sc. costâ, circa $4^{\text {tâ }}$ a suturâ, in carinam postice currente); metasterno longiusculo. Antennæ breviusculæ, crassiusculæ, calvæ, pone medium rostri insertæ; funiculi (4-articulati, compacti) art. $^{\circ} 2^{\text {do }}$ sequentibus vix longiore ; capitulo magno, ovali, solido, ad apicem ipsum velutinopubescenti. Pedes longiusculi, antici ad basin sensim separati ; tibiis (præcipue versus apicem) gracilibus ; tarsis gracillimis, filiformibus, art. ${ }^{\circ} 3^{\text {tio }}$ angusto, simplici, unguiculis minutissimis.

Hab. Europam.-

Dryophthorus.

5. Corpus et cæt. fere ut in Dryophthoro, sed illo magis parallelo-fusiformi (sc. in elytris lateraliter compresso), prothorace sensim majore, elytris versus apicem multo latius cariniformibus (sc. costâ, circa $6^{\text {tâ }}$ a suturâ, nec $4^{\text {ta }}$, in carinam valde exstantem postice currente), rostro, antennis pedibusque (præsertim tarsis) brevioribus, rostro vix ampliato ad (nec distinctius et ante) antennarum insertionem, coxisque anticis paulo magis, sed posticis minus (quam in Dryophthoro) separatis.

Hab. ins. Japonicas (et, nisi fallor, in Pacificis, Americâ, et cat.).-

Tetratemnus. 
III. Funiculus 5-art. . . . . Subfam. Pentarthrides. (Tibiis apice uncinatis; tarsis pseudotetrameris.)

\section{a. Oculi distincti.}

\section{b. Corpus lutosum; scutello haud, vel vix, observando.}

6. Corpus ellipticum aut breviter fusiforme, grossissime sculpturatum, subsericato-lutosum, Dryophthori formam simulans ; capite immerso ; rostro elongato, robusto, arcuato-cylindrico, ad antennarum insertionem obsoletissime vix subampliato; oculis angustissimis, valde transversis, demissis, supra subapproximatis, subtus omnino confluentibus; prothorace (elytris multo angustiore) subovali-cylindrico, antice leviter constricto; elytris fusiformibus antice late et valde truncatis, postice attenuatis sed haud cariniformibus, costatis (costis alternis magis elevatis); metasterno brevi, lato ; abdomine ut in Dryophthoro, sc. segm. ${ }^{\text {tis }} 1^{\mathrm{mo}}$ et $2^{\mathrm{do}}$ singulatim convexis necnon lineâ impressâ distincte divisis. Antennæ crassæ, calvæ, mox pone medium rostri insertæ; funiculo (5-articulato, compacto) ab art. ${ }^{\mathrm{do}}$ (sequentibus paulo longiore) gradatim multo latiore; capitulo maximo, ovali, solido, ad apicem internum late oblique truncato et ibidem dense velutino. Pedes longissimi et valde incrassati, antici ad basin contigui, intermedii minime separati, sed postici latissime distantes ; tibiis elongatis, subcurvatis, versus apicem obsolete subangustioribus, unco valde inflexo, posterioribus ad angulum internum spinâ brevi robustâ armatis; tarsis crassiusculis, filiformibus, art. ${ }^{\circ} 1^{\text {mo }}$ paulo elongato, $3^{\text {tio }}$ simplici.

(Genus mirabile, anomalum, et formâ generali, sculpturâ, vestitû, rostro, antennis, oculis transversis demissis, abdominis structurâ, tibiisque apicem versus gradatim subangustioribus Dryophthorum primâ facie simulans; sed funiculo 5-, nec 4-articulato, tarsorumque art. $^{\circ} 4^{\text {to }}$ minutissimo, immerso. Præterea exstat rostro elongato, arcuatocylindrico; oculis latissimis, sc. supra subapproximatis et subtus etiam omnino confluentibus suffusis; capite immerso ; funiculo latitudine paulatim valde crescentibus; capitulo maximo, solido, ad apicem internum oblique truncato et ibidem dense velutino; prothorace elytris multo angustiore, subcylindrico ; elytris antice latis, apice acuminatis sed ibidem haud cariniformibus; pedibus longissimis et valde incrassatis, anticis ad basin contiguis et etiam

TRANS. ENT. SOC. 1873.-PART IV. (OCT.) K K 
intermediis minime separatis, sed posticis latissime distantibus ; tarsisque crassiusculis, art. ${ }^{\circ} 3^{\text {tio }}$ simplici.)

Hab. ins. Borneo (ad Sarawak captus).-Synommatus.

7. Corpus cylindrico-oblongum, opacum, Dryophthorum et Tetratemnum simulans, sed paulo minus grosse (præsertim in prothorace), tamen densissime, sculpturatum; rostro, antennis, pedibusque brevioribus ac multo crassioribus, nostro parallelo, lato, depresso, antennis in medio (nec pone medium) rostri insertis, oculis minoribus, multo magis prominentibus, ac rotundatis (nec transversis); elytris ad humeros porrectis, utrinque versus apicem (ut in Tetratemno) late cariniformibus et minutissime serratis. Antennæ brevissimæ; funiculi (5-articulati) art. $^{\circ} 2^{\text {do }}$ sequentibus haud longiore; capitulo parvo, solido. Pedes breves, valde incrassati, anteriores sensim magis approximati quam in Dryophthoro ; tarsis brevibus, crassis, art. $^{\circ}$ $1^{\mathrm{mo}}$ haud elongato, $3^{\text {tio }}$ latiusculo, bilobo, subtus pubescenti.

(A Pentecopto differt corpore majore, prothorace minus angustato, elytris utrinque ad apicem (ut Tetratemno) late cariniformibus, coxis anterioribus sensim magis approximatis, abdominisque segm. ${ }^{\text {tis }} 1^{\text {mo }}$ et $2^{\text {do }}$ inter se multo minus recte (sc. valde sinuate) divisis.)

Hab. Europam australem.-

Chærorrhinus.

8. Corpus breviter parallelo-oblongum, opacum, grosse sculpturatum; rostro brevi, lato, parallelo, depresso, oculis valde prominentibus; prothorace elytris angustiore; metasterno breviusculo. Antennæ brevissimæ, in medio rostri insertæ; funiculi (5-articulati) art. $^{\circ} 2^{\text {do }}$ haud sequentibus longiore; capitulo parvo, solido. Pedes breves, crassi ; tarsis crassis, art. ${ }^{\circ} 1^{\text {mo }}$ haud elongato, $3^{\text {tio }}$ latiore, bilobo.

Hab. ins. Japonicas.-

Pentacoptus.

9. Corpus angustum, cylindricum, opacum, grosse sculpturatum; rostro elongato, angusto, parallelo, oculis prominentibus; prothorace ovali-cylindrico, elytrorum latitudine; metasterno elongato. Antennæ subgraciles, in medio rostri insertæ; funiculi (5-articulati) art. ${ }^{\circ} 2^{\text {do }}$ sequentibus sensim longiore; capitulo angusto, longiusculo, solido. Pedes crassi; tarsis brevibus, crassis, art. ${ }^{\circ}$ $1^{\text {mo }}$ brevi, $3^{\text {tio }}$ dilatato et profunde bilobo. Hab. ins. Malayenses (in Sula captus).- Lyprodes. 


\section{bb. Corpus (in Sericotrogo et Leptomint parte exceptis) calvum; scutello conspicuo.}

10. Corpus elongate cylindrico-ovatum, convexiusculum, nitidissimum, castaneum ; rostro brevi, lato sed ad basin valde contracto aut strangulato, deflexo, oculis demissis; prothorace (elytris conspicue angustiore) subparvo, cylindrico-ovato, antice subintegro (i. e. vix constricto); elytris elongate cylindrico-ovatis, basi subsinuate truncatis; metasterno longiusculo, et, una cum abdominis segm. ${ }^{\text {to }} 1^{\text {mo }}$, paulo concavo. Antennæ crassiusculæ, mox ante medium rostri insertæ; scapo breviusculo; funiculi (5-articulati) art. ${ }^{\circ} 1^{\mathrm{mo}}$ magno, antice recte truncato, reliquis brevibus, subæqualibus, submoniliformibus; capitulo magno, ovali. Pedes longiusculi, ad basin fere ut in Phlocophago (sc. antici subcontigui, intermedii paululum magis distantes, postici sat late separati); tarsis longiusculis, art. ${ }^{\circ} 1^{\text {mo }}$ longiusculo, $3^{\text {tio }}$ paulo latiore et minute bilobo.

(Genus prothorace sat parvo angustulo, corpore elongate cylindrico-ovato, coxisque anterioribus, præsertim anticis, valde approximatis Phloophagum simulans, sed funiculo 5-, nec 7-articulato, scutello conspicuo, antennisque et rostro aliter constructis. Inter Pentarthrides insignum est rostro brevi lato sed ad basin profunde strangulatim constricto, oculis demissis, prothorace parvo angustulo, elytris elongate cylindrico-ovatis, coxisque anterioribus, sc. ut in Phloeophago, multo magis approximatis.)

Hab. Americam australem (in Novâ Granadâ degens).Phlocophagomorphus.

11. Corpus fere ut in Pentarthro, sed minus, ac breviter cylindricum, Phlooophagum primâ facie simulans (tamen minus ovatum), convexum, calvum, nigrum; rostro breviore ac paulo latiore, parallelo, oculis paulo minus prominentibus; prothorace minus elongato et magis ovali (nec ovato-triangulari); elytris cylindricis; metasterno conspicue breviore. Antennæ ut in Pentarthro, sed mox ante medium rostri insertæ. Pedes anteriores magis approximati (sc. ut in Phloophago),-antici fere contigui, necnon etiam intermedii leviter solum distantes; tarsis art. $^{\circ} 1^{\mathrm{mo}}$ vix elongato ; $3^{\text {tio }}$ simplici.

Hab. Americam borealem (in Mexico captum).- 
12. Corpus fere ut in Pentarthro, sed multo minus; rostro breviore, sublatiore, ad basin multo magis conspicue strangulatim contracto; antennis versus basin ejus insertis, scapo elongato excurvato et robuste clavato sed ad apicem internum longe et oblique truncato, funiculi (5-articulati, brevis) art. ${ }^{2} 2^{\text {do }}$ brevissimo (sc. sequentibus etiam subbreviore), capitulo maximo ovali valde abrupto; oculis majoribus, sc. maximis ac valde prominentibus; scutello minuto; pedibus brevioribus; tibiis præcipue brevioribus ac magis triangularibus (i. e. apicem versus magis dilatatis), unco apicali in posterioribus brevi recto spiniformi sed in anticis brevissimo obsoleto, tamen anticis ad angulum internum in spinam magnam pubescentem unciformem excurvatam productis; tarsis ad basin incrassatis (sc. art. ${ }^{\text {is }}$ $1^{\text {mo }}, 2^{\text {do }}$ et $3^{\text {tio }}$ crassis, subæqualibus), ult. $^{\text {mo }}$ graciusculo.

Hab. ins. Malayenses.-

Xenosomatium.

13. Corpus vel cylindricum vel fusiformi-cylindricum, subnitidum (rariss. subopacum), vel piceum vel castaneum; rostro (interdum in $q$ graciliore, ut in $P$. Huttoni, et minus sculpturato) plus minus elongato (nunquam longissimo), parallelo; prothorace sat magno: metasterno valde elongato. Antennæ circa (aut interdum in $\widehat{\delta}$ mox ante, sed in $\$$ mox pone) medium rostri insertæ; scapo recto, robusto, gradatim valde clavato; funiculi (5-articulati) art.o $2^{\text {do }} \mathrm{vel}$ (ut in P.Huttoni), paululum, vel haud, sequentibus longiore; capitulo sat parvo subsolido. Pedes crassiusculi; tarsis art. $^{\circ} 1^{\text {mo }}$ haud elongato, $3^{\text {tio }}$ sæpius latiusculo cordato, sed interdum (ut in P. cylindrico) angusto, simplici.

Hab. Europam, Nov. Zealand., Americam austr., ins. Malayenses ac Japonicas, et cet.-

Pentarthrum.

14. Corpus et cæt. fere ut in Pentarthro, sed illud minus, angustius, sensim minus parallelum (sc. magis fusiforme), necnon subæneo-micans pubeque grossâ demissâ subæneocinereâ parce vestitum; capite magis exserto, rostro vix longiore et graciliore magisque curvato ac fere parellelo, aut (saltem in $\hat{\sigma}$ ) pone antennas vix subangustato, oculis valde prominentibus; antennis magis ante medium rostri insertis, subgracilioribus ; scapo præcipue graciliore; funiculi (5-articulati, laxi) art. ${ }^{\circ} 2^{\text {do }}$ sequentibus paulo longiore; capitulo sat magno, et paululum magis abrupto ; prothorace convexiore et magis ovali (i. e. minus triangulari et minus cylindrico), ad latera subæqualiter rotundato, 
antice fere integro, et subtus subconcavo; elytris minus parallelis (sc. antice sensim angustatis), ad apicem ipsissimum integris (nec subrecurvis, nec singulatim subrotundatis); metasterno minus elongato; abdominis segment. ${ }^{\circ}$ $1^{\mathrm{mo}}$ (in $\hat{\boldsymbol{}}$ ) longitudinaliter concavo; tarsorumque art. ${ }^{\mathrm{o}} 3^{\text {tio }}$ multo latiore, et profundius latiusque bilobo.

Hab. Nov. Zealandiam (ab Auckland missus).-

Sericotrogus.

15. Corpus angustissimum, parallelum, depressum, subnitidum, vel nigrum vel pallidius, sæpe minutum; capite magno, crasso, elongato-ovali, valde exserto ; rostro (præsertim in $q$ ) elongato, graciusculo, subparallelo sed apicem versus facile sublatiore, oculis omnino demissis, supra haud latissime separatis; prothorace subovato-trianguli; elytris (prothorace haud latioribus) parallelis, apice minute pubescentibus; metasterno longissimo. Antennæ longe pone medium rostri insertæ; funiculi (5-articulati) art. $^{\circ} 2^{\text {do }}$ haud sequentibus longiore. Pedes (præsertim posteriores) brevissimi, omnes ad basin parum et æqualiter distantes (nec antici magis approximati); tarsis brevibus, art. $^{\circ} 1^{\mathrm{mo}}$ brevi, $3^{\text {tio }}$ paulo latiore set fere simplici.

(A Pentarthro præcipue differt corpore angustiore, depressiore; capite longiore, crassiore, ovali, et multo magis exserto ; rostro, præsertim in $\&$, longiore, graciliore, versus apicem facile subdilatato; oculis omnino demissis, et supra magis approximatis; prothorace magis triangulari, et pone apicem minus constricto; elytris apice sensim pubescentibus; pedibus, saltem posterioribus, multo brevioribus, necnon omnibus ad basin æqualiter separatis.

Etiam Catalethro interdum confunditur, sed ab hôc differt funiculo 5-, nec 7-, articulato; corpore minore, graciliore, et postice minute pubescenti ; capite majore, crassiore, elongato, exserto; rostro versus apicem sensim latiore; prothorace magis triangulari, et antice minus constricto; pedibus posterioribus brevioribus; tarsorum art. ${ }^{\circ} 3^{\text {tio }}$ simplici ; coxisque omnibus æqualiter separatis.)

Hab. ins. Malayenses, et Cuba.-

Stenotrupis.

16. Corpus angustum, parallelum, depressum, nitidum, pallidum, minutum ; capite magno, crasso, elongato-ovali, valde exserto; rostro breviusculo, lato, subparallelo sed apicem versus facile latiore; oculis maximis, subprominulis, supra haud late separatis; prothorace magno, elongato, 
ovato-triangulari ; elytris (prothorace haud latioribus) parallelis; metasterno longissimo; abdominis segm. ${ }^{\text {tis }} 3^{\text {tio }}$, $4^{\text {to }}$ et ult. ${ }^{\text {mo }}$ ad basin punctis magnis (in lineâ transversâ positis) marginatis. Antennæ mox ante basin rostri inserts ; scapo curvato; funiculi (5-articulati) art. $^{\circ} 2^{\mathrm{do}}$ vix sequentibus longiore. Pedes omnes ad basin late et æqualiter distantes (nec antici magis approximati); tarsis brevibus, art. ${ }^{\circ} 1^{\mathrm{mo}}$ brevi, $3^{\text {tio }}$ paulo latiore sed fere simplici.

(Capite crasso, elongato, valde exserto, corpore angusto parallelo depresso, coxisque omnibus ad basin aqualiter separatis, gen. Stenotrupis congruens; sed differt corpore etiam minore et paulo minus angustato, coxis latius distantibus, rostro breviore et latiore, oculis majoribus, elytris ad apicem haud pubescentibus, necnon antennis multo magis versus basin rostri insertis.)

Hab. Nov. Guinea (ad Saylee captus).-

Microcossonus.

17. Corpus fusiformi-parallelum, depressum, subnitidum, pallido-variegatum ; rostro breviusculo, crasso, parallelo, oculis maximis et valde prominentibus; prothorace (elytris sensim angustiore) triangulari-ovato, inæquali ; elytris subparallelis, postice gradatim subattenuatis ; metasterno elongato; abdominis segm..$^{\text {tis }} 1^{\text {mo }}$ et $2^{\text {do }}$ lineâ rectâ distinctâ arcte divisis. Antennæ in medio (aut mox ante medium) rostri inserts; funiculi (5-articulati, laxi) art. ${ }^{\circ} 2^{\text {do }}$ sequentibus distincte longiore ; capitulo magno, abrupto, conspicue annulato. Pedes elongati, robusti, ad basin valde (etiam antici late) separati; femoribus (prasertim anticis) valde clavatis, necnon intus parcissime minutissimeque subtuberculato-asperatis; tibiis intus sinuatis, et ad apicem internum in spinulam distinctam productis; tarsis elongatis, art. ${ }^{\circ} 1^{\mathrm{mo}}$ breviusculo, $3^{\text {tio }}$ valde dilatato et profunde bilobo, ult. ${ }^{\text {mo }}$ elongato, unguiculis magnis.

(Genus inter Pentarthrides valde anomalum, et Cossoni formam simulans. Conspicuum est corpore magno, fusiformi-parallelo, depresso, profunde sculpturato ; oculis maximis et valde prominentibus; funiculi art. ${ }^{\circ} 2^{\text {do }}$ sequentibus distincte longiore; pedibus elongatis, robustis ; femoribus valde clavatis et intus obsolete subasperatis; tibiis intus sinuatis, et ad angulum internum in spinulam conspicuam productis; tarsisque elongatis, art. ${ }^{\circ}$ ult. ${ }^{\mathrm{mo}}$ elongato, unguiculis magnis.)

Hab. Australiam occidentalem.-

Cossonidius. 
18. Corpus oblongo-ellipticum, latiusculum, depressiusculum, nitidiusculum, castaneo-piceum ; capite parvo, oculis haud late separatis, rostro (an in utroque sexu?) gracillimo, parallelo, polito; prothorace brevi, transverso; metasterno longiusculo. Antennæ graciles, longe pone medium rostri insertæ; scapo breviusculo, valde incurvo, intus flexuose subexcavato; funiculi (5-articulati, laxi) art. $^{\circ} 2^{\text {a o }}$ sequentibus multo longiore; capitulo ovali. Pedes crassi, omnes ad basin (etiam antici) late separati; tarsis longiusculis, art. ${ }^{\circ} 1^{\text {mo }}$ haud elongato, $3^{\text {tio }}$ latiusculo et distincte profundeque bilobo.

Hab. ins. Japonicas (in Awasima captus).-

Tychiodes.

19. Corpus et cæt. fere ut in Tychiodes, sed illud majus ac depressius; rostro (ut in illo) gracillimo, parallelo, polito, sed etiam paulo longiore, atque antennis vix pone (nec longe pone) medium ejus insertis; antennis longioribus, scapo præcipue longiore ac minus (tamen conspicue) arcuato, intus haud flexuose subexcavato, funiculo gradatim multo latiore, quare capitulo (longiore) minus abrupto; prothorace (parvo) magis triangulari, sc. antice magis angustato ; prosterno, inter coxas anticas, fulvo-pubescenti; pedibus longioribus; tibiisque anticis intus versus apicem obsolete emarginatis, emarginatione postice setuloso-penicillatâ.

Hab. ins. Philippine.-

Tychiosoma.

20. Corpus angustissimum, parallelum, subdepressum, opacum, densissime sculpturatum, vel subcalvum vel setuloso-pubescens, brunneum ; capite parvo ; rostro longissimo, gracillimo, parallelo; oculis subprominulis (vix omnino demissis), supra haud latissime separatis; prothorace longissimo, subovato-triangulari, mox pone apicem valde profunde constricto; elytris (prothorace haud latioribus) parallelis; metasterno longissimo ; etiam abdominis segm. ${ }^{\text {tis }} 3^{\text {tio }}$ et $4^{\text {to }}$ minus abbreviatis quam in Cossonidis typicis. Antennæ elongatæ, graciles, vel mox ante vel mox pone medium rostri insertæ; scapo elongato; funiculi (5-articulati, laxi) art. ${ }^{\circ} 2^{\text {do }}$ sequentibus multo longiore. Pedes posteriores breves; intermedii parum late separati, sed antici et postici magis et æqualiter approximati ; unco tibiali parvo; tarsis art. ${ }^{1 \mathrm{mo}}$ brevi, $3^{\text {tio }}$ multo latiore et profunde bilobo. 
(Genus conspicuum corpore angustissimo, parallelo, opaco, densissime sculpturato, et interdum setulosopubescente; rostro longissimo, gracillimo; prothorace valde elongato; antennis gracillibus, funiculi art. $^{\circ} 2^{\text {do }}$ sequentibus multo longiore; necnon coxis intermediis parum late separatis, sed anticis et posticis magis ac æqualiter approximatis.)

Hab. ins. Malayenses (in Gilolo captus).-Leptomimus.

bbb. Corpus calvum, vel rarius minute pubescens; scutello obsoleto.

21. Corpus elongato-fusiforme, nitidum, vel parce breviter pubescens, vel subcalvum, æneum (rarius nigrescens); rostro longissimo, gracillimo, in to ante medium (ad antennarum insertionem) paulo ampliato, sed in of etiam longiore graciliore cylindrico ac magis polito; prothorace subovato, basi truncato; metasterno brevi, et (una cum abdominis segm. ${ }^{\text {to }} 1^{\mathrm{mo}}$ ) concavo. Antennæ elongatæ, graciles, longe ante medium rostri (in utroque sexu) insertæ; scapo recto, gracili, ad apicem ipsum leviter clavato ; funiculi (laxi, 5-articulati) art. ${ }^{\circ} 2^{\text {do }}$ longissimo, sequentibus multo longiore; capitulo magno, elongatoovali. Pedes longissimi, anteriores sensim magis approximati quam in Microxylobio ; tarsis longissimis, art. ${ }^{\circ} 1^{\mathrm{mo}}$ elongato, $3^{\text {tio }}$ late dilatato ac profunde bilobo, ult. ${ }^{\text {mo }}$ longissimo, clavato, curvato, unguiculis magnis armato.
Hab. ins. Ste Helence.-
Lamprochrus.

22. Corpus vel fusiforme, vel ovatum, nitidissimum, minus sculpturatum, calvum, æneum (rarius nigrescens); rostro plerumque paulo longiore et graciliore quam in Microxylobio, plus minus parallelo; prothorace vel ovato basi truncato, vel conico; metasterno brevissimo, et (una cum abdominis segm. ${ }^{\text {to }} 1^{\mathrm{mo}}$ ) sæpius concavo. Antennæ pone apicem rostri insertæ; funiculi (5-articulati) art. ${ }^{\circ} 2^{\text {do }}$ (sed vix in $A$. monilicorni) sequentibus distincte longiore. Pedes robusti; femoribus posticis vel (ut in speciebus typicis) supra spinâ armatis, vel muticis; tarsi art. ${ }^{\circ} 1^{\text {mo }}$ vix longiore, $3^{\text {tio }}$ latiusculo et profunde bilobo.

Hab. ins. Sta Helence.-

Acanthomerus.

23. Corpus vel fusiforme, vel ovato-fusiforme, subopacum, aut minutissime parceque pubescens, aut calvum, 
nigrum (rariss. aut picescens, aut subæneo-tinctum); rostro breviusculo, crassiusculo (vel parallelo, vel subtriangulari); prothorace magno, sæpius ovato basi truncato; metasterno brevi, et (una cum abdominis segm..$^{\text {to }} 1^{\mathrm{mo}}$ ) sæpius concavo. Antennæ longe ante medium rostri insertæ; funiculi (5-articulati) art. ${ }^{2} 2^{\text {do }}$ sequentibus vix longiore. Pedes breviusculi, robusti; tarsis art. $^{\circ} 1^{\mathrm{mo}}$ vix secundo longiore, $3^{\text {tio }}$ latiusculo bilobo.

Hab. ins. Ste Helence.-

Microxylobius.

24. Corpus fusiforme, subnitidum, fere calvum (solum versus elytrorum basin pilis perpaucis obsitum), nigropiceum; capite convexo, rostro longiusculo, graciusculo, parallelo, oculis parvis sed prominentibus, superioribus (i. e. supra haud latissime separatis); prothorace magno, ovali (ad latera valde et æqualiter rotundato), convexo, antice leviter constricto ; elytris fusiformibus basi truncatis, ad basin præsertim versus humeros pilis perpaucis obsitis; metasterno brevi, et postice (una cum abdominis segm.to $\mathrm{I}^{\mathrm{mo}}$ ) paululum concavo. Antennæ longiusculæ, mox ante medium rostri insertæ; funiculi (5-articulati, laxi) art. ${ }^{\circ} 2^{\text {do }}$ sequentibus conspicue longiore, reliquis tres subglobosis, submoniliformibus, vix crescentibus; capitulo magno, valde abrupto. Pedes longiusculi, crassiusculi ; tarsis art. ${ }^{\circ}$ $1^{\text {mo }}$ vix elongato, $3^{\text {tio }}$ multo latiore et profunde bilobo.

(Genus inter formas proximas distinctum rostro longiusculo subgracili parallelo, oculis parvis sed valde conspicuis prominulis atque supra minus late separatis, prothorace magno ovali in medio latiusculo, elytris fusiformibus neenon ad basin pilis perpaucis obsitis, funiculi laxi art. ${ }^{\circ} 2^{\text {do }}$ sequentibus conspicue longiore, capitulo magno abrupto, tarsarumque art. ${ }^{\circ} 3^{\text {tio }}$ lato ac valde profundeque bilobo.)
Hab. Novam Zealandiam.-
Microtribus.

25. Corpus angustulo-fusiforme, nitidum, calvum, piceum; rostro breviusculo, latiusculo, subparallelo (postice vix latiore), oculis minutissimis sed prominulis, distinctis (nec obsoletis); prothorace elongato, triangulari-ovato, antice integro (nec constricto); elytris cylindrico-fusiformibus basi truncatis, convexiusculis; metasterno breviusculo, et (una cum abdominis segm. ${ }^{\text {to }} 1^{\mathrm{mo}}$ ) paululum concavo. Antennæ breves, in medio rostri insertæ; scapo recto, breviusculo ; funiculi (5-articulati) art. ${ }^{\circ}{ }^{\mathrm{do}}$ haud sequentibus longiore; capitulo haud abrupto. Pedes breves, 
crassiusculi; tibiis ad angulum internum in spinulam parvam productis; tarsis art..$^{\circ} 1^{\mathrm{mo}}$ haud elongato, $3^{\text {tio }}$ vix latiore et fere simplici.

(Genus Mesoxenum, i. e. Amaurorrhinum, simulans, sed oculis distinctis, tamen minutis prominulis, nec obsoletis; corpore, præcipue in prothorace, angustiore; rostro paulo breviore, latiore, ac magis parallelo, nec pone medium facile contracto; antennis multo brevioribus et in medio, nec ante medium, rostri insertis; pedibus brevioribus, anticis et posticis vix magis approximatis ; tarsorum art.o $3^{\text {tio }}$ magis simplici; metasternoque, tamen breviusculo, sensim longiore et minus concavo.)

Hab. Africam australem (a Caffrariâ missus). -

Mesoxenomorphus.

\section{aa. Oculi obsoleti.}

\section{c. Scutellum distinctum.}

26. Corpus parvum, angustum, parallelum, subdepressiusculo-cylindricum, nitidum, calvum, piceo-castaneum; rostro brevi et (præsertim in o) latissimo, postice paulo angustiore, a capite (supra et subtus) lineâ diviso; prothorace elongato, ovato-triangulari, pone apicem leviter constricto; elytris (prothorace etiam subangustioribus) parallelis; metasterno elongato; abdominis segm. ${ }^{\text {to }} 1^{\text {mo }}$ in of obsolete longitudinaliter concavo. Antennæ pone apicem rostri insertæ; scapo brevi, robusto, subito et valde clavato; funiculi (5-articulati) art. ${ }^{\circ} 2^{\text {do }}$ haud sequentibus longiore; capitulo breviter ovali. Pedes breves, crassiusculi, ad basin (etiam antici) late separati (posteriores subæqualiter distantes); tarsis breviusculis, art. ${ }^{\circ} 1^{\mathrm{mo}}$ haud elongato, $3^{\text {tio }}$ angusto, simplici.

(Inter Pentarthrides insigne oculis obsoletis, ægerrime observandis, tamen scutello conspicuo; et præterea exstat corpore parvo angusto parallelo, rostro brevi latissimo postice sensim angustiore necnon a capite lineâ distinctâ diviso, scapoque brevi et abrupte clavato.)

Hab. Nov. Zealandiam.-

Heteropsis.

\section{cc. Scutellum obsoletum.}

27. Corpus ovato-fusiforme, nitidum, calvum, piceocastaneum ; rostro longiusculo, subparallelo sed pone medium paululum angustiore; prothorace subovato, convexo, pone apicem vix constricto; elytris vel elongato- 
ovatis vel fusiformibus, basi truncatis, convexis; metasterno brevi, et (una cum abdominis segm. ${ }^{\text {to }} 1^{\mathrm{mo}}$ ) sæpius longitudinaliter concavo. Antennæ longe ante medium rostri insertæ; scapo subgracili, curvato; funiculi (5-articulati) art. ${ }^{\circ} 2^{\text {do }}$ vel (ut in $A$. Moniziano) distincte, vel vix sequentibus longiore; capitulo parum abrupto. Pedes crassiusculi; tarsis art ${ }^{\circ} .1^{\text {mo }}$ vix elongato, $3^{\text {tio }}$ paulo latiore et sensim sed minute bilobo.

Hab. Europam austr., et ins. Maderens. et Canariens.Amaurorrhinus.

28. Corpus et cæt. fere ut in Amaurorrhino, sed illud (præcipue in elytris) angustius ac minus fusiforme; rostro sensim breviore, crassiore, et elongate subtriangulari (nec subparallelo et postice paululum angustiore); prothorace majore, ovali (etiam elytris sublatiore), antice subintegro (vix constricto); elytris angustioribus, magis parallelis, minus convexis, subcylindricis; metasterno sensim longiore, et (una cum abdominis segm. ${ }^{\text {to }} 1^{\mathrm{mo}}$ ) convexo, nec concavo; antennis pedibusque brevioribus, his quoque minus incrassatis; tibiis ad angulum internum in spinulam parvam productis ; tarsis gracilibus, art. ${ }^{\circ} 3^{\text {tio }}$ angusto, simplici.

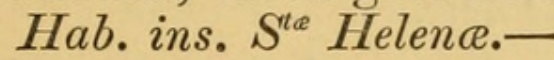

Pseudomesoxenus.

29. Corpus fusiforme, nitidiusculum (saltem antice), parce sed longe pilosum, piceum; rostro breviusculo, crasso, parallelo; prothorace sat magno, subovali, convexo, antice integro (nec constricto); elytris et subtus dense punctato-asperatis; metasterno breviusculo. Antennæ breves, crassæ, circa medium rostri insertæ; scapo brevi ; funiculi (5-articulati) art. $^{\circ} 2^{\text {do }}$ haud sequentibus longiore; capitulo solido. Pedes crassi ; tibiis subfossoriis, unco apicali magno, in posterioribus ad basin compressoampliato; tarsis art. ${ }^{\circ} 1^{\text {mo }}$ vix elongato, $3^{\text {tio }}$ angusto, simplici.

Hab. ins. Canarienses, et ins. Cap. Verde.-

Pentatemnus.

\section{aaa. Oculi nulli.}

30. Corpus ovato-fusiforme, nitidum, parce sed longissime pilosum, pallide rufo-piceum; rostro breviusculo, crasso, parallelo; prothorace ovali; elytris inæqualibus et (præsertim postice) asperatis; metasterno breviusculo. Antennæ breves, crassæ, circa medium rostri insertæ; 
scapo brevi, robusto; funiculi (5-articulati) art. ${ }^{\circ} 1^{\mathrm{mo}}$ magno, sub-obtriangulari, $2^{\text {do }}$ brevi (sequentibus etiam breviore); capitulo magno, solido. Pedes breviusculi, crassiusculi; tibiis subfossoriis, flexuosis, ad angulum internum in spinam distinctam productis, unco apicali in anterioribus (præsertim anticis) magno, in posticis breviore et fere spiniformi; tarsis anterioribus angustulis, filiformibus, posticis latioribus; art. $^{\circ} 1^{\mathrm{mo}}$ vix secundo longiore, $3^{\text {tio }}$ simplici, ult. ${ }^{\text {mo }}$ brevi, parvo, subovali, unguiculis minutissimis (ægerrime observandis) armato. [N.B.-In specimine descripto tarsi postici fracti sunt, articuli 3 basales solum manent; sed anteriores sunt integri.]

Hab. Australiam occidentalem (ad Freemantle captus).Halorhynchus.

\section{Funiculus 6-art. . . Subfam. Onycholipides.}

(Corpus pallidum, plus minus pilosum; metasterno brevi, interdum brevissimo; tibiis fossoriis, plus minus compressis ac ciliatis, apice haud uncinatis; tarsis vere 4-articulatis.)

\section{d. Oculi distincti.}

31. Corpus ovale, convexiusculum, subopacum, rufopiceum sed dense pallidulo-squamosum, pilisque longissimis præsertim postice et subtus adspersum; rostro brevi, lato, apice late truncato; oculis magnis, transversis, sed demissis; prothorace lato, subtriangulari-ovato, antice leviter constricto; scutello parvo; elytris (subter squamis) leviter punctato-striatis, necnon in interstitiis subpunctulato-asperatis; metasterno brevi; abdominis segm. ${ }^{\text {tis }} 1^{\text {mo }}$ et $2^{\text {do }}$ lineâ haud valde distinctâ divisis. Antennæ breves, robustæ, versus basin rostri insertæ; scapo brevi, longissime piloso ; funiculi (6-articulati, compacti) art. $^{\circ} 1^{\text {mo }}$ magno, crasso, $2^{\text {do }}$ haud sequentibus longiore; capitulo ovali, solido. Pedes longiusculi, validi, fossorii, longe et densissime hirsuti, antici omnino et intermedii fere contigui, postici parum late separati; tibiis ad apicem ipsissimum breviter et dense (in anticis densissime et compacte) setuloso-marginatis, necnon (præsertim anterioribus) ad angulum internum spinâ robustâ armatis, anticis ad angulum externum in lobum obtusum (nec uncum) productis ; tarsis (4-articulatis) elongatis, angustis, filiformibus, art. ${ }^{\circ} 1^{\mathrm{mo}}$ elongato, unguiculis gracilibus.

Hab. Americam australem (prope Montevideo captus).Georrhynchus. 


\section{dd. Oculi nulli.}

e. Rostrum breve, latum. Antenne brevissima. Scutellum distinctum. Unguiculi nulli.

32. Corpus globoso-ovatum, convexum, nitidiusculum, parce sed longissime pilosum, testaceum, inæquale (sc. grosse sed leviter varioloso-punctatum); rostro brevi, lato, subtriangulari, apice late truncato; prothorace transverso, ad latera rotundato; scutello sat magno, triangulari (sed haud facile observando); elytris (præsertim postice) parce asperatis ; metasterno breviusculo; abdominis segm. ${ }^{\text {ti }} 1^{\mathrm{mo}}$ et $2^{\text {do }}$ inter se lineâ distinctâ divisis. Antennæ brevissimæ, circa medium rostri insertæ; scapo brevissimo (in scrobe auriculiformi profundâ omnino abscondito); funiculi (6-articulati) art. ${ }^{\text {is }} 1^{\text {mo }}$ et $2^{\text {do }}$ maximis crassis subæqualibus, sequentibus parvis, brevibus; capitulo magno, solido. Pedes breves, validi, fossorii, antici omnino et intermedii fere contigui; femoribus brevissimis; tibiis anticis ad apicem externum in lobum (vix uncum) longissimum tectiformem productis, posterioribus extus fortiter spinulosis, ad apices (externum et internum) compressis ac lobato-ampliatis; tarsis valde anomalis; anticis longe pone apicem tibiarum lobatum insertis (ergo superne haud observandis), vere 4-articulatis (art. ${ }^{\text {us }}$ quintus omnino abest), brevissimis, filiformibus, art. ${ }^{\circ}$ ult. $^{\text {mo }}$ ovali et ad apicem pilis perpaucis longissimis instructo ; posterioribus quasi 4-articulatis (art. ultimus et penultimus, nisi fallor, inter se omnino commiscentur, - articulum bifurcatum anomalum efficientes), art. ${ }^{\text {is }} 2^{\text {do }}, 3^{\text {tio }}$ et ult. ${ }^{\text {mo }}$ ad angulos anticos longissime spinoso-lobatis (articulos tres longe bifurcatos formantibus), - art. $^{\circ} 1^{\mathrm{mo}}$ brevi, intra apicem tibiarum compressum abscondito, $2^{\text {do }}$ majore longiore et, una cum $3^{\text {tio }}$ (minore graciliore), lobis duobus longissimis spiniformibus aucto, $4^{\text {to }}$ (nisi fallor) minuto, inter spinas tertii immerso, et in ultimum (apice bifurcatum, sed haud unguiculatum) omnino suffuso.

Hab. ins. Canarienses (ad radices plantarum, in arenosis aridis submaritimis crescentium, fodiens).-

Onycholips.

\section{ee. Rostrum longius, gracilius. Antenna longiores. Scutellum nullum. Unguiculi magni.}

33. Corpus longo-fusiforme, nitidinsculum, profunde sed parce sculpturatum, fere calvum (sc. setulis brevibus valde remotis postice saltem, parcissime obsitum), rufopiceum; rostro elongato, subparallelo sed in medio sensim 
angustiore; prothorace ovali (ad latera æqualiter rotundato); elytris elongato-ellipticis basi truncatis, ad latera versus apicem utrinque carinæformibus; metasterno brevissimo; abdominis segm. ${ }^{\text {tis }} 1^{\text {mo }}$ et $2^{\text {do }}$ (illo longissimo) inter se arctissime connatis, necnon late profundeque concavis. Antennæ elongatæ, mox pone apicem rostri insertæ ; scapo elongato; funiculi (6-articulati) art. ${ }^{\circ} 2^{\text {do }}$ sequentibus sensim longiore, reliquis submoniliformibus; capitulo maximo, abrupto, distincte 3-annulato. Pedes valde incrassati, anteriores leviter, sed postici latissime separati ; tibiis compressis, a basi gracili gradatim late triangulariter dilatatis, sed extus versus apicem longe excavatis (excavatione, saltem in posterioribus, dense pectinato-setosâ); tarsis brevissimis, latis, crassis, subtus longe pilosis, 4-articulatis (certe haud pseudotetrameris), art. $^{\text {is }} 1^{\text {mo }}, 2^{\text {do }}$ et $3^{\text {tio }}$ brevibus, æqualibus, transversis, submoniliformibus, ult. ${ }^{\text {mo }}$ paulo majore, ovali, unguiculis maximis armato.

Hab. Europam australem (sub lapidibus et cat. fodiens).Raymondionymus.

34. Corpus fere ut in Raymondionymo, sed minutissimum, paulo depressius ac sensim magis setuloso-pilosum, necnon pallidius (sc. clare testaceum), subtranslucidum, atque in specie typicâ (sc. A. carinulatâ) multo minus profunde sculpturatum ; rostro paulo minus elongato ; antennis (in specie typicâ) ab apice sensim remotius insertis, funiculi (6-articulati) art. ${ }^{\text {is }} 1^{\mathrm{mo}}$ et $2^{\mathrm{do}}$ conspicue longioribus, hôe sequentibus sensim longiore (nec subrotundato); abdominis segm. ${ }^{\text {tis }} 1^{\text {mo }}$ et $2^{\text {do }}$ minus profunde concavis. Pedes (licet robusti) minus incrassati, tibïs posterioribus solum triangulariter (et minus late) dilatatis, anticis conspicue angustioribus subintegris (sc. extus versus apicem paululum truncatis,-nullò modo excavatis).

Hab. Europam australem (in Sardiniâ capta).Alaocyba.

V. Funiculus 7-art. .... Subfam. Cossonides. in Tetracoptus (4-art.), in Pentammus et Tomolips (5-art.), et in Hexarthrum (6-art.) exceptis.

(Tibiis apice uncinatis, rariss. inarmatis ; tarsis pseudotetrameris.)

f. Oculi nulli.

35. Corpus elongato-ovatum, convexum, subopacum, parce sed longe pilosum, rufo-brunneum ; rostro-brevius- 
culo, crassiusculo, subparallelo sed in medio sensim contracto ; prothorace (elytris angustiore) ovato basi truncato; elytris ovatis basi late emarginato-truncatis, substriatis ac minutissime asperatis; metasterno breviusculo. Antennæ breviusculæ, mox ante medium rostri insertæ; funiculi art. ${ }^{\circ} 2^{\text {do }}$ haud sequentibus longiore. Pedes validi, ad basin ut in Phloophago (sc. antici fere contigui, intermedii paulo distantiores, postici parum remoti); tibiis subfossoriis, compressis, unco apicali magno obtuso, ad angulum internum in spinam productis; tarsis art. ${ }^{\circ} 1^{\mathrm{mo}}$ longiusculo, $3^{\text {tio }}$ simplici.

Hab. ins. Maderenses (in ins. Portu Sancto capta).-

Lipommata.

\section{ff. Oculi distincti.}

g. Scutellum aut nullum, aut obsoletum.

h. Metasternum brevissimum.

36. Corpus longe fusiformi-ovatum, depressiusculum, calvum, pallidulum; rostro elongato, parallelo, gracili, arcuato, oculis (conspicue superioribus) parvis sed prominulis ; prothorace (elytris angustiore) inæquali, sc. plus minus tricarinato et longe pone apicem profunde constricto ; elytris ovato-ellipticis; abdominis segm. ${ }^{\text {tis }} 1^{\mathrm{mo}}$ et $2^{\mathrm{do}}$ (illo longissimo) inter se arctissime connatis ac longitudinaliter impresso-concavis. Antennæ elongatæ, longe ante medium rostri insertæ; scapo elongato; funiculi (laxi) art. ${ }^{\circ} 2^{\text {do }}$ sequentibus longiore; capitulo abrupto. Pedes longiusculi, subgraciles, antici paululum, intermedii latius, postici latissime separati ; tibiis elongatis, gracilibus, unco apicali parvo et valde inflexo; tarsis breviuseulis, art. ${ }^{\circ} 1^{\text {mo }}$ vix elongato, $3^{\text {tio }}$ lato bilobo, unguiculis magnis.

(Genere Cotaster entomologicis confusum; sed differt, teste $C$. uncipes, corpore majore depressiore pallidiore et nudo, nec setis obsito, rostro longiore graciliore, oculis minoribus ac magis superioribus, prothorace inæquali plus minus tricarinato et antice constricto, nec convexo æquali, antennis longioribus gracilioribus ac magis versus apicem rostri insertis, funiculi magis laxi art. ${ }^{\circ} 2^{\text {do }}$ longiore, capitulo magis abrupto, pedibus, præcipue tibiis, longioribus gracilioribus, unco apicali minore et magis inflexo, tarsorum art. ${ }^{\circ} 3^{\text {tio }}$ latiore et distincte bilobo, unguiculisque multo majoribus.)

Hab. Europam australem, et Africam borealem.-

Styphloderes. 
37. Corpus ovatum, convexum, subopacum, parce pubescens (in elytris setis elongatis suberectis obsitum), piceum ; rostro longiusculo, cylindrico, subgracili, subarcuato, oculis subprominulis; prothorace subovali, convexo, antice fere haud constricto ; elytris convexis, ovatis basi truncatis, ad latera rotundatis, pone medium prothorace latioribus; metasterno brevissimo, et, una cum abdominis segm. ${ }^{\text {to }} 1^{\text {mo }}$ (breviusculo), late subconcavis. Antennæ ante medium rostri insertæ; scapo subarcuato, gradatim valde clavato ; funiculi art. ${ }^{\circ} 2^{\text {do }}$ haud sequentibus longiore; capitulo haud abrupto. Pedes crassiusculi, ad basin fere ut (sed postici paulo magis separati quam) in Phloophago (sc. antici subcontigui, intermedii sensim distantiores, postici remoti); tarsis breviusculis, art. ${ }^{\circ} 1^{\mathrm{mo}}$ vix elongato, $3^{\text {tio }}$ paulo latiore sed fere simplici, unguiculis minutissimis.

(Genus primâ facie Acalles simulans, et in hâc familiâ insignum corpore convexo, ovato, subopaco, parce sericato atque in elytris setis elongatis suberectis obsito. Aliter conspicuum est rostro longiusculo cylindrico, metasterno brevissimo, abdominis segm. ${ }^{\text {to }} 1^{\mathrm{mo}}$ minus quam in Cossonidis typicis elongato, unguiculisque minutissimis.)

Hab. Europam australem (in Croatiâ captus).-

Cotaster.

38. [Corpus oblongum, elongatum, inæquale (antice et subtus subvariolosum), nigrum vel brunneo-nigrum ; rostro robusto, subquadrangulari, arcuato, a fronte profunde strangulatim diviso; oculis parvis, transversis, demissis ; prothorace elongato-subquadrato, antice breviter et subito constricto; elytris prothorace haud latioribus, basi leviter arcuatim emarginatis, profunde punctato-striatis; metasterno brevissimo. Antennæ ante medium rostri insertæ ; funiculi art. ${ }^{2} 2^{\text {do }}$ sequentibus longiore; capitulo parum abrupto, subgloboso. Pedes anteriores ad basin anguste separati; tibiis gracilibus; tarsis brevissimis, filiformibus.

Hab. Americam borealem.]-

Lymantes.

39. [Corpus ovale, minute pubescens, brunneum ; capite parvo, sat profunde immerso; rostro elongato, subgracili, subcylindrico, leviter arcuato; prothorace parvo, elytris multo angustiore, subgloboso, antice leviter constricto; elytris ovalibus, convexis. Antennæ pone apicem rostri 
insertæ, subgraciles ; funiculi art. ${ }^{\circ} 2^{\text {do }}$ sequentibus sensim longiore. Pedes longiusculi ; tarsis art. ${ }^{0} 3^{\text {tio }}$ bilobo.

$$
\text { Hab. Europam (in Transylvaniâ captum).] Aparoprion. }
$$

40. [Corpus ovale, convexum, nitidum, glabrum, metallico-tinctum, antice minus sculpturatum; capite parvo; rostro brevi, robusto, cylindrico; oculis parvis, rotundatis; prothorace conico; elytris ovalibus, antice arcuatim subemarginatis; metasterno brevissimo. Antennæ graciles, in medio rostri insertæ; funiculi art. $^{\circ} 2^{\text {do }}$ sequentibus longiore; capitulo parvo, acuminato. Pedes anteriores anguste separati; tarsis art. ${ }^{\circ} 1^{\mathrm{mo}}$ breviusculo, $3^{\text {tio }}$ sat magno, bilobo.

Hab. ins. Sandwich, juxta Honolulu degens.]-

Oodemas.

\section{hh. Metasternum breve (vix brevissimum).}

41. Corpus fusiforme vel elliptico-ovatum, convexum, sæpius subopaculum (rarius omnino nitidum) sed tamen plus minus metallico-tinctum, minus sculpturatum, calvum; rostro, antennis, metasterno (brevi) pedibusque fere ut in Phloephago (sc. funiculi art. ${ }^{\circ} 2^{\text {do }}$ sequentibus conspicue longiore), sed prothorace magis conico, fere esculpturato, basi haud marginato, prosterno (pone coxas anticas) distinctius carinulato, pedibus ad basin (præsertim posticis) sensim magis separatis, tarsorumque art. ${ }^{\circ} 1^{\text {mo }}$ paulo minus elongato, necnon $3^{\text {tio }}$ latiore ac distinctius bilobo.
Hab. ins. Maderenses.-
Caulotrupis.

42. Corpus sæpius ovatum, convexum, nitidiusculum, calvum (interdum parce pilosum); rostro plus minus longiusculo, graciusculo, parallelo, (rarius brevi crassiusculo); prothorace sæpius subovali basi truncato, ad latera rotundato, antice integro (haud constricto); scutello interdum punctiformi, observando (licet ægerrime); metasterno breviusculo. Antennæ subgraciles, circa vel mox ante medium rostri insertæ; scapo breviusculo, curvato ; funiculo art. ${ }^{\circ} 2^{\text {do }}$ sequentibus sensim (rarius vix) longiore. Pedes breviusculi, subgraciles, antici fere contigui, intermedii paulo distantiores, postici parum remoti; tarsis longiusculis, gracilibus, art. ${ }^{\text {mo }}$ elongato, $3^{\text {tio }}$ sæpius minute bilobo.

Hab. Europam, et ins. Atlanticas.-

Phlcophagus.

TRANS. ENT. SOC. 1873.-PART IV. (OCT.)

L L 


\section{gg. Scutellum plus minus conspicuum. \\ i. Corpus ænео-piceum.}

43. Corpus oblongo-cylindricum, nitidiusculum, sericatum, æneo-piceum; rostro crassiusculo, parallelo, oculis demissis; prothorace subovato basi late truncato, antice subintegro ; scutello parvo, sed parum distincto, sub-perpendiculari; mesosterno (inter coxas intermedias) minute cariniformi; metasterno brevi. Antennæ longiusculæ, graciles, mox ante medium rostri insertæ; scapo longiusculo, curvato ; funiculi art. ${ }^{\circ} 2^{\text {do }}$ sequentibus sensim longiore; capitulo sat magno, abrupto. Pedes longiusculi, anteriores conspicue magis approximati quam in Rhyncolo et paululum magis etiam quam in Phloophago (sc. antici fere omnino contigui, et intermedii anguste separati); tarsis elongatis, gracilibus, art. ${ }^{\circ} 1^{\mathrm{mo}}$ elongato, $3^{\text {tio }}$ minute bilobo.

Hab. ins. Maderenses, et ins. Azoricas.-

Pseudophloeophagus.

ii. Corpus nunquam eneo-tinctum.

\section{k. unco tibiali obsoleto. (Oculi maximi.)}

44. Corpus breviter oblongum, crassum, convexiusculum, nitidiusculum, pallidulo-sericatum, piceum sed in elytris rufo-testaceum; rostro breviusculo, crassiusculo, parallelo, oculis maximis ac parum prominentibus; prothorace (elytris multo angustiore) parvo, subovali-quadrato basi truncato, submalleato-inæquali sed antice vix constricto ; scutello valde distincto, subquadrato ; elytris breviter cylindricis, basi undulatim truncatis; metasterno brevissimo; abdominis segm. ${ }^{\text {tis }} 1^{\mathrm{mo}}$ et $2^{\mathrm{do}}$ subæqualibus, et lineâ haud valde distinctâ divisis. Antennæ elongatæ, graciles, in medio rostri insertæ; scapo longiusculo ; funiculi (elongati, laxi) art. ${ }^{\mathrm{d}} 2^{\mathrm{do}}$ sequentibus sensim longiore; capitulo elongato, angusto, acuminato. Pedes elongati crassi, ad basin fere ut in Pseudophloeophago (sc. antici contigui, intermedii angustissime separati, et etiam postice haud latissime distantes) ; tibiis inarmatis, sc. unco apicali obsoleto (i. e. in anticis minuto brevissimo incurvato, sed in posterioribus, præsertim posticis, vix observando); tarsis elongatis, crassis, art. ${ }^{\circ} 1^{\text {mo }}$ elongato, $3^{\text {tio }}$ lato, valde et pro funde bilobo, unguiculis magnis et multo divergentibus.

(Genus unco tibiali obsoleto inter Cossonidas anomalum, et præcique conspicuum corpore breviter oblongo convexo crasso sericato et in parte pallidulo, rostro breviusculo crassiusculo parallelo, oculis maximis, prothorace parvo 
inæquali et elytris multo angustiore, metasterno brevissimo, antennis elongatis gracilibus, funiculo elongato laxo, capituloque elongato angusto, pedibus elongatis crassis, anticis contiguis et etiam intermediis minime separatis, tarsisque elongatis crassis, art. ${ }^{\circ} 3^{\text {tio }}$ latissime profundeque bilobo.)

Hab. Australiam meridionalem.- Thaumastophasis.

\section{kk. unco tibiali (in Amorphocero, Lipancylo, Aoro et} Xenocnema exceptis) plus minus conspicuo.

1. oculis subinferioribus, superne vix observandis.

m. Corpus pubescens, piceum.

45. Corpus angustum, cylindricum, depressiusculum, nitidiusculum, longe sed parce pubescens, rufo-piceum; rostro angustulo, parallelo, ad basin a fronte evidenter diviso tamen haud constricto; oculis subinferioribus, demissis; prothorace ovato-triangulari, antice sat profunde constricto; elytris parallelis; metasterno elongato, et postice, una cum abdominis segm..$^{\text {to }} 1^{\mathrm{mo}}$, longitudinaliter leviter concavo ; abdominis segm. ${ }^{\text {tis }} 3^{\text {tio }}, 4^{\text {to }}$ et ult. $^{\text {mo }}$ punctis magnis (in lineâ transversâ positis) postice marginatis. Antennæ mox ante medium rostri insertæ, valde hirsutæ; scapo breviusculo, recto, robusto ; funiculi articulis $\left(1^{\mathrm{mo}} \mathrm{ex}-\right.$ cepto) submoniliformibus, $2^{\text {do }}$ haud sequentibus longiore; capitulo sat magno, abrupto. Pedes breviusculi, omnes ad basin (etiam antici) late separati (sc. antici late, intermedii etiam latius, postici paulo latius quam int., distantes); tarsis art. ${ }^{\circ} 1^{\text {mo }}$ longiusculo, $3^{\text {tio }}$ fere simplici.

(Genus conspicuum corpore angusto, parallelo, cylindrico, sed vix convexo, rufo-piceo, et sat longe sed parce fulvo-piloso ; capite convexo, esculpturato, rostro angustulo parallelo, oculis subinferioribus, i. e. late separatis, fere e visu superne absconditis; elytris dense et grosse striatopunctatis ; prothorace antice constricto ; metasterno elongato, coxisque omnibus conspicue distantibus.)

\section{Hab. Indiam australem (a Malabar missum).- \\ Himatium.}

46. Corpus angustulum, subcylindricum, subopacum, piceum sed squamis setisque mágnis subcinereis plus minus vestitum; capite sub-immerso ; rostro angusto, elongato, fere parallelo (postice vix crassiore), recto, ad basin a fronte evidenter diviso tamen haud constricto ; oculis subinferioribus, demissis (i. e. supra late separatis, sed subtus subapproximatis); prothorace ovato-triangulari, antice 
leviter constricto; scutello minuto; elytris (prothorace sensim latioribus) subparallelis; metasterno longiusculo; abdominis segm. ${ }^{\text {tis }} 1^{\text {mo }}$ et $2^{\text {do }}$ lineâ impressâ parum distinctâ divisis. Antennæ subgraciles, in medio rostri insertæ, valde hirsutæ; scapo breviusculo; funiculi articulis ( $1^{\mathrm{mo}}$ excepto) parvis, submoniliformibus, $2^{\text {do }}$ brevi ; capitulo magno, abrupto. Pedes crassi, squamosi, anteriores parum et æqualiter separati, postici late distantes; tarsis art. ${ }^{\circ} 1^{\text {mo }}$ longiusculo, $3^{\text {tio }}$ paulo latiore et profunde bilobo.

(Inter Cossonidas anomalum corpore grosse subcinereosquamoso et setoso, sed subter squamis densissime rugoseque sculpturato. Aliter exstat corpore piceo subopaco, rostro longiusculo graciusculo subparellelo, antennis in medio ejus insertis, oculis subinferioribus, sc. superne vix perspicuis, pedibusque crassis squamosis, tarsorum art. ${ }^{\circ} 3^{\text {tio }}$ bilobo.)

Hab. Borneo (ad Sarawak captus).- Pholidonotus.

47. Corpus vel angustum subcylindricum, vel paulo latius et parallelo-oblongum, subopacum, parce et breviter setulosum, piceo-nigrum ; rostro angusto, elongato, parallelo, arcuato, ad basin valde strangulatim constricto (quare a fronte lineâ profundâ diviso); oculis magnis, transversis, demissis, subinferioribus (i. e. supra late separatis, sed subtus subapproximatis); prothorace (vel vix vel multo elytris angustiore) suboblongo basi truncato, antice subintegro, in disco postico foveâ valde profundâ rotundatâ notato ; elytris subfusiformi-parallelis, basi bi-arcuatim truncatis, apice pygidium vix tegentibus; mesosterno postice (inter coxas posticas) in lobum curvatum obtusum producto; mestasterno brevi, antice triangulariter lobato; abdominis segm..$^{\text {tis }} 1^{\mathrm{mo}}$ et $2^{\mathrm{do}}$ elongatis, inter se lineâ parum distinctâ divisis, longitudinaliter concavis. Antennæ ante medium rostri insertæ valde hirsutæ; scapo subrecto, subito clavato, et setulis elongatis perpaucis obsito; funiculi art. ${ }^{\circ} 2^{\text {do }}$ sensim longiusculo, reliquis gradatim multo latioribus; capitulo magno, elongato, tamen haud abrupto. Pedes elongati, valde robusti, antici fere contigui, intermedii angustissime separati, sed postici parum late distantes; femoribus subtus denticulo acuto medio armatis, anticis pone denticulum pubescentibus ; tibiis valde arcuatis, anticis ad sed posterioribus pone apicem externum subfasciculatim pectinato-setosis; tarsis art. $^{\circ} 1^{\mathrm{mo}}$ longiusculo, $3^{\text {tio }}$ lato et conspicue bilobo.

(Corpore plus minus setuloso, rostro elongatulo gracili arcuato necnon a fronte profunde strangulatim diviso, 
oculis valde demissis subinferioribus, prothorace in disco postico foveâ rotundatâ profundâ impresso, funiculo gradatim conspicue dilatato, quare capitulo, tamen magno, minus abrupto, coxis anticis fere contiguis, femoribus omnibus subtus denticulatis, tibiisque arcuatis, ac versus apicem externum minute pectinato-setulosis inter genera vicina insigne.)
Hab. Borneo, et Java.-
Coptorhamphus.

\section{mm. Corpus calvum, atrum.}

48. Corpus angustum, subcylindricum (postice vix latius), depressiusculum, nitidum, calvum, nigrum ; rostro breviusculo, crasso, elongato-subtriangulari, oculis subinferioribus (sc. superne vix observandis), demissis ; prothorace ovato-cylindrico, antice leviter constricto; scutello transverso ; elytris (prothorace vix latioribus) subparallelis ; metasterno elongato. Antennæ longiusculæ, subgraciles, ante medium rostri insertæ; funiculi art. ${ }^{\circ} 2^{\text {do }}$ sequentibus paululum longiore; capitulo sat magno, abrupto. Pedes longiusculi, subgraciles, ad basin (ut in Rhyncolo) paulo magis distantes quam in Phloophago; tarsis elongatis, gracilibus, art. ${ }^{\circ} 1^{\text {mo }}$ elongato, $3^{\text {tio }}$ simplici, ult. ${ }^{\text {mo }}$ longissimo.

(Genus aliquo modo inter Phlophagum et Rhyncolum situm,-cum illo antennis pedibusque gracilioribus, funiculi art. $^{\circ} 2^{\mathrm{do}}$ sequentibus sensim longiore, capitulo abrupto, oculis demissis, tarsorumque art. ${ }^{\circ} 1^{\text {mo }}$ elongato, sed cum hôc corpore minus convexo magisque parallelo, rostro robustiore, scutello conspicuo, prothorace metasternoque longioribus melius congruens. Tamen oculi subinferioribus, e visu superne absconditis, corpore angusto subcylindrico, metasternoque valde elongato etiam Himatium simulat. Præterea corpore nigro, nitido, calvo, rostro elongate triangulari, scutello transverso, tarsisque longissimis gracilibus, art. ${ }^{\text {is }} 1^{\mathrm{mo}}$ et ult. ${ }^{\mathrm{mo}}$ elongatis, $3^{\text {tio }}$ parvo simplici est conspicuum.)

Hab. ins. Cape Verde (in S. Antonio lecta).-

Aphanommata.

11. oculis superne conspicuis (vel lateralibus, vel subapproximatis.)

n. coxis anterioribus plus minus separatis. o. scapo brevissimo. (rostro subtriangulari.)

49. Corpus suboblongum, convexiusculum, nitidiusculum, calvum, atrum; rostro brevi, crasso, triangulari, 
oculis sub-superioribus (i.e. supra minus separatis quam in generibus vicinis), demissis; prothorace ovali, convexo, ad latera subæqualiter rotundato, antice leviter constricto; scutello magno; elytris (prothorace conspicue latioribus) subparallelis; metasterno breviusculo, convexo. Antennæ crassiusculæ, ante medium rostri insertæ; scapo brevissimo ; funiculi art. ${ }^{\circ} 1^{\mathrm{mo}}$ magno, sub-obtriangulari, reliquis laxis, subæqualibus ( $2^{\mathrm{do}}$ vix sequentibus longiore); capitulo elongato, distincte aunulato. Pedes ad basin ut in Phloophago (sc. antici fere contigui, intermedii paulo magis distantes, postici latius sed haud valde separati); tarsis art. ${ }^{\circ} 1^{\mathrm{mo}}$ vix elongato, $3^{\text {tio }}$ fere simplici.

(Genus valde alatum, necnon inter formas vicinas rostro brevi triangulari, oculis subapproximatis scapoque brevissimo anomalum, et aliquo modo generibus sub-Hylastidicis congruens; sed tamen in hôc loco nisi fallor rectius ponendum,-funiculi, capituli, prothoracis, adominisque structurâ, coxarum separatione, formâque generali Phloophagum melius simulans.)

Hab. Africam australem (a Caffrariâ missus).-

Brachyscapus.

oo. scapo plus minus elongato, interdum brevi, nunquam brevissimo.

50. Corpus vel fusiformi-, vel longe subovato-cylindricum, nitidiusculum, calvum, aut nigrum aut (rarius, ut in typo) piceum ; rostro plus minus elongato, graciusculo, parallelo, rarius vel in medio (subg. АмоRPHORHYNCHUs, mihi) vel ad basin paulo ampliato, oculis subdemissis, sæpius in fronte haud latissime separatis; prothorace plerumque elongato, ovato-triangulari, antice leviter constricto; metasterno longiusculo, postice in medio argute canaliculato; abdominis segm. ${ }^{\text {tis }} 3^{\text {tio }}$, $4^{\text {to }}$ et ult. ${ }^{\text {mo }}$ punctis magnis (in lineâ transversâ positis) postice marginatis. Antennæ longiusculæ, subgraciles, circa medium rostri insertæ; funiculi art. ${ }^{\circ} 2^{\text {do }}$ vel haud vel vix sequentibus longiore; capitulo magno, abrupto, parum distincte annulato. Pedes ad basin fere ut in Rhyncolo, sed intermedii sensim magis distantes (sc. antici parum evidenter separati, posteriores multo magis et sæpe subæqualiter remoti); tibiis ad angulum internum in spinulam parvam productis; tarsis art. ${ }^{\circ} \mathrm{I}^{\mathrm{mo}}$ vel haud vel vix elongato, ${ }^{\text {tio }}$ paulo latiore sed plerisque fere simplici, rarius sub-bilobo.

(Genus rostro antennisque longiusculis, graciusculis, 
capituloque abrupto cum Phloophago parum congruens; sed corpore sæpius majore angustiore et minus convexo, rostro, prothorace metasternoque longioribus, scutello conspicuo, funiculi art. ${ }^{\circ} 2^{\mathrm{do}}$ necnon tarsorum $1^{\mathrm{mo}}$ brevioribus, coxis anterioribus latius separatis, tibiisque ad angulum internum in spinulam evidenter productis. A Rhyncolo præcipue differt corpore majore, rostro antennisque longioribus gracilioribus, his in medio illius insertis, capitulo majore ac magis abrupto, oculis minus prominentibus ac sæpius in fronte sensim magis approximatis, metasterno paulo magis elongato, coxisque intermediis sensim magis distantibus.)

Hab. ins. Japonicas, Malayenses, Indiam, Nov. Zealand., et cat.Phloeophagosoma.

51. Corpus angusto-fusiforme (in medio parallelum, antice et postice attenuatum), opacum, dense setuloso-squamosum; rostro longiusculo, subparallelo sed in medio paululum angustiore, oculis valde prominentibus; prothorace (elytris paulo angustiore) ovato-cylindrico; elytris parallelis ; metasterno elongato. Antennæ elongatæ, ante medium rostri insertæ; scapo elongato ; funiculi art. ${ }^{\circ} 2^{\text {do }}$ vix sequentibus longiore. Pedes longiusculi, antici ad basin parum separati; unco tibiali in posterioribus parvo ; tarsis elongatis, art. ${ }^{\circ} 1^{\mathrm{mo}}$ haud elongato, $3^{\text {tio }}$ lato et profunde bilobo, ult. ${ }^{\mathrm{mo}}$ magno, elongato, et valde clavato.

(Genus inter Cossonidas insignum corpore dense setuloso-squamoso, angusto-fusiformi, in medio parallelo sed antice et postice acuto, antennis tarsisque longiusculis, oculis valde prominentibus, tarsorumque art. ${ }^{\circ} 3^{\text {tio }}$ profunde bilobo.)

Hab. ins. Japonicas.-

Pholidoforus.

52. Corpus fusiforme, opacum, profunde sculpturatum, lutosum ; rostro longiusculo, subparallelo sed apicem versus leviter subattenuato, oculis demissis; prothorace (elytris angustiore) triangulari-ovato; elytris costatis, ad apicem ipsum recte truncatis; metasterno longiusculo. Antennæ mox ante medium rostri insertæ; scapo robusto; funiculi art. $^{\circ} 2^{\text {do }}$ hand sequentibus longiore. Pedes breviusculi, robusti; tibiis ad angulum internum in spinulam parvam distinctam productis, unco apicali magno; tarsis brevibus, filiformibus, art. ${ }^{\circ} 1^{\text {mo }}$ haud elongato, $3^{\text {tio }}$ simplici.

(Genus Calandram aliquo modo simulans, et conspicuum corpore fusiformi, lutoso, grosse sculpturato; rostro apicem 
versus obsolete subattenuato, oculis valde demissis; elytris costatis, et ad apicem ipsum recte truncatis; pedibus breviusculis, robustis, tibiis ad angulum internum spinulâ evidenter armatis, tarsisque brevibus, filiformibus, art. ${ }^{\circ} 3^{\text {tio }}$ simplici.)

Hab. ins. Japonicas.-

Coprodema.

53. Corpus et cæt. fere ut in Coprodema, sed illud paulo majus ac paulo magis parallelum (i. e. minus fusiforme), rostro paululum crassiore, oculis vix majoribus, antennis sensim longioribus, capitulo submajore, necnon mox ante medium (nec omnino in medio) rostri insertis, elytris integris (nec ad apicem truncatis), metasterno sublongiore, pedibus conspicue longioribus,-femoribus sensim minus clavatis, et tarsis (multo longioribus) haud filiformibus, art. ${ }^{\circ} 3^{\text {to }}$ evidenter latiore ac bilobo.

Hab. ins. Japonicas.-

Exodema.

54. Corpus parallelo-fusiforme, opacum, dense sculpturatum, parce lutosum, necnon in elytris (oculo fortissime armato) minutissime parce pubescens, niger ; rostro lato, robusto, depresso, canaliculato, subparallelo sed postice paululum contracto, oculis valde prominentibus; prothorace subovato, ad latera rotundato, mox pone apicem valde profunde constricto; elytris parallelis, sat grosse substriatopunctatis; metasterno longiusculo. Antennæ longiusculæ, crassæ, mox ante medium rostri insertæ; scapo robusto; funiculi (valde compacti, crassi, fere quasi subsolidi) art. ${ }^{\circ}$ $2^{\text {do }}$ vix sequentibus longiore; capitulo angusto, minime abrupto. Pedes validi, valde incrassati, ad basin (etiam antici) late separati; tarsis crassis, art. ${ }^{\circ} 1^{\text {mo }}$ haud elongato, $3^{\text {tio }}$ paulo latiore et sensim bilobo.

(In hâc familiâ conspicuum corpore nigro, opaco, dense sculpturato, sed hinc inde lutoso, elytris sub lente etiam minutissime et parce sericatis, rostro lato, depresso, canaliculato, oculis valde prominentibus, prothorace elytris sensim angustiore et mox pone apicem valde profunde constricto, funiculo crasso et valde compacto, capitulo angusto, pedibusque robustis, multo incrassatis.)

Hab. ins. Madagascar.-

Melarhinus.

55. Corpus fusiforme, dense sculpturatum, nigrum; rostro breviusculo, crassiusculo, robusto, subparallelo sed. postice paululum contracto, oculis prominulis; prothorace (elytris vix angustiore) elongato, triangulari-subcylindrico, 
mox pone apicem constricto; elytris fusiformibus antice valde truncatis, costatis ac profunde sulcatis; metasterno longiusculo; abdominis segm. ${ }^{\text {tis }} 1^{\mathrm{mo}}$ et $2^{\circ}$ inter se magis evidenter divisis quam in Cossonidis typicis, illo in maribus in medio rotundate impresso, impressione pilis fulvescentibus dense repletâ. Antennæ longiusculæ, circa medium rostri insertæ; scapo robusto; funiculi (valde compacti) art. ${ }^{\text {do }}$ haud sequentibus longiore; capitulo angustulo, nec abrupto. Pedes validi, crassi, ad basin (etiam antici) valde separati; femoribus anticis sensim crassioribus ; tarsis art. ${ }^{\circ}$ $1^{\text {mo }}$ haud elongato, $3^{\text {tio }}$ latiore et vix bilobo, ult. ${ }^{\text {mo }}$ elongato, valde clavato.

(Genus inter Cossonidas insignum corpore opaco, tamen calvo et dense punctato, Calandram aliquo modo simulans; rostro crasso subcylindrico, prothorace magno elongato, elytris grosse sulcato-lineatis, abdominisque $\operatorname{segm}^{\text {tis }} 1^{\text {mo }}$ et $2^{\text {do }}$ inter se magis conspicue divisis quam in hâc familiâ plerumque obtinet, illo in maribus in medio rotundate impresso, impressione pilis fulvescentibus repletâ.)

Hab. Ceylon, et peninsulam Malayensem.-

Psilosomus.

56. [Corpus oblongum, dense sculpturatum, nigrum; rostro longiusculo, robusto, arcuato, subparallelo sed postice paululum incrassato; elytris convexis, antice parallelis, distincte sulcatis. Antennæ in medio rostri insertæ ; funiculi art. $2^{\text {do }}$ sequentibus sensim longiore. Pedes mediocres; tarsis breviusculis, art. ${ }^{\text {is }} 1^{\mathrm{mo}}$ et $2^{\mathrm{do}}$ tenuibus, $3^{\text {tio }}$ paulo latiore sed simplici.

Hab. Africam australem (Caffrariam).]- Mimus.

57. Corpus cylindrico-oblongum, latiusculum, depressiusculum, nitidum, profunde et grosse (sed haud dense) sculpturatum, vel calvum vel parce setulosum, nigrum; rostro mediocri, robusto, parallelo, oculis prominulis ; prothorace magno, vel subovato vel subovali, basi valde truncato, pone apicem leviter constricto; scutello magno; elytris (prothoracis medii latitudine) parallelis, postice obtuse rotundatis, grosse striato-punctatis; metasterno breviusculo; abdominis segm. ${ }^{\text {tis }} 3^{\text {tio }}, 4^{\text {to }}$ et ult. ${ }^{\text {mo }}$ punctis magnis (in lineâ transversâ positis) marginatis. Antennæ breves, crassæ, longe pone medium rostri insertæ; scapo brevi, valde clavato sed versus apicem internum longe oblique subtruncato; funiculo brevi, crasso, valde compacto, gradatim multo latiore, art. ${ }^{\circ} 1^{\mathrm{mo}}$ magno lato, $2^{\text {do }}$ 
haud sequentibus longiore ; capitulo parvo, brevi, minime abrupto. Pedes breviusculi, validi, antici ad basin paulo sed posteriores latius ac subæqualiter separati (etiam intermedii paululum magis remoti quam postici); tibiis triangularibus, compressis (i. e. a basi gracili gradatim valde dilatatis), unco apicali (saltem ad angulum externum) obsoleto, sc. brevi recto spinuliformi, sed tamen apice longe bispinosis necnon spinulâ alterâ minore (versus angulum externum) armatis; tarsis art. ${ }^{\circ} 1^{\mathrm{mo}}$ vix elongato, $3^{\text {tio }}$ lato et profunde bilobo.

Hab. Africam australem.-

Amorphocerus.

58. Corpus angustulum, subcylindricum, depressiusculum, nitidiusculum, (nisi oculo fortissime armato) calvum (sed vere subtilissime, vix perspicue, parcissimeque pube adspersum), nigrum; rostro elongato, gracillimo, cylindrico, subarcuato; oculis magnis, oblongis, demissis, haud late separatis; prothorace elongato-subquadrato, antice et postice valde truncato, ad latera (præsertim postice) subrecto, depressiusculo, antice integro (haud constricto), omnino æquali; scutello subquadrato; elytris parallelis, ad apicem ipsissimum singulatim rotundatis, ad basin conjunctim sub-biarcuatis ; metasterno mediocri; abdominis segm. ${ }^{\text {tis }} 1^{\mathrm{mo}}$ et $2^{\text {do }}$ haud valde elongatis, sed $3^{\text {tio }} 4^{\text {to }} q u e$ multo minus abbreviatis quam in Cossonidis typicis. Antennæ graciles, mox ante medium rostri insertæ; scapo gracili ; funiculi art. ${ }^{\circ} 2^{\text {do }}$ vix sequentibus longiore. Pedes longiusculi, crassi, ad basin magis approximati quam in generibus vicinis (sc. antici sub-approximati, intermedii paulo magis remoti, et etiam postici haud late separati); genubus anticis angulatim extantibus; tibiis longiusculis, unco apicali obsoleto, sed ad angulum internum in spinam robustam productis; tarsis longissimis, latis, art. ${ }^{\circ} 1^{\mathrm{mo}}$ longiusculo, $3^{\text {tio }}$ valde dilatato et profunde latissimeque bilobo, unguiculis parvis.

(Aoro affinitate proximum, et inter Cossonidas anomalum,-cum illo congruens unco tibiali obsoleto, rostro gracillimo elongate cylindrico, oculis transversis demissis, corpore angusto parallelo et sub lente vix omnino calvo, prothorace integro, coxis minus separatis, tarsis elongatis latis art. $^{\circ} 3^{\text {tio }}$ valde bilobo, necnon unguiculis minutis; sed differt rostro minus elongato, oculis majoribus, funiculo art. ${ }^{\circ} 2^{\text {do }}$ brevi, corpore depressiore, prothorace longiore, sc. elongato-subquadrato, ac multo magis parallelo, scutello majore, elytris ad apicem singulatim rotundatis, tibiis 
intus haud muricatis, necnon abdominis segm. ${ }^{\text {tis }} 1^{\mathrm{mo}}$ et $2^{\mathrm{do}}$ minus elongatis, sed tamen $3^{\text {to }} 4^{\text {to }} q$ ue multo minus abbreviatis.)

\section{Hab. Americam australem (prope Amazon captus).- \\ Lipancylus.}

59. Corpus angustulum, cylindricum, vix subnitidum, profunde sculpturatum, (nisi oculo fortissime armato) calvum, brunneo-piceum; capite fere ad oculos immerso ; rostro longissimo, gracillimo, cylindrico, valde arcuato, fere haud sculpturato ; oculis angustis, transversis, omnino demissis; prothorace ovali antice et postice truncato, ad latera æqualiter rotundato, convexo, antice subintegro (vix constricto) ; elytris parallelis, cylindricis, sat grosse substriato-punctatis; metasterno haud valde elongato. Antennæ longiusculæ, subgraciles, mox ante medium rostri insertæ; funiculi art. ${ }^{\circ} 2^{\text {do }}$ sequentibus multo longiore. Pedes longiusculi, ad basin multo magis approximati quam in Cossonidis plerisque (sc. antici fere contigui, intermedii vix magis distantes, et etiam postici leviter separati); tibiis intus parcissime muricatis, unco apicali obsolete sed anterioribus ad angulum internum spinosis; tarsis elongatis, latis, art. ${ }^{\circ} 1^{\mathrm{mo}}$ longiusculo, $3^{\text {tio }}$ dilatato et valde bilobo, unguiculis parvis.

Hab. Africam occidentalem.-

Aorus.

60. Corpus parallelo-oblongum, valde depressum, subopacum, minutissime setuloso-sericatum, rufo-ferrugineum; rostro longissimo, gracillimo, parallelo, recto, scrobe rectissimo et ab apicem usque ad oculum currente; oculis maximis sed demissis, oblongis, supra haud latissime separatis; prothorace (elytris angustiore) quadrato-ovali, ad latera æqualiter subrotundato, antice leviter constricto, in disco valde et latissime depresso; scutello magno; elytris subparallelis; metasterno brevi. Antennæ elongatæ, graciles, ad apicem rostri insertæ; scapo elongato; funiculi (laxi) art. $^{\circ} 2^{\text {do }}$ sequentibus multo longiore; capitulo elongato, angusto, conspicue 3-annulato. Pedes elongati, crassiusculi, omnes æqualiter (ergo antice late) separati; femoribus subtus denticulo minuto medio armatis; tibiis ad apicem penicillato-pubescentibus, unco parvo; tarsis elongatis, latis, art. ${ }^{\circ} 1^{\mathrm{mo}}$ elongato, $3^{\text {tio }}$ multo latiore et profunde bilobo, unguiculis magnis et late divaricatis.

(Inter Cossonidas valde anomalum, atque in rostro longissimo gracillimo lineari recto longitudinaliter strigoso, 
antennis elongatis ad apicem ejus insertis, pedibus elongatis, femoribusque subtus denticulatis genera quadam Erirhinidum aliquo modo simulans; sed abdominis structura, coxæ anteriores late separatæ, tibiæque ad apicem uncinatæ ad hanc familiam recte pertinent. Aliter exstat corpore valde deplanato, ferrugineo, subopaco et minute sericato; funiculi laxi art. ${ }^{\circ} 2^{\text {do }}$ elongato; capitulo elongato, angusto, conspicue annulato; prothorace in medio latissime depresso; tibiis ad apicem penicillato-pilosis, unco parvo; tarsorumque art. $^{\circ} 3^{\text {tio }}$ lato et valde bilobo.)

Hab. ins. Americce centralis (in $S^{t}$. Domingo degens).Homaloxenus.

61. Corpus angustissimum, parallelum, depressiusculum, subopacum, minus profunde sculpturatum, minute sericeum, minus durum, pallidum; rostro longissimo, gracillimo, parallelo sed postice facillime vix latiore; capite elongato, oculis parvis sed prominentibus, supra haud latissime separatis; prothorace elongato, oblongo-triangulari, antice valde constricto, (præsertim postice) canaliculato, subtus subconcavo; elytris (prothoracis medio subangustioribus) parallelis; metasterno valde elongato, antice utrinque plicâ transversâ subfoveiformi instructo; abdominis segm. ${ }^{\text {tis }} 1^{\mathrm{mo}}$ et $2^{\text {do }}$ longitudinaliter concavis. Antennæ elongatæ, graciles, in medio rostri in $\delta$, sed in of pone medium, insertæ; funiculi laxi art. $^{\circ} 2^{\text {do }}$ sequentibus distincte longiore ; capitulo elongato, abrupto. Pedes crassi, et (præsertim antici) elongati, intermedii sensim minus separati quam in Mesites, sc. anteriores æqualiter distantes, postici paulo magis remoti ; tarsis art. ${ }^{\circ}$ $1^{\text {mo }}$ brevi, $3^{\text {tio }}$ valde profunde et latissime bilobo, unguiculis minutis.

(Genus valde distinctum corpore elongato, angustissimo, pallido, minutissime sericato, minus duro, ac minus profunde sculpturato; rostro longissimo, gracillimo; oculis minutis, prominulis; antennis gracilibus, funiculi art. ${ }^{\circ} 2^{\text {do }}$ sequentibus sensim longiore; prothorace metasternoque elongatis, illo subtus concavo, hôc convexo ; pedibus elongatis, crassis; tarsorum art. ${ }^{\circ} 3^{\text {tio }}$ valde dilatato, latissime bilobo, unguiculisque minutis.)

Hab. ins. Maderenses (in Maderâ degens).-

Stenotis.

62. Corpus angustum, parallelum, depressum, subopacum, piceum sed in elytris sensim pallidius, (oculo fortissime armato) subtilissime et parcissime sericatum; 
rostro subparallelo sed apicem versus (necnon in o ad antennarum insertionem) facile vix sublatiore, in $\delta^{\circ}$ sat robusto, sed in of graciliore et multo longiore (sc. longissimo); capite elongato, oculis parvis, subtransversis, demissis, supra haud latissime separatis; prothorace elongato, ovato-triangulari, antice valde constricto, subtus obsolete subconcavo; elytris (prothorace haud latioribus, etiam subangustioribus) parallelis; metasterno valde elongato; abdominis segm. tis $1^{\text {mo }}$ et $2^{\text {do }}$ lineâ bi-arcuatâ sat distincte divisis, illo in of tuberculo medio magno instructo. Antennæ graciles, pone medium rostri insertæ; funiculi art. ${ }^{\circ}$ $2^{\mathrm{do}}$ sequentibus vix longiore; capitulo angusto. Pedes (præsertim posteriores) breviusculi, anteriores late et subæqualiter distantes, postici vix magis remoti; tarsis art. ${ }^{\mathrm{mo}}$ brevi, $3^{\text {tio }}$ latiusculo et profunde bilobo, unguiculis minutis.

(Genus Pentarthro et Stenotrupide primâ facie subsimile, sed funiculo 7-, nec 5-articulato. Corpore depresso, rostro in $q$ elongato gracillimo, antennis longe pone medium ejus insertis, oculisque demissis cum hôe melius congruit ; sed differt capite minus incrassato, rostro etiam graciliore, prothorace longiore, tarsorumque art. ${ }^{\circ} 3^{\text {tio }}$ latiore ac profunde bilobo.)

Hab. Americam austr. (juxta Amazon et in Braziliâ captus).-

Eucoptus.

63. Corpus parallelum, subcylindricum, nitidiusculum, calvum (rarius minute pubescens), plus minus piceum vel castaneum; rostro longiusculo, in of robusto subparallelo sed ad antennarum insertionem subampliato, in + gracili polito et ad basin ipsam solum ampliato ; capite crassiusculo, oculis transversis; prothorace oblongo, antice subito et valde constricto, vix carinulato et postice vix canaliculato; elytris parallelis; metasterno longiusculo, postice longe canaliculato. Antennæ breviusculæ, crassæ, in $\hat{0}$ pone medium sed in $q$ ad basin ipsam rostri insertæ; scapo brevi, robusto, excurvato ; funiculi (crassi) $\operatorname{art.}^{\circ} 2^{\mathrm{do}}$ haud sequentibus longiore; capitulo sat parvo, angusto. Pedes (præsertim antici) robusti, antice ad basin parum, intermedii paulo latius, postici sat late (nec latissime) separati ; tarsis art. ${ }^{\mathrm{mo}} 1^{\mathrm{mo}}$ elongato, $3^{\text {tio }}$ simplici.

(A Rhopalomesites et Odontomesites differt corpore magis convexo, cylindrico, nitido; prothorace oblongo, nec subtriangulari ; capite crassiore, oculis minus approxi- 
matis ; rostro in $\delta$ breviore robustiore ac magis parallelo, sc. ad antennarum insertionem vix ampliato; antennis brevioribus, crassioribus, scapo præcipue breviore ac magis excurvo, funiculo crassiore, art. ${ }^{\circ}$ ejus $2^{\text {do }}$ haud elongato, capitulo minore angustiore; metasterno paulo magis elongato; coxisque omnibus minus distantibus.)

Hab. Europam.Mesites.

64. Corpus ut in Mesites, sed paulo minus cylindricum (sensim magis fusiforme), et paulo minus convexum, minus nitidum, sæpe minutissime sericatum; rostro in $\mathbf{0}$ longiore, graciliore, necnon ad antennarum insertionem magis ampliato; capite minus incrassato, oculis sensim magis approximatis; prothorace ovato-triangulari (nec oblongo), antice valde profunde constricto, in $\hat{\delta}$ (præsertim postice) canaliculato, sed in $q$ carinulato; elytris paulo minus parallelis (sc. sensim magis subfusiformibus basi truncatis); metasterno sub-breviore, et postice brevius canaliculato. Antennæ multo longiores ac graciliores, in of vel ante vel circa (nec pone) medium rostri insertæ; scapo præsertim longiore, ac magis in- (nec ex-) curvato; funiculi (laxioris, gracilioris) art. $^{\circ} 2^{\text {do }}$ multo magis evidenter elongato ; capitulo majore, longiore, magis abrupto. Pedes paulo longiores, necnon ad basin sensim magis distantes; tarsorum art. $^{\circ} 3^{\text {tio }}$ latiore et evidenter bilobo (nec omnino simplici).

Hab. Europam occidentalem, et ins. Atlanticas.

Rhopalomesites.

65. Corpus ut in Rhopalomesites, sed sæpius magis depressum ac sensim magis fusiforme (sc. postice evidenter attenuatum); rostro in $\delta$, ab antennarum insertionem usque ad apicem, utrinque pilis elongatis fimbriato, in + ad basin minus abrupte ampliato. Pedes paulo magis incrassati, intermedii ad basin sensim magis distantes; femoribus subtus in obtuse subdentatis; tarsorum art. ${ }^{\circ}$ $3^{\text {tio }}$ (ut in Mesites) simplici.

Hab. ins. Canarienses, et ins. Cap. Verde.-

Odontomesites.

66. [Corpus elongatum, parallelum, depressum, nitidum, setulosum, nigrum sed in elytris ferrugineum, Mesites simulans; rostro longiusculo, in $\delta$ a basi usque ad medium crassiusculo, dein graciliore, cylindrico, sed in $q$ ad basin 
solum incrassato; prothorace subquadrato, elytris paulo angustiore; metasterno longitudinaliter concavo (excavatione ad utrumque latus subcarinatâ). Antennæ in $\hat{o}$ breves et in medio, sed in $q$ breviores et ad basin rostri insertæ; scapo in $\delta$ magis clavato quam in $q$; capitulo parvo. Pedes breves, ad basin late separati; tarsis brevibus, art. ${ }^{\circ} 1^{\text {mo }}$ brevi, $3^{\text {tio }}$ latiusculo bilobo.

Hab. Africam australem.]-

Porthetes.

67. Corpus parallelum, valde depressum, nitidum, calvum, nigrum ; rostro in $\mathbf{o}$ longiusculo et antice (ut in Cossono) dilatato, necnon in medio grosse canaliculato, sed in $q$ breviusculo, subgracili, depressiusculo, subparallelo sed postice gradatim paululum angustiore, integro (vix canaliculato); oculis subrotundatis, prominulis ; prothorace (elytris sensim angustiore) sat parvo, brevi, subovali basi truncato, antice subito sed leviter constricto, basi trisinuato, præsertim postice carinulato et ibidem in medio impresso ; scutello magno rotundato; elytris parallelis, costatis; metasterno mediocri. Antennæ (præsertim in $\hat{\delta}$ ) elongatæ, crassæ, in $\delta$ longe ante sed in $q$ longe pone medium rostri insertæ ; scapo sinuate subcompresso, valde (præsertim in $\hat{\delta}$ ) sed longe clavato (quare intus postice quasi subexcavato); funiculi art. ${ }^{\circ} 2^{\mathrm{do}}$ sequentibus vix longiore; capitulo magno, longissimo, parallelo-oblongo et dense velutino. Pedes antici latissime separati, sc. vix minus remoti quam posteriores, his subæqualiter distantibus; unco tibiali breviusculo; tarsis gracilibus, art. ${ }^{\circ} 1^{\text {mo }}$ elongato, $3^{\text {tio }}$ simplici, unguiculis magnis.

(Conspicuum inter genera vicina corpore parallelo et valde depresso, rostro in $\delta$ longiusculo antice dilatato sed in $q$ breviusculo subgracili depresso et postice gradatim subangustiore, oculis rotundatis, nec transversis, prothorace brevi, elytris grosse sculpturatis ac costatis, scapo sinuate subcompresso et præsertim in $\delta$ abrupte clavato, capitulo magno longissimo ac densissime velutino, coxisque anticis late separatis.)

Hab. Americam borealem (in Mexico degens).-

Megalocorynus.

68. Corpus angustum, elongatum, parallelo-fusiforme, depressum, nitidum, calvum, plus minus piceum vel castaneum ; rostro (a fronte convexâ conspicue diviso) elon- 
gato, et (præsertim in $\$$ ) gracili, subparallelo sed plerumque apicem versus facillime paulo sublatiore, necnon versus basin sensim facile subincrassato (tamen ad basin ipsissimam sæpius obsoletissime subcontracto); oculis transversis, demissis, supra subapproximatis; prothorace elongato, vel ovato- vel oblongo-triangulari, pone apicem valde constricto, antice plus minus obsolete carinulato et postice plus minus obsolete longitudinaliter impresso; scutello magno; elytris (prothoracis medio vix latioribus) vel elongate subfusiformibus basi truncatis, vel fere parallelis, ad apicem ipsissimum minute singulatim subrotundatis; metasterno longissimo, interdum, una cum abdominis segm. ${ }^{\text {to }} 1^{\mathrm{mo}}$ longitudinaliter concavo; abdominis segm. ${ }^{\text {tis }} 3^{\text {to }}, 4^{\text {to }}$ et ult. ${ }^{\text {mo }}$ punctis magnis (in lineâ transversâ positis) postice marginatis. Antennæ breviusculæ, crassiusculæ, longe pone medium (interdum etiam versus basin ut in C. basali) rostri insertæ; scapo breviusculo; funiculi art. ${ }^{\circ} 2^{\text {do }}$ haud sequentibus longiore (sæpius etiam subbreviore); capitulo angusto, haud abrupto, acuminato. Pedes breviusculi, crassi, anterioriores leviter et æqualiter separati, postici magis (sed haud valde) distantes; tibiis ad angulum internum in spinam distinctam productis; tarsis brevibus crassis, art. ${ }^{\circ} 1^{\text {mo }}$ brevi, $3^{\text {tio }}$ multo latiore et profunde bilobo, ult. ${ }^{\text {mo }}$ brevi, crasso, conico, unguiculis minutis.

(A generibus vicinis conspicuum corpore elongato, angusto, vel parallelo-fusiformi vel parallelo, depresso, calvo ; rostro longiusculo, graciusculo, antice et postice facillime plus minus latiore, a capite convexo distincte diviso; antennis conspicue pone medium ejus insertis, crassiusculis, funiculi art. ${ }^{\circ} 2^{\mathrm{do}}$ brevi; oculis transversis, supra subapproximatis; prothorace metasternoque elongatis; scutello magno; coxis anterioribus æqualiter, et posticis vix magis late, separatis; pedibus crassis; tibiis ad angulum internum in spinam productis, tarsorumque art. ${ }^{\circ} 3^{\text {tio }}$ latiusculo et conspicue bilobo, ult. ${ }^{\text {mo }}$ brevi, crasso, conico.)

Hab. Americam (et borealem, et australem).-

Catolethrus.

69. Corpus et cæt. ut in Catolethro, sed sensim minus depressum, antennis in medio (nec longe pone medium) rostri insertis ; rostro magis parallelo (cylindrico) et etiam distinctius a fronte valde convexâ diviso, oculis valde demissis, ægerrime observandis; prothorace longiore (sc. 
longissimo, ovato-cylindrico) et æquali (nec carinulato, nec canaliculato) antice minus constricto ; scutello minore; elytris magis parallelis; coxis omnibus æqualiter remotis, etiam anticis late separatis; tarsisque multo minus incrassatis, art. $^{\circ} 3^{\text {tio }}$ parvo, simplici (nec dilatato, nec profunde bilobo). Corpus minutum, angustissimum, calvum, fere nigrum.

Hab. Americam australem (in Braziliâ degens).-

Stenotribus.

70. [Corpus fere ut in Catolethro, sed rostro graciliore, cylindrico; antennis brevioribus, gracilioribus, funiculi art. $^{\circ} 2^{\text {do }}$ sequentibus longiore, capitulo majore, magis abrupto, breviter ovali; prothorace antice gradatim angustiore. Pedes graciliores, tarsis art. ${ }^{\circ} 3^{\text {tio }}$ simplici, reliquis haud latiore.

Hab. Madagascar.]-

Proëces.

71. Corpus angustum, elongatum, parallelo-fusiforme, subdepressum, nitidum, calvum, piceum ; rostro (a fronte subconvexâ conspicue diviso) elongato, lato, subparallelo (a basi usque ad apicem facillime gradatim sublatiore), supra depresso ; oculis transversis, subdemissis, supra subapproximatis; prothorace elongato, subtriangulari-oblongo, pone apicem valde constricto, antice obsolete carinulato et postice leviter longitudinaliter impresso ; scutello magno ; elytris (prothoracis medii latitudine) elongate subfusiformibus basi truncatis, ad apicem ipsissimum minute singulatim subrotundatis; metasterno elongato; abdominis segm. ${ }^{\text {tis }}$ $1^{\mathrm{mo}}$ (ante medium) et $2^{\mathrm{do}}$ (ad basin) lenticulis duâbus rotundatis granulorum compositis (ocellos! simulantibus, necnon in illo majoribus ac magis remotis) instructis, $1^{\mathrm{mo}}$ longitudinaliter concavo, $3^{\text {tio }}, 4^{\text {to }}$ et ult. ${ }^{\mathrm{mo}}$ punctis magnis (in lineâ transversâ positis) postice marginatis, ult.."o in medio carinato et utrinque foveolato. Antennæ breviusculæ, crassiusculæ, mox pone medium rostri insertæ; scapo breviusculo ; funiculi art. ${ }^{\circ} 2^{\text {do }}$ brevi (etiam sequentibus subbreviore), capitulo angusto, haud abrupto, acuminato. Pedes valde incrassati, ad basin fere ut in Catolethro (sc. anteriores paulo et subæqualiter separati, postici magis sed haud valde distantes); femoribus posticis subtus in medio breviter fulvo-piloso-fimbriatis; tibiis ad angulum internum in spinam valde robustam (in posterioribus latam,

TRANS. ENT. SOC. 1873.-PART IV. (OCT.) 
bipartitam) productis, posticis arcuatis necnon intus versus basin fasciculo pilorum instructis; tarsis brevibus, valde incrassatis, art. ${ }^{\circ} 1^{\text {mo }}$ brevi, $3^{\text {tio }}$ latiore et profunde bilobo, ult. $^{\text {mo }}$ brevi, crasso, conico, unguiculis minutis.

(Catolethro affinis, sed discedens corpore majore, rostro multo latiore depressiusculo necnon a basi usque ad apicem latitudine facillime crescente, antennis magis versus medium ejus insertis, prothorace minus triangulari, abdominis segm. ${ }^{\text {tis }} 1^{\text {mo }}$ et $2^{\text {do }}$ lenticulis 4 granularum instructis, pedibusque magis incrassatis, femoribus posticis subtus in medio breviter piloso-fimbriatis, tibiis omnibus ad angulum internum fortius spinosis, necnon posticis arcuatis, et intus versus basin fasciculo pilorum auctis.)

Hab. Americam australem (in Braziliâ degens).-

Phacegaster.

72. Corpus angustulum, elongatum, fusiforme, convexum, nitidissimum, minus sculpturatum, calvum, nigrum sed rufo-variegatum; capite elongato; rostro (a fronte haud lineâ diviso) plus minus elongato, postice gradatim angustato, quare antice plus minus (interdum valde) latiore, et ibidem depressiusculo; oculis (longe ante marginem prothoracis sitis) subrotundatis, parum prominentibus, supra late separatis; prothorace (elytris paululum angustiore) postice subovali, antice subito et valde constricto, convexo et æquali (nec carinulato, nec impresso), subtus plus minus concavo; elytris fusiformibus basi truncatis, ad apicem ipsissimum integris; metasterno valde elongato; abdominis segm. ${ }^{\text {tis }} 1^{\mathrm{mo}}$ et $2^{\mathrm{do}}$ inter se omnino suffusis, $3^{\text {to }}, 4^{\text {to }}$ et ult. $^{\text {mo }}$ punctis magnis (in lineâ transversâ positis) postice marginatis. Antennæ longiusculæ, crassæ, vel in medio vel mox ante medium rostri insertæ; scapo longiusculo, robusto ; funiculi (crassi, compacti) art. $^{\circ} 2^{\text {do }}$ sequentibus etiam sub-breviore; capitulo elongato, angusto, haud abrupto, acuminato. Pedes elongati, crassi, antici late sed posteriores paulo magis ac subæqualiter separati; tibiis ad angulum internum in spinam robustam (in posterioribus latam, bipartitam) productis; tarsis brevibus, valde incrassatis, art. ${ }^{\circ} 1^{\text {mo }}$ breviusculo, $3^{\text {tio }}$ lato dilatato et valde profunde bilobo, ult. ${ }^{\text {mo }}$ breviusculo subconico, unguiculis parvis.

(Genus valde conspicuum corpore magno, fusiformi, subconvexo, minus sculpturato, politissimo, necnon nigro rufoque variegato; capite elongato, valde exserto ; rostro 
versus apicem gradatim plus minus late dilatato, interdum antice latissimo spatuliformi; antennis crassis, et circa medium ejus insertis, funiculi art. ${ }^{\circ} 2^{\text {do }}$ brevissimo, capitulo angusto acuminato ; tibiis posterioribus ad angulum internum in spinam valde robustam productis; tarsisque breviusculis, crassissimis, art. $^{\circ} 3^{\text {tio }}$ lato et profunde bilobo.)

Hab. ins. Malayenses (in Nov. Guinea et Sula capta).Gloodema.

73. Corpus angustulum, elongatum, fusiforme, convexum, nitidissimum, minus sculpturatum, calvum, atrum ; capite elongato; rostro breviusculo, lato, depressiusculo, et [an in utroque sexu?] fere parallelo; oculis parum prominentibus, late separatis; prothorace (elytris paululum angustiore) elongato, cylindrico-ovato, antice constricto, subconvexo, æquali, subtus leviter concavo; elytris fusiformibus basi truncatis; metasterno elongato ; abdominis segm. ${ }^{\text {tis }} 1^{\mathrm{mo}}$ et $2^{\mathrm{do}}$ inter se omnino suffusis. Antennæ longiusculæ, crassæ, conspicue ante medium rostri insertæ; scapo breviusculo, robusto; funiculi (crassi, compacti) art. ${ }^{\circ} 1^{\mathrm{mo}}$ crasso lato, $2^{\mathrm{do}}$ sequentibus haud longiori ; capitulo elongato, angusto, haud abrupto, acuminato. Pedes crassi, valde robusti, antici parum anguste sed posteriores latius ac subæqualiter (tamen haud valde) separati; tibiis crassis, rectis, ad angulum internum in spinam robustam (in posterioribus sub-bipartitam, sed in anticis longissimam acutam horizontalem) productis, anticis intus pone apicem longe subemarginatis et ibidem fortiter ciliatis; tarsis brevissimis, valde incrassatis, art. ${ }^{\circ} 1^{\text {mo }}$ breviusculo, $3^{\text {tio }}$ crasso sed simplici, ult. ${ }^{\text {mo }}$ brevissimo conico, unguiculis parvis.

(Præstans corpore fusiformi, minus sculpturato, politissimo, atro; rostro breviusculo, lato, fere parallelo; antennis crassis, et ante medium ejus insertis; pedibus valde incrassatis, anticis anguste separatis; tibiis anticis ad angulum internum in spinam longissimam acutam horizontalem productis, et pone spinam fortiter ciliatis; tarsisque brevissimis, crassissimis, art. ${ }^{\circ} 3^{\text {tio }}$ simplici, ult. ${ }^{\text {mo }}$ brevissimo et valde conico.)

Hab. Madagascar.-

Glooxenus.

74. Corpus angustum, elongatum, parallelum, cylindricum, convexum, nitidum, calvum, nigrum sed rufo-variegatum; capite lato, convexo, subelongato; rostro brevius- 
culo, lato, vel parallelo vel [an character sexualis?] antice gradatim paulo latiore; oculis subrotundatis, prominentibus, late separatis; prothorace (in medio latitudine elytrorum) elongato, triangulari-subcylindrico, antice valde constricto, subconvexo et æquali (nec carinulato, nec impresso), subtus in medio [an character sexualis?] profunde et subito excavato-concavo, postice grosse marginato; scutello parvo; elytris fere parallelis, basi marginatis, ad apicem ipsissimum utrinque subrecurvo-marginatis ; metasterno longissimo; abdominis segm. ${ }^{\text {tis }} 1^{\mathrm{mo}}$ et $2^{\mathrm{do}}$ inter se omnino suffusis. Antennæ crassæ, vel in medio vel mox ante medium rostri insertæ; scapo robusto, excurvato; funiculi (crassi, compacti) art. ${ }^{\circ} 2^{\mathrm{do}}$ sequentibus etiam subbreviore ; capitulo elongato, angusto, haud abrupto, acuminato. Pedes longiusculi, crassi, omnes ad basin subæqualiter separati; tibiis (valde robustis, anticis biflexuosis) ad angulum internum in spinam robustam (in posterioribus sub-bipartitam) productis, cavernâ apicali (pro tarsorum receptione) magnâ et valde apertâ; tarsis brevibus, et valde incrassatis, art. ${ }^{\circ} 1^{\text {mo }}$ breviusculo, $3^{\text {tio }}$ latiore et profunde bilobo, ult. ${ }^{\mathrm{mo}}$ brevi, conico, unguiculis minutis.

(Conspicuum inter genera vicina corpore sat magno, angusto, elongato, cylindrico; capite rostroque latis, hôc breviusculo, in $\dot{t}$ parallelo, sed in $\delta$ antice paulo latiore; elytris antice rufis; coxis omnibus subæqualiter separatis; pedibus longiusculis, crassis ; tibiis valde robustis, cavernâ apicali magnâ et late apertâ, anticis biflexuosis; tarsisque brevibus, crassis, art. ${ }^{\circ}$ ult. $^{\text {mo }}$ brevi, conico.)

Hab. ins. Malayenses (in Tondano et cret. captus).-

Exonotus.

75. Corpus angustum, elongatum, parallelo-fusiforme, sublepressum, nitidum, calvum, nigrum (interdum rufovariegatum); rostro (a fronte haud diviso) vel elongato vel breviore, subparallelo sed pone medium (versus antennarum insertionem) obsolete facillime subincrassato, rarius [an character sexualis?] antice gradatim latiore; oculis magnis, subroduntatis, prominentibus, supra late separatis; prothorace triangulari-ovato, pone apicem leviter constricto, æquali (nec carinulato, nec impresso), postice tenuiter marginato ; elytris (prothoracis medii latitudine) fere parallelis, basi apiceque haud marginatis; metasterno elongato; abdominis segm. ${ }^{\text {tis }} 3^{\text {tio }}, 4^{\text {to }}$ et ult. ${ }^{\text {mo }}$ punctis magnis (in lineâ transversâ positis) postice margi- 
natis. Antennæ longiusculæ, crassiusculæ, mox pone medium rostri insertæ ; funiculi art. ${ }^{\circ} 2^{\text {do }}$ haud sequentibus longiore ; capitulo angustulo, haud abrupto. Pedes breviusculi, crassi, antici parum late sed posteriores latius ac subæqualiter separati; tibiis ad angulum internum in spinulam distinctam productis ; tarsis brevissimis, crassis, art. ${ }^{\circ} 1^{\text {mo }}$ brevi, $3^{\text {tio }}$ vix latiore sed distincte bilobo, ult. $^{\text {mo }}$ brevissimo, crasso, conico, unguiculis minutis.

(Corpus Catolethrum aliquo modo simulans, sed minus depressum; rostro paulo magis parallelo et haud a fronte diviso ; oculis majoribus, magis rotundatis, magis prominentibus, ac latius separatis; prothorace omnino æquali, nec carinulato, nec impresso; scutello subminore; elytris ad apicem integris, nee singulatim subrotundatis; coxis anterioribus, præsertim intermediis, latius separatis, quare posterioribus, nec anterioribus, subæqualiter distantibus; tarsisque etiam brevioribus art. ${ }^{\circ}$ ult $^{\mathrm{mo}}$ brevissimo.)

Hab. ins. Japonicas et Malayenses.- Pseudocossonus.

76. Corpus et cæt. ut in Catolethro, sed rostro crassiore et omnino parallelo (nec antice et postice sublatiore), atque haud a fronte diviso; capite majore, ac magis exserto, oculis rotundatis, subprominentibus (nec transversis, demissis), necnon in fronte multo latius separatis ; prothorace minus elongato (sc. antice et postice magis truncato), sensim convexiore, æquali (nec carinulato, nec postice impresso); elytris magis parallelis (nec facile gradatim subattenuatis), et ad apicem ipsissimum integris (nec singulatim subrotundatis); antennis in medio (nec conspicue pone medium) rostri insertis, scapo multo longiore, capituloque magis abrupto ac minus acuminato; coxisque intermediis latius separatis (sc. posterioribus, nec anterioribus, subæqualiter distantibus).

(A Pseudocossono differt, inter alia, corpore depressiore, prothorace breviore, sc. antice et postice magis truncato, oculis minoribus, antennis in medio, nec pone medium, rostri magis paralleli insertis, tarsisque longioribus, art. ${ }^{\circ}$ ult. $^{\text {mo }}$, tamen brevi, sensim minus abbreviato.)

Hab. Indiam orientalem.-

Catolethromorphus.

77. Corpus angustulum, parallelum, depressiusculum, nitidum, calvum, pallidulum, Catolethromorphum aliquo modo simulans, sed multo minus; rostro parum robusto 
(ut in illo) et omnino parallelo, tamen paulo minus elongato; oculis magnis, sed subdemissis, sat late distantibus; prothorace triangulari-ovato, antice minus constricto, æquali (nec carinulato, nec postice impresso); elytris parallelis; metasterno longiusculo; abdominis segm. ${ }^{\text {to }} 1^{\text {mo }}$ (in $2^{\text {dum }}$ omnino suffuso) obsolete longitudinaliter concavo, $3^{\text {tio }}$, $4^{\text {to }}$ et ult. $^{\text {mo }}$ punctis maximis (in lineâ transversâ positis) postice marginatis. Antennæ crassiusculæ, mox pone medium rostri insertæ; scapo longiusculo, robusto, excurvato; funiculi (brevi, crassi, compacti) art. ${ }^{\circ} 2^{\text {do }}$ brevissimo, fere e visu abscondito, capitulo elongato, magno, sed haud valde abrupto. Pedes crassiusculi, posteriores (nec anteriores) subæqualiter distantes (sc. intermedii late separati, etiam sublatius quam postici); tibiis ad angulum internum in spinulam parvam productis; tarsis brevibus, crassiusculis sed subfiliformibus, art. $^{\circ} 1^{\text {mo }}$ haud elongato, $3^{\text {tio }}$ angusto, simplici.

(Genus conspicuum corpore parvo, subparallelo, depressiusculo pallidulo; rostro parallelo, sat robusto, oculis magnis sed subdemissis, antennis mox pone medium ejus insertis ; funiculi brevi crassi compacti art. ${ }^{\circ} 2^{\text {do }}$ brevissimo, fere abscondito; capitulo elongato, magno, sed haud valde abrupto; coxis intermediis late separatis ; tarsisque breviusculis, crassiusculis, sed art. ${ }^{\circ} 3^{\text {tio }}$ angusto, simplici.)

Hab. ins. Borneo (prope Sarawak repertus).-

Brachychænus.

78. Corpus et cæt. fere ut in Micromimo, sed angustius, magis parallelum, minus nitidum, atque in elytris (oculo fortissime armato) minutissime et parcissime sericatum; rostro longiore, graciliore, ac omnino parallelo (nec postice etiam subangustiore), antennis in medio (nec ante medium) ejus insertis; oculis magis rotundatis, ac valde prominentibus (nec demissis); prothorace magis triangulari, et antice profundius constricto; elytris longioribus, sed tamen postice minus acuminatis (pygidium vix omnino tegentibus); tibiis ad angulum internum spinulâ minutâ distinctius terminatis; tarsisque gracilioribus.

Hab. Americam australem (in Braziliâ captus).-

Stenomimus.

79. Corpus minutum, angustulum, parallelo-fusiforme, depressiusculum, nitidum, calvum, rufo-testaceum, a aut piceum; rostro (haud a fronte lineâ diviso) subparallelo 
(postice vix contracto), lato; oculis maximis, transversis, demissis, supra haud late separatis; prothorace elongato, triangulari-ovato, pone apicem leviter constricto, postice plus minus obsolete longitudinaliter impresso; scutello magno; elytris (prothoracis medio haud latioribus) subparallelis; metasterno longiusculo (nec valde elongato); abdominis segm. ${ }^{\text {tis }} 3^{\text {tio }}, 4^{\text {to }}$ et ult. ${ }^{\mathrm{mo}}$ punctis magnis (in lineâ transversâ positis) postice marginatis. Antennæ breves, crassiusculæ, mox ante medium rostri insertæ; scapo brevissimo, subito clavato; funiculi art. ${ }^{\text {is }}$ brevibus, $2^{\text {do }}$ haud sequentibus longiore; capitulo magno, parum abrupto, acuminato. Pedes breviusculi, omnes (etiam antici) late separati et subæqualiter distantes (sc. antici vix magis approximati quam posteriores); tarsis brevibus, subfiliformibus, art. ${ }^{\circ} 1^{\mathrm{mo}}$ paululum elongato, $3^{\text {tio }}$ simplici, unguiculis minutis.

(Genus conspicuum corpore minuto, depressiusculo, sæpius pallido; rostro brevi, lato, subparallelo, sc. postice vix angustiore; oculis maximis, transversis, sed omnino demissis; scapo brevissimo, subito clavato, et mox ante medium rostri inserto; coxis omnibus, etiam anticis, late separatis ; tarsorumque art. ${ }^{\circ} 3^{\text {to }}$ simplici.)

(A Catalethro discedit corpore minore, minus elongato; rostro multo breviore, latiore, magis parallelo, necnon haud a fronte diviso; oculis majoribus; antennis brevioribus, et ante medium rostri insertis; scapo multo breviore, magisque clavato; elytris ad apicem ipsissimum integris; metasterno minus elongato; coxis latius separatis ; tarsisque gracilioribus, art. ${ }^{\circ} 3^{\text {tio }}$ simplici.)

Hab. Americam (sc. juxta Amazon, ins. Trinidad, Mexico, et cet.).Micromimus.

80. Corpus angustulum, parallelum, valde deplanatum, politissimum, calvum, fere haud sculpturatum, in parte pallidulum; capite elongato-quadrato, angustulo, valde exserto, depresso, oculis magnis sed demissis, subtus subapproximatis; rostro brevissimo, lato, sed fere parallelo (ad basin ipsam paululum contracto); prothorace triangulari-quadrato, basi recte truncato, aut etiam subconcavo (nullo modo sinuato), ad apicem truncato et haud (aut tamen obsoletissime sub-) constricto, æquali; scutello magno; elytris parallelis, ad basin subarcuatis (nec sinuatis); metasterno longiusculo; abdominis segm. ${ }^{\text {tis }} 1^{\mathrm{mo}}$ et $2^{\text {do }}$ inter se omnino suffusis. Antennæ mox ante basin 
rostri insertæ; scapo longissimo, excurvato, versus apicem subcompresso et longe subitoque clavato sed intus oblique truncato (angulum internum efficiente); funiculo brevissimo, compacto, a art. ${ }^{\circ} 2^{\text {do }}$ (brevi) gradatim multo latiore; capitulo maximo, abrupto, elongato, ovali, dense velutino. Pedes (præsertim posteriores) breves, politissimi, omnes ad basin latissime separati (sed antici paulo minus quam intermedii, et his paulo minus quam postici); femoribus valde clavatis; tibiis brevibus; tarsis subgracilibus, filiformibus, art. ${ }^{\circ} 1^{\mathrm{mo}}$ longiusculo, $3^{\text {to }}$ simplici.

(Cossoni formam primâ facie simulans, sed tamen genus anomalum corpore supra et subtus valde deplanato, politissimo, fere esculpturato ; capite elongato-quadrato, valde exserto, depresso ; oculis magnis, sed demissis, subtus subapproximatis; rostro brevissimo, lato, subparallelo, antennis versus basin ejus insertis, scapo excurvato, angulatim clavato, funiculo brevissimo, capituloque maximo; prothorace æquali, antice haud constricto, postice recte truncato; coxis omnibus latissime separatis; femoribus valde clavatis ; tibiisque brevibus.)

Hab. ins. Malayenses (in Morty et Gilolo degens).-

Glœotrogus.

81. Corpus fere ut in Gloetrogo, sed paulo magis (tamen levissime) sculpturatum, ac minus politum; capite (ut in illo, elongato et valde exserto, tamen) multo angustiore, convexiore, ovali (nec deplanato, subquadrato), oculis supra magis approximatis; rostro multo longiore, convexiore, et postice magis gracili, quare haud parallelo (sc. antice lato, sed pone antennarum insertionem subito et longe contracto); prothorace etiam magis quadrato, et ad apicem ipsum evidentius constricto, tamen valde æquali ; abdominis segm. ${ }^{\text {tis }} 3^{\text {tio }}, 4^{\text {to }}$ et ult. ${ }^{\text {mo }}$ punctis magnis (in lineâ transversâ positis) postice marginatis. Antennæ paulo longiores quam in Glaotrogo, necnon conspicue ante (haud pone) medium rostri insertæ; scapo rectiore et minus excurvato, tamen leviter biflexuoso, apicem versus minus clavato, et intus obsoletissime solum subtruncato (quare vix angulum efficiente); funieuli art. $^{\circ} 2^{\text {do }}$ sensim longiore; capitulo (ut in illo) maximo. Pedes sensim longiores; femoribus (saltem posterioribus) paulo minus clavatis; tibiisque minus abbreviatis.

Hab. ins. Malayenses (in Coram et Batchian captus).Homalotrogus. 
82. Corpus valde deplanatum, ut in genere præcedenti (et paulo magis Cossoni formam simulans), sed majus, multo profundius sculpturatum; rostro magis parallelo, postice multo minus contracto (quare antice haud subito ampliato); capite sensim crassiore (tamen angusto, ovali, exserto); antennis in medio (aut tamen vix ante medium) rostri insertis, scapo intus versus apicem vix evidentius subangulatim truncato, funiculique art. $2^{\text {do }}$ brevi (nullo modo sequentibus longiore); prothoraceque (punctis perpaucis maximis ubique notato) longiore, magis oblongo, necnon ad basin evidentius sub-trisinuato.

Hab. ins. Malayenses (in Batchian repertus).-

Isotrogus.

83. Corpus fere ut in Cossono, sed valde deplanatum, paulo magis fusiforme, atque lætius variegatum ; oculis paulo magis prominentibus; prothorace (nec carinulato, nec postice impresso) fere impunctato,-_solum punctis perpaucis maximis, in seriebus duâbus dorsalibus positis, notato; abdominisque segm. ${ }^{\text {tis }} 1^{\mathrm{mo}}$ et $2^{\mathrm{do}}$ inter se omnino suffusis.

Hab. Nov. Guinea (ad Dorey deprehensus).-

Heterophasis.

84. Corpus parallelum, plus minus angustulum et depressiusculum, sæpius nitidum et calvum (rarius opacum, et rariss. minute subpubescens), plerumque grosse sculpturatum et nigrum, vel ferrugineum (rariss. lætius coloratum); rostro postice contracto, antice (ad antennarum insertionem) plus minus valde rotundato-ampliato; oculis ovalibus, sæpius demissis, supra haud latissime separatis; prothorace plus minus triangulari-quadrato, mox pone apicem sæpius subito et profunde constricto, necnon ad basin trisinuato, postice in medio plus minus carinato atque plus minus longitudinaliter triangulariter impresso; elytris parallelis, vel sensim vel vix prothorace latioribus; metasterno haud valde elongato. Antennæ pone apicem rostri insertæ; funiculi art. ${ }^{\circ}{ }^{\mathrm{do}}$ vel paulo vel haud sequentibus longiore; capitulo magno, abrupto. Pedes ad basin late separati (plerumque anteriores subæqualiter, et postici paulo magis, distantes); tarsis art. ${ }^{\circ} 1^{\mathrm{mo}}$ plus minus elongato, $3^{\text {tio }}$ simplici.

Hab. fere in toto orbe terrarum.-

Cossonus. 
85. Corpus fere ut in Cossono, sed minutissime et parce setuloso-pubescens, supra omnino opacum; rostro multo latiore, brevi, et fere parallelo (sc. postice solum subangustiore); capite latiore, oculis magis rotundatis, magis prominentibus, ac multo latius separatis; prothorace (antice constricto, et postice profunde bisinuato) paulo breviore ac magis ovali (i. e. minus quadrato), necnon ubique grosissime densissimeque æqualiter punctato, postice sensim carinulato sed haud impresso ; elytris elongatis, valde parallelis; metasterno longiusculo. Pedes intermedii ad basin latius (sc. latissime) distantes, omnes late separati; femoribus (præsertim posterioribus) minus clavatis; tibiis paulo longioribus ac subflexuosis; tarsisque longioribus, unguiculis majoribus.

Hab. peninsulam Malayensem (in Singapore captus).-
Hyponotus.

86. Corpus fere ut in Cossono, sed rostro breviore, crassiore ac fere parallelo (sc. postice vel haud vel vix angustato); oculis majoribus, magis rotundatis, ac magis prominentibus, supra paulo latius separatis ; funiculi art. ${ }^{\circ}$ $2^{\mathrm{do}}$ vel haud vel vix sequentibus longiore; prothorace magis æqualiter densiusque punctato, postice vix carinulato et haud longitudinaliter impresso; metasterno longiore; coxis omnibus minus late separatis; tarsorumque art. ${ }^{\circ} 3^{\text {tio }}$ minus simplici (sc. minutissime sub-bilobo).

Hab. Americam borealem (in Mexico degens).-

Borophlous.

87. Corpus crassum, sub-parallelum, convexum, nitidum, calvum, grossissime sculpturatum, atrum; capite lato, crasso, oculis demissis et haud latissime separatis; rostro brevi, lato, crasso, subtriangulari-parallelo (sc. postice vix latiore), supra in medio paululum gibboso; prothorace (elytris vix angustiore) elongato, cylindrico-oblongo postice subrecte truncato (vix sinuato), antice integro (nee constricto), grossissime subæqualiter punctato, carinulâ obsoletâ mediâ læviore ; scutello magno; elytris parallelis, ad basin subrecte truncatis (nec 3 -sinuatis); metasterno breviusculo. Antennæ crassiusculæ, mox ante medium rostri insertæ; scapo breviusculo; funiculi (haud compacti) art. ${ }^{\circ} 2^{\text {do }}$ sequentibus vix longiore; capitulo ovali, abrupto. Pedès robusti, antici parum late sed posteriores latius ac subæqualiter separati; tibiis (anticis simplicibus) longius- 
culis, unco apicali magno; tarsis art. $^{\circ} 1^{\text {mo }}$ elongato, $3^{\text {tio }}$ simplici, unguiculis magnis.

(Genus præstans corpore magno, crasso, robusto, convexo, subparallelo, cylindrico, grossissime sculpturato; capite rostroque latis, crassis, hồc brevi, subtriangulariparallelo; oculis demissis, haud latissime separatis; prothorace antice haud constricto et postice subrecte truncato, grossissime et æqualiter punctato; necnon scapo breviusculo.)

Hab. Americam australem (in Chili degens).-
Pachytrogus.

88. Corpus angustulum, sub-parallelum, convexiusculum, nitidum, calvum, grosse sculpturatum, atrum; capite latiusculo, oculis subrotundatis, prominentibus, et late separatis; rostro brevi, lato, subquadrato, parallelo (sc. postice vix angustiore ), postice plus minus breviter canaliculato (canaliculâ e foveâ minutâ frontali surgente); prothorace (pone medium vix latitudine elytrorum) elongato, cylindrico-ovato, antice profunde constricto, postice leviter trisinuato, parce punctato (punctis in parte grossis, et in parte minutis), plus minus carinato, et postice ad basin ipsissimam sub-biimpresso; elytris subfusiformi-parallelis; metasterno mediocri. Antennæ crassiusculæ, ante medium rostri insertæ; scapo breviusculo; funiculi (crassi subcompacti) art. ${ }^{\circ} 2^{\mathrm{do}}$ paululum sequentibus longiore ; capitulo sat magno, sed haud valde abrupto. Pedes (præsertim antici) robustissimi, valde incrassati, antici ad basin parum (nec late), posteriores paulo latius et æqualiter, separati; femoribus (præsertim anticis) valde incrassatis; tibiis brevibus, latis, et (præsertim anticis) subcompressis, unco apicali maximo, anticis (pone angulum spiniformem internum) etiam lamellato-ampliatis ac posterius concavis, posterioribus triangularibus; tarsis art. ${ }^{\circ} 1^{\mathrm{mo}}$ paulo elongato, $3^{\text {tio }}$ simplici.

(Inter Cossonides conspicuum pedibus robustissimis, valde incrassatis ; tibiis brevibus latis subcompressis, anticis intus pone angulum internum triangulariter lamellatoampliatis. Aliter exstat rostro brevi, lato, subquadrato, postice in medio canaliculato; capite multo latiore quam in Cossono, oculis magis prominentibus latiusque separatis, prothorace longiore, coxisque omnibus, præsertim anticis, minus distantibus.)

Hab. ins. Malayenses.-

Stereoborus. 
89. Corpus et cæt. ut in Stereoboro, sed capite sensim minus lato; rostro (rarius longiore et pone antennas angustato) ad apicem subtus plus minus barbato, postice grosse et profunde sed breviter lateque fisso (nec subtenuiter canaliculato); oculis paulo magis prominentibus; funiculi magis compacti art. ${ }^{\circ} 2^{\text {do }}$ sub-breviore; tibiarumque anticarum lamellâ internâ a spinâ robustâ (pone angulum internum spiniformem sitâ) surgente.

Hab. ins. Malayenses, et Ceylon.-

Stereotribus.

90. Corpus (angustulum, magnum, parallelum, nitidum) et cæt. fere ut in Stereoboro et Stereotribo, sed illud paulo majus, ac minus atrum (sc. antice et subtus piceum); rostro sensim longiore et antice magis rotundato-ampliato (quare postice, ut in speciebus Stereotribi ins. Ceylon colentibus, conspicue angustato), postice profunde canalicudato (canaliculâ e foveâ frontali rotundatâ profundâ surgente); oculis prominentibus, et paululum minus late separatis ; prothorace (ut in illo, magno) magis oblongo, ac minus grosse sculpturato, basi rectius truncato (vix sinuato); elytris magis parallelis, basi rectius truncatis (nec bi-arcuatis). Antennæ magis incrassatæ (sc. crassissimæ), ac remotius ab apice rostri quam in generibus illis insertæ; scapo sub-tortuoso, valde robusto, et valde clavato ; funiculo latissimo, tamen articulis inter se profunde divisis (nec ut in Stereotribo arcte adpressis), $2^{\mathrm{do}}$ haud sequentibus longiore; capitulo minore (sc. parvo, et minime abrupto). Pedes paulo longiores minusque incrassati (tamen valde robusti) quam in generibus illis; tibiis longioribus, necnon ad angulum internum spinâ subhorizontali distinctius armatis (spinâ in posterioribus, ut in generibus circa Phacegaster, sub-bipartitâ), anticis intus minus evidenter lamellato-ampliatis.

Hab. Australiam meridionalem.-

Stereomimetes.

91. Corpus angustulum, parallelum, cylindricum, convexum, nitidissimum, calvum, lævius sculpturatum, atrum ; capite lato, crasso, oculis magnis, valde anterioribus, subrotundatis, parum prominentibus, latissime separatis ; rostro brevissimo, latissimo (capite vix angustiore), sed tamen parallelo, ad apicem subtus plus minus barbato, necnon emarginatione superiore apicali (pro labri receptione) lobo centrali plus minus repletâ,--lobo vel (ut in gen. Stereotribo) magno sed in medio fisso (quare rostro 
ad apicem ipsissimum minute trifisso), vel (ut in $S$. pacifico) brevissimo, obsoleto, integro ; rostro vel simplici, vel postice in medio tuberculo centrali armato ; fronte vel integrâ, vel (ut in $S$. pacifico) minutissime brevissimeque incisâ (lateribus fissuræ in tuberculos duos minutissimos incrassatis); prothorace (pone medium circa latitudine elytrorum) valde elongato, subconico, antice leviter constricto, postice subrecte truncato (vix sinuato), æquali; elytris parallelis, cylindricis; metasterno longiusculo. Antennæ in medio rostri insertæ; scapo brevi ; funiculi (crassi, sed vix compacti) art. $^{\circ} 2^{\text {do }}$ haud sequentibus longiore; capitulo sat magno, longiusculo. Pedes breviusculi, et (præsertim antici) robustissimi, antici parum, posteriores paulo latius et subæqualiter separati ; femoribus (præsertim anticis) valde incrassatis; tibiis brevibus, latis, unco apicali maximo, anticis (pone angulum spiniformem internum) compresso-ampliatis, parte ampliatâ e spinâ robustâ secundâ surgente, posterioribus triangularibus; tarsis art. ${ }^{\circ} 1^{\mathrm{mo}}$ paulo elongato, $3^{\text {tio }}$ simplici.

(Genus præstans corpore parallelo, cylindrico, convexo, nitidissimo, atro, minus profunde sculpturato ; rostro brevissimo, latissimo, sc. capite vix angustiore, sed parallelo, supra interdum tuberculo armato, apice sæpius minute trifisso, et subtus interdum barbato; prothorace magno, valde elongato, cylindrico-conico, æquali, postice subrecte truncato ; elytris parallelis, breviter cylindricis; oculis latissime separatis; pedibusque robustissimis, femoribus anticis valde incrassatis et tibiis anticis in dimidio basali interno compresso-ampliatis,-parte auctâ e spinâ robustâ, pone angulum internum spiniformem sitâ, surgente.)

Hab. ins. Malayenses, et ins. "Fiji." - Stereoderus.

92. Corpus angustum, elongatum, fusiforme (antice et postice attenuatum), nitidum, calvum, nigrum ; rostro elongato, subgracili, vix parallelo, sc. postice (pone antennas) paulo angustato, quare antice obsolete latiore; oculis rotundatis, prominentibus, parum late separatis; prothorace (in medio vix elytris angustiore) elongato, subovali, antice profunde constricto, æquali (nec carinulato, nec impresso); scutello parvo; elytris postice gradatim attenuatis, ad apicem ipsissimum minute singulatim subrotundatis; metasterno elongato. Antennæ elongatæ, in medio aut mox ante medium rostri insertæ ; scapo longiusculo ; funiculi art ${ }^{\mathrm{O}} 2^{\mathrm{do}}$ haud sequentibus lon- 
giore ; capitulo ovali, haud valde abrupto. Pedes elongati, antici late et posteriores latius sed vix æqualiter separati (sc. postici sub-magis distantes quam intermedii); tibiis ad angulum internum in spinulam parvam productis ; tarsis art. ${ }^{\circ} 1^{\text {mo }}$ haud elongato, $3^{\text {tio }}$ paulo latiore et profunde bilobo.

(Genus conspicuum corpore magno, elongato, angusto, fusiformi, antice et postice attenuato, nigro ; rostro elongato, subgracili, in dimidio postico paululum angustato ; oculis rotundatis, et valde prominentibus ; elytris ad apicem ipsissimum obsolete singulatim rotundatis ; antennis pedibusque elongatis; coxis anticis late separatis ; tarsorumque art. $^{\circ} 3^{\text {tio }}$ conspicue bilobo.)

Hab. ins. Malayenses, et Ceylon.-

Oxydema.

93. Corpus elongatum, fusiforme, nitidiusculum, Oxydema propinquans, sed subconvexius, minus angustatum, postice minus attenuatum, et omnino minus nigrum ; rostro paulo breviore, et postice minus distincte (tamen evidenter) angustato; antennis (ut in illo, in medio aut mox ante medium rostri insertis) paulo gracilioribus, funiculi art. ${ }^{\circ}$ $2^{\mathrm{do}}$ minus valde abbreviato, capituloque subminore ; oculis valde prominentibus; prothorace (elytris conspicue angustiore) minus elongato, et antice minus profunde constricto ; scutello minus transverso ; metasterno paulo minus elongato ; tarsisque gracilioribus, art. $^{\circ} 3^{\text {tio }}$ minore, angustiore, et minutius (tamen evidenter) bilobo.

Hab. Australiam.-

Notiosomus.

94. Corpus angustum, elongatum, parallelo-fusiforme, depressum, subnitidum, calvum, nigrum ; rostro longiusculo, subgracili, parallelo; oculis rotundatis, parum prominentibus; prothorace (in medio latitudine elytrorum) elongato, triangulari-ovato, antice profunde constricto, postice in medio late et leviter longitudinaliter impresso ; scutello parvo; elytris parallelo-fusiformibus basi truncatis ; métasterno elongato, et, una cum abdominis segm. ${ }^{\text {tis }}$ $1^{\mathrm{mo}}$ et $2^{\mathrm{do}}$ (inter se distincte divisis), paulo longitudinaliter concavo ; abdominis segm. ${ }^{\text {tis }} 3^{\text {tio }}, 4^{\text {to }}$ et ult. ${ }^{\text {mo }}$ punctis magnis (in lineâ transversâ positis) postice marginatis, ult. ${ }^{\text {no }}$ in medio [an character sexualis?] foveâ rotundatâ profundâ impresso. Antennæ elongatæ, in medio aut mox ante medium rostri insertæ; funiculi art. ${ }^{\circ} 2^{\text {do }}$ haud sequentibus longiore ; capitulo parvo, valde angusto, acuminato. 
Pedes elongati, crassiusculi, antici ad basin parum, intermedii latius, sed postici paulo magis separati; tibiis ad angulum internum in spinulam parvam productis; tarsis art. ${ }^{\circ} 1^{\text {mo }}$ haud elongato, $3^{\text {tio }}$ lato et profunde bilobo, ult. ${ }^{\text {mo }}$ breviusculo.

(Corpore magno, angusto, elongato, subfusiformi, nigro, rostro longiusculo, tarsorumque art. ${ }^{0} 3^{\text {tio }}$ conspicue bilobo genus Oxydema simulans; sed differt, inter alia, corpore depressiore, postice minus attenuato, densius minutiusque sculpturato, rostro subbreviore et omnino parallelo, nec postice angustato, capitulo multo minore, minus abrupto necnon apice acuminato, prothoraceque postice in medio late sed leviter impresso, nec æquali.)

Hab. Australiam meridionalem.-

Aphanocorynes.

95. Corpus et cæt. fere ut in Aphanocorynes, sed illud magis depressum ac magis parallelum, elytris ad apicem ipsissimum (ut in Rhyncolo reflexo, Europæ) singulatim recurvis; antennis mox pone medium (nec in medio) rostri insertis, capitulo multo majore, latiore, ac magis abrupto, sc. ovali (nec acuminato); oculis majoribus ; prothorace magis triangulari (postice elytrorum latitudine), omnino æquali, antice levius constricto ; elytris parallelis, ad basin rectissime truncatis; pedibus minus incrassatis, anterioribus ad basin magis et æqualiter separatis, posticis etiam subminus distantibus quam anteriores; tibiis rectioribus; tarsorumque art. ${ }^{\circ} 3^{\text {tio }}$ multo minore ac fere simplici (nec lato et profunde bilobo), ult. ${ }^{\text {mo }}$ longiore.

Hab. ins. Malayenses.-

Orthotemnus.

96. Corpus angustum, elongatum, vel parallelum vel subfusiformi-parallelum, nitidum, calvum, nigrum ; rostro breviusculo, robusto, parallelo sed ad basin plus minus obsolete substrangulatim contracto ; oculis magnis, prominentibus; prothorace elongato, triangulari-cylindrico, antice parum constricto, æquali; elytris vel parallelis vel subfusiformi-parallelis ; metasterno elongato ; abdominis segm..$^{\text {to }} 1^{\mathrm{mo}}$ interdum longitudinaliter concavo, $3^{\text {tio }}, 4^{\text {to }}$ et ult. ${ }^{\mathrm{mo}}$ punctis magnis (in lineâ transversâ positis) postice marginatis. Antennæ vel in medio vel mox pone medium rostri insertæ ; funiculi (compacti) art. ${ }^{\circ} 2^{\text {do }}$ haud sequentibus longiore; capitulo parvo, haud abrupto, sed tamen haud acuminato. Pedes breviusculi, antici parum sed posteriores latius et subæqualiter separati ; tibiis ad angu- 
lum internum in spinulam distinctam productis; tarsis crassiusculis, art. ${ }^{\circ} 1^{\text {mo }}$ haud elongato, $3^{\text {tio }}$ fere simplici, vel in anticis obsolete bilobo.

(Rhyncolum propinquans, sed tamen forma generalis cum generibus præcedentibus melius congruit. A Rhyncolo discedit corpore sæpius majore, longiore, angustiore et magis parallelo, minus convexo minusque ovato, nitidiore et atro; rostro parallelo sed ad basin plus minus obsolete etiam substrangulatim contracto, nunquam ibidem subcrassiore; oculis majoribus, ac magis prominentibus; prothorace metasternoque longioribus; capitulo paulo minus angusto minusque acuminato; coxisque anterioribus sensim magis separatis.)

Hab. ins. Japonicas, et Ceylon.- Macrorhyncolus.

97. Corpus angustum, elongatum, fusiforme (antice et postice acutum), convexum, subnitidum, calvum, nigro et rufo-ferrugineo variegatum; capite parvo, angusto; rostro breviusculo, subgracili, vix parallelo, sc. postice gradatim paulo angustiore, ad apicem recte truncato; oculis haud valde prominentibus, ac haud late separatis; prothorace (elytris sensim angustiore) elongato, cylindrico-triangulari, antice longe et profunde constricto, æquali, dense punctulato; scutello parvo; elytris fusiformibus basi truncatis, plus minus pallidis; metasterno subelongato; abdominis segm. ${ }^{\text {tis }} 1^{\text {mo }}$ et $2^{\text {do }}$ inter se omnino suffusis, $3^{\text {to }}, 4^{\text {to }}$ et ult. ${ }^{\text {mo }}$ punctis magnis (in lineâ transversâ positis) postice marginatis. Antennæ subgraciles, vel in medio vel mox ante medium rostri insertæ; funiculi art. ${ }^{\circ} 2^{\mathrm{do}}$ brevi; capitulo ovali, sat abrupto. Pedes elongati, subgraciles, antici parum late sed intermedii multo latius, quare posteriores æqualiter, separati; femoribus ad basin gracilibus; tibiis subflexuosis, anticis ad angulum internum in spinulam distinctam productis; tarsis elongatis, art. ${ }^{\circ} 1^{\mathrm{mo}}$ longiusculo, $3^{\text {tio }}$ paulo latiore et evidenter bilobo, ult. ${ }^{\text {mo }}$ elongato, in $\delta$ clavato sed in s subconico.

(A generibus vicinis conspicuum corpore fusiformi, convexo, in elytris plus minus pallido et nigro-picto; capite angusto, oculis haud late separatis ; rostro breviusculo, robusto, sed haud valde lato, postice obsolete angustiore, apice recte truncato; prothorace dense punctulato, antice valde angustato ac longe constricto; antennis pedibusque subgracilibus, his elongatis, intermediis ad basin late separatis, quare posterioribus æqualiter distantibus; 
femoribus ad basin gracilibus; tibiis obsolete subflexuosis; tarsisque elongatis, art. $^{\circ} 3^{\text {tio }}$ minute bilobo, ult. ${ }^{\text {mo }}$ elongato, in 8 clavato sed in of subconico.)

Hab. ins. Japonicas. -

Heterarthrus.

98. Corpus angustum, elongatum, cylindricum, convexum, subnitidum, calvum, nigrum ; capite lato, crasso ; rostro breviusculo, lato (capite paulo solum angustiore), vel parallelo vel [an character sexualis ?] antice gradatim obsolete angustiore; oculis prominentibus, late separatis; prothorace (pone medium latitudine elytrorum) elongato, triangulari-cylindrico, antice longe constricto, æquali, subtus antice [an character sexualis?] concavo; scutello parvo, sæpius sub-perpendiculari; elytris parallelis; metasterno longissimo; abdominis segm. ${ }^{\text {tis }} 1^{\text {mo }}$ et $2^{\mathrm{do}}$ sæpius longitudinaliter leviter concavis. Antennæ crassiusculæ, in medio vel mox ante medium rostri insertæ; funiculi (crassi, compacti) art. $^{\circ} 2^{\text {do }}$ sequentibus etiam sub-breviore; capitulo parvo, subrotundato. Pedes elongati, crassiusculi, antici parum late sed posteriores latius ac subæqualiter separati; tibiis anticis valde biflexuosis, omnibus ad angulum internum in spinulam parvam productis; tarsis elongatis, art. ${ }^{\circ} 1^{\mathrm{mo}}$ longiusculo, $3^{\text {tio }}$ paulo latiore et evidenter bilobo, ult. ${ }^{\mathrm{mo}}$ longiusculo et [an character sexualis?] conico, interdum basi valde incrassato.

(Genus Heterarthro affinis, sed corpore majore, magis parallelo, cylindrico, et omnino nigro; capite multo latiore, crassiore, magisque exserto, quare oculis multo latius separatis; rostro multo latiore et interdum omnino parallelo; prothorace minus triangulari; scutello sæpius subperpendiculari; antennis crassioribus, funiculo magis compacto et gradatim multo latiore quare capitulo minus abrupto; pedibusque magis incrassatis, tibiis anticis multo magis flexuosis, tarsorum art. ${ }^{\circ}$ ult. ${ }^{\mathrm{mo}}$, an in utroque sexu?, interdum multo crassiore ac magis conico.)

Hab. ins. Malayenses. -

Conarthrus.

99. Corpus et cæt. fere ut in Conarthro sed illud minus parallelum, aut magis fusiforme, levius sculpturatum, et rufo-ferrugineum, antice et postice paulo obscuratum (nec omnino nigrum), rostro in utroque sexu parallelo, minus lato ac paulo magis arcuato, scutello horizontali (nec declivi), prothorace ad basin paululum minus recte truncato

TRANS. ENT. SOC. 1873.-PART IV. (OCT.) 
(sc. obsolete subsinuato), elytris ad apicem ipsissimum (ut in Heterarthro) sæpius obsolete et minute singulatim subrotundatis, abdominis segm. ${ }^{\text {tis }} 1^{\mathrm{mo}}$ et $2^{\mathrm{do}}$ convexiculis (vix longitudinaliter subconcavis), tarsorumque art. ${ }^{\circ}$ ult. $^{\text {mo }}$ minus conico.

Hab. ins. Malayenses, et Ceylon.-

Eutornus.

100. Corpus angustum, parallelum, subdepressum, subnitidum, calvnm, rufo-piceum aut fere piceo-ferrugineum; rostro brevi, latissimo (capite vix angustiore) sed parallelo, valde arcuato, apice recte truncato; oculis maximis, valde prominentibus, late separatis; prothorace (elytris vix angustiore) elongato, ovali-cylindrico, antice leviter constricto, æquali; elytris parallelis; metasterno elongato; abdominis segm. ${ }^{\text {tis }} 3^{\text {tio }}, 4^{\text {to }}$ et ult. ${ }^{\text {mo }}$ punctis magnis (in lineâ transversâ positis) postice marginatis. Antennæ ante basin rostri insertæ; scapo valde excurvato; funiculi (brevis, compacti) art. $^{\circ} 2^{\text {do }}$ brevissimo, fere abscondito; capitulo sat magno, ovali, abrupto. Pedes breviusculi, ad basin omnes (etiam antici) late et subæqualiter separati ; tarsis art. ${ }^{\circ} 1^{\mathrm{mo}}$ brevi, $3^{\text {tio }}$ simplici, ult. ${ }^{\text {mo }}$ longiusculo, gracili.

(Conspicuum corpore parvo, parallelo, depressiusculo, piceo-ferrugineo; oculis maximis, et valde prominentibus; rostro brevi, latissimo, sc. capite vix angustiore, sed parallelo, valde arcuato, apice recte truncato; antennis versus basin ejus insertis, funiculi art. ${ }^{\circ} 2^{\text {do }}$ brevissimo, capitulo abrupto; coxis omnibus, etiam anticis, late et subæqualiter separatis ; tarsorumque art. ${ }^{\circ} 3^{\text {tio }}$ simplici, ult. ${ }^{\text {mo }}$ gracili.)

Hab. ins. Malayenses (in Nov. Guinea et Sula captus).- -

Coptus.

101. Corpus angustum, parallelum, convexiusculum, cylindricum, subnitidum, calvum, profunde sculpturatum, nigrum; capite lato, crasso, convexo, valde exserto ; rostro brevi, latissimo (capite paululum angustiore) sed parallelo, arcuato; oculis prominentibus, latissime separatis; prothorace (pone medium latitudine elytrorum) elongato, conico-cylindrico, antice leviter constricto, æquali sed in medio tenuiter carinulato; elytris parallelis; metasterno longissimo; abdominis segm. ${ }^{\text {tis }} 1^{\mathrm{mo}}$ et $2^{\mathrm{do}}$ inter se valde suffusis, $3^{\text {tio }}, 4^{\text {to }}$ et ult. ${ }^{\text {mo }}$ punctis magnis (in lineâ transversâ positis) postice marginatis. Antennæ elongatæ, circa medium rostri insertæ; scapo elongato, excurvato; funiculi (brevis, compacti) art. ${ }^{\circ} 2^{\mathrm{do}}$ brevissimo; capitulo magno, 
rotundato-ovali, abrupto, compresso. Pedes breves, antici paululum sed posteriores latius ac subæqualiter (tamen haud valde) separati; tarsis art. ${ }^{\circ} 1^{\mathrm{mo}}$ paululum elongato, $3^{\text {tio }}$ fere simplici.

(Præstans inter genera vicina corpore elongato, angusto, parallelo, convexiusculo, profunde sculpturato; capite magno, crasso, valde exserto; rostro brevi, lato, sc. capite paululum angustiore ; prothorace metasternoque elongatis, illo subconico ; capitulo magno, subrotundato, compresso; coxisque, præsertim anticis, minus late separatis.)

Hab. Borneo (prope Sarawak captus).- Pachyops.

102. Corpus angustum, parallelum, convexum, cylindricum, nitidum, calvum, nigrum; capite lato, crasso, convexo, valde exserto; rostro brevi, latissimo (capite paululum angustiore) sed parallelo, arcuato; oculis valde prominentibus, latissime separatis; prothorace (pone medium elytris vix angustiore) elongato, conico-cylindrico, antice truncato subintegro (vix constricto), æquali; elytris parallelis; metasterno longiusculo; abdominis segm. $^{\text {tis }}$ $1^{\text {mo }}$ et $2^{\text {do }}$ inter se parum suffusis, $3^{\text {tio }}, 4^{\text {to }}$ et ult. ${ }^{\text {mo }}$ punctis magnis (in lineâ transversâ positis) postice marginatis. Antennæ longiusculæ, mox pone medium rostri insertæ; scapo elongato, excurvato; funiculo 5-articulato, crasso, art. $^{\circ} 2^{\text {do }}$ haud sequentibus longiore; capitulo sat magno, subrotundato, abrupto, subcompresso. Pedes crassi, antici parum sed posteriores magis ac subæqualiter separati; tibiis subflexuosis, latis ; tarsis art. ${ }^{\circ} 1^{\mathrm{mo}}$ paululum elongato, $3^{\text {tio }}$ simplici.

(Genus insignum funiculo 5-articulato, sed tamen subfamiliæ Pentarthridum nullo modo pertinens. Corpore sat magno, cylindrico, nigro, nitido, rostroque lato brevissimo crasso arcuato, scapoque elongato excurvato gen. Pachyops simulat; sed differt, inter alia, antennis paulo magis versus basin rostri insertis, funiculo 5-, nec 7-articulato, capitulo minore, scutelloque minus transverso.)

Hab. Australiam, et Tasmaniam.- Pentamimus.

103. Corpus et cæt. fere ut in Pentamimo, sed illud minus ac multo levius sculpturatum; rostro etiam subbreviore (sc. brevissimo et capite vix angustiore), antice canaliculato; prothorace submajore, sublatiore, et antice paulo distinctius constricto; scutello minore; antennis sensim brevioribus, funiculo 4- (nec 5-) articulato, capituN N 2 
loque submajore (sc. maximo, rotundato, valde abrupto); pedibus (præsertim tibiis) brevioribus, tarsisque subgracilioribus, unguiculis minutis.

Hab. Nov. Guinea (ad Dorey captus).-

Tetracoptus.

104. Corpus angustulum, vel cylindricum vel fusiformicylindricum, convexum, nitidissimum, calvum, atrum ; capite crasso ; rostro brevi, latissimo (capite vix angustiore), in $\delta$ valde parallelo, sed in $q$ paulo breviore et apicem versus obsoletissime facillimeque subangustiore, arcuato; oculis parum prominentibus; prothorace (elytris vix angustiore) elongato, cylindrico-ovato, antice leviter constricto, æquali; scutello vel subrotundato, vel minore et transverso; elytris parallelis; metasterno longiusculo; abdominis segmentis $1^{\mathrm{mo}}$ et $2^{\mathrm{do}}$ inter se distincte divisis. Antennæ breviusculæ, circa medium rostri insertæ; scapo excurvato ; funiculi (brevis, crassi) art. ${ }^{\circ} 2^{\text {do }}$ haud sequentibus longiore; capitulo abrupto, subrotundato, compresso. Pedes robusti, antici late sed posteriores multo latius ac subæqualiter separati (intermedii etiam subremotiores quam postici); tarsis elongatis art. ${ }^{\circ} 1^{\mathrm{mo}}$ paululum elongato, $3^{\text {tio }}$ angusto, simplici, integerrimo.

(Genus præstans corpore aterrimo, polito, cylindrico, minus sculpturato; capite rostroque crassis, latitudine subæqualibus, hôc brevi sed fere parallelo; antennis crassiusculis, capitulo subrotundato, compresso ; abdominis segm. ${ }^{\text {tis }} 1^{\text {mo }}$ et $2^{\text {do }}$ inter se distincte divisis ; coxisque, præsertim intermediis, late separatis.)

Hab. ins. Malayenses.-

Xestoderma.

105. Corpus et cæt. fere ut in Xestoderma, sed illud paulo latius, crassius, interdum politissimum et leviter, sed interdum subopacum et grossius sculpturatum; rostro antice late canaliculato; antennis mox ante medium ejus insertis, longioribus; scapo præcipue longiore, valde excurvato et robuste clavato; capitulo majore (sc. maximo), nigrescente, et densissime velutino, nunc subrotundato nunc ovali; scutello vel minuto brevissimo transverso, vel majore ac magis rotundato ; coxis intermediis paulo minus separatis (tamen posterioribus æqualiter distantibus); tarsorumque art. ${ }^{\circ} 3^{\text {tio }}$ minus simplici, sc. præsertim in anticis minutissime cordato.

Hab. ins. Malayenses.-

Xestosoma. 
106. Corpus oblongo-cylindricum, latiusculum, calvum, subnitidum, nigrum ; capite lato ; rostro brevissimo, latissimo (capite paululum angustiore) sed parallelo, in medio subconcavo, postice transversim esculpturato politissimo ; oculis valde prominentibus, latissime separatis ; prothorace magno, convexo, subovali, ad latera subæqualiter rotundato, (in medio) elytrorum latitudine; scutello subquadrato; elytris breviter cylindricis, antice recte truncatis, postice obtusis et minutissime sed parce asperatis; metasterno abdominisque segm..$^{\text {to }} 1^{\text {mo }}$ (a $2^{\text {do }}$ distinctius diviso) haud valde elongatis, convexis; abdominis segm. $.^{\text {tis }} 3^{\text {tio }}, 4^{\text {to }}$ et ult. $^{\mathrm{mo}}$ punctis magnis (in lineâ transversâ sitis) postice marginatis. Pedes omnes (etiam antici) late separati, sc. posteriores vix magis remoti quam antici necnon æqualiter distantes; tibiis (saltem anticis) subflexuosis; tarsis art. ${ }^{\circ}$ $1^{\text {mo }}$ haud elongato, $3^{\text {tio }}$ simplici.

(Distinctum corpore latiusculo, parallelo-oblongo, antice et postice sub-obtuso; rostro brevissimo, latissimo, sed tamen subparallelo, et postici in medio esculpturato polito; oculis prominentibus; prothorace magno, convexo, in medio latitudine elytrorum; elytris postice minute asperatis ; coxisque, etiam anticis, late distantibus.)

Hab. ins. Nov. Guinea.-

Lissopsis.

107. Corpus fusiformi-cylindricum, levius minutiusque sculpturatum, vix calvum (sc. in elytris et subtus, oculo fortissime armato, minute sericatum), subnitidum, brunneonigrum ; capite lato ; rostro brevissimo, lato sed parallelo, canaliculato ; oculis valde prominentibus, latissime separatis ; prothorace elytris subangustiore, subcylindrico-ovato ; elytris cylindricis; metasterno abdominisque segm. ${ }^{\text {to }} 1^{\mathrm{mo}}$ (a $2^{\text {do }}$ distinctius diviso) elongatis. Antennæ elongatæ, mox ante medium rostrí insertæ; scapo elongato ; funiculi art. ${ }^{\circ}$ $2^{\mathrm{do}}$ haud sequentibus longiore; capitulo magno, rotundato, valde abrupto. Pedes elongati, subgraciles, ad basin valde et subæqualiter distantes (sc. etiam antici late separati); tibiis elongatis, anticis subflexuosis ; tarsis elongatis, art. ${ }^{\circ}$ $1^{\mathrm{mo}}$ elongato, $3^{\text {tio }}$ vix latiore sed minutissime bilobo.

(Genus præcipue insignum rostro brevissimo, canaliculato, sed parallelo; antennis elongatis, scapo elongato, funiculo brevi, capitulo magno rotundato abrupto; oculis valde prominentibus; pedibusque subæqualiter separatis, sc. anticis magis sed posticis minus remotis quam plerumque obtinet, tibiis anticis subflexuosis; tarsorum art. ${ }^{\circ}$ 
$1^{\text {mo }}$ elongato; corporeque subtus, atque etiam in elytris subtilissime sed parce sericato.)

Hab. ins. Japonicas (in Kushiu captus).-

Spharocorynes.

108. Corpus fusiforme, convexum, nitidum, levissime sculpturatum, calvum, atrum; rostro longiusculo (præsertim in \$), latiusculo, robusto, postice paulo angustato, quare antice gradatim paulo latiore; oculis maximis, prominentibus; prothorace (subtus subconcavo) magno, elongato, subtriangulari-ovali, antice fere integro (sc. pone apicem levissime constricto), æquali; scutello parvo ; elytris fusiformibus basi truncatis; metasterno breviusculo; abdominis segm. ${ }^{\text {tis }} 1^{\mathrm{mo}}$ et $2^{\mathrm{do}}$ inter se distincte divisis. Antennæ elongatæ, crassæ, longe ante medium rostri insertæ ; scapo elongato, recto; funiculi (crassi) art. ${ }^{\circ} 2^{\text {do }}$ haud sequentibus longiore; capitulo abrupto, rotundatoovali, compresso. Pedes longiusculi, crassi, ad basin omnes (etiam antici) late separati (sed intermedii latius quam antici, necnon postice latissime, distantes); tarsis elongatis, art. ${ }^{\circ} 1^{\mathrm{mo}}$ paululum elongato, $3^{\text {tio }}$ fere simplici.

(Genus incertæ sedis, cum Xestoderma et Xestosoma corpore convexo nitido atro leviter sculpturato, capitulo abrupto compresso, prothorace magno, tarsis elongatis, abdominisque segm. ${ }^{\text {tis }} 1^{\text {mo }}$ et $2^{\text {do }}$ distincte divisis congruens; sed capite angustiore, rostro longiore, minus incrassato et postice angustato, corporeque fusiformi, nec parallelo, ab illis discedit. Aliter exstat oculis magnis prominentibus, scapo elongato recto, necnon prothorace antice fere integro.)

Hab. ins. Malayenses.-

Xenotrupis.

109. Corpus cylindrico-fusiforme, convexum, calvum, antice subopacum sed postice subnitidum, nigrum; rostro longiusculo, subparallelo sed postice obsoletissime gradatim sublatiore, in $\delta$ valde robusto sed in $q$ graciliore; oculis valde prominentibus, exstantibus (in $\delta$ postice abrupte terminatis, antice gradatim declivibus); prothorace magno, valde elongato, triangulari-ovato, antice fere integro (vix constricto); scutello minutissimo, punctiformi; elytris fusiformibus basi truncatis; metasterno breviusculo, in + postice in medio subconcavo et ibidem carinulâ mediâ minutâ abbreviatâ (antice subito terminatâ) instructo, in 
of magis (una cum abdominis segm. ${ }^{\text {to }} 1^{\mathrm{mo}}$ ) concavo sed haud carinulato. Antennæ elongatæ, crassæ, mox ante medium rostri insertæ; scapo elongato, recto, et etiam a basi usque ad apicem (præsertim in to valde robusto, quare minus clavato; funiculi art. ${ }^{\circ} 2^{\text {do }}$ haud sequentibus longiore; capitulo ovali, sed haud valde abrupto. Pedes elongati, valde incrassati, antici ad basin paululum, intermedii latius, et postici parum late separati ; tarsis robustis, art. ${ }^{\circ} 1^{\mathrm{mo}}$ haud elongato, $3^{\text {tio }}$ latiore et evidenter bilobo.

(Genus præstans corpore fusiformi, convexo, antice subopaco sed postice subnitido; prothorace magno, valde elongato, antice vix constricto ; rostro longiusculo, et præsertim in $\delta$ robusto; oculis valde exstantibus, et in $\delta$ postice abrupte sed antice facilius terminatis; scutello minuto, punctiformi ; antennis pedibusque elongatis, incrassatis; scapo præcipue elongato, recto, atque etiam a basi robusto, quare minime clavato; metasternoque in + carinulâ mediâ minutâ abbreviatâ, antice abrupte terminatâ, postice instructo.)

Hab. Americam australem (in Chili degens).-_Pachystylus.

110. Corpus elongatum, angustum, parallelum, convexiusculum, cylindricum, subopacum, hand omnino calvum (sc., oculo fortissime armato, postice et subtus minutissime parceque sericatum); rostro (valde et subito angustato, depresso, canaliculato) brevi sed parallelo, oculis valde prominentibus; prothorace suboblongo-cylindrico, antice sat profunde constricto, æquali sed in medio tenuiter carinulato; elytris elongatis, cylindricis, ad apicem singulatim rotundatis necnon ibidem minutissime asperatis; metasterno elongato; abdominis segm. ${ }^{\text {tis }} 1^{\text {mo }}$ et $2^{\mathrm{do}}$ inter se parum distincte divisis. Antennæ subgraciles, mox ante medium rostri insertæ; funiculi art. ${ }^{\circ} 2^{\text {do }}$ haud sequentibus longiore (tamen haud brevissimo); capitulo abrupto, subrotundato-ovali. Pedes elongati, ad basin minus distantes quam in generibus vicinis (sc. antici paululum, et posteriores paulo latius et æqualiter separati); tibiis elongatis, et (præsertim anticis) subflexuosis; tarsis elongatis, art. ${ }^{\circ} 1^{\mathrm{mo}}$ longiusculo, $3^{\text {tio }}$ (saltem in anticis) vix simplici, ult. ${ }^{\mathrm{mo}}$ valde elongato.

(Genus inter vicina conspicuum corpore elongato, angusto, valde parallelo, cylindrico, subopaco, dense sculpturato, necnon postice minutissime pubescenti et 
asperato; rostro brevi, sed parallelo, usque a basi subito angustato; oculis valde prominentibus ; capitulo subrotundato, abrupto, elytris ad apicem singulatim rotundatis; pedibus, præsertim tarsis, elongatis; tibiis, præsertim anticis, subflexuosis; coxisque præsertim anticis, minus late separatis.)

Hab. ins. Japonicas.-

Xenomimetes.

111. Corpus cylindricum, profunde sculpturatum, calvum, subnitidum, nigrum ; capite rostroque latis, crassis, hôc brevissimo sed subparallelo, oculis valde prominentibus; prothorace magno, elongato, ovato-cylindrico, pone apicem constricto, (mox pone medium) elytrorum latitudine; elytris cylindricis; metasterno abdominisque segm. ${ }^{\text {to }} 1^{\text {mo }}$ elongatis. Antennæ valde incrassatæ, mox ante medium rostri insertæ; scapo breviusculo, crasso, funiculi (crassissimi, compacti) art. ${ }^{\circ} 2^{\text {do }}$ brevissimo, sc. præcedente fere abscondito; capitulo angusto, minime abrupto. Pedes crassi, ad basin tarsisque ut in Rhyncolo.

(Rhyncolo primâ facie simillimum, sed corpore majore, magis cylindrico, et profundius sculpturato, prothorace longiore magis cylindrico et antice evidentius constricto, rostro breviore et latiore, oculis magis prominentibus, antennisque multo crassioribus, sc. funiculo crassissimo et art. $^{\circ} 2^{\text {do }}$ brevissimo, fere e visu abscondito.)

Hab. Europam australem, et ins. Canarienses.-

Eremotes.

112. Corpus sæpius subovato-, aut fusiformi-cylindricum, calvum, nitidiusculum; rostro vel breviusculo crasso, vel longiore graciliore parallelo, oculis prominulis; prothorace plus minus triangulari-ovato; elytris sæpius vel ovato-, vel fusiformi-cylindricis, basi truncatis ; metasterno longiusculo. Antennæ crassiusculæ, vel ante vel circa medium rostri insertæ; funiculi (plus minus compacti) art. $^{\circ} 2^{\text {do }}$ haud sequentibus longiore; capitulo angusto, minus abrupto. Pedes sæpius crassiusculi (anteriores magis distantes quam in Phloophago); tarsis robustis, art. $^{\circ} 1^{\mathrm{mo}}$ vix elongato, $3^{\text {tio }}$ vel evidenter latiore et sub-bilobo, vel simplici.

Hab. regiones varias, pracipue in Europâ et Americâ.Rhyncolus. 
113. Corpus et cæt. fere ut in Rhyncolo, sed rostro (omnino parallelo) a fronte obsolete subdiviso ; antennarum capitulo multo majore crassiore, tamen apice magis acuto, funiculo sensim minus incrassato (art. ${ }^{\circ} 1^{\text {mo }}$ sc. multo minore, articulisque ulterioribus brevissimis), scapoque magis clavato; oculis multo majoribus, ac supra magis approximatis; scutello submajore; elytrisque sensim magis parallelis. Tarsorum art. ${ }^{\circ} 3^{\text {tio }}$ simplici.

Hab. in ins. Maderâ.-

Caulophilus.

114. Corpus crassum, parallelum, latiusculum, depressiusculum, dense et argute sculpturatum, calvum sed postice minute pubescens, subnitidum, piceo-ferrugineum; rostro brevi, robusto (sed haud latissimo), parallelo, a capite lineâ diviso; oculis prominentibus; prothorace (elytris vix angustiore) magno, elongato, subquadrangulari, pone apicem profunde constricto ; elytris parallelis, costatis, basi recte truncatis; metasterno longiusculo; abdominis segm. ${ }^{\text {tis }} 1^{\mathrm{mo}}$ et $2^{\mathrm{do}}$ (præsertim hôc) haud valde elongatis atque inter se distincte separatis, hôc in planum inferiorem depresso, $3^{\text {tio }}, 4^{\text {to }}$ et ult. ${ }^{\text {mo }}$ punctis magnis (in lineâ transversâ sitis) postice marginatis. Antennæ breviusculæ, subgraciles, circa medium rostri insertæ; funiculi (valde compacti) art. $^{\circ} 1^{\mathrm{mo}}$ antice late truncato et intus minute subproducto, $2^{\text {do }}$ haud sequentibus longiore; capitulo sat magno, abrupto, distincte annulato. Pedes breviusculi, robusti, antici parum distincte et posteriores paulo remotius ac subæqualiter (sed haud valde) separati; tibiis latis, compressis, subtriangularibus, ad angulum internum spinâ robustâ (in anticis elongatâ, subhorizontali) armatis, ad externum haud uncinatis tamen (præcipue in posterioribus) subito ampliatis, parte ampliatâ dense spinulosâ; tarsis art. ${ }^{\circ} 1^{\text {mo }}$ elongato, $3^{\text {tio }}$ vix latiore sed minute subbilobo et subtus longe piloso.

(Genus inter Cossonidas valde anomalum,-tibiarum structurâ necnon abdominis segm. . $^{\text {tis }} 1^{\mathrm{mo}}$ et $2^{\mathrm{do}}$ inter se profunde divisis cum Hylesinidis melius congruens, tamen, nisi fallor, ad hanc familiam vere pertinens. Præcipue exstat unco tibiali obsoleto, tamen tibiis versus apicem externum abrupte spinoso-ampliatis, necnon ad internum calcari robusto, in anticis elongato subhorizontali, munitis. Inter alia distinguiter corpore crasso parallelo latiusculo subdepresso piceo-ferrugineo ac dense arguteque sculpturato, elytrorum interstitiis costiformibus, sed costis quasi e 
duâbus efformantibus, rostro breviusculo parallelo necnon a fronte conspicue diviso, prothorace magno subquadrangulari, abdominisque segm. ${ }^{\text {tis }} 1^{\mathrm{mo}}$ et $2^{\mathrm{do}}$ minus elongatis et distincte divisis, illo convexo sed hôc in planum inferiorem adjecto.)

Hab. Novam Zealandiam (ab Auckland missa).-

Xenocnema.

nn. coxis anterioribus vel fere vel omnino contiguis. (oculi demissi.)

p. rostro brevi, triangulari-cylindrico.

115. Corpus fere ut in Rhyncolo (et sc. Hexarthrum simulans), sed magis breviter-cylindricum, postice obtusius terminatum, prothorace convexiore, antice haud constricto, oculisque valde demissis, nec prominentibus. Antennæ (pone medium rostri insertæ) breves, glabræ; scapo præcipue brevi; funiculi articulis ( $1^{\mathrm{mo}}$ excepto) compactis, inter se arcte adpressis; capitulo compresso, solido, subobconico aut obtriangulari (apice recte truncato). Pedes (anteriores magis approximati quam in Rhyncolo) breviores; femoribus, præsertim anticis, magis clavatis et subtus quasi obtuse angulato-subdentatis ; tarsis gracilioribus, filiformibus, art. ${ }^{\circ} 1^{\text {mo }}$ longiore, $3^{\text {tio }}$ angusto, simplici. Aliter conspicuum est rostro breviusculo crassiusculo, in $\delta$ subparallelo, sed in o breviore subtriangulari.

Hab. Europam.-

Stereocorynes.

116. Corpus (ut in Stereocorynes) breviter cylindricum, postice obtuse terminatum, subcalvum (sc. oculo fortissime armato subtilissime parcissimeque sericatum), piceum; rostro brevi, vel angustulo- vel latiusculo-subtriangulari, oculis valde demissis; prothorace convexo, antice vel haud vel leviter constricto, basi fere immarginato ; elytris (præsertim postice) minutissime asperatis; metasterno abdominisque segm. ${ }^{\text {to }} 1^{\text {mo }}$ (a $2^{\text {do }}$ distinctius diviso) haud valde elongatis. Antennæ (circa medium rostri insertæ) brevissimæ, glabræ; scapo præcipue brevi; funiculo 6-articulato, articulis ( $1^{\mathrm{mo}}$ excepto) brevissimis compactis, inter se arcte adpressis ; capitulo compresso, solido, subrotundato, antice interdum oblique subtruncato. Pedes (magis approximati quam in Rhyncolo) breves, anteriores fere contigui, et etiam postici haud late distantes; femoribus anticis conspicue clavatis; tarsis gracilibus, filiformibus, art. ${ }^{\circ} 1^{\mathrm{mo}}$ 
longiusculo, $3^{\text {tio }}$ angusto, simplici. Aliter conspicuum est rostro in of paululum longiore ac magis parallelo (i. e. minus triangulari) quam in ㅇ.
Hab. Europam, ins. Maderenses, et ins. Japonicas.-
Hexarthrum.

117. Corpus et cæt. fere ut in Hexarthro, sed illud majus, minus breviter cylindricum (sc. interdum parallelosubfusiforme, postice minus obtuse rotundatum, subproductum), ac multo grossius sculpturatum; oculis majoribus, ac magis superioribus (i. e. supra minus late separatis); prothorace magno, apice integro (nec constricto), basi distincte sed anguste marginato; elytris basi undulatim sinuatis (nec recte truncatis), ad humeros subito et acute porrectis, postice grosse sed parce asperatis, necnon interdum ad apicem ipsissimum minute singulatim subrotundatis (nec truncato-desilientibus). Antennæ (circa medium rostri insertæ) brevissimæ, crassæ, glabræ; scapo etiam subbreviore quam in Hexarthro ; funiculo 5- (nec 6-) articulato, articulis ( $1^{\mathrm{mo}}$ excepto) brevibus, compactis; capitulo compresso, solido, et (ut in Stereocorynes) subobtriangulari, sc. antice truncato. Pedes ut in Hexarthro (sc. anteriores fere contigui), sed interdum tibiis anticis ad angulum internum calcari compresso bifido armatis.

Hab. Americam borealem (in Mexico degens).-

Tomolips.

pp. rostro brevissimo, lato, crasso, triangulari.

(caput crassum.)

q. scutello conspicuo.

118. Corpus vel ovato-cylindricum vel cylindricum, grosse sculpturatum, aut calvum aut subcalvum, nitidum; rostro crasso, oculis demissis; prothorace (postice elytrorum latitudine) magno, ovato-cylindrico, antice subintegro (i. e. obsolete constricto), utrinque pone medium sinuato; elytris ovato-cylindricis vel cylindricis, postice argute muricatis; metasterno longiusculo; abdominis segm. ${ }^{\text {tis }} 1^{\mathrm{mo}}$ et $2^{\text {do }}$ distinctius divisis. Antennæ brevissimæ, crassæ; scapo brevissimo ; funiculi (compacti) art. ${ }^{\circ} 1^{\mathrm{mo}}$ lato, antice latissime truncato; capitulo magno, abrupto, rotundato. Pedes antici fere contigui, intermedii vix magis distantes, postici leviter separati; tarsis longissimis, gracilibus, fili- 
formibus, art. ${ }^{\circ} 1^{\mathrm{mo}}$ valde elongato, $3^{\text {tio }}$ angusto, simplici, integerrimo, ult. ${ }^{\text {mo }}$ elongato.

(Brachytemno affinitate proximum, sed differt corpore postice dense muricato-asperato, tarsis multo longioribus, art. $^{\circ} 1^{\mathrm{mo}}$ valde elongato, prothorace majore, oculisque latius separatis. A Stenoscelide discedit scutello distincto, prothorace longiore, tarsorumque art. ${ }^{\circ} 1^{\mathrm{mo}}$ magis elongato et $3^{\text {tio }}$ integerrimo, nec minutissime bilobo.)

\section{Hab. ins.Ceylon, et Malabar.- Dendroctonomorphus.}

119. Corpus ovato-cylindricum, grossissime sculpturatum, calvum, nitidum; rostro crasso, oculis demissis, supra minus late separatis; prothorace magno, ovalicylindrico, antice integro (nec constricto), utrinque pone medium obsolete sinuato; elytris cylindrico-ovatis; metasterno longiusculo; abdominis segm. ${ }^{\text {tis }} 1^{\mathrm{mo}}$ et $2^{\text {do }}$ distinctius divisis. Antennæ brevissimæ, crassæ, glabræ; scapo brevissimo ; funiculi (brevissimi, compacti) art. ${ }^{\circ} 1^{\mathrm{mo}}$ magno, lato, antice latissime truncato ; capitulo magno, parum abrupto, compresso, rotundato sed antice truncato. Pedes graciles, antici fere contigui, intermedii vix magis distantes, postici parum (sed haud valde) separati; tarsis gracilibus, filiformibus, art. ${ }^{\circ} 1^{\mathrm{mo}}$ longiusculo, $3^{\text {tio }}$ simplici.

\section{Hab. Europam (presertim australem).-}

Brachytemnus.

120. Corpus cylindricum, postice vix latius et ibidem obtusum, grossissime sculpturatum, calvum, nitidum ; rostro crasso, oculis demissis, supra minus late separatis; prothorace magno, subovato-cylindrico, antice subintegro, postice in medio valde profunde triangulariter excavato; scutello magno ; elytris grossissime sulcatis et alte costatis, utrinque ad apicem (obtuse truncato-rotundatum) acute cariniformibus; metasterno breviusculo; abdominis segm. ${ }^{\text {tis }}$ $1^{\mathrm{mo}}$ et $2^{\mathrm{do}}$ inter se suffusis, sed hôc in planum inferiorem depresso. Antennæ brevissimæ, crassæ; scapo (brevissimo) funiculoque (crasso, compacto) fere ut in Brachytemno ; capitulo magno, lato, abrupto, transverso, subpoculiformi (aut fere calyciformi), ad apicem latissime recteque truncato et ibidem velutino. Pedes crassi, antici fere contigui, intermedii vix magis distantes, postici parum (sed haud valde) separati; tibiis anterioribus ad angulum internum in spinam robustam productis; unco apicali magno ; tarsis elongatis, gracilibus, art. ${ }^{\circ} 1^{\text {mo }}$ elongato, $3^{\text {tio }}$ angusto, simplici, integerrimo, ult. ${ }^{\mathrm{mo}}$ longissimo. 
(Genus valde distinctum corpore cylindrico, rostro brevissimo triangulari, oculis demissis ac supra subapproximatis, prothorace magno necnon postice in medio profunde arguteque triangulariter excavato, scutello magno, elytris grossissime costatis ac sulcatis, antennis brevissimis, capitulo subpoculiformi, necnon tarsis elongatis gracilibus filiformibus, art. ${ }^{\circ} 3^{\text {tio }}$ angusto integerrimo, ult. ${ }^{\mathrm{mo}}$ longissimo.)

Hab. Americam Australem (in Brasiliâ captus).Calyciforus.

qq. scutello agre observando,

121. Corpus cylindricum, dense sculpturatum, calvum, subnitidum ; rostro crasso, oculis demissis, supra minus late separatis; prothorace (elytris subangustiore) subovato-cylindrico, antice subintegro; elytris cylindricis, parum grosse sulcatis et costatis, antice in medio dense transversim rugulosis, postice minutissime subserratuloasperatis; metasterno breviusculo; abdominis $\mathbf{s e g m} .{ }^{\text {tis }}$ $1^{\mathrm{mo}}$ et $2^{\mathrm{do}}$ lineâ argute divisis. Antennæ breves, minus incrassatæ ; scapo brevi ; funiculi art. ${ }^{\circ} 1^{\mathrm{mo}}$ magno, reliquis gradatim latioribus brevioribus, ult. ${ }^{\text {mo }}$ lamelliformi, necnon ad capitulum (maximum, valde abruptum, transversum, latissimum, antice velutinum) sat arcte adpresso. Pedes elongati, antici fere contigui, intermedii vix magis distantes, postici parum (sed haud valde) separati ; tarsis elongatis, gracilibus, filiformibus, art ${ }^{\circ} 1^{\text {mo }}$ elongato, $3^{\text {tio }}$ angusto integerrimo, ult $^{\mathrm{mo}}$ longissimo.

(Genus inter Calyciforum et Stenoscelidem situm,illum simulans oculis magis approximatis, prothorace minus brevi, capitulo plus minus lato et anomalo, elytris sulcatis, pedibus magis robustis, anterioribus minus contiguis, tarsorumque art. $^{\circ} 3^{\text {tio }}$ integerrimo; sed scutello fere obsoleto, necnon elytris antice subplicatulo-rugulosis et postice subasperatis cum hôc melius congruens. Tamen antennarum structurâ præcipue exstat,-funiculi sc. articulis paulatim brevissimis, ult. ${ }^{\text {mo }}$ etiam lamelliformi, necnon ad capitulum maximum valde abruptum transversum latissimum sat arcte adpresso.)

Hab. Americam australem (in Braziliâ deprehensus).Eurycorynes.

122. Corpus breviter cylindricum, dense sculpturatum, calvum, subnitidum; rostro crasso, oculis valde demissis; prothorace brevi, cylindrico-ovato, postice valde truncato, 
antice paulo constricto, necnon ad latera in medio subsinuato ; elytris antice transversim subplicato-rugosis, postice parce tuberculato-asperatis ; metasterno breviusculo; abdominis $\operatorname{segm}^{\text {tis }} 1^{\mathrm{mo}}$ et $2^{\text {do }}$ lineâ rectâ argute divisis. Antennæ breves, subgraciles ; scapo brevi ; funiculi (minus compacti) art. ${ }^{\circ} 1^{\mathrm{mo}}$ magno, antice recte truncato ; capitulo rotundato-ovali. Pedes subgraciles, anteriores contigui ; tarsis elongatis, gracilibus, art. ${ }^{\circ} 1^{\mathrm{mo}}$ elongato, $3^{\text {tio }}$ vix latiore sed minutissime bilobo, ult. ${ }^{\text {mo }}$ elongato. Hab. ins. $S^{\text {te }}$ Helence, Africam australem, et ins. Japo-
nicas.-
Stenoscelis.

1. Notiomimetes (nov. gen.).-If the minute insect (scarcely one line in length) from which the details for the present genus have been compiled, and which I have received from Mr. Pascoe as having been captured on the sea-shore at King George's Sound in the south of Australia, be (as I think, from the structure of its abdomen, antennæ, and general facies, that it is) a veritable member of the Cossonida, it appears to me to be absolutely necessary to erect a separate subfamily to receive it; for although in its most significant character of a 4-jointed funiculus, as well as in its fusiform outline and obsolete scutellum, it agrees sufficiently with the Dryophthorides, it is nevertheless so radically different from the exponents of that section in the fact of its tibiæ being free from a terminal hook, in its very widely separated coxæ (which are more remote from each other than in any Cossonid which I have yet seen), and in its pseudotetramerous feet, that I do not believe it can possibly be associated with them. Indeed its apically-unarmed tibiæ would, in my opinion, have almost sufficed to exclude it from the Cossonidce altogether, was not that particular feature one of the main characteristics of the subfamily Onycholipides, which I have regarded (and, I cannot but think, correctly so) as aberrant, fossorial Cossonids. Moreover its immersed head and obsolete eyes, as well as its bald and rather shining surface (which is entirely free from mud-like scales), are characters which are quite unprecedented in any of the hitherto-known representatives of the Dryophthorides.

In other respects (each of them of considerable importance), Notiomimetes recedes from the Dryophthorides 
in its exceedingly minute size; in its surface, although deeply sculptured, being very much less so than in that subfamily ; in its slenderer rostrum, which has the antennæ implanted a trifle before (instead of behind) the middle ; in its elytra being more attenuated posteriorily, and without any trace either of costæ or of the cariniform structure on either side of their apex ; in its antennæ (which are much less incrassated) having their scape suddenly thickened into a very elongate apical knob, their funiculusjoints (the second one of which is appreciably longer than those which follow it) more loosely connected inter se, and their club larger and more abrupt; in its femora being: armed beneath with a very small and indistinct tooth; and in its feet (which, as just stated, are pseudotetramerous) being broader and more abbreviated,- - the first and second articulations (particularly the latter) being transverse, the third one deeply bilobed (but with the lobes not divaricating), and the ultimate one (the claws of which are very largely developed) short and thick.

2. Psilodryophthorus (nov. gen.).--In its 4-jointed funiculus, transverse eyes, obsolete scutellum, costate elytra, and slender, pentamerous feet, the remarkable insect for which the present genus is established, and which has been communicated by $\mathrm{Mr}$. Pascoe as having been taken by Mr. Wallace at Saylee, in the north-west of New Guinea, is essentially a Dryophthorid; and yet it is an exceedingly anomalous member of its subfamily, more especially in the fact of its surface (instead of being opake and thickly besmeared with dirty, mud-like scales) being slightly shining, and almost bald,- the punctures only (or a certain portion of them) being filled-up with the particular kind of brown deposit which is so characteristic of the immediately-allied forms. And it is further conspicuous for its prothorax (which is largely developed) being almost as wide behind as the base of the elytra, and nearly even,--there being scarcely any indication of inequalities, or of an anterior constriction; and for its elytra being broadly and distinctly scooped-out in front (causing the shoulders to appear prominent, or porrect), and without any tendency to be cariniform at their apex. Its rostrum is rather short, thick, and cylindrical (being of nearly equal breadth throughout), and is not roughened as in the generality of the Dryophthorides. 
3. Stenommatus (nov. gen.).-The very interesting little insect on which I have founded the present genus is from Mexico, and has been communicated by Mr. Fry. While possessing all the essential features of the Dryophthorides (as instanced by its 4-jointed funiculus, elliptical body, transverse eyes, obsolete scutellum, conspicuously 5 -articulated feet, and minute claws), it recedes completely from Dryophthorus proper (and, therefore, à fortiori, from Tetratemnus) in several most important particulars,especially however in its considerably longer, slenderer, more parallel and arcuated rostrum ; in its very much narrower and more transverse eyes (which are so narrowed, and prolonged, beneath the head, as to be nearly confluent); and in all its coxæ, though particularly the four posterior ones, being more widely separated. In other respects it differs from Dryophthorus in its smaller size and still more elliptic outline, which is a good deal attenuated at its hinder apex; in its surface (instead of being unequally besmeared with a kind of coarse, mudlike, scaly deposit) being densely and evenly covered with an extremely fine, velvety, somewhat silken, cinereous pubescence; in its elytra not being cariniform at their extremity, though with their second costa (or raised costiform interstice) more conspicuously elevated, or prominent, behind; in its antennæ (particularly as regards the scape) being longer, and with the club more developed; and in its metasternum being a little shorter.

4. Dryophthorus (Schönherr, Curc. Disp. Meth. 332. 1826).-Although I have had no opportunity of examining them, I believe that the majority of the species which have been referred to Dryophthorus are generically distinct from the European D. lymexylon, which is expressly stated to be the type of the group; and I suspect therefore that the genus Tetratemnus, which I lately enunciated in order to receive an insect which was taken abundantly by Mr. G. Lewis in Japan, will be found eventually to embrace them. Be this however as it may, the genus Dryophthorus, as represented by its acknowledged type, is too well known to require comment; suffice it to observe that the various published diagnoses of it (not even excepting that of Lacordaire) appear to me to be at fault in their definition of some of its most important characters,the result apparently of their having been drawn out, not from the type alone, but partially also from some of the 
allied forms which I regard as Tetratemni. In Dryophthorus proper, however, the anterior coxæ are rather more approximated than in Tetratemnus, the body is more elliptic (or medially-widened), the prothorax is a trifle less developed, the elytra are not so broadly cariniform at their apex, and the rostrum, antennæ, and legs are appreciably longer. Nevertheless in their opake and very coarselysculptured surface (which is more or less densely besmeared with whitish-brown, mud-like scales), as well as in their costate elytra and 4 -jointed funiculus, and in the fact of the fourth articulation of their slender, filiform feet being (instead of minute and hidden) exposed and distinct, the two genera are coincident. The D. lymexylon, which (as just stated) may perhaps prove to be the only Dryophthorus proper hitherto made known, appears to occur, more or less sparingly, throughout northern and central Europe.

5. Tetratemnus (Wollaston, Trans. Ent. Soc. Lond.9. 1873). - As already implied, the members of this genus, which (if my conclusions be correct) are extra-European and appear to be widely spread over the world, present many characters which, as it seems to me, cannot but distinguish them generically from the European Dryophthorus lymexylon. Not to speak however of those species which I have had no opportunity of examining, and which may or may not prove to be Tetratemni, I may add that at any rate the Japanese Cossonid (the T. sculpturatus, Woll.) for which the group was proposed, recedes from the $D$. lymexylon in its anterior coxæ being rather more widely separated, whilst the hinder pair, on the contrary, are not quite so remote as in that insect; in its antennæ, rostrum, and legs being a little shorter; in its prothorax being proportionately a trifle more developed; in its elytra being narrower and more parallel (or laterally-compressed) and very much more broadly cariniform on either side of their apex; and in its tarsi being especially more abbreviated. Its rostrum also is less appreciably widened immediately in front of the particular point at which the antennæ are inserted. Its dark and opake surface however is as coarsely sculptured, and besmeared with the same kind of whitish-brown, mud-like scales (or, as it were, scaly deposit), as in Dryophthorus proper. Although it is probable that the group has a wide geographical range, the $T$. sculpturatus is, (for the reason already

TRANG. ENT. SOC. 1873.-PART IV. (OCT.) O O 
given, the only member of it for which $I$ am at present in a position to vouch; and that one appears to be common in the Japanese archipelago, having been met with by Mr. G. Lewis near Nagasaki in the island of Kushiu, and at Hiogo in the island of Nipon.

6. Synommatus (nov. gen.).-If there had been any question concerning the intimate relationship which exists between the Dryophthorides and Pentarthrides (of which I have never myself entertained the slightest doubt), it would have been thoroughly dispelled by a genus like the present one,-which, although pertaining to the latter, is at first sight so unmistakeably a Dryophthorid that it is difficult to conceive that it can belong to any other group. Yet the most essential features of that well-marked subfamily, namely a 4-jointed funiculus and ordinary pentamerous feet, are entirely wanting to it,-the former in Synommatus being five-articulate, and the latter on the usual Rhynchophorous pattern. Yet so marvellously do its external facies, sculpture, and clothing, no less than its narrow, transverse, sunken eyes, the general proportions of its rostrum and antennæ (barring the extra funiculusjoint), and the structure of its abdomen and tibiæ accord with Dryophthorus that one can scarcely resist the conviction that it is as much a member of the one subfamily as of the other ; and my own opinion, consequently, is that it is as nearly as possible osculant between the two. Although agreeing very much better than Pentacoptus and Chcrorrhinus do with the Dryophthorides, yet in conjunction with those genera (in the latter of which the elytra are cariniform on either side of the apex) it may be said to constitute a most complete passage between the subfamilies in question,- - though of necessity claimed by the Pentarthrides (with which, however, it has far less, primâ facie, in common) on account of the structure of its funiculus and feet.

In the formation of its eyes Synommatus stands alone amongst all the Cossonideous types with which I am acquainted, the nearest approach to it being the genus Stenommatus from Mexico; for not only are they very much more approximated on the upper-side than is the case in any of the Dryophthorids which have hitherto been brought to light, but (which is still more anomalous) they are completely confluent beneath,- the two together, consequently, well-nigh encircling the entire head! 
Amongst other peculiarities, our present insect is remarkable for its elliptic outline, for its long and parallel but arcuated rostrum, for its funiculus being gradually much increased in width towards the club, and for the latter being extremely large and solid,- though obliquely truncate at the inner apex, at which particular point it is densely clothed with a velvety pubescence. Its prothorax (which is but slightly constricted in front) is nearly cylindrical, and very much narrower than the elytra, the latter (which have their interstices, especially the alternate ones, costiform) are wide in front but acuminated behind, its legs are exceedingly long and thickened, its tibiæ are somewhat curved (the four hinder ones moreover being armed at their apical angle with a short but robust spine), its third tarsal joint is simple, and its front coxæ are contiguous, the intermediate ones but very slightly separated, and the hinder pair exceedingly remote.

The $S$. confuens is from the collection of $\mathrm{Mr}$. Pascoe, and was taken by Mr. Wallace at Sarawak in Borneo.

7. Charorrhinus (Fairmaire, Ann. de la Soc. Ent. de France, 742. 1857).--I am indebted to John Gray, Esq., for an opportunity of inspecting the European genus Charorrhinus, of Fairmaire; and it is not without the greatest astonishment that I have observed the excessive inaccuracy of the original diagnosis in assigning it to the Dryophthorides, - an inaccuracy which is quite unpardonable, and which has misled every subsequent author (including even Lacordaire) who has been content to trust to the published details, and not to examine them for himself. The prima facie aspect of its opake, deeply-sculptured surface, which is besmeared with dirty, mud-like scales, in conjunction with the cariniform structure on either side of its elytral apex, are without doubt marvellously suggestive of Dryophthorus, - so much so indeed that it may fairly be regarded as establishing, in conjunction with Synommatus, a curious affinity between the Dryophthorus-type and the subfamily Pentarthrides (to which it belongs); but there the resemblance altogether ceases; and it is surprising how any careful Coleopterist could be misled by characters so eminently superficial. In real fact its funiculus is five-articulate, which at once removes it from the Dryophthorides - in which that organ is composed of only four joints. Then its feet are on the ordinary pseudotetramerous pattern, instead of as in the о $о$ o 2 
Dryophthorides distinctly 5-jointed (the fourth one in that subfamily not being minute and hidden, but appreciable and unreceived). Yet so completely was Lacordaire led into error by the original diagnosis, that he not only accepted the insect (on account of the supposed structure of its funiculus) as a Dryophthorid, but naturally enough felt compelled so far to modify the characters of that welldefined subfamily so as to admit within its bounds the ordinary pseudotetramerous foot! It is, however, in reality, a normal member of the Pentarthrides, and is very intimately related to my genus Pentacoptus which was detected by Mr. G. Lewis in Japan. It completely lacks, moreover, the fusiform, or subelliptic, outline of the Dryophthorides; whilst its exceedingly incrassated legs and tarsi are in strange contrast with those of that subfamilyin which those parts are comparatively thin and wiry; and its eyes (instead of being sunken, transverse, and depressed) are rounded and very prominent-as in the Pentarthrideous Pentacoptus. Its metasternum too is shorter than that of the Dryophthorides; and its four anterior coxæ are perceptibly more approximated.

From the Japanese Pentacoptus (to which it is intimately allied), Charorrhinus differs mainly in its larger size and less narrowed prothorax, in the cariniform structure on either side of its elytral apex, in its anterior coxæ being rather less widely separated, and in its first and second abdominal segments being divided by a very deeply sinuated line, instead of a perfectly straight one.

The Chcerorrhini appear to occur in southern Europe, the genus having been first met with in Sicily.

\section{Pentacoptus (Wollaston, Trans. Ent. Soc. Lond.} 12. 1873).- - In its very coarsely sculptured and opake, though somewhat besmeared surface, its short, broad, parallel rostrum, nearly obsolete scutellum, and costate elytra, the present remarkable little genus has almost as much in common, at first sight, as Cherorrhinus has, with the Dryophthorides; nevertheless its 5-jointed funiculus, and its small, rounded, and prominent eyes, in conjunction with its elytra showing no traces of the peculiar cariniform structure at their apex which is so marked a feature in that group, its comparatively incrassated legs, and its ordinary pseudotetramerous feet (the third joint of which is a good deal widened and bilobed), will of themselves at once remove it from the members of that sub- 
family. I have already pointed out in what it principally differs from Chcerorrhinus. It was detected by Mr. G. Lewis in the Japanese archipelago,-namely at Nagasaki, in the island of Kushiu.

9. Lyprodes (nov. gen.). - The single example from which I have compiled the diagnosis of the present genus, which was captured by Mr. Wallace in Sula, one of the islands of the Malay archipelago, has been communicated by Mr. Pascoe; and it is especially important as supplying another well-defined type in the subfamily Pentarthrides - in which the funiculus is only 5 -articulate. Moreover its opake and deeply sculptured surface, which is densely besmeared with mud-like scales (or, as it were, a kind of dirty-whitish, scaly deposit), added to its almost obsolete scutellum, and its thick, abbreviated feet (the first joint of which is short, and the third one wide and very deeply bilobed), place it in the immediate vicinity of Pentacoptus and Cherorrhinus. It is abundantly distinct, however, from both of those groups, not merely in its much narrower and cylindric body (which is of nearly equal breadth throughout), but likewise in its much longer and slenderer rostrum, its less incrassated and less abbreviated antennæ (which have their second funiculus-joint appreciably longer than those which follow it), and in its more elongated metasternum (which indeed is scarcely shorter than that of Pentarthrum and Stenotrupis). Its eyes, although prominent, are less remarkably so than in Pentacoptus; and its elytral interstices are not so costate. In prima facie aspect the insect calls to mind what we might almost suppose to be an exceedingly diminutive state of the European Lyprus cylindricus, - a circumstance which, however fanciful, has suggested both its generic and specific names.

10. Phlgophagomorphus (nov. gen.). - In its rather lengthened cylindric-ovate outline, which is narrowed in front and gradually expanded behind (the prothorax being considerably reduced in size, and much narrower than the elytra), as well as in the fact of its four anterior coxæ being (especially as regards the front pair) greatly approximated, the present genus has much the primâ facie aspect of Phloophagus ; nevertheless its funiculus is only 5 -articulate, its scutellum is conspicuous, and its rostrum and (much thicker and more abbreviated) antennæ are very 
differently constructed. In reality it belongs to that particular section of the Pentarthrides in which the scutellum is developed and the surface bald, and it is remarkable amongst the immediately-allied forms for its somewhat convex, Phlcophagus-like body, for its (rather short and broad) rostrum being a good deal contracted, or as it were pinched-in, at the base, for its eyes being (instead of prominent) depressed, and for its four anterior legs being (as in the Phloophagi) much more approximated at their base. Its surface (which is shining) is of a reddish, and slightly pellucid, chestnut hue,-with the head, rostrum, and femora a little darker than the rest; its antennæ are somewhat thickened, with their second funiculus-joint not at all elongate; and its feet have their first articulation (as in Phloophagus) appreciably lengthened, and their third one minutely (and not very distinctly) bilobed. The example from which the generic details have been compiled is South-American (having been received from New Granada), and has been communicated by Mr. Fry.

11. Pseudopentarthrum (nov. gen.).-The rather obscure little Cossonid which forms the type of the present genus, is from Mexico, and has been communicated by Mr. Fry; and its primâ facie aspect is so much that of a minute and cylindrical Phlceophagus, that until I observed that its funiculus is only 5 -jointed I had regarded it as a member of that group. In reality however it is very close, in affinity, to Pentarthrum,--from which it nevertheless recedes in its very much smaller size and shortly-cylindrical body, in its more abbreviated and relatively broader (though equally parallel) rostrum, in its prothorax and metasternum being very much less elongated, and in its anterior coxæ being much more approximate. Indeed the latter are almost exactly the same as in Phloophagus, the front pair being nearly contiguous; and its prothorax also, which is oval (instead of elongate and subtriangular), is almost on the Phloophagus-pattern. Its under-segments are slightly scooped-out, or concave, after the fashion which obtains in so many of the Pentarthrides; its surface is completely bald, black, and but very slightly shining; and the third articulation of its feet is simple.

In point of fact, however, the present genus is somewhat intermediate between Pentarthrum and Phloophagomorphus, agreeing with the latter in its more approximated anterior coxæ; nevertheless it entirely wants the 
very peculiar rostrum of the latter, which is curiously pinched-in (or suddenly constricted) at its base ; and it is likewise smaller and more cylindrical (the prothorax being proportionately wider, and the elytra more parallel), of a darker hue and duller surface, with its metasternum and limbs more abbreviated, and with the first joint of its feet less elongate, and the third one more decidedly simple.

\section{Xenosomatium (nov. gen.).-The very minute} Pentarthrid for which I have established the present genus has been communicated by Mr. Pascoe, and was captured by $\mathrm{Mr}$. Wallace in the Malayan archipelago. A part from its diminutive size and 5-articulated funiculus, its greatly abbreviated second funiculus-joint, and its abrupt, largely developed club, it is at once remarkable for the structure of its tibiæ,-which are rather short, broad, and triangular, and have their terminal hook in the four posterior ones abbreviated, straight, and spiniform, but still shorter (in fact obsolete) in the front pair (where it is replaced by a robust and outwardly-curved pubescent spine which arises from the inner angle). This tibial modification is very peculiar, and one which I do not remember to have observed in any other Cossonideous group. In minor details Xenosomatium is conspicuous for its (somewhat short, broad, and arcuated) rostrum being a good deal constricted at the base, behind the insertion of the antennæ (which arise nearer to the base than is usual in the Pentarthrideous types); for its scape being long: and backwardly-curved, as well as greatly clavate (though, at the same time, obliquely lopped-off at the inner apex); for its eyes being extremely large and prominent; and for its feet having their first three joints thickened and subequal, but the ultimate one rather slender. In its piceoferruginous hue Xenosomatium agrees with the majority of these immediate forms, but its sculpture is finer and lighter than is usually the case.

13. Pentarthrum (Wollaston, Ann. Nat. Hist. xiv. 129. 1854).-Judging from the twelve exponents which have hitherto been brought to light, the Pentarthra are more or less narrow and parallel insects, closely sculptured, nearly always free from scales and pubescence, either piceous or castaneous in hue, and but very slightly shining. Their eyes are prominent, and, together with the scutellum, conspicuous; their prothorax is rather large, and, like the 
metasternum, elongate; their rostrum (which varies in length according to the species, but which is never very long) is robust and linear, though sometimes obsoletely constricted towards the base; and their third tarsal joint is either slightly bilobed, or else narrow and simple. In the European $P$. Huttoni, which must be regarded as the type of the genus, as well as in the $P$. Zealandicum, and in the two species from Chili, the second articulation of the 5-jointed funiculus is appreciably a little longer than those which follow it; but this is less evidently the case in the other members of the group which have hitherto been observed. The Pentarthra are somewhat peculiar in their habits,-attaching themselves to old planks, boards, rafters, casks, \&c., on the dry, and often tinder-like, wood of which they appear to subsist (and that too, occasionally, when the latter are even partly buried in the soil); a mode of life which is equally indicated in (the nearly blind) Amaurorrhinus, and in Hexarthrum of the true Cossonides. On this account we may expect that their acquired areas of distribution will be found eventually to be wide; and, in accordance with this conjecture, it is a significant fact that the exponents which have hitherto been discovered should occur in countries so remote from each other as western Europe,*

* Until quite recently I had looked upon the P. Huttoni as peculiar to Fngland, and indeed it has not as yet been recorded for any other country; but, having, a few weeks ago, received some Cossonida from Dr. Sharp, I was surprised to find that two typical examples (which were included amongst them), of the "Rhyncolus Hervei" of Allard (Abeille, v. 475. 1869), and which appear to have been captured at Rennes, are identical with my Pentarthrum Huttoni, described (fifteen years before) from examples taken near Exeter. In the Munich Catalogue the department of Finisterre is given as the locality for the "Rhyncolus Hervei ;" so that at any rate the extreme western portion of Brittany is the only region, beyond England, in which it has hitherto been observed ; and it is a significant fact, from a geographical point of view, that that particular district is exactly opposite to Devonshire-on the southern side of the Channel. Its preeise places of capture in this country are, up to the present date, three,namely, the vicinity of Exeter (where it was met with originally, at Alphington, by my nephew, the Rev. H. W. Hutton); Teignmouth (where on two or three different occasions I have myself found it), and Plymouth (where it was detected by $\mathrm{Mr}$. Reading) Apart from its many other characters, the fact of its funiculus being composed of only five joints ought certainly to have prevented it from being re-described as a khyncolus -in which that organ has invariably seven articulations; but the slovenly manner in which continental entomologists are apt to mount their specimens, every limb and joint being hopelessly concealed beneath, will perhaps explain a blunder which is nevertheless utterly unpardonable. It is scarcely less fragrant however than the similar miscalculation of the funiculus-joints in Cherorrhinus, which has resulted in that genus having been assigned hitherto to a subfamily with which it has next to nothing in 
the island of Ascension,* the Malayan and Japanese archipelagos, New Zealand, Chili, and Brazil. $\dagger$

14. Sericotrogus (nov. gen.).-I am indebted to Dr. Sharp for the very curious little Pentarthrid for which the present genus is established; and he appears to have obtained it from Mr. Lawson, of Scarborough, by whom it was received from Auckland in New Zealand. Its distinct scutellum and largely-developed eyes place it very near to Pentarthrum proper; nevertheless in its smaller bulk, and slenderer aud more fusiform outline (the elytra, as in Amaurorrhinus, being narrowed anteriorly), and in its somewhat brassy surface, which is sparingly clothed with a coarse, silken, decumbent æneo-cinereous pubescence, as well as in its less elongated metasternum (which is likewise more on the Amaurorrhinus type), and the widely bilobed third joint of its feet, it altogether recedes from the members of that group. Its rostrum, too, is a trifle longer, thinner, and more curved than in the majority of the Pentarthra, and has the antennæ implanted into it rather more conspicuously before the middle ; the latter are a little less thickened; its head is more exserted; its prothorax (which is slightly concave beneath) is convexer, more regularly rounded at the sides (it being neither subtriangular nor subcylindrical), and is nearly free from an anterior constriction: and its elytra have apparently no tendency to be separately rounded-off, and subrecurved, at their extreme apex.

\section{Stenotrupis (nov.gen.).-The exceedingly narrow,}

common; or than placing Hexarthrum amongst the Rhyncoli, because the articulations of the same organ were incorrectly counted! But if collectors will not take the trouble to expand their specimens so that the parts may be distinctly seen, how can we wonder at the inevitable results ? Still, one would at least have supposed that before enunciating a new form, the microscope would, as a matter of necessity, have been appealed to.

* The presence of my P. cylindricum in the island of Ascension appears to have been (as indeed I always anticipated) merely accidental ; for an example is now before me which was captured by Mr. Fry in Brazil, and another which was taken by Mr. Wallace in Gilolo of the Malayan archipelago. In all probability therefore it is a species which, like certain others, is liable to follow in the wake of civilization.

$\dagger$ The little insect from St. Helena which I described two years ago as an aberrant Pentarthrum, under the name of $P$. subcecum, proves on a closer examination to be no Pentarthrum at all, but-more intimately related to Amaurorrhinus (or Mesoxenus). It is, however, distinct from even the latter, and forms the type of my genus Pseudomesoxenus,enunciated below. 
and sometimes minute, insects for which the present genus is proposed appear to have been confounded hitherto with Catolethrus - into which they seem to have been admitted as abnormally small members; and, in accordance with this, a very pallid and diminutive one, from Cuba, has been communicated by $\mathrm{Mr}$. Pascoe with a very old label appended to it, bearing the name "Catolethrus palmeus, Schön." There is no species, however, of supposed Catolethrus, so far as I can ascertain, which bears that specific title, either in the 'Genera Curculionidum' or the Munich catalogue; and I am compelled, therefore, to conclude that it is an unpublished one; yet the fact itself tends nevertheless to prove that the exponents of the present genus have, as just mentioned, been associated inadvertently with the Catolethri. But in reality, when closely inspected, they will be seen to belong to even a different subfamily from the latter,- their 5-jointed funiculus assigning them at once to the Pentarthrides. In addition, however, to this primary distinction, Stenotrupis recedes from Catolethrus in the insects which compose it being smaller and narrower; in their head being much longer, thicker, more oval and very much more exserted (or exposed); in their rostrum being slenderer still, a little widened towards the tip, and not appreciably divided from the forehead; in their prothorax being more triangular, and less constricted behind its apex; in their scutellum being less conspicuous; in their elytra being minutely pubescent at the apex; in their four hinder legs being shorter; in all their coxæ being equally separated, or apart; and in the third joint of their feet being unexpanded and simple.

In point of fact, however, Stenotrupis is much nearer to Pentarthrum,-particularly to such members of it as the $P$. angustissimum, from Japan; yet its species are still narrower and more depressed; their head is longer, thicker, oval and exserted; their rostrum (particularly in the female sex) is more elongated and slender, and appreciably widened in front; their eyes (instead of being rounded and prominent) are completely sunken, ovate and more approximated above; their prothorax is more triangular and less constricted behind its apex; their elytra are minutely pubescent at the tip; their legs, particularly the four posterior ones, are much shorter; and their coxæ are, all of them, equally separated.

In all probability Stenotrupis will be found to have a 
wide geographical range, though it is perhaps more strictly tropical than Pentarthrum. At any rate one of the species now before me is from Cuba, and another was captured by Mr. Wallace in Makian-one of the islands of the Malay archipelago.

16. Microcossonus (nov.gen.).-The minute Cossonid (which was taken by Mr. Wallace at Saylee on the northwest coast of New Guinea, and which has been communicated by Mr. Pascoe) from which the characters for the present genus have been drawn out, is manifestly a good deal allied to Stenotrupis, - with which it agrees in its thickened, elongate, greatly exserted head, its narrow and parallel outline, its depressed surface, and in the fact of its legs being equally distant at their base. Nevertheless, if the example before me may be taken as a type of its group, the body is even still smaller than in Stenotrupis (the entire length being scarcely one line), but relatively not quite so slender; its rostrum (which, as in most of the members of that genus, is appreciably dilated towards the apex) is much shorter and wider; its eyes are considerably more developed, and not so flattened; its elytra are free from minute pubescence at their apex; its antennæ are inserted very much nearer to the base of the rostrum; and its coxæ (although, as in that group, equally separated) are distinctly more remote. Its general contour and outline are somewhat that of an exceedingly diminutive, flattened, and pallid Mesites; but its 5-jointed funiculus and the peculiar construction of its rostrum, as well as its numerous other features, entirely remove it from the subfamily Cossonides.

17. Cossonideus (nov. gen.).-In its comparatively large and Cossonus-like body (which is much depressed, deeply sculptured, parallel-fusiform in outline, and of a rather pale, though somewhat variegated, hue) the curious insect for which this genus is proposed, and which is communicated by Mr. Pascoe as having been received from Champion Bay in western Australia, seems altogether anomalous amongst the Pentarthrides; nevertheless its 5jointed funiculus, and the structure of its robust, parallel rostrum are quite in accordance with the members of that subfamily. Apart, however, from the characters just enumerated, it may be known by its excessively large and 
prominent eyes; by its antennæ, which have their second funiculus-joint conspicuously longer than those which follow it, being inserted about the middle of the rostrum; and by its exceedingly elongate and greatly developed legs, - the femora of which are much incrassated, or clavate, and are rather roughened with a few minute and indistinct asperities, or tubercles, on their inner surface; whilst the tibiæ are sinuated internally, and produced into a small but evident spinule at their inner angle, and the tarsi (especially their terminal articulation) are elongate.

Cossonideus may very possibly be the representative of an important Pentarthrideous form in Australia; but in external facies it nevertheless recedes greatly from the Pentarthrides as hitherto known; though at the same time it must be admitted that the (comparatively diminutive) Microcossonus Wallacei, from New Guinea, makes likewise a decided approach (though certainly a less striking one) towards the Cossonus and Mesites type.

18. Trchiodes (Wollaston, Trans. Ent. Soc. Lond. 16. 1873).- This is altogether one of the most curious of the Cossonideous forms with which I am acquainted,-its rather wide, subdepressed, oblong-elliptic body (which, as in most of the allied groups, is slightly shining, castaneopiceous, and free from pubescence), in conjunction with its extremely slender and cylindrical rostrum (I believe in both sexes), its short, transverse prothorax, and thickened legs, giving it more the appearance at first sight of some member of the Erirhinides, in the vicinity of Tychius, than of a Cossonid. Its antennæ (which are rather slender, and implanted considerably behind the middle of the rostrum) have their scape short and a good deal flexuose (and, as it were, obscurely scooped-out on the underside), and likewise the second articulation of their lax, 5-jointed funiculus considerably longer than those which follow it. Its scutellum is very conspicuous, and its feet (which are rather thick, and largely developed) have their third articulation deeply bilobed. Its metasternum is a little less elongated than is the case in Pentarthrum, Stenotrupis, Lyprodes, Leptomimus, and others. It was detected by Dr. A. Adams in the Japanese archipelago, - namely on the island of Awasima, off the northwest coast of Nipon. 
19. Trсniosoma (nov. gen.).-The insect for which I have founded the present genus is from the Philippine Islands, and has been communicated by Mr. Pascoe. It is very closely allied to the Japanese Tychiodes Adamsii, - from which, however, it differs in being not only larger and more depressed and with the limbs longer, but likewise in having its antennæ more medially inserted, with the scape especially more lengthened, less arcuate, and without any tendency to be hollowed-out internally, and with the funiculus gradually much more widened, and consequently with the club (which is itself longer) less abrupt. In addition to which, its prothorax (which is equally small) is more triangular, or less transverse, as well as (together with the under-segments) extremely shining and almost unsculptured; its prosternum is clothed, between the anterior coxæ, with fulvescent pile; and its front tibix (instead of being simple) are slightly scooped-out towards their inner apex, the emargination being barbed posteriorly with strong fulvescent hairs.

20. Leptomimus (nov. gen.).-The two species now before me for which the present genus is established, and which have been communicated by Mr. Pascoe as having been obtained by Mr. Wallace in the island of Gilolo, of the Malayan archipelago, combine many very curious features which are essentially their own. In their bodies being exceedingly narrow and parallel they agree with Stenotrupis; but they nevertheless entirely want the elongate, thickened, exserted head, and the completely depressed eyes, of that genus; their rostrum too is very much more lengthened and slender (not being subdilated anteriorly); their prothorax and antennæ, as well as their second funiculus-joint, are much more elongated; the third articulation of their feet is more expanded and bilobed; and their legs (instead of being equidistant from each other at the base) have the intermediate coxæ rather widely separated, but the front and hinder pairs appreciably (and equally) more approximate. This last-mentioned peculiarity is rather anomalous amongst the Cossonida, and particularly so amongst the Pentarthrides. In other respects Leptomimus is remarkable for the opake, reddishbrown, and most closely sculptured surface of its two hitherto-discovered exponents,- - one of which, moreover, is clothed with a short, setiform pubescence, whilst the other appears to be bald. In all probability the group 
will be found to play an important part in the Rhynchophorous fauna of the Malay archipelago, the L. delicatulus having (as I am informed by Mr. Pascoe) been stated by Mr. Wallace to be common amongst the bamboos.

\section{Lamprochrus (nov. gen.).-The superb Cossonid*} for which the present genus is proposed, and which was discovered by Mr. Melliss at St. Helena, I admitted two years ago (albeit not without some hesitation) to Microxylobius, - having been content at the time to cite it as a large and aberrant member of that locally-important group; yet a closer inspection of its real structural details would certainly imply that it must be treated in reality as altogether distinct,-its extremely elongate and slender rostrum (which in the male sex is rather more robust and sculptured, and slightly dilated before the middle, at the insertion of the antennæ, much after the fashion which obtains in Mesites of the true Cossonides), in conjunction with its equally elongated antennæ, legs, and feet (the first of which have their second funiculus-joint, and the last their basal one, greatly lengthened), being of themselves more than sufficient to establish its claims for separation. In its fusiform outline and shining, brassy surface it might well be mistaken at first sight for a gigantic exponent of that section of Acanthomerus in which the femora are unarmed; but the characters above enumerated (in addition to its slightly pubescent body, as in certain of the Microxylobii proper) will at once distinguish it from the members of that genus. The fact, however, of its funiculus being 5 -articulate, its scutellum obsolete, and its third tarsal joint deeply bilobed, added to its fusiform outline and its metallic lustre, is too significant not to indicate its manifest relationship with the other Pentarthrideous genera (Microxylobius proper and Acanthomerus) which are so remarkably developed, as regards their specific modifications, in the little island of St. Helena.

22. Acanthomerus (Boheman, Res. Eugen. 141. 1858). - The Acanthomeri, which are peculiar to the island of St. Helena, may be said to be those members of Microxylobius (as hitherto understood) in which the body is highly polished, less sculptured, and brassy, and totally free from any traces of even the minutest pubescence, 
and in which the second joint of the funiculus is conspicuously longer than any of those which follow it. Their rostra, too, are usually a trifle longer, and relatively a little less thickened, than in Microxylobius proper, with the antennæ implanted just perceptibly nearer to the apex; and in the typical members of the group (the $A$. armatus, conicollis, and monilicornis) the two hinder femora are furnished with an acute spine at the base of their upper edge. In the four remaining species which have as yet been detected (namely the terebrans, obliteratus, debilis, and angustus) the femora are unarmed. The A. monilicornis, however, presents a slight exception as regards its funiculus-joints, the last four of which are almost of equal length and breadth,--the first of them being scarcely at all elongated; but in every other respect it is typical.

23. Microxylobius (Chevrolat, Trans. Ent. Soc. Lond. i. 98. 1836).-A more careful examination of the many remarkable and dissimilar Cossonids, from St. Helena, which I have hitherto recorded (chiefly on account of their funiculus being 5-articulate) as Microxylobii, has convinced me that it will be better (indeed perhaps necessary) to treat them as exponents of two distinct genera,-or, if we include the comparatively gigantic " $M$. cossonoides" (which was enunciated by myself, as such, two years ago), of three. As thus restricted, the dark and almost unmetallic members of the group will be the Microxylobii proper,-in which moreover the surface, instead of being highly polished and perfectly bald, is subopake, more or less roughened, and with a tendency to be sparingly studded with a very minute pubescence (which, however, is sometimes barely traceable even beneath a high magnifying power). In fact, although distinct in the M. vestitus, and just appreciable in the lacertosus and dimidiatus, this pubescence may be said in the Westwoodii and lucifugus to be almost, if not indeed entirely, absent. These five species moreover, with the exception of the last, are the smallest of the assemblage, and have their rostra relatively a trifle broader and thicker (it being in some instances almost subtriangular), and the second articulation of their funiculus hardly at all longer than those which follow it. In the excessive brevity of their metasterna, Microxylobius, Acanthomerus, Lamprochrus, and Amaurorrhinus are nearly coincident; though perhaps it is in Microxylobius that it is more particularly shortened. 
24. Microtribus (nov. gen.).-The very remarkable little Cossonid for which the present genus has been established is from the collection of $\mathrm{Mr}$. Pascoe, and was captured by my nephew, Captain F. W. Hutton, in the Waikato district of North Island in New Zealand; and it is peculiarly interesting as adding another well-defined type to the escutellate section of the Pentarthrides in which the eyes are nevertheless fully developed. In its fusiform outline, dark-piceous hue, slightly shining surface, and rather shortened, subconcave metasternum, it is in entire accordance with most of the immediately-allied genera; but it is conspicuous for its rostrum being rather narrow, elongated, and parallel, for its eyes (although small) being prominent and less wide apart from each other than is usual, for its prothorax being oval, regularly rounded at the sides, and largely developed, and for the second joint of its exceedingly lax funiculus being very appreciably lengthened, and the third one of its feet much expanded and deeply bilobed. But one of its most significant features consists in the fact that, whilst the rest of its body is completely bald, the base of its elytra and the extreme hinder margin of its prothorax are studded, in unrubbed specimens, with a few very fine, elongated hairs, - thus feebly shadowing-forth what is so strongly expressed in the nearly-blind Pentatemni (of the Atlantic archipelagos), and still more so in Halorhynchus (firom western Australia), the anomalous Onycholips (of the Canarian group), and the Madeiran genus Lipommata,the last three of which are totally devoid of sight. Whether however it at all indicates (as I am rather inclined to suspect) a sand-infesting mode of life, as it clearly does in the groups to which allusion has just been made, I have no positive information. The exact position of Microtribus, amongst the various forms which up to the present time have been made known, appears to be between Microxylobius, from St. Helena, and Mesoxenomorphus from southern Africa.

It has given me great pleasure to name the type of this interesting genus after Captain Hutton, to whose indefatigable researches we are gradually becoming indebted for a more complete knowledge of the New Zealand fauna than has hitherto been brought to light.

25. Mesoxenomorphus (nov. gen.).-The three examples for the reception of which I have been compelled 
to establish the present genus have been communicated by Mr. Janson, and are from British Caffraria in southern Africa. In their fusiform outline, piceous hue, shining, unpubescent surface, and obsolete scutellum, they are at first sight very similar to Mesoxenus (now merged into Amaurorrhinus); nevertheless the fact of their eyes (although minute) being present, instead of obsolete, throws them into a different, though proximate, section of the Pentarthrides. And, when closely inspected, they will be seen, further, to recede from Amaurorrhinus, not only in their relatively narrower body and more elongated prothorax and elytra, but likewise in their shorter, broader and more parallel rostrum, into which their very much more abbreviated antennæ are implanted further from the apex, in their legs (the front and hind pairs of which are a trifle more approximate at their respective bases) being also shorter, in their metasternum being appreciably more elongated, and (together with their first abdominal segment) less scooped-out, or concave, and in the third joint of their feet being more decidedly simple.

26. Heteropsis (nov. gen.).-I am indebted to Dr. Sharp for the remarkable little Cossonid for which the present genus is proposed, and which was captured at Auckland in New Zealand by Mr. Lawson,-after whom I have had much pleasure in naming the species. Its 5jointed funiculus and obsolete eyes (which are minute, sunken, and very rudimentary) place it near to Amaurorrhinus; nevertheless it differs from the latter, and the cognate forms, in having a developed scutellum; whilst in its extremely short and broad rostrum (particularly of the male sex), which is a little contracted posteriorly and is divided from the head by a distinct frontal line, and its abbreviated, abruptly-clavate scape, it possesses features which are essentially its own. In other respects, Heteropsis is conspicuous for its small size, and its narrow, cylindrical, but somewhat depressed body, for its shining, piceo-castaneous surface (which is very lightly sculptured anteriorly), and for its rather short legs and elongated metasternum.

27. Amaurorrhinus (Fairmaire, Ann. de la Soc. Ent. de France, 629. 1860).-Although the exceedingly short and imperfect diagnosis which M. Fairmaire has given of

TRANS. ENT. SOC. 1873.-PART IV. (OCT.) P P 
this genus does not call attention to a single structural peculiarity beyond the fact that its funiculus is composed of but five joints, I have nevertheless no hesitation in identifying it with my Mesoxenus (from the Madeiran and Canarian archipelagos), seeing that his specific description of the type, namely the $A$. Bonnairii (= A. narbonnensis, Bris.), from Corsica and the south of France, seems to accord so well with an insect now before me, from Corfu, which is unquestionably a Mesoxenus, as to leave little doubt in my mind that it is even the actual species referred to by Fairmaire. This particular example has been communicated by Mr. Janson; and it is so closely allied to the Mesoxenus Bewickianus, from Madeira, that I had at first sight imagined it must be identical with it. A more critical inspection however has convinced me that the two are specifically distinct, though it is impossible to have the slightest hesitation in assigning them to at all events the same group; and I do not think, therefore, this being the case, that Mesoxenus should be kept apart from Amaurorrhinus. Nevertheless I ought perhaps to mention that Fairmaire makes no allusion whatever to the obsoleteness of its eyes, which is the most important feature in the insects now before me; and that he likewise speaks of the antennæ as " in medio rostri insertæ," whereas those organs are implanted considerably before the middle in the only three representatives of my genus Mesoxenus which I have hitherto examined. Still, the manifest looseness, and brevity, of his diagnosis is sufficient to account for these omissions; and it is my belief, as just stated, that the genera in question are identical.*

Regarding therefore the Amaurorrhini and Mesoxeni as coincident, I may add that the members of this genus have the bald, rufo-castaneous, and slightly shining surface of Pentarthrum; nevertheless their obsolete eyes and scutellum, and abbreviated metasternum, throw them into a totally different section of the present subfamily. They

* In size, colour, outline and sculpture, the species from Corfu (which I believe to be the $A$. Bonnairii of Fairmaire) almost exactly resembles the Madeiran A. Bewickianus,--from which it merely differs in its prothorax being a little less widened (or rounded-outwards) behind the middle, in its rostrum being just appreciably slenderer and less expanded in front of the antennæ (which are themselves not quite so thick), in its second funiculusjoint being perhaps a trifle more elongate (though not so much so as in the A. Monizianus), in its club being somewhat less developed, and in its metasternum and first abdominal segment being more convex (or hardly at all scooped-out, or concave). 
are also more fusiform, or less parallel, insects than the Pentarthra; their prothorax is more rounded and convex; their elytra are less straightened, and more lightly sculptured; their rostrum is a little longer and less robust; and their antennæ (which are implanted a trifle nearer to the apex of the latter) have their scape slenderer and more curved. There is also a peculiarity about their undersides (which is likewise the case in most of the Microxylobii and Acanthomeri, as well as in Lamprochrus, and in many of the true Cossonides), - the first abdominal segment and the (very short) metasternum being deeply impressed (at any rate in the two Atlantic-island species) down the central region, causing them to be hollowed-out, or concave. Two out of the three Amaurorrhini with which I am acquainted (namely the $A$. Monizianus and Bewickianus) are found in the Madeiran archipelago, and one of them likewise at the Canaries, whilst the other occurs in the south of Europe; but the slight singularity in their modes of life, which appear to be much the same as those of Pentarthrum (as well as of Hexarthrum, of the true Cossonides), renders it probable that they will be found eventually to possess a more extended range.

28. Pseudomesoxenus (nov. gen.).-The little insect (hitherto unique) for the reception of which the present genus is established was taken in the island of St. Helena by Mr. Melliss; and it was recorded by myself, three years ago, as a blind, aberrant Pentarthrum, under the name of $P$. subcrecum. ${ }^{*}$ It is evident however that it has a far closer affinity with Amaurorrhinus,-with which indeed its obsolete eyes and scutellum, and its convex, largely-developed prothorax, would tend to affiliate it. Still, an accurate examination of its structural details has convinced me that it cannot be treated as even an Amaurorrhinus ; for not only is its metasternum very appreciably more elongated, and its rostrum thicker and subtriangular, but its elytra likewise are narrower and more parallel and cylindrical, and its limbs are shorter and less thickened, - the feet especially being slenderer and filiform, with their third joint almost unexpanded and simple. The underside moreover is convex, and has no trace of the concavity which gives so remarkable an appearance to

* Vide 'Ann. Nat. Hist.' iv. 410 (1869). 
the first abdominal segment and greatly abbreviated metasternum of Amaurorrhinus and the allied groups.

29. Pentatemnus (Wollaston, Trans. Ent. Soc. Lond. 2nd ser. v. 385. 1861).- - In its obsolete scutellum and eyes (the latter of which are very minute and indistinct, being composed of only about six small lenses), and its dark piceous hue, and the fact of its funiculus being 5 -articulate, Pentatemnus agrees with Amaurorrhinus; but it differs from it essentially in most of its other details, as well as in its subfossorial mode of life. Thus, not only is its body (instead of being bald) sparingly studded with elongate silken hairs, but its elytra and under-surface are curiously and thickly asperated with obliquely-impinged punctures, its rostrum and antennæ (the former of which is more strictly parallel, and the latter are more medially inserted) are much shorter and thicker, its legs are considerably more incrassated, and its third tarsal joint is simple. Its tibial hooks too are very much more developed,- the four hinder ones being exceedingly powerful, and rather expanded, and compressed, at their base, causing the tibiæ. to seem as though slightly rounded-outwards at their external angle. The Pentatemni are sand-infesting, and somewhat fossorial, in their habits (as indeed their pilose bodies, obsolete eyes, and strongly-developed legs and tibial hooks would partially imply), residing around the roots of shrubby plants which stud the arid tracts of loose, drifting sand in certain islands of the Canarian and Cape-Verde archipelagos,where they often descend to a considerable depth beneath the surface. In such situations I have met with them in Lanzarote, Fuerteventura and Grand Canary of the former, and in Sâo Vicente of the latter.

30. Halorhynchus (nov. gen.).-The insect for which the present genus has been proposed is from the collection of Mr. Pascoe, by whom it was received from Freemantle in Western Australia; and it is perhaps the most important of all the forms which he has communicated to me,as establishing most completely the manifest relationship which exists (of which, despite the opinion of Lacordaire, I have never myself entertained the slightest doubt) between the Pentarthrides and that singular department of aberrant, fossorial Cossonids, to receive which I have established the subfamily Onycholipides. Indeed so much has it in common with Onycholips (with which it also 
agrees in its total freedom from even the rudiments of eyes) that I had at first sight supposed it to be a member of that actual genus; nevertheless its 5 -jointed funiculus, parallel outline and obsolete scutellum, in conjunction with its less completely approximated four anterior legs and the structure of its abdominal segments and tibiæ, show it to belong unmistakeably to that particular section of the Pentarthrides which contains Pentatemnus. In point of fact it is very intimately allied to the latter genus,-from which it nevertheless recedes in its eyes being altogether absent, in its tibiæ being armed at their inner angle (as in Lipommata) with a distinct spinule, and in the two hinder ones having their apical hook reduced in size and almost spiniform, in its four anterior tarsi being more narrow and linear, whilst the hinder pair are comparatively robust, and in its claws being so exceedingly minute as to be barely traceable even beneath the microscope. In its general outline and sculpture, as well as in its rather pallid hue, it is exactly intermediate between Pentatemnus and Onycholips, - a fact which is equally borne-out by its nearly rudimentary ungues, and the somewhat spiniform structure of its hinder tibial unci.

In its prothorax being appreciably narrower than the elytra, as well as in its inner tibial angle being produced into a very evident, robust spinule, and in its eyes being totally absent, Haloryhnchus embodies some of the most characteristic features, likewise, of Lipommata (in the true Cossonides),- -thus bearing still further testimony to that strange and mysterious resemblance which seems, as it were, to bind together the whole of these immediate pilose, posteriorly-asperated, fossorial, sand-infesting forms, in the three subfamilies Pentarthrides, Onycholipides, and Cossonides.

31. Georrhynchus (Roelofs, Ann. Soc. Belg. x. 241. 1866 ; and xi. 78. 1867).-I am indebted to M. Roelofs, of Brussels, for the opportunity of examining his unique type of the very curious insect (captured near Montevideo, in South America) for the reception of which he established the present genus; and although I will not venture to record more than a desultory opinion concerning its affinities, which Lacordaire (vide Gen. vii. 348, note) and others have justly regarded as very obscure; yet, after a careful examination of its several parts, I cannot but think that it 
is perhaps more correctly placed at no great distance from the equally anomalous group Onycholips than in any other situation with which I am at present acquainted. And if it can be shown that the subfamily Onycholipides is its true status, there can be but little doubt (despite the anomalousness of its structure) that it is a veritable member (although, like its immediate associates, an aberrant one) of the Cossonida;-for Onycholips is so intimately connected, on the one hand (through Halorhynchus and Pentatemnus), with the Pentarthrides, and on the other (by means of Raymondionymus, Alaocyba, and Lipommata) with the Cossonides proper, that there is scarcely room for question as to where, in any system of arrangement which professes to be a natural one, it should be stationed.

Although very differently modified, there is a remarkable degree of correspondence between Georrhynchus and Onycholips, - not merely in the exact parts selected for modification, but likewise, to a certain extent, even in the kind of their development; whilst in their subfossorial, sand-infesting modes of life they appear to possess another, and a very sigmificant, point of union. Thus, in both cases, the number of the funiculus-joints is reduced to the very unusual one of six, and that of the tarsal ones to four; and both genera are almost equally conspicuous for their comparatively pale, hairy, convex, and slightly asperated bodies; for their greatly abbreviated antennæ, rostra, and metasterna; and for their tibiæ (although different in detail) being on a compressed and burrowing type, and moreover (which is of the utmost importance) free from an apical hook. In each instance, too, the scutellum is distinct, and (which is especially to be noted) the front coxæ are contiguous and the intermediate ones but barely separated. It is true that the eyes and claws, which are absent in Onycholips, are present in Georrhynchus; but that may indicate a mere generic difference, such as we see paralleled in other groups of the Cossonida which are universally admitted to be in juxta-position; and I think therefore that enough has been said to render it at least probable that the two genera in question are not very remote, as regards the several peculiarities of their structure, from each other. And if this fact can be but once established, it seems to me that we have then sufficient evidence to show (as may be gleaned from my observations 
under Onycholips and the following groups) that the true position of Georrhynchus must be, of necessity, amongst the Cossonids.

32. Onycholips (Wollaston, Trans. Ent. Soc. Lond. v. 389. 1861).- - It was not without some degree of hesitation in the first instance, that I decided on recognising the anomalous genus Onycholips as the type of a subfamily of the Cossonidar; more especially since Lacordaire has expressed a doubt as to its true location, and hints that it may perhaps be necessary to establish a distinct family of the Rhynchophora to receive it,-along perhaps with Georrhynchus (the almost equally unintelligible Curculionid just alluded to, with apparently somewhat similar subfossorial habits, detected at Montevideo). Yet, despite its many eccentricities, some of which would seem to debar it from nearly every department of the weevils which has hitherto been defined (and which must remain, consequently, anomalies wherever the genus be placed), the more I study its various details (structural and external), and its fossorial mode of life, the more convinced am I, as at first, of its not very distant relationship with such blind members of the Cossonida as Pentatemnus, Halorhynchus, and Lipommata (particularly the former), and even more so perhaps with the equally blind Raymondionymus and Alaocyba,-all of which have either burrowing or sandinfesting habits, and slightly pilose bodies, and which show some kind of tendency for unusual tibial developments; the last two, moreover, having a 6-jointed funiculus, and quadriarticulate feet. Perhaps the most significant points however, which have been urged as tending to remove it from the Cossonide are embodied in the twofold fact that its first and second abdominal segments are not completely soldered, and that its intermediate coxæ are almost (like the anterior ones) contiguous; but, on the other hand, there are many undoubted Cossonids in which the first and second segments of the abdomen are not absolutely confluent, being (as in Hexarthrum, Brachytemnus and Spharocorynes) separated from each other by a most conspicuous sutural line; whilst certain, also, of the subHylastideous genera of the true Cossonides have (like Hexarthrum, Stereocorynes, Tomolips, Brachytemnus, Stenoscelis, and others) their intermediate legs (no less than their anterior ones, almost completely in contact, and I think therefore that neither of those characters will 
suffice, of itself, to exclude a manifestly erratic form like Onycholips from being regarded as the type of a new department of the present family, the exponents of which are thus anomalously (though variously) modified.

A part from its totally blind condition, its 6-jointed funiculus* and quadriarticulate feet, as well as from the fact of its anterior coxæ being entirely and its intermediate ones almost contiguous, and its apparent freedom from tarsal claws, Onycholips is at once remarkable for its rather globose and testaceous body, which is sparingly beset with exceedingly long silken pile, and the surface of which is somewhat uneven (being marked, or pitted, with large but shallow varioles, or irregular punctiform impressions) and slightly asperated, for its rostrum being short, broad, depressed, and subtriangular, for its scutellum being distinct, and for its antennæ and legs being greatly abbreviated. Indeed, the former are of a most curious structure, their scape being so reduced in length as to be absolutely concealed within the short and deep auriculiform scrobs; whilst its funiculus has the first two (!) articulations very largely and subequally incrassated, with the remaining four minute; and their club is extremely solid, and apically-pilose. And the latter, which are very short (especially as regards their femora), are still more extraordinary, - the two front tibiæ being produced at their outer angle into an exceedingly elongated, tectiform lobe (which represents the ordinary hook); whilst the four hinder ones are powerfully developed, and spinulose along their exterior edge, and compressed at each of their angles (inner and outer) into a small obtuse lobiform plate,between which the feet are implanted. These latter are on a pattern which is quite without precedent in any Coleopterous insect with which I am acquainted: for while the anterior pair are abnormally shortened, narrow, filiform, and quadri-articulate (the fifth joint being apparently lost, and the fourth, or terminal, one being surmounted by a tuft of elongate pile as though to represent the ungues), the remaining ones have their basal joint abbreviated, the two following produced into a divaricating spiniform lobe at each of their angles, and the fourth, as I believe, minute and completely soldered to, or merged into, the fifth (which, like those which precede it, is apically-

* Lacordaire, in his ' Genera' (vide vii. 347 ), has inadvertently recorded Onycholips as possessing a 7 -jointed funiculus. 
divaricate),-the two together thus constituting a single joint, bifurcated at its tip. And from the analogy of the similar (though more enlarged) lobes at the angles of the joints which precede it, I conclude that these two terminal diverging processes do not represent the claws (which seem to be altogether absent), but rather the prolongations of the anterior angles of the ultimate joint.

In its habits Onycholips appears to be much the same as Pentatemnus and Lipommata, though more decidedly fossorial,-its spinulose posterior tibiæ being eminently on a burrowing pattern; and it is still more conspicuously beset (like so many sand-infesting insects), with remote, elongated hairs. Indeed, these latter are not confined to the body alone, both the scape and club of the antennæ being singularly pilose. I have captured it in the three eastern islands (Lanzarote, Fuerteventura, and Grand Canary) of the Canarian archipelago, - where it resides on, and beneath, the surface of the sandy hillocks, in the vicinity of the coast, which have accumulated gradually around the roots of the few shrubby plants which stud those arid spots.

33. Raymondionymus (= Raymondia, pars, Aubé, Ann. de la Soc. Ent. de France, 195. 1861). - The blind and anomalous genus Raymondionymus (or Raymondia* $^{*}$, which appears to occur in Mediterranean latitudes, has somewhat the fusiform outline, rather elongated rostrum, and rufo-piceous hue of Amaurorrhinus; but its funiculus is composed of six articulations (instead of only five), its metasternum is shorter still, its tibiæ (which have no terminal hook) are compressed and triangularly dilated, and its feet are short, broad, and thick, furnished with long:

* I regret that it should be absolutely necessary to change the name of this genus,- "Raymondia" having been preoccupied by M. Frauenfeld, for a group of the Diptera (vide Sitzungsb. d. Wien. Acad. x viii. 320), six years before it was employed by Aubé. In real fact, however, this is perhaps the less to be deplored, since I strongly suspect (judging from the diagnosis and figure) that Aubé's $R$. fossor is not actually congeneric with the larger species which have subsequently been associated with it,--but more properly with Alaocyba, as recently enunciated by Perris; and if this should be the case, it follows that the larger species, of which I would regard the $R$. Marqueti as the type, have not yet been separated generically from the smaller ones. Be this however as it may, the title "Raymondia" must of necessity be altered; and therefore, being unwilling to disconnect the group with the name of the eminent Coleopterist to whom it was originally dedicated, I have (rather than take the opposite alternative) proposed for it, instead, the perhaps not altogether euphonious one of Raymondionymus. 
hairs beneath, and (instead of being on the ordinary pseudotetramerous type) strictly four-jointed. Its sculpture is very peculiar, the punctures (which are lighter towards the apex of the elytra) being exceedingly large and few in number (somewhat after the fashion of what obtains in Onycholips); its rostrum (as in Alaocyba and Lipommata) is appreciably, and gradually, narrowed in the middle ; its surface, although appearing at first sight to be quite bald, will be seen beneath a high magnifying power to be studded (at any rate behind) with a few short bristles; and its legs are eminently fossorial; and greatly incrassated,- the triangularly expanded tibiæ being deeply scooped-out, or emarginate, towards their external angle, the excavation being more or less filled-up, or pectinated (at any rate in the posterior ones), with strong ciliæ, or bristles. Its antennæ (which are elongate, and almost terminal as regards their insertion) have the second joint of their funiculus perceptibly, though slightly, longer than those which follow it, and their club excessively large, abrupt, and distinctly annulated; and its tarsal claws are considerably developed. The concave, or longitudinally impressed, structure, also, of its first and second abdominal segments should be noticed; but this I think has been made too much of as a peculiarity,- - since the same feature exists (more or less expressed) not only in Alaocyba, but likewise in several genera of the Pentarthrides, such as Amaurorrhinus, Microxylobius, Acanthomerus, and Lamprochrus; and we also find it in Cotaster, of the true Cossonides. In no genus, however, that I have yet examined, is the concavity so deep, and so well defined, as it is in Raymondionymus. In their modes of life the species of Raymondionymus seem to be in entire accordance with the members of the present curious subfamily,their compressed, dilated, setulose, apically unarmed tibiæ indicating fossorial habits ; whilst their total freedom from eyes would tend still further to imply a partially subterraneous propensity. And it is not surprising therefore that the few which have hitherto been brought to light (principally in the south of France) should have been met with in such situations as beneath stones deeply imbedded in the soil, within crevices of clay, and in the nests of ants. I should add that the particular species from which my diagnosis is compiled, and for a type of which I am indebted to John Gray, Esq., is the R. Marqueti, Aubé, from Narbonne. 
34. Alaocyba (Perris, in Abeille, vii. 31. 1870).I am indebted to Dr. Sharp for a type of the very rare genus Alaocyba,-namely the diminutive $A$. carinulata, which was taken by M. Raymond in Sardinia; and, after a very careful inspection of its details, I feel satisfied that it is truly distinct from Raymondionymus as represented by the larger species which have been referred to that group, though I am less convinced that it differs generically from the smaller ones which are equally cited as Raymondice (or Raymondionymi). Indeed one of them, the " $R$. Delarouzeei," which has been communicated by John Gray, Esq., appears to me to possess all the essential characters of Alaocyba, as contradistinguished from Raymondionymus; and I have no hesitation therefore in regarding it as pertaining to the former, rather than to the latter; and it is not unlikely that one or two of the others, when properly overhauled, may prove to be Alaocyba. Be this however as it may (for I have had no opportunity of examining them), I consider the carinulata and Delarouzeei as at any rate belonging to Alaocyba, and the much larger, darker, and in many respects differently constructed, Marqueti as a Raymondionymus proper; and it is on this understanding that I have compiled my diagnoses of the two groups.

As thus defined, Alaocyba may be said to differ from Raymondionymus in the much smaller size, extremely pallid hue, and more depressed (and perhaps rather more setulose) bodies of the insects which compose it,-in which moreover the sculpture is less coarse (particularly in the A. carinulata, which must be regarded as the type), the prothorax is furnished with a more evident medial line, or keel, and the elytra are free from the cariniform structure (on either side) towards their apex. And, moreover (which is of greater importance still), the funiculus joints are more decidedly moniliform (the second one being as short and rounded as those which follow it), the legs are less thickened, and the tibiæ are less broadly dilated,especially the front pair, which are not scooped-out like the other four towards their external apex, but merely a little truncated. The rostrum, too, is proportionately not quite so elongate; and in the $A$. carinulata the antennæ are implanted a trifle further from its apex. In their habits the Alaocyba appear to be very similar to the Raymondionymi, - the structure of their compressed tibiæ, although a little less strongly pronounced, being eminently 
fossorial. The A. carinulata, which (as just stated) is the type of the genus, was detected by M. Raymond in Sardinia.

35. Lipommata (Wollaston, Cat. Mad. Col. 100. 1857). - In the relative length and shape of its (nevertheless thicker) rostrum, which (instead of being quite parallel) is rather contracted in the middle, as well as in its total freedom from eyes, its sparingly pilose surface, obsolete scutellum, and subfossorial mode of life, Lipommata has manifestly more in common (despite its comparatively large, convex, Phloophagus-like body) with Raymondionymus and Alaocyba of the preceding section (in which nevertheless the funiculus is 6-jointed, the feet quadriarticulate, and the tibial hook absent) than Cotaster has; and therefore I have given it the first place in the Cossonideous division of the family; - though at the same time it is true that in Cotaster the greatly abbreviated metasternum, uneven prothorax, and primâ facie aspect would indicate a considerable affinity with those two genera. In reality, however, I believe that Lipommata is still more closely connected with the (equally subfossorial) Pentatemnus, of the Pentarthrides, - which it greatly resembles, both in appearance and habits; but, not to mention other points of dissimilarity, that genus has the funiculus only 5(instead of 7-) articulate, and the eyes (instead of being, as in Lipommata, altogether wanting) merely obsolete. At first sight, indeed, Lipommata might almost be regarded as a blind Phloeophagus, - so greatly does its ovate outline, obsolete scutellum, and convex, pilose surface, agree with certain members of that group: nevertheless its total freedom from eyes, its minutely asperated, basally-subemarginate elytra (the shoulders of which are, consequently, somewhat unusually porrect), and its rather differentlydeveloped tibiæ, will of themselves at once separate it from the Phlcophagi. The single exponent of it which has hitherto been brought to light seems to possess the same sand-infesting propensities as Pentatemnus and Onycholips; it having been detected by myself in the Madeiran archipelago,-where it occurs about the roots of certain plants (often at a considerable depth beneath the surface), on the sandy slopes behind the sea-beach, in the island of Porto Santo. It is the only true member, so far as I am aware, of the subfamily Cossonides, in which the organs of sight are completely wanting. 
36. Styphloderes (nov. gen. ; Cotaster, Mots., pars).--In its exceedingly abbreviated metasternum, obsolete scutellum, and elongated antennæ (which are implanted considerably before the middle of the rostrum), as well as in its more or less pallid hue and subelliptical elytra, Styphloderes has much manifestly in common with Raymondionymus and Alascyba, of the preceding subfamily; nevertheless it differs very essentially from them both, not only in its much larger size, and in its funiculus being 7- (instead of 6-) articulate, but likewise in its eyes being developed, and in the structure of its much longer legs,--the tibiæ of which (instead of being spinulose, compressed, fossorial, and apically unarmed) are elongate, narrow, and (as in all the Cossonida except the Notiomimetides and the Onycholipides) uncinated at their outer angle; whilst the feet, instead of being simple and quadriarticulate, are on the ordinary pseudotetramerous type,the third joint being expanded and bilobed, and the fourth one minute and hidden. With these most important discrepancies, it seems to me quite impossible (despite the opinion of Lacordaire) to admit Styphloderes into the same actual section as those two genera; yet I have nevertheless acknowledged the points of agreement between the three (which consist mainly in their much-abbreviated metasternum and pallid hue) by placing them almost in juxta-position,-namely at the end and nearly at the begimning, respectively, of two distinct subfamilies. In its mode of life, no less than in its structural details, Styphloderes does not appear to be fossorial; though it is nevertheless stated by Motschoulsky (vide Guér. Rev. de Zool. 427. 1851) to have been found beneath marine rejectamenta on the sea-shore near Marseilles. It belongs essentially to Mediterranean latitudes, having been captured in the south of Europe and the north of Africa.

The only member of this genus with which I am acquainted (viz. the exsculptus, Boh., or littoralis, Mots.) has been hitherto associated with Cotaster; but if we are to regard the Phloophagus uncipes, of Boheman, as the type of the latter (and it is expressly stated to be so), it seems absolutely necessary to propose an additional group to receive the former,-which differs essentially, in nearly every one of its details, from the uncipes. Thus, not only is it larger, and more pallid and depressed, but its rostrum is relatively very much longer, and rather narrower, its eyes are considerably smaller, its prothorax is uneven, 
tricarinated, and constricted in front (instead of being convex and simple), its antennæ are more elongated and slender, inserted nearer to the apex of the rostrum, and with the (less compact) funiculus-joints (especially the second one) longer, its legs also (particularly as regards the tibiæ) are longer and thinner, and its feet have the third articulation more evidently expanded and bilobed, and the claws conspicuously more developed. The body moreover, instead of being coarsely, though sparingly, pubescent (with the pubescence developed on the elytra into elongate, erect setæ), is bald.*

37. Cotaster (Motschoulsky, Guér. Rev. Zool. 425. 1851).- In prima facie aspect this is one of the most remarkable genera of the Cossonida with which I am acquainted; and, although European, it appears to be somewhat scarce in collections. I am however indebted to Mr. Gray and to Mr. E. W. Janson for the opportunity of examining several types-which, judging from labels which are appended to them, appear to have been captured by M. Hampe in Croatia. Before an accurate inspection, it has much the appearance of a small and rather narrow Acalles,-its convex, ovate body, and nearly opake, reddish-brown surface (which is sparingly clothed with decumbent fulvo-cinereous pile, which however is developed on the alternate interstices of the elytra into elongate erect bristles), giving it a character which is strongly suggestive of certain members of that group. Its rostrum is rather long and cylindrical; its prothorax (which is narrower than the elytra, at any rate than the widest portion of them) is suboval, closely punctured, and even (being scarcely at all constricted behind the apex); its elytra are ovate and punctate-striated, with the interstices convex and remotely studded (at any rate as regards the alternate ones) with the elongate setæ to. which I have above alluded; its antennæ (which have their scape robust, slightly curved, and considerably thickened towards the apex, and their second funiculus-joint not at all lengthened) are inserted a little before the middle of the rostrum; its legs are a good deal incrassated; its claws are exceedingly

* I have had no opportunity of inspecting the cuneipennis, Aubé ; but, judging from the diagnosis, my belief is that it will be found to be a true Cotaster (and therefore congeneric with the uncipes), and not referable to the group which I have established for the reception of the $e x-$ sculptus. 
minute; its metasternum is very short, and the first segment of its abdomen is likewise more abbreviated than is usually the case amongst the Cossonida.

[38. Lymantes (Schönherr, Gen.et Spec. Curc. iv. 1085. 1838). - The present genus, together with the two following, I have not been able to inspect; and consequently the few diagnostic characters which are given of it in my summary I cannot vouch for as being in precise accordance with the type. It seems to have been founded on a single species, from North America,-the S. scrobicollis, Bohm, -which is described as rather elongate and oblong, of either a black or brownish hue, somewhat variolose anteriorly and beneath, and with the elytra (which are not wider than the prothorax) deeply punctate-striate. Its metasternum is much abbreviated; its rostrum is robust, and separated by a deep stricture from the forehead; its eyes are small and depressed; its prothorax is elongatequadrate; and its feet are short and filiform.]

[39. Aparoprion (Hampe, Wien. Ent. Monatsch. v. 68. 1861).- As just stated, this genus (although European) I have not been able to procure for examination; and consequently I cannot speak with any precision concerning the very few diagnostic features which I have extracted concerning it from Lacordaire. Indeed even the latter does not appear to have been acquainted with it except through the very short and imperfect description given by M. Hampe; and we may presume therefore that it is of great rarity in collections. It was established to receive a small insect (the $A$. costatum) from Transylvania, which is said to be of a brownish colour and finely pubescent, - with the prothorax subglobose and much narrower than the elytra (which latter are oval and convex), the head minute, the rostrum (into which the antennæ are inserted towards the apex) rather long and subcylindric, and the third tarsal joint bilobed.]

[40. Oodemas (Boheman, Res. Eugen. 138. 1859).This genus, like the two preceding ones, I have not been able to inspect; and my short diagnosis is, consequently, a mere epitome of the one given by Lacordaire. It appears to have been founded by Boheman to receive a small insect taken near Honolulu, in the Sandwich Islands; which is described as regularly oval, glabrous, shining, 
and of a greenish-brassy tint,- - somewhat resembling, at first sight, according to Lacordaire, my Pentarthrideous Acanthomerus conicollis, of St. Helena. It appears to be very slightly sculptured anteriorly, but with the elytra longitudinally punctured (the punctures being large in front, but evanescent behind); its rostrum is said to be short and cylindrical, with the antennæ (which are slender) inserted at about the middle point; its anterior coxæ are but feebly apart, and the third joint of its feet is large and bilobed.]

41. Caulotrupis (Wollaston, Ins. Mad. 308. 1854). -In a paper which I published, in 1861, on the ' Atlantic Cossonides,' I expressed a doubt (vide Trans. Ent. Soc. Lond. v. 375) as to whether Caulotrupis should be regarded as more, in reality, than a slight geographical phasis of Phloeophagus peculiar to the Madeiran archipelago; and Lacordaire, taking advantage of this hesitation on my part, did not scruple to cite it (Gen. des Col. vii. 342) as absolutely identical with that group. Yet a more critical inspection of it than I had formerly been able to bestow has convinced me, as at first, that it will be better to treat it as generically distinct,-more especially since the presence, at the same time, of Phloophagus proper in the Madeiran islands would seem to imply that it can scarcely be a local development, at all events, of that widely-spread type. Moreover the Caulotrupides play so important a part in the Rhynchophorous fauna of Madeira, where they attach themselves principally to the old and decaying stalks of various shrubby plants (though a few of them occur likewise beneath the bark of timber trees), that there is an additional advantage in keeping them separate; and it is with the greater satisfaction therefore that I am able to detect certain structural characters which I cannot but think, however small when taken separately into account, must fully warrant, when combined, my original conclusions with respect to them.

The Caulotrupides have a peculiar aspect, which, when once seen, can scarcely fail to distinguish them, even primâ facie, from the Phloophagi. Thus they are more elliptical, or fusiform, in outline, much more lightly sculptured (particularly as regards their prothorax), and have, most of them, a greater or less tendency for a metallic lustre,- the terebrans, Chevrolatii and conicollis being completely brassy. Yet, in spite of this, their surface 
(which for the most part is perfectly bald) is more or less alutaceous, being in some instances so conspicuously so as to appear nearly opake. Their prothoraces are more or less conical, and unmargined along the posterior edge, their scutella are generally quite untraceable, their prosternum is very distinctly carinulated behind the anterior coxæ, their legs are a little wider apart at the base than is the case in the true Phloophagi (the hinder pair being especially remote), and the first joint of their feet is less evidently elongated.

42. Phlqophagus (Schönherr, Gen. Curc. iv. 1047. 1838). - The genus Phlocophagus has often been a good deal confused with Rhyncolus, certain species having been assigned by different authors to either group according as their rostra happened to be either slender or robust; and indeed if the gracility of that organ were their main distinguishing feature, it would perhaps be difficult to draw a line of positive demarcation between the two,- for there are undoubted members of both genera which have their rostrum narrow, and others which have it incrassated. Yet on the average the rostrum is certainly both longer and slenderer in Phlcoophagus than it is in Rhyncolus. There are other characters, however, which would tend (according to the arrangement which seems to me to be most natural for the Cossonides) to place the groups in question far asunder; and perhaps none is more important than the presence or absence of a scutellum,-which in Phloeophagus is either altogether untraceable, or else is so minute and punctiform as to be with difficulty detected. The Phloophagi also are more convex and ovate than the Rhyncoli; their prothorax is usually less developed, but more rounded at the sides; their metasternum is appreciably shorter ; their anterior coxæ are more approximated (indeed the front ones are nearly contiguous); and their antennæ and legs are slenderer,-the former of which, likewise, as well as the tarsi, are generally more lengthened. The Phlocophagi moreover have the second joint of their funiculus and the basal one of their feet longer than is the case in Rhyncolus, and also the club of their antennæ more enlarged and annulated ; and their third tarsal articulation is for the most part minutely bilobed, rather than simple ; - though this character, last mentioned, is, in both genera, a variable one. The Phlooshagi are principally

TRANS. ENT. SOC. 1873.-PART IV. (OCT.) Q Q 
either dark or piceous, in hue (more often the former); and some of them have a very faint brassy tinge ; and, unlike the Rhyncoli, certain of the species (though by no means the majority of them) are sparingly pubescent. They appear to be widely distributed over the world; and although specifically few in number throughout Europe, they are rather unusually dominant in some of the islands of the Atlantic archipelagos.*

43. Pseudophleophagus (nov. gen.).-This genus, which is established to receive the Phloophagus tenax from Madeira and the Azores, combines in a remarkable degree the structural peculiarities of Rhyncolus and Phloophagus,--agreeing with the former in its more parallel outline, less inflated body, and conspicuous (though rather small, transverse, and sub-perpendicular) scutellum; but with the latter in its abbreviated metasternum, and in its comparatively slender antennæ and tarsi, the first of which have (as in Phloophagus) their second funiculusjoint appreciably longer than those whieh follow it, and their club enlarged and abrupt, whilst in the feet the basal articulation is considerably lengthened, and the third one minutely bilobed. In its greatly approximated anterior coxæ it is more on the Phloophagus than the Rhyncolus pattern, and in its sericeous surface it is likewise more in accordance with (at any rate a certain section of) the former; but its coxæ are, if anything, still less separated than in even the Phloophagi (the front ones being practically contiguous), whilst the minute keel, or lobe, of its mesosternum (between the intermediate coxæ) appears to me to be more developed than in either of those groups. Its type (the $P$. tenax) is a very common insect in the higher elevations of Madeira, where it occurs in great profusion in the rotten wood, and beneath the bark, of old trees,-more particularly those of the laurel tribe; and it has been met with also in the Azorean archipelago.

* The European $P$. aneopiceus is a less typical member of the group than the various other species which I have examined; for not only does it recede in outline from the latter, but it has also manifest indications of a scutellum,- which, although not very easy to be detected, is certainly appreciable. Indeed, I am not quite sure that it would not be more natural to admit it (along with the tenax, from Madeira and the Azores) into the genus Pseudophlœophagus; nevertheless since the characters alluded to are not very pronounced ones, I will not disturb it in its usually-received position. 
44. Thaumastophasis (nov. gen.).- It is for an insect which was captured at Gawler in Southern Australia, and which has been communicated by $\mathrm{Mr}$. Pascoe, that the present genus is proposed; and so remarkable is it in many of its structural details that I could at first scarcely persuade myself that it was a member of the Cossonidce at all. But since at least three other forms (outside the anomalous subfamily Onycholipides ), namely Aorus, Lipancylus, and Xenocnema, have the tibial hook obsolete, and are nevertheless veritable Cossonids, one at any rate of its most significant features may be regarded as not altogether unparalleled even in the present department of the Rhynchophora. And certainly in Thaumastophasis the tibial uncus is strictly "obsolete" (and not completely absent),-for, when examined beneath a high magnifying power, its presence may readily be detected in the anterior pair, and I am not altogether sure that I cannot recognize traces of it in the four posterior ones likewise (though I will not be quite positive on this point); whilst the fact of its front coxæ being contiguous, and the intermediate ones but barely separated, is almost in exact accordance with what we observe in Pseudophloophagus, and which is likewise unmistakeably approached in even Phloophagus proper.

I need scarcely add that the affinities of Thaumastophasis are extremely difficult; but, nevertheless, having once decided that it is a veritable member of the present family, I am inclined to think that it will be better to place it near to Pseudophloophagus than elsewhere,-with which (despite its many eccentricities) it agrees at all events in the shape and proportions of its (rather thick and linear) rostrum, and in its antennæ being long and slender, as well as in its body (although short) being parallel, sericeous and convex, its metasternum much abbreviated, its front coxæ contiguous (or practically so) and the intermediate pair but faintly apart, and in its feet (which however are considerably thicker) having their basal joint (like the second one of the funiculus) appreciably lengthened, and the third one (although very much more conspicuously so) expanded and bilobed.

In other particulars Thaumastophasis is remarkable for its perfectly enormous eyes (which however are not extremely prominent), for its slender and acuminated club, for its prothorax (which is small, and very much narrower than the elytra) being slightly uneven, or as it were

$$
\text { Q Q } 2
$$


malleated, but nevertheless nearly unconstricted in front, for its legs being a good deal thickened, and for its body being of a piceous hue, with the exception of the elytrawhich are conspicuously paler, or of a clear rufo-testaceous.

45. Hrmatium (nov. gen.).--In its narrow, parallel, cylindric, but not very convex, body-which is of a rufopiceous hue, and sparingly studded with elongate, partiallyerect, fulvescent hairs-the interesting little Cossonid for which the present genus is proposed, and which has been communicated by Mr. Fry as having been received from Malabar in southern India, will be easily recognized. Its surface is slightly shining, and (with the exception of the head, which is convex and almost free from punctation) coarsely and very densely sculptured; its rostrum is parallel, but nevertheless somewhat narrow and not very elongate; its eyes are depressed, and greatly separated from each other, - so much so indeed that they are barely visible when the insect is viewed from above; its antennæ (which are inserted just before the middle of the rostrum) have their scape rather abbreviated, straight, and robust, and their funiculus-joints (with the exception of the first one), short, subequal, and submoniliform; its prothorax is oval, and a good deal constricted in front; its metasternum is elongate; its coxæ (even the anterior pair) are wide apart, and the third articulation of its feet is nearly simple.

46. Pholidonotus (nov. gen.).- - I am indebted to $\mathrm{Mr}$. Pascoe for the loan of the somewhat obscure and insignificant little insect (captured by $\mathrm{Mr}$. Wallace at Sarawak, in Borneo) to contain which the present genus is proposed; and, apart from its rather diminutive size, and piceous, opake, densely-sculptured surface, it is remarkable amongst the Cossonida for being one of the very few forms the surface of which is clothed (as in Pholidoforus from Japan) with scales,- some of them being coarse and mud-like, and others thick, robust, and setiform. In - the inferior position of its depressed eyes (which are scarcely visible when the specimen is viewed from above), as well as in the structure of its rather long and narrow, but straightened, rostrum, and in the fact of its surface being piceous and (at any rate) clothed, I think there can be little doubt that it displays a certain degree of affinity with the Indian genus Himatium; but, in addition to its 
squamose covering and smaller stature, its surface is more opake and closely sculptured, its rostrum is relatively more elongate and slender, its antennæ are more medially inserted, its scutellum is much less developed, and its legs are setose and proportionately thicker,- - with the posterior coxæ wider apart, and the third tarsal joint more evidently bilobed.

47. Coptorhamphus (nov. gen.).-The present genus is founded on two species which have been communicated by Mr. Pascoe (obtained, I presume, by Mr. Wallace),one of them from Sarawak in Borneo, and the other from Java. Its affinities are extremely difficult to determine; nevertheless I believe it to be a member of the Cossonida, and am inclined to think that the rather inferior position of its transverse and greatly depressed eyes, in conjunction with the fact that its rostrum is conspicuously divided from the forehead, and its surface clothed, or setulose (though in one of the representatives very sparingly so), will tend to place it at no great distance from Himatiuman Indian genus (in the collection of $\mathrm{Mr}$. Fry) from Malabar. Yet its rostrum is considerably longer, slenderer, and more curved than that of Himatium, and also very much more separated from the head, the extreme base being far more constricted than what we observe in the groups around even Catolethrus; and its body, instead of being pubescent, is more or less scaly and setulose. Coptorhamphus moreover is remarkable for many peculiarities which are not indicated in any of the types with which I have nevertheless considered it the most natural to associate it. Thus, for instance, its funiculus (which has the second joint appreciably elongated) is gradually much increased in width, causing the club, although large, to be by no means abrupt; its front coxæ are nearly, if not indeed altogether, contiguous (even more so than in Phloophagus); its femora are armed beneath with an acute tooth ; its tibiæ are greatly curved, and are furnished towards their outer apex (more or less evidently), with a pectinated tuft of setæ; and its prothorax has a large, rounded, sharply-defined, and deep fovea just behind the middle of the disk. This last-mentioned character is so unusual, that I at first thought it must be the result of accident; but since it is conspicuous in both of the species, I cannot but regard it as a generic eccentricity. 
48. Aphanommata (nov. gen.).-The insect which constitutes the type of the present genus was taken by myself, from out of rotten Euphorbia-stems, in the island of St. Antonio of the Cape Verde archipelago; and, to a certain extent, it combines in a remarkable degree the characters of Phloophagus and Rhyncolus, -agreeing with the former in its comparatively slender limbs, and its more elongated first tarsal and second funiculus joints, as well as in the fact of its club being abrupt and its eyes depressed; but with the latter in its body being less convex and more parallel, its rostrum shorter and thicker, its scutellum conspicuous, and in the greater length both of its metasternum and (more cylindrical) prothorax. It possesses, however, many distinctive features of its own, in which it recedes from both of those genera,-such, for instance, as the inferior position of its small and sunken eyes (which are scarcely visible when the insect is viewed from above), its narrower and more parallel outline, and its greatly elongated metasternum; in all of which respects it approaches far nearer to Himatium. And it is further remarkable for its black, shining, and completely bald surface, for its triangular (though, at the same time, somewhat elongate-triangular) rostrum, for its transverse scutellum, and for the third articulation of its exceedingly long and slender feet being small and simple.

49. Brachyscapus (nov. gen.).-The affinities of this curious genus (which is founded on an insect from Natal which has been communicated by Mr. Fry) are somewhat obscure; for while it possesses the short and triangular rostrum, the rather approximated eyes, and the greatly abbreviated scape of certain of the sub-Hylastideous forms of the Cossonides, I nevertheless do not believe that it has in reality anything to do with those particular genera,its completely suffused first and second abdominal segments, and the exact degree of separation of its coxæ, no less than the structure of its funiculus and elongate, conspicuously annulated club, its external contour and sculpture, and the shape and proportions of its prothorax (which is regularly oval, and distinctly narrower than the elytra), being all of them far more on the pattern which obtains amongst the Phlocophagi. And moreover, when we further consider that there is a considerable approach to its peculiar shape of rostrum in the preceding genus, Aphanommata (in which too the surface is shining, bald, 
and of a deep black), and that a considerable reduction in the length of the scape is indicated (though to a less extent) in Himatium, I feel satisfied that the position in which I have placed it is a far more natural one than amongst the (more or less asperated, posteriorly-obtuse) types bordering on the Hylastida. In addition to the characteristics above mentioned, Brachyscapus has its scutellum a good deal enlarged, and its under-wings considerably developed.

50. Phlqophagosona (Wollaston, Trans. Ent. Soc. Lond. 23. 1873).-The present genus is perhaps, on the whole, somewhat less satisfactorily defined than most of the others; and I think it is far from unlikely that it may be found eventually to include more than a single type of form; yet, being unwilling to multiply genera unnecessarily, I have thought it better to treat it as admitting a rather wider amount of structural variation than would seem to be indicated in the neighbouring groups; and we may possibly therefore regard it, in this particular respect, as somewhat analogous to Cossonus. It was established by myself, originally, to receive two slightly discordant species which had been collected by Mr. G. Lewis in the Japanese archipelago; and, if I am correct as regards the material now before me, I might define it as embracing a number of insects, sometimes a good deal differing from each other, which have a wide inter-tropical range, and which would seem, to at all events a certain extent, to represent the Phloeophagi and Rhyncoli of European latitudes. Indeed a considerable proportion of them have, I think, done duty for the former, and are consequently still cited as such in the various catalogues; but nevertheless they cannot, strictly speaking, be associated with the Phloeophagi, any more than they can with the Rhyncoli, -as interpreted by the structural features of the respective (and universally-acknowledged) types of those two groups. Thus, whatever be their discrepancies inter se, they recede essentially from Phlocophagus in having a largely developed scutellum, a comparatively elongate metasternum and prothorax, and in the second joint of their funiculus, and the basal one of their feet, being conspicuously more abbreviated. Moreover they are, on the average, much larger, less ovate, and less convex, their rostrum is proportionately more lengthened, and their four anterior coxæ are wider apart. 
From Rhyncolus, on the other hand, (with which they agree better in their more separated coxæ, more elongate bodies, and developed scutellum), the members of Phloophagosoma differ in their very much slenderer and more lengthened rostrum, in their less thickened and more medially implanted antennæ, which have a larger and more abrupt club, and in their less prominent eyes. And they are also larger than the Rhyncoli, and have their anterior coxæ (particularly however the intermediate pair) rather more remote from each other,-though these two characters are less strongly expressed than they were as compared with the corresponding ones of Phloophagus. *

The species now before me, which I should regard as pertaining to Phloophagosoma, are from Japan, New Zealand, the islands of the Malay archipelago, Malacca, Ceylon, Malabar, and southern Africa. The one from the last-mentioned of those regions (which has been communicated by Mr. Janson) has the name "Phloophagus ebeninus, Schön." appended to it, but it scarcely seems to me to tally with the published diagnosis of that insect.

51. Pholidoforus (Wollaston, Trans. Ent. Soc. Lond. 18. 1873).- The present genus was proposed in order to receive a very singular Curculionid which appears to be common in the Japanese archipelago,-where it was detected near Nagasaki, in the island of Kushiu, by Mr. G. Lewis. It is at once remarkable amongst the "Cossonida for the thick, cinereous, bristle-like scales with which it is densely studded,-a type of clothing with which we are very familiar in other departments of the Rhynchophora, but which is of the rarest occurrence in the Cossonids. In other respects it is conspicuous by its narrowish-fusiform outline (which is parallel in the middle, but much attenuated both before and behind), for its rather elongated antennæ and feet, for its eyes being exceedingly prominent, and for its third tarsal joint being a good deal expanded and bilobed.

52. Coprodema (Wollaston, Trans. Ent. Soc. Lond. 20. 1873).-Like the last genus, the present one was

- In the species of Phløophagosoma, which I regard as the more typical ones, the rostrum is of equal breadth throughout; but in others it is either (as in the P. curvirostris from Japan) a little thickened at the base, or else (as in the $P$. fusirostris from New Guinea) slightly and gradually so behind the middle. 
detected by Mr. G. Lewis in Japan, - namely, in the islands of Kushiu and Nipon; and it is remarkable from bearing a certain prima facie resemblance to some of the smaller members of Calandra; whilst likewise its deeply sculptured, besmeared surface, rather elliptic outline, and costate elytra recall to mind some of the features of the Dryophthorides : nevertheless its 7 -jointed funiculus and pseudotetramerous feet affiliate it at once with the true Cossonids. In other respects it is conspicuous for its rostrum being faintly attenuated towards the tip, for its eyes being exceedingly depressed, for its elytra being lopped-off straightly at their extreme apex, for its legs being rather short and robust, for its tibiæ (which have their hook powerfully developed) being armed with a small though robust spinule at their inner angle, and for its feet being very short and filiform,-with their third articulation not at all expanded or bilobed.

53. Exodema (Wollaston, Trans. Ent. Soc. Lond. 22. 1873).- The unique insect on which this genus was founded is, like Coprodema and Pholidoforus, from the Japanese archipelago,-where it was captured by Mr. G. Lewis. Its primâ facie aspect indeed, and opake, densely sculptured surface (which is sparingly besmeared with a sort of dirty-whitish, scaly, mud-like deposit), are so strongly suggestive of the former that it might well be regarded, at first sight, as a second member of that group; yet when closely inspected it differs so essentially in the structure of its feet, which are not only much longer but have their third joint (instead of small and simple) conspicuously widened and bilobed, that I cannot but think that it should be treated as the type of a nearly-allied but distinct genus. As regards its less important details, its antennæ are a trifle more elongate, and not quite so medially inserted (being implanted just perceptibly before the middle of its rather thicker rostrum), its eyes are a little more developed, its elytra are not at all truncated at their apex, and its metasternum and legs (especially the latter) are appreciably longer. Its femora also, at any rate the anterior pair, are proportionately not quite so clavate.

54. Melarhinus (nov. gen.).-The insect from which the characters for the present genus have been drawn out 
is a native of Madagascar, and has been communicated by $\mathrm{Mr}$. Pascoe. It is rather larger in size than the other members of the immediate department into which I have admitted it; nevertheless it agrees with them in its surface being dark, closely sculptured, and opake, and more or less besmeared with dirty, mud-like scales. In other respects it is remarkable for its rostrum being broad and depressed, channeled down the middle, and with the eyes exceedingly prominent; for its prothorax being appreciably narrower than the elytra, a good deal rounded at the sides, and very deeply constricted behind the apex; for its elytra (which, when viewed beneath the microscope, are most minutely and very sparingly pubescent) having their somewhat large punctures arranged in longitudinal rows, but scarcely in striæ; and for its antennæ and legs being much thickened, - the former moreover having their funiculus-joints very closely pressed together, or compact, and their club narrow and not at all abrupt.

55. Psilosomus (nov. gen.). - The present genus is remarkable amongst the Cossonida for the dark and opake (yet bald and densely punctured) surface of the somewhat Calandra-shaped insect for the reception of which it is proposed, and which has been communicated to me-by Mr. Janson as a native of Ceylon, and by Mr. G. Lewis, who captured it at Paulo Penang, in the Malay peninsula. And it is further distinguished by the comparative largeness of its prothorax, by its widely-sulcated elytra, and by its first abdominal segment (which is more conspicuously separated from the second one than is usual in this family) having in the male sex a deep rounded depression in the centre which is curiously filled up with fulvescent pile. Its rostrum is rather short, broad, and subparallel, though a little longer in the males than in the females, with the antennæ inserted at about the middle point; and its legs (which are robust and a good deal thickened, especially as regards their anterior femora) have their tarsi considerably developed, - with the ultimate joint elongate, and furnished with powerful claws.

I have little doubt that the affinities of Psilosomus are with such forms as Coprodema and Exodema, from Japan, -in which the elytra are costate, and the body (although very much smaller) is equally opake and densely sculptured. Nevertheless in both of those groups the surface, instead 
of being bald, is more or less besmeared with mud-like scales.*

56. [Mrmus (Fåhraeus, Öfvers. Vet. Ak. Förh. 283. 1871).- Not having been able to procure a type of the species (from Southern Africa) for which the present was established by Fåhraeus, I know nothing whatever concerning either its structure or its affinities,- the former, if we may judge from the diagnosis, being of the most commonplace description, and such as might apply equally to two-thirds of the entire Cossonida ; whilst so far as the latter are concerned, not a syllable is recorded by Fåhraeus except that the group represents a new. "tribe" of the family. But why this should be the case it is impossible to conjecture, seeing that his description does not indicate so much as a single structural anomaly. Since he speaks however of the elytra as sulcate (no allusion being made to punctured striæ), and the body as black and closely sculptured, I am inclined (on the merest conjecture) to place the genus next to Psilosomus (from Ceylon and the Malayan peninsula), - in which the elytra are emphatically "sulcated," and the punctation is altogether dense.]

57. Amorphocenus (Schönherr, Curc. Disp. Meth. 329. 1826).-The South-African genus Amorphocerus, for types of which (the A. rufipes, Boh., and the A. zamia, Boh.) I am indebted to Mr. Pascoe and Mr. Janson, has many peculiarities of its own,-one of which, namely the construction of its tibiæ, would rather tend to remove it from the present family. These latter are decidedly abnormal for the Cossonida,-being not only unusually broad, triangular, and compressed, but with their apical hook (understanding that almost universal appendage as a prolongation of the outer angle) obsolete. It is true that a long and curved spine is conspicuous, but then it does not proceed from the external angle (which is merely surmounted with a very short and straight spinule); and also

* I think it is far from unlikely that the insect which forms the type of the genus Psilosomus is the one which was described by $\mathrm{Mr}$. Walker (Ann. Nat. Hist. iv. 218, 1859) under the name of " Cossonus? hebes; but since his diagnosis is contained in ten words, and is unaccompanied by a single remark, it is impossible without an examination of the type itself to decide this point. But in any case the generic characters have not hitherto been defined; and I have thought it worth while therefore, even if the species should prove eventually to be the one alluded to by Mr. Walker, to place them on record. 
that there is a second spine, from the inner angle of the tibia, of almost equal length, besides an additional smaller one between the elongated central one and the outer angle,-an anomalous structure (amongst the Cossonids), which causes the whole apex to be essentially spinulose. Yet there is a little indication of an irregularity of (at all events) partially the same character, in the (likewise African) genus Aorus and the South-American Lipancylus, - which I have consequently placed in juxta-position with Amorphocerus, and in which at any rate the terminal uncus appears (as it seems to me) to be obsolete.

In other respects Amorphocerus is remarkable for its rather depressed, broadish, parallel-oblong, posteriorlyobtuse body, dark hue, and very deeply (though not very densely) sculptured surface; for its rostrum being parallel and somewhat robust, though not very long; for its prothorax being largely developed, though not wider (at its broadest part) than the elytra, and but very little constricted in front; and for its antennæ, which are implanted considerably behind the middle of the rostrum) being short and thick, - with the funiculus (the first joint of which is much enlarged) exceedingly solid and compact, and the club small and not at all abrupt. Its scutellum is very conspicuous, and the third articulation of its feet is considerably expanded and bilobed.

58. Lipancylus (nov. gen.).- - I am indebted to Mr. Janson for the loan of the very extraordinary insect for which the present genus is established, and which is South-American,-it having been taken, I presume by Mr. Bates, in the region of the Amazon. I have not the slightest doubt that its true affinities are with Aorus from western Africa,- with which it agrees in the most anomalous character (for the Cossonida) of its tibial hook being obsolete, as well as in its elongated, extremely slender and cylindrical (though less curved) rostrum, its narrow, parallel body (which, as in that genus, will be seen, when viewed beneath a high magnifying power, to be not altogether bald), in its unconstricted prothorax, its wide and greatly developed feet (the third joint of which is much expanded and bilobed), its minute claws, and in the fact of its long and thickened legs being more approximated at their base than is usual in the members of this family. Nevertheless, although approaching Aorus in so many important respects, Lipancylus has an abun- 
dance of very remarkable features which are essentially its own, amongst which the proportions of its abdominal segments are by far the most significant,-the first and second of them being less elongated, while the third and fourth are considerably more so, than is customary amongst the Cossonids. The shape of its prothorax, likewise, is very peculiar,- -it being somewhat elongate-quadrate, and rather wider (if anything) before than behind; its scutellum is rather large and squarish; its elytra are bi-arcuated in front, and separately rounded-off at their extreme apex; its antennæ are slender; and its tibiæ, especially the anterior ones, are armed at their inner angle with a distinct spine. The two last-mentioned characters, however, are almost equally indicated in Aorus.

59. Aorus (Schönherr, Gen. et Spec. Curc. iii. 253. 1836).-The genus Aorus was established by Schönherr to contain an insect which is found in western Africa, and for an opportunity of inspecting which I am indebted to Mr. Pascoe. It was placed by Schönherr amongst the Cholides; and although removed by Lacordaire into the Cossonida, it is by no means a very typical member (any more than Amorphocerus is) of the latter,-for its unusually approximated coxæ, narrow, transverse eyes, and, as it seems to me (for the example before me is a good deal mutilated), obsolete tibial hook, are all points of great significance which would certainly tend to remove it from the Cossonids. Still, its other features being on the Cossonideous type, I have admitted it into the family,-content to call attention to these particular characters (whatsoever they may be worth) of manifest divergence. In other respects, Aorus is remarkable for its exceedingly long, slender, and very arcuated rostrum (into which the antennæ are implanted a little before the middle), for its transverse eyes being altogether depressed, for the second joint of its funiculus being considerably elongated, for its tibiæ (the four anterior ones of which are armed with a spine at their inner angle) being sparingly asperated, or muricate, internally, for its third tarsal articulation being a good deal expanded and bilobed, and for its claws being unusually minute. In outline it is somewhat long and narrow,-with the elytra cylindrical and rather convex, and the prothorax (the widest part of which is, if anything, a little wider than the elytra) large, convex, regularly oval, and a good deal (and equally) rounded at the sides. 
60. Homaloxenus (nov.gen.).--I am indebted to John Gray, Esq., for the very curious little insect, from the West Indian island of St. Domingo, to receive which the present genus is proposed; and it is so perfectly distinct from every other Cossonideous form with which I am acquainted that $I$ had some hesitation at first in admiting it into the present fagmily at all; nevertheless the unmistakeable structure of its abdominal segments, in conjunction with its tibial hook and other details, are sufficient I think to indicate its affinities. Its distinctly annulated club however, added to its elongate, slender, straightened, and longitudinally-strigose rostrum, into which the antennæ are implanted at the apex, are anything but in accordance with the usual modifications of the Cossonid type, being primâ facie somewhat suggestive of certain groups amongst even the Erirhinides, - an analogy which (however superficial) its uni-dentate femora would not tend to invalidate. But apart from these various peculiarities, Homaloxenus is remarkable for its rather broad and extremely depressed body - which is subopake, ferruginous, and sparingly clothed with a very minute decumbent subcinereous pubescence; for its entire prothoracic disk being very curiously flattened, or impressed; for its antennæ being long and slender, with the second joint of their funiculus (which is remarkably lax) conspicuously lengthened; and for its tibiæ (which have their hook very small) being barbed, or pencilled, at their apex with fulvescent hairs. Its scutellum is largely developed, its metasternum is somewhat short, and the third articulation of its feet is much expanded and bilobed.

61. Stenotis (Wollaston, Ins. Mad. 316. 1854).The Madeiran genus Stenotis is founded on one of the most remarkable little Cossonids with which I am acquainted,-its extremely narrow, elongate outline, pallid hue, and subdepressed, delicately sericeous surface, added to the excessive length and slenderness of its rostrum, its elongated prothorax and metasternum, its thickened legs, and its unusually widened and deeply bilobed third tarsal joint, giving it a character essentially its own. Its subsericeous surface indeed, and general structure, show it to belong, unmistakeably, to the same department as Mesites; nevertheless I believe that its nearest known ally is the South-American genus Eucoptus, from Brazil and the region of the Amazon,-with which it has a good deal in 
common, not only as regards its narrow, parallel, somewhat flattened, and very minutely sericated body, its elongated, slender rostrum, its greatly lengthened prothorax and metasternum (the former of which is very powerfully constricted in front), the conspicuously bilobed third joint of its feet, and the minuteness of its claws, but likewise in the smallness of its eyes, and in the curious tendency of its prothorax to be concave beneath.

In other respects Stenotis is remarkable for its narrow and porrected head, for its intermediate coxæ being not in the least degree more remote from each other than the anterior ones, and for its metasternum (which is remarkably convex) being furnished on either side in front with a minute transverse plait (or perhaps, rather, a cluster of plaits), which have somewhat the appearance of two roughened foveæ. Its antennæ (which are medial in the males, but post-medial in the females) are rather long and slender, with their second funiculus-joint appreciably lengthened; its sculpture is less coarse than in most of the immediately-allied groups; and its prothorax, as in the forms around Mesites and Cossonus, is widely channeled behind. Its type (the $S$. acicula, Woll.) is one of the rarest insects of the Madeiran archipelago, being found amongst the laurels at a high elevation,- - on the foliage of which it appears to subsist.

62. Eucoptus (nov. gen.).- - I am indebted to $\mathrm{Mr}$. Pascoe for the loan of a female example, and to Mr. Fry for a male one, of the interesting little insect from which the characters for the present genus have been compiled. They are both of them South-American,- the former, judging from a label which is appended to it, having been captured (I presume by Mr. Bates) in the region of the Amazon, and the latter in Brazil (I believe near Rio Janeiro). In size and outward appearance Eucoptus has very much in common with such forms as Pentarthrum and Stenotrupis; but its funiculus is composed of seven, instead of only five, joints; and it is clear to me that its affinities, in reality, are with the types which cluster around Mesites,-particularly with the remarkable Stenotis acicula of Madeira. I have already called attention to the many characters which it possesses in common with that insect; and I need here, therefore, only state that Eucoptus is conspicuous for its narrow, parallel, depressed, and piceous body (the elytra however being of a paler, or more rufo- 
castaneous, hue), which at first sight appears to be perfectly bald, but which when viewed beneath a high magnifying power will be seen to be very minutely and sparingly sericeous; for its rostrum (which is just appreciably widened towards the apex) being elongated and slender in the female sex; for its antennæ being implanted into the latter considerably behind the middle; for its rather porrected head and depressed eyes; for the sharpness, and fineness, of its sculpture; for its limbs (particularly the hinder legs) being somewhat short, its club rather narrow, and its third tarsal joint bilobed; for its prothorax and metasternum being a good deal lengthened; and for the first and second segments of its abdomen (the former of which, in the male sex, has, apparently, a large and rounded tubercle in the centre) being separated from each other by a $b i$-arcuated line. Its prothorax is free from a longitudinal groove; and its elytra have their striæ nearly simple, and the interstices somewhat transverselyreticulated.

63. Mesites (Schönherr, Gen. et Spec. Curc. iv. 1043. 1838). - A very careful examination of the various species from the Madeiran, Canarian, and Cape-Verde archipelagos, which I have hitherto referred to Mesites, has convinced me that they connot properly be admitted into that group - as represented by its European members, of which the $M$. pallidipennis is the universally-acknowledged type; and therefore I have no choice but to restrict Mesites to the particular insects (namely the $M$. pallidipennis and cunipes, and the more recently enunciated M. aquitanus) which it was originally intended to embrace, -the M. Tardii, of western Europe, belonging manifestly to one of the Atlantic types.

As thus understood, Mesites may be said to differ from its more immediate allies (comprised in the two following genera) in its body being more parallel, cylindrical, and convex, as well as somewhat more shining; in its prothorax being more strictly oblong (instead of subtriangular); in its head being more incrassated, and with the eyes wider apart; in its male rostrum being shorter, and relatively more robust and linear,-it being less appreciably widened at the insertion of the antennæ; in the latter being much thicker and more abbreviated, particularly as regards their scape (which is likewise more outwardly curved); in its funiculus (the second joint of which 
is not lengthened) being especially more incrassate, and its club comparatively small and narrow; in its metasternum being a trifle more elongate; and in its coxæ being a little less widely separated.

64. Rhopalomesites (nov. gen.).-The type of this genus I regard to be the $M$. Tardii, of western Europe, -an insect which ranges likewise to the Azores; and associated with it are several species from the Madeiran and Canarian archipelagos, two of which (namely the maderensis, and the Teneriffan and Gomeran persimilis), although with small distinctive features of their own, may possibly prove to be, in reality, but geographical modifications of the Tardii. The members of this group differ from Mesites proper, chiefly, in their male rostrum being considerably longer and slenderer, and proportionately a little more widened at the point where the antennæ are inserted; in the latter (which are implanted either in or before the middle, in that particular sex, instead of behind it) being very much thinner and more elongate, with the scape especially, and second funiculus-joint, more lengthened, and with the club very much larger and more abrupt; in their head being less incrassated and their eyes more approximate; in their legs being relatively a little longer, and rather more widely separated at the base; and in the third articulation of their feet being appreciably, though minutely, bilobed. They are also a trifle less cylindrical than the true Mesites (having a more evident tendency to be subfusiform), as also a little less convex, and not quite so shining; their prothorax is more triangular (or less oblong), and is more conspicuously channelled behind in the males and carinated in the females; and they are often sparingly clothed with an exceedingly delicate sericeous pubescence.

65. Odontomesites (nov.gen.). - Two of the (so-called) Mesites from the Canarian archipelago, and one from the Cape Verdes, I had long ago detached from the remainder,-making them to constitute a distinct section of the genus, in which the body is more fusiform and depressed, and the male femora are furnished beneath with an obtuse anguliform tooth; and it is quite clear, therefore, that if the Tardii and its immediate associates be

TRANS. ENT. SOC. 1873.-PART IV. (OCT.) R R 
disunited from Mesites proper (as I cannot but think is absolutely necessary), these three species must likewise form a separate, though closely allied, group. In their smaller size, more fusiform outline, and general structure, they are of course nearer to Rhopalomesites than to Mesites; nevertheless they have a more decided tendency to posteriorattenuation than even the smaller members of the former, and (in addition to the subdentate femora to which I have just alluded) they possess a very peculiar feature in the fact of their male rostrum being fringed with elongate fulvescent hairs, on either side, from the point at which the antennæ are inserted to the apex. Added to which, their rostrum in the opposite sex is less abruptly thickened at its extreme base; their legs are proportionately a trifle more incrassated, and the intermediate coxæ wider apart; and the third joint of their feet is, as in Mesites proper, quite unexpanded and simple.

The species of Odontomesites, so far as I have hitherto observed, are attached exclusively to the rotten stems and branches of the various Euphorbias.

[66. Porthetes (Schönherr, Gen. et Spec. Curc. iv. 1041. 1838).-The genus Porthetes was founded to receive a Cossonid (the P. zamia, Bohem.) from southern Africa; and although I have not been able to procure an example for inspection, the published diagnosis appears to be sufficient to render its peculiarities intelligible. It is described as having much the primâ facie aspect of Mesites,-the type being a little shorter, but a trifle wider, than the European Cossonus ferrugineus, and of a blackish hue, with the elytra ferruginous. As in Mesites and its immediate allies, the rostrum (and to a certain extent, even the antennæ) vary according to the sex,-it being in the males thickened throughout its basal half, with the anterior portion narrow and cylindrical (the exact reverse, be it observed, of what is the case in the forms around Mesites), but in the females incrassated (as in those groups) at the extreme base only. Its antennæ (which are abbreviated) are shorter in the females than in the males, and are basally-inserted in the former sex but medially in the latter ; and the scape is more powerfully clavate in the males than in the females. In its third tarsal joint, too, being somewhat expanded and bilobed Porthetes recedes from Mesites and Odontomesites, and is more on the Rhopalomesites pattern.] 
67. Megalocorynus (nov. gen.).- It is for the Cossonus depressus and conicirostris, of Boheman, and a closely allied species (or perhaps only local variety) which has been communicated by Mr. Janson, all of them from Mexico, that the present genus is proposed; and, apart from every other character, they may be immediately distinguished from the Cossoni, not only by their largelydeveloped club, but by the sexual disparity in the structure of their rostrum and antennæ,-in both of which respects indeed, no less than in their more evenly and densely punctured prothorax, they are far nearer, in reality, to the groups around Mesites than to Cossonus.

Not to mention its parallel and extremely flattened body, Megalocorynus is at once remarkable for the enormous size and length of its capitulum - which is parallel-oblong, and densely clothed with a velvety pubescence; and its scape is peculiar from being somewhat twisted and subcompressed,- - the inner edge (on account of the abrupt, but elongate, apical clavation) seeming to be almost scooped-out, or at any rate sinuated, posteriorly. Its rostrum, too, in the female sex, is of a very unusual shape,-being rather short and narrow, but nevertheless flattened, and gradually a little contracted towards the base; whilst in the males it is longer, and dilated anteriorly much after the fashion of the ordinary Cossoni. Its eyes (instead of being transverse) are nearly round; its prothorax is somewhat small and abbreviated, and a good deal rounded at the sides; its elytra (which are appreciably wider than the prothorax) are parallel and deeply sculptured, with the interstices almost costate ; and its coxæ (even the front ones) are exceedingly remote. Its antennæ in the male sex are inserted a long way before, but in the females a long way behind, the middle of the rostrum; and they are likewise longer and more robust in the former case than in the latter, and have their scape more conspicuously clavate, and their capitulum, if anything, even still more developed.

68. Catolethrus (Schönherr, Gen. et Spec. Curc. iv. 1077. 1838). - The genus Catolethrus is composed of a few elongated (occasionally minute), narrow, somewhat shining, depressed Cossonus-like insects, of which the main distinguishing features seem to consist, so far at least as I am able to detect them, in their rostrum being (especially in the female sex) rather elongate and slender, 
but nevertheless a little, and gradually, widened both towards its base and apex, and divided from the forehead by a very appreciable line ; in their eyes being exceedingly depressed, transverse, and slightly approximated above; in their prothorax and metasternum being a good deal lengthened; in their scutellum being very conspicuous; in their elytra (which are just perceptibly broader than the prothorax) being deeply sulcated towards the apex-where they are separately, and minutely, rounded off; in their antennæ and legs (the former of which are inserted considerably behind the middle of the rostrum, and have the second funiculus-joint exceedingly abbreviated) being rather short and incrassated ; and in their feet being much thickened, with the third articulation conspicuously dilated and bilobed. Their four anterior coxæ are about equally wide apart, and the hinder ones are but slightly more remote from each other.

I am indebted to Mr. Fry, and also to Mr. Janson, for the opportunity of inspecting types of the $C$. longulus, Bohm., from Mexico; and several other species are now in my possession (all of them South American) from the exceedingly rich collection of Mr. Fry. My own belief is, that the genus, as properly defined, is essentially an American one ; for although it is true that three or four supposed representatives have been described from the islands of the Pacific, and elsewhere, I think it is nevertheless far from unlikely that these latter will be found, on a more critical examination, to pertain to some other group,-perhaps to Catolethromorphus, or even to the Pentarthrideous genus Stenotrupis.

69. Stenotribus (nov. gen.).-The type of this genus is a minute and narrow Brazilian Cossonid (communicated by Mr. Fry as having been received from Bahia), which is without doubt very closely allied to Catolethrus - for one of the smaller members of which it might well at first sight be mistaken. An accurate inspection, however, will show that it cannot in reality be associated with the Catolethri,-from which it differs in its antennæ being inserted into the middle (instead of considerably behind the middle) of its rostrum; in the latter being more parallel and cylindric (there being scarcely any tendency to either an anterior or a posterior thickening), and even still more conspicuously divided from the remarkably convex forehead; in its prothorax being extremely elon- 
gated, less constricted in front, and perfectly even (there being no traces either of keel or depression); in all its coxæ being subequally apart (even the anterior ones being widely separated); and in its feet being much less incrassated, and with their third joint small and simple. Its elytra too are more decidedly parallel (or less fusiform) than in Catolethrus; its body is less depressed; its colour is nearly black; and its eyes are so extremely sunken as to be with difficulty detected.

[70. Prö̈ces (Schönherr, Gen. et Spec. Curc. iv. 1080. 1838). - The present genus is one of six which I have not been able to inspect; but the two species to contain which it was established by Schönherr, and which are apparently peculiar to Madagascar, are stated by Lacordaire to be very similar at first sight to the smaller members of Catolethrus, and quite as narrow. Their rostrum however is said to be slenderer and more cylindrical; their antennæ are shorter and less thickened,with the second funiculus-joint longer, and the club larger and more abrupt; and their legs are thinner, with the third articulation of the feet simple and not at all wider than those which precede it.]

71. Phacegaster (nov. gen.).-Although it does not tally precisely with the diagnosis, I have little doubt that the insect for which the present genus is proposed is the Catolethrus nasalis of Boheman, from Brazil. At any rate several examples are now before me (collected by Mr. Fry near Rio Janeiro, and in the province of $\mathrm{S}^{\text {ta }}$ Catharina) which I feel satisfied are congeneric, and I believe also conspecific, with the nasalis; but it is nevertheless quite evident that they cannot be associated with the Catolethri. Not to mention their much larger size, they differ essentially from the latter in the form of their rostrum-which is very much broader, somewhat depressed above, and gradually (though not very considerably) widened from its base to its apex; and the antennæ are implanted into it nearer to the middle point. In other respects, Phacegaster is remarkable for a great peculiarity in its first and second abdominal segments - each of which are furnished with two rounded, acelli-like spaces, filled up with coarse granules. The two on the basal segment are rather larger and more widely separated from each other than those on the second one, and are placed before the middle; whereas 
those on the latter are not only more approximate, but are situated close behind the anterior margin. And there is also another feature which distinguishes this genus from every other with which I am acquainted, - namely the fact that its two hinder femora are fringed beneath, in the middle, with a narrow edging of short fulvescent pile; whilst the tibiæ (of the same pair of legs) are arcuated, and furnished on their inner side, towards the base, with a fascicle of elongated hairs. The legs are thicker than in Catolethrus, and the spine at the internal angle of the tibiæ (especially the four posterior ones) is larger and more robust.

72. Gleodema (nov.gen.).-The two beautiful insects, communicated by Mr. Pascoe, on which the present genus is founded (and which were captured by Mr. Wallace at Dorey and Saylee in New Guinea), are so remarkably alike in colour, outline, and sculpture that I cannot feel altogether certain that the very peculiar discrepancy which they display in the construction of their rostrum may not be merely sexual; and if this should prove to be the case, it follows that they must be treated eventually as members of a single species. With but a solitary example however of each of them to judge from, I feel scarcely warranted in assuming that a character so important and conspicuous is indicative only of the sex; and I have therefore regarded them as specifically distinct. The feature to which I allude is the shape and length of the rostrum,- - which in one of the individuals now before me (and, I may add, very much the larger one of the two) is gradually widened towards the tip to a most marvellous extent, whilst in the other it is but slightly increased in breadth.

In other respects Gloodema is remarkable for the large size, fusiform outline, and somewhat convex, highlypolished, almost unsculptured surface of the insects of which it is composed,-which moreover are anomalously variegated with red and black (a very unusual combination amongst the Cossonida). Their head is elongate, and greatly exserted; their eyes are rounded, rather prominent, and wide apart ; their prothorax is convex, and perfectly even (being quite free both from depressions and keel); and their limbs are long, but much incrassated,the second funiculus-joint being remarkably shortened, the club narrow and acuminated, the four hinder tibiæ (as in Phacegaster, Exonotus, and others of the immediately- 
allied forms) armed with a powerful and compressed spine at their inner angle, and the feet short and thick, with their third articulation expanded and deeply bilobed. Their prothorax, too, (as in the Madeiran Stenotis) appears to be more or less concave beneath; and their antennæ are implanted either about or a trifle before the middle of the rostrum.

73. Glemoxenus (nov. gen.).- - It is for an insect from Madagascar (which has been communicated by John Gray, Esq.) that I have proposed the present genus; and its primâ facie aspect and fusiform outline are somewhat those of a gigantic, deep-black, highly-polished, and lightlysculptured Rhyncolus. When more closely examined however it will be seen to belong, in reality, to a totally different group,- the robust and peculiarly-shaped spine at the inner angle of its four posterior tibia, in conjunction with its much abbreviated and thickened feet (the terminal joint of which is extremely short and conical) affiliating it, most unmistakeably, with the types around Gloodema, Phacegaster, Exonotus, and Pseudocossonus. Its rostrum is rather broad, depressed, and nearly parallel (though whether this is equally the case in both sexes I have no means of judging); its limbs are incrassated and exceedingly robust; the third articulation of its feet, although greatly thickened, is simple; and the spine at the inner apex of its front tibiæ is marvellously lengthened and developed,-in which latter respect it differs from every other Cossonideous form with which I am acquainted. As in most of these immediate genera, its club is narrow and somewhat acuminated; but its antennæ are inserted a little more evidently before the middle than is usual in the majority of its allies.

74. Exonotus (nov.gen.).-A genus the type of which (captured by Mr. Wallace in the islands of the Malayan archipelago) is well distinguished by its elongate, narrow, and parallel outline, rather large size, and convex, shining surface,-which is of a deep black, with the anterior portion of the elytra red. Its head and rostrum are broad, and of nearly equal width,- the latter (which seems to be linear in the females, but rather expanded anteriorly in the males) being somewhat short; its coxæ are all of them about equally separated; its legs are exceedingly thick and robust; its tibiæ (the front pair of which are 
conspicuously biflexuose) have their apical cavities, for the reception of the tarsi, unusually large and open; and the latter (as in most of these immediately-allied forms) are remarkably short and incrassated, with the third joint deeply bilobed, and the ultimate one abbreviated and conical. The prothorax and elytra are very distinctly margined at their respective bases (the latter of them likewise at the apex); and, as in the neighbouring groups, the antennæ are thick, with the second funiculus-joint much reduced in length, and the club narrow and acuminated.

75. Pseudocossonus (Wollaston, Trans. Ent. Soc. Lond. 27. 1873). - The genus Pseudocossonus was founded by myself a short time ago to receive two insects which were captured by Mr. G. Lewis in Japan; and a third exponent is now before me, from the collection of Mr. Pascoe, which was obtained by Mr. Wallace at Dorey in New Guinea. There can be no doubt, I think, that its affinities are with such forms as Catolethrus and Phacegaster, from America; though still more so with Exonotus, from the Malayan archipelago, and the Indian Catolethromorphus - with which it agrees in its rostrum being more parallel, and not divided from the forehead by a basal line, as well as in the fact of its eyes being rounder, more prominent, and more widely separated, in its prothorax being perfectly even (or free alike from keel and depression), in its elytra being entire at their extreme apex, and in its four posterior coxæ (instead of the four anterior ones) being equidistant. As in most of the allied groups, the tibiæ of Pseudocossonus are furnished at their inner angle with a rather robust spinule; and the feet are abbreviated and thick, with the third joint bilobed, the terminal one very short and conical, and the claws exceedingly minute. Indeed this shortness of the tarsi is even still more expressed in Pseudocossonus than it is in any of the genera to which I have above alluded,- the basal and ultimate articulations being greatly reduced in length. Its body is shining, nearly parallel, and slightly depressed; and the sculpture anteriorly and underneath is somewhat fine. Although usually dark, its elytra (which do not appear to be margined at their extreme base, or at their apex) are occasionally rufo-castaneous, especially in front,-a peculiarity of coloration which is equally indicated in Exonotus. 
76. Catoléthromorphus (nov. gen.).-The present genus is founded on a single example from the East Indies (I have no note as to the exact region) which has been communicated by Mr. Fry; and we may perhaps look upon it as the Asiatic representative of the American group Catolethrus, to which in external aspect and structure it is a good deal allied. Yet it manifestly cannot be associated with the Catolethri, the most essential features of which (as regards rostrum, eyes, and antennæ) it does not possess. Thus, not only is its rostrum thicker and more strictly parallel (there being no indication of the slight, and gradual, widening towards the base and apex which is so characteristic of that group), and undivided by a frontal line from the head, but the latter is more exserted and largely developed, and has the eyes (instead of transverse, subapproximated, and depressed) rounded, comparatively wide apart, and slightly prominent. Its prothorax also is considerably shorter (being more truncated both before and behind), as well as more even and convex,-there being no trace of either a keel in front, or of a groove-like depression behind; its elytra are more strictly parallel, and entire (instead of separately and minutely rounded-off) at their apex; its antennæ (which are inserted in the middle of the rostrum, instead of considerably behind it) have their scape very much longer, and their club more abrupt and less acuminated; and its intermediate coxæ are more remote. This last-mentioned peculiarity has a certain importance amongst these immediate groups,-occasioning the four posterior legs (instead of, as in Catolethrus, the four anterior ones) to be equidistant at their base.

77. Brachychenus (nov. gen.).--In its rather narrow, parallel, and depressed body (which is of a palish, rufoferruginous hue), as well as in its linear and somewhat robust rostrum, its even prothorax, and the fact of its four posterior legs being subequally distant at their base (occasioned by the intermediate pair being rather wider apart than is usual), the little Cossonid from which the details for the present genus have been compiled, and which has been communicated by Mr. Pascoe as having been taken by Mr. Wallace at Sarawak in Borneo, has a good deal in common with Catolethromorphus ; nevertheless its type is very much more minute than that of the latter, its rostrum is relatively not so elongated, its 
antennæ (which are inserted rather behind the middle, instead of at the middle point) have their funiculus much shorter, as well as more robust and compact, with the second joint so greatly abbreviated that it is almost concealed from view, and its feet are less elongate, with the third articulation simple (instead of expanded and bilobed). Its capitulum, too, although not particularly abrupt, is very largely developed; and its eyes, although not prominent, are likewise large.

78. Stenomimus (nov. gen.).-The present group is founded on a very minute, narrow, and pallid little Brazilian Cossonid, several examples of which were captured by Mr. Fry near Rio Janeiro ; and it may perhaps be looked upon as the more southern representative, in South America, of the preceding genus-which occurs from, at all events, the West Indian islands to the region of the Amazon. It is indeed very closely allied to Micromimus,-from which it nevertheless differs in its narrower, and relatively more parallel and elongated, outline; in its surface being less shining, and (at any rate so far as the elytra are concerned) minutely and sparingly sericeous; in its rostrum being longer, slenderer, and more strictly parallel; in its antennæ being medial as regards their insertion (instead of ante-medial); in its eyes being more rounded, and (instead of depressed) extremely prominent; in its prothorax being more triangular, and more deeply constricted in front; in the elytra being proportionately rather longer and more linear, but at the same time less acuminated at their extreme apex, where the pygidium is but barely covered; in its tibiæ being more evidently armed at their inner angle with a minute spinule; and in its tarsi being slenderer.

79. Micromimus (nov. gen.).-The two minute and rather closely allied species for which the present genus is proposed, are from the collection of Mr. Fry. One of them is West-Indian, having been taken in Trinidad; and the other was captured, apparently by Mr. Bates, in the region of the Amazon. They are remarkable for their pallid hue, and shining, deeply sculptured, somewhat depressed surfaces; for their rostrum being short, broad, and nearly parallel (it being but very slightly narrowed posteriorly); for their eyes being transverse and extremely large, but nevertheless completely sunken or 
depressed; for their antennæ (which are implanted a little before the middle of the rostrum) having their scape greatly abbreviated, but rather unusually (and suddenly) clavate at its apex; for all their coxæ (even the front ones) being widely, and subequally, separated; and for the third joint of their feet being simple. Their rostrum is not divided from the forehead by a basal line as in Catolethrus; and their body, as in that genus, seems to be perfectly free from pubescence.

80. Glaetrogus (nov. gen.).-Although primâ facie on the Cossonus type, the curious insect which I have made to constitute the type of the present genus, and which has been communicated by $\mathrm{Mr}$. Pascoe and $\mathrm{Mr}$. Janson as having been captured by $\mathrm{Mr}$. Wallace in the islands of Morty and Gilolo of the Malay archipelago, is one of the most anomalous members of the family with which I am acquainted,-being conspicuous not only for its highly-polished, almost unsculptured, and extremely flattened body (both above and below); but likewise for its greatly exserted, depressed, elongate-squarish head; its large but sunken eyes, which are a good deal approximated on the under side of the latter; for its exceedingly short and broad, but nevertheless almost parallel rostrum (which is merely a little contracted at the base); for its antennæ (which are inserted considerably behind the middle of the latter) having their scape elongate, outwardly curved and compressed, and greatly clavate anteriorly (where however it is obliquely lopped-off on the inner side, occasioning a tolerably well defined angle to be shaped-out at some distance from the tip), their funiculus much abbreviated, but with the joints increasing gradually, but very conspicuously, in width towards the club-which is exceedingly large, elongate-oval, and densely clothed (as with velvet); for its prothorax being straightly truncated (or even, if anything, perhaps, a little scooped-out), instead of trisinuated, behind, unconstricted in front, and perfectly even; and for its legs (which are short, especially the hinder ones) being very widely separated at their base, with the femora much clavate, and with the tarsi (the third joint of which is simple) rather slender and filiform.

81. Homalotrogus (nov. gen.).-The present genus, together with the one which precedes and the one which follows it, belong clearly to the same geographical type 
(or, more strictly, perhaps, to the same cluster of types),peculiar, apparently, to the islands of the Malay archipelago; and yet $\dot{I}$ scarcely think that they could be regarded as representing even distinct sections of a single group. At any rate, if I were to treat them now as such, I feel that the time would assuredly arrive when (as I have lately done with the forms which cluster around Mesites) they would be separated; and hence I have thought it desirable to forestall that event by detaching them at once.

With this preliminary remark, I may state that Homalotrogus differs from Glootrogus in its type being a little more evidently (though at the same time very lightly) sculptured, and not so highly polished; in its head being much narrower, more convex, and oval (instead of flattened and subquadrate); in its eyes being consequently less widely separated; in its rostrum being much longer and more convex, and (instead of nearly parallel) with the hinder half comparatively slender and contracted, and with therefore the anterior one suddenly dilated (much as in Cossonus); in its prothorax (which is exceedingly even) being, if anything, squarer still, though more evidently constricted at its extreme apex; in the last three segments of its abdomen being margined behind with a row of large punctures; in its antennæ (which are inserted conspicuously before, instead of behind, the middle of its much longer rostrum) having their scape straighter and less outwardly curved, and only obsoletely truncate towards the inner apex (and therefore with but a very slight tendency for the anguliform projection which is so marked a feature in Glootrogus), and having their second funiculus-joint appreciably less shortened; and in its legs being longer, with the femora (at any rate the posterior four) somewhat less clavate, and with the tibiæ less abbreviated. Judging: from the labels which are appended to them, the types now before me (which are from the collection of $\mathrm{Mr}$. Pascoe) were taken by $\mathrm{Mr}$. Wallace in the islands of Coram and Batchian, of the Malay archipelago.

82. Isotrogus (nov. gen.).-This genus makes a nearer approach to the normal Cossonus pattern than either of the preceding two; yet it certainly is not identical with that group,-its extremely flattened body and unimpressed prothorax, and the peculiar construction of its scape (which is biflexuose, and shows a more distinct tendency 
than even the last genus does, for the inner anguliform projection which is so conspicuous a feature in Gloetrogus), added to its abbreviated funiculus, its greatly enlarged capitulum, its elongate, oval, much exserted head, and the fact of its large but depressed eyes being considerably approximated on the underside, affiliating it unmistakeably with the small assemblage of types which appear to be characteristic of the islands of the Malayan archipelago.

As compared with Homalotrogus, the present genus is remarkable for the body being both larger and very much more deeply and coarsely sculptured; for its rostrum being more parallel (i.e. much less contracted behind, and therefore less expanded in front); for its head being a little thicker (or less narrowed); for its antennæ (which are more strictly medial as regards their insertion, instead of ante-medial) having their scape rather more evidently sinuated internally, and their second funiculus-joint not in the slightest degree lengthened; and for its prothorax being longer, or more oblong, and more decidedly trisinuated along its basal edge. The two species from which my generic diagnosis has been compiled were collected by Mr. Wallace in the island of Batchian.

83. Heterophasis. (nov. gen.).-The very beautiful insect, so remarkable for its rufescent prothorax, and the other, totally dark one, on which the present genus is established, are from the collection of $\mathrm{Mr}$. Pascoe, and were captured by Mr. Wallace at Dorey in New Guinea. In the more ordinary construction of their rostrum and antennæ they make a still nearer approach to Cossonus than the members of any of the three preceding groups. Nevertheless I think they may fairly be separated from the true Cossoni,-from which they may be said to differ not only in their surface being at times more elegantly coloured (a fact of great significance in this department of the Rhyncophora), but likewise (which is equally important) in their more fusiform, or less parallel, outline, their extremely depressed surface (in which respect they agree with the three preceding genera), their rather more prominent eyes, and in their prothorax (which is alike free from a keel and a depression) being almost totally unsculptured - with the exception of being impressed down either side of its central region (and in the anterior constriction) with a row of punctures-which in $H$. ruficollis are extremely large, but almost obsolete in the concolor. 
The first and second segments, also, of their abdomen are more completely fused into each other than is the case with any of the Cossoni which I have hitherto examined. Although rather more parallel in outline, I believe that the Cossonus glabricollis, Bohm., from southern Africa, will enter into this genus.

84. Cossonus (Clairville, Ent. Helv. i. 58. 1798).-The genus Cossonus, so widely distributed over the world, presents a great amount of structural instability as regards the degree of rounded-dilatation towards the apex of its rostrum and the coarseness of its sculpture; and I think it far from unlikely that a close comparison of its numerous representatives (as at present acknowledged) might enable us to separate them into two or three tolerably distinct groups; nevertheless as it is not my object in this memoir to monograph the closely-allied species of genera which are, on the whole, sufficiently well understood, I shall not attempt to do more than detach a few forms which are readily accessible to me, and concerning the claims of which for separation there can, I think, be no reasonable doubt. Amongst, however, its multitude of specific modifications, Cossonus is by no means unsatisfactorily defined, - the more or less narrow, parallel, depressed, deeplysculptured, dark, and shining bodies of the insects of which it is composed, in conjunction with the form of their rostrum (which is always contracted behind, though often very shortly so, and spatulate, or expanded in front,sometimes to an extraordinary, and at others to merely a slight, extent), its more or less longitudinally-impressed prothorax, rather widely separated anterior coxæ, and the unexpanded third joint of its feet, giving it a character which it is impossible to mistake. Its antennæ are inserted into the roundly-expanded apical portion of its rostrum; its eyes are transverse, oval, and not very widely separated across the forehead; and its surface is nearly always free from every trace of pubescence.

85. Hyponotus (nov. gen.).- $\mathrm{I}$ am indebted to $\mathrm{Mr}$. Pascoe for the loan of the curious insect for which the present genus has been erected; and, judging from a label which is appended to it, it appears to have been captured by Mr. Wallace at Singapore, in the Malay peninsula. Its elongated, parallel outline, and dark, opake, closely sculptured surface, give it somewhat the appearance at 
first sight of a minute Tenebrio ; and although it is manifestly much allied to Cossonus, I feel satisfied that it cannot be admitted amongst the numerous specific modifications of that extensive group. Thus, not only is its opake upper-surface sparingly besprinkled with very short and minute fulvescent setæ (a circumstance of great significance in this particular department of the present family), but its head is considerably broader and more developed, with the eyes (which are rounder and more prominent) consequently much more remotely separated; its rostrum likewise is wider, shorter, and more parallel (it being merely a trifle narrowed, and gradually so, behind), its prothorax (which is relatively more abbreviated and more oval) is very coarsely, densely, and uniformly punctured all over, but unimpressed (although sub-carinulated) posteriorily, and its legs (the intermediate ones of which are extremely wide apart) have their femora (the four hinder ones of which are less clavate), their tibiæ (which are slightly flexuose), and their tarsi, each of them, proportionately, more elongated.

86. Borophleus (nov. gen.).-The members of the present genus, which appear to be North-American (one of them having been communicated by Mr. Fry as coming from Mexico, and the other by Mr. Janson), are, I suspect, in most collections treated as small Cossoni ; nevertheless it seems to me to be scarcely possible to refer them to Cossonus, as rigidly defined,-firom which they differ, not only in their rostrum being relatively shorter, broader, and nearly parallel (indeed completely so as regards one of the species), but also in their eyes being larger, rounder, more prominent, and more widely separated, in their prothorax being more equally and closely (though very coarsely) punctured, and unimpressed behind, in their metasternum being longer, their coxæ more approximate, and the third joint of their feet less decidedly simple (it being, although very minutely so, sub-bilobed).

87. Pachytrogus (nov. gen.).-The affinities of this genus, which is founded on an insect from Chili communicated by Mr. Janson, are extremely difficult; for whilst the large size and robust general aspect of its type, in conjunction with its somewhat shortened scape, is at first sight entirely suggestive of Stereoborus and Stereotribus, its still thicker and broader rostrum (the tendency 
of which is rather to be subtriangular, than posteriorly narrowed), and its depressed, less widely separated eyes, added to its very grossly and equally punctured prothorax (which is free from a constriction in front, and is nearly unsinuated at the base), and its convex body, are far more in accordance with what obtains in such sub-Hylastideous groups as Brachytemnus. On the whole, however, I think it will be more natural to retain it in the vicinity of the former,-and more especially since their is no appearance of the excessive reduction in the length of the scape which is so characteristic of the latter; nor yet of the obtuselydesilient apical region of the elytra, the subcontiguous anterior coxæ, and the slender feet, of those particular types. Its tibiæ are not so abbreviated as in Stereoborus and Stereotribus, and the front pair seem to be simple (or un-augmented internally; its scutellum is largely developed; and its rostrum, although unprovided with any anomalous tubercles and channel-like fissures, is nevertheless obsoletely gibbose, or uneven, on its upper surface.

88. Stereoborus (nov. gen.).- The insects which I would include under the present genus and the following one, although apparently (for the most part) undescribed, are some of them (on account, doubtless, of their rather large size, and dark, shining, deeply-sculptured surfaces) mixed-up in collections with the Cossoni-from which, however, they are, nevertheless, totally distinct. Indeed in the construction of their extremely robust and thickened legs they are very peculiar,- the femora (though especially the anterior ones) being greatly incrassated, whilst the tibiæ are unusually short, broad, and somewhat compressed, with the terminal hook powerfully developed; the front pair moreover being abnormally augmented on their inner edge (at some distance behind the internal angle) by a kind of lamelliform triangular plate (which however only becomes conspicuous when the insect is viewed obliquely). In other respects Stereoborus recedes from Cossonus in its head being considerably larger and broader ; in its eyes (which are rounder and more prominent) being consequently much wider apart ; in its rostrum (which is furnished with a narrow, anteriorly-evanescent channel in the centre, arising out of a minute frontal fovea) being conspicuously shorter, broader, and more parallel (in fact nearly quadrate); in its prothorax being longer, and somewhat more cylindrical; and in its coxæ 
(though particularly the front ones) being more approximate. Its antennæ (which are implanted before the middle of the rostrum) are rather thick, with their scape slightly abbreviated, and their funiculus (the second joint of which is but very little longer than those which follow it) tolerably compact,- - though not so compact as in Stereotribus.

The genus seems to be peculiar (so far as I am aware) to the islands of the Malayan archipelago,--the specimens now before me (from the collections of Mr. Fry and Mr. Pascoe) having been captured by Mr. Wallace at Dorey in New Guinea, and in the islands of Gilolo and Matabello.

89. Stereotribus (nov. gen.).-The members of the present group are very closely allied, in external aspect and general structure, to those of the preceding one,from which they seem mainly to differ in their head being a little less widened, and their rostrum (which in the S. incisus and tuberculifrons, from Ceylon, is rather longer, and distinctly narrowed towards the base) being not only furnished behind with a very deep, short, wide, and somewhat gaping slit, or (as it were) gash (often accompanied by posterior frontal tubercles and inequalities), which takes the place of the narrow channel in Stereoborus, but likewise more or less bearded beneath, at the apex, with elongated hairs. Their eyes, too, are a little more prominent; their funiculus (the second joint of which is not at all longer than those which follow it) is more solid, or compact; and the additional lamelliform process which augments the inner edge of the two front tibix is armed at its base with a very conspicuous and robust spine (which is best seen when the insect is viewed obliquely and from behind). Like that genus, it is widely spread over the islands of the Malayan archipelago,-_examples, obtained by Mr. Wallace in Batchian and Tondano, having been communicated to me by Mr. Pascoe; and it appears to range eastward, in however a slightly modified form (as witnessed by its somewhat longer and more posteriorlynarrowed rostrum, and its more developed club), to at all events Ceylon -from whence several individuals (representing my S. incisus and tuberculifrons) are now before me from the collection of Mr. Fry.

I have thought it desirable to append a subgeneric title

TRANS. ENT. SOC. 1873.-PART IV. (OCT.) 
to the two species from Ceylon, in the event of its being: found desirable ultimately to detach them from the others; though I scarcely imagine that their slight structural peculiarities of rostrum and club are of sufficient importance to indicate more than perhaps a geographical modification of a rather plastic type.

90. Stereommetes (nov. gen.). - The rather large Cossonid which constitutes the type of the present genus, and which Mr. Pascoe has communicated as coming from Champion Bay in Western Australia, is manifestly akin to Stereoborus and Stereotribus, though at the same time approaching in the outline, colour, and sculpture of its oblong prothorax, as well as in the bipartite structure of the spine which arises from the inner angle of its four posterior tibiæ, the genus Phaeegaster. However it entirely wants the short conical feet and the peculiarly formed rostrum of the latter, and of the groups which are allied to it; and its affinities appear to me to be clearly with Stereotribus, - with the aberrant members of which, from Ceylon, it very much agrees in (amongst other details) the shape of its robust, posteriorly-narrowed rostrum.

Despite however the undoubted relationship of this genus to Stereotribus, not only does the form of its almost basally-unsinuated prothorax and elytra and the structure of its inner tibial spur shew it to be unmistakeably distinct; but its antennæ (which are implanted further from the apex of the rostrum) are considerably thicker and differently constituted,--their scape being extremely robust, sub-tortuous, and powerfully clubbed, their funiculus remarkably broad, but with the joints nevertheless (instead of being compact) sharply and deeply separated from each other, and their capitulum small and narrow (as in the Rhyncoli). Its rostrum, which is a good deal rounded-outwards anteriorly, has a wide channel behind (which arises from a large frontal fovea); its eyes (as in the neighbouring groups) are very prominent; its prothorax is much less coarsely punctured, and its elytra are more strictly parallel, than is the case in Stereotribus and Stereoborus; its legs are longer, and not quite so broad,--both of which points are particularly observable as regards the tibiæ; and the front pair of the latter are less decidedly augmented internally by a lamelliform portion towards their base. Its colour, too, is less intensely black,-the anterior segments 
and the underside being (at any rate in the example now before me) piceous, with the limbs of a still clearer tint.

91. Stereoderus (nov. gen.).-The present genus is manifestly allied to Stereoborus and Stereotribus,-though the rather smaller size to which its members would appear to descend, added to their more convex, cylindrical bodies, more lightly sculptured surface, and their more conical, unimpressed prothorax, gives them more the appearance at first sight of such forms as Xestoderma and Xestosoma (which are equally dark and highly-polished, and have a broad, abbreviated rostrum) in the vicinity of the Rhyncoli. Nevertheless, the peculiar construction of its rostrum, which is often barbed beneath with long fulvescent hairs, and has three small clefts in the upper anterior excavation which receives the labrum, as well as a curious tendency to be armed with one or more tubercles in the centre behind (all of which exist, more or less modified, in Stereotribus), is too significant to be misunderstood. And when we add to this the characteristic shortness of its scape, the excessive robustness of its limbs, and the internally dilated basal half of its anterior tibiæe (the superadded triangular portion arising from a robust spinule, situated at some distance behind the spiniform inner angle), each of which is conspicuously expressed in that genus, there can be no longer the slightest room for doubt as to its true affinities. Its eyes are large, very wide apart, and somewhat anterior in their position ; and its third tarsal joint, as in most of these immediate groups, is simple.

Stereoderus is a genus which would seem to have a rather extended geographical range,-out of the three species now before me (all of which are from the collection of Mr. Pascoe), two having been captured by Mr. Wallace in the islands of the Malayan archipelago, whilst the other is from the Fiji islands in the Pacific. The latter, however, although $I$ think it is impossible to regard it as generically distinct, shows a slight structural difference in the minute emargination at the extreme apex of its rostrum,- - the large medially-cleft lobe, which nearly fills up the cavity in the other two species (causing the whole central piece to appear trifid) being so short, small, and entire as to be strictly obsolete. But so diminutive a character, even though structural, can scarcely be regarded as more than a trivial one. 
92. Oxydema (nov. gen.).- The present genus is established to embrace three large and very closely allied species,-two of which (taken by Mr. Wallace in the islands of the Malayan archipelago) are from the collection of Mr. Pascoe, and the other (from Ceylon) in that of Mr. Janson. They are at once conspicuous for their elongate, narrow, and fusiform outline being a good deal attenuated both before and behind (particularly the latter), their dark hue, and their somewhat slender, considerably lengthened rostrum,-which however is not quite parallel, being appreciably broader in its anterior half (in front of the antennæ) than it is posteriorly. Their eyes are rounded and prominent, their prothorax is even and much constricted in front, their elytra are gradually narrowed from the base to the apex (where they have a tendency to be separately and minutely rounded-off), their anterior coxæ are very remote, and their antennæ and legs (the latter of which have the third tarsal joint bilobed) are rather long.

93. Notiosomus (nov.gen.).-Three insects now before me-two of which have been communicated by Mr. Pascoe as coming from western Australia, whilst the other (bearing the label "New Holland") is from the collection of Mr. Fry,-although, I think, specifically distinct, belong unquestionably to the same genus, and that genus is certainly not far removed from Oxydema. Nevertheless I feel satisfied that they cannot be actually associated with the members of the latter, which moreover appear to have a more tropical range,-occurring in (at any rate) the Malayan archipelago and Ceylon; and I would therefore regard them as pertaining to an Australian type, which perhaps may have other representatives in its own particular province.

Primâ facie, however, the present genus has much in common with Oxydema,-with which it agrees in its rather large size, and in the fact of its rostrum being a little reduced in width behind the insertion of the antennæ; nevertheless it recedes from the exponents of that group in the body being altogether (proportionately) less nar- rowed, and much less attenuated posteriorly, as well as less shining and sometimes less black; in its rostrum being rather shorter, and not quite so distinctly contracted along its basal half; in its antennæ (which are somewhat thinner) having the second funiculus-joint less decidedly 
abbreviated, and the club less developed; in its prothorax being generally more conspicuously narrower than the elytra, less elongate, and not so deeply constricted in front; in its scutellum being less transverse; in its metasternum being appreciably shorter; and in its feet being slenderer, with their third articulation usually smaller and narrower, and much more minutely bilobed. Its eyes, as in Oxydema, are extremely prominent, and its sculpture is rather coarse. The first of the three species, however, which are described in this paper (-namely the $O$. major), I may add, is not quite so typical of the group as the other two; nevertheless I do not think it can be looked upon as an Oxydema.

94. Aphanocorynes (nov. gen.)-In its rather large size, elongate, narrow, subfusiform outline, and deep-black hue the insect for which the present genus is founded, and which has been communicated by Mr. Pascoe (as having been captured by Dr. Masters at King George's Sound, in southern Australia), has somewhat the appearance at first sight of Oxydema-which occurs in Ceylon and the islands of the Malayan archipelago. Nevertheless it differs in its body being more depressed, and much more finely and closely sculptured, in its elytra being less attenuated posteriorly, and without any tendency to be separately rounded-off at their extreme apex, in its rostrum being a litle shorter and entirely parallel, and in its club being very much less developed. Indeed this latter is even smaller, narrower, and more acuminated than in even the typical Rhyncoli. Its prothorax too (which however, as in that genus, is deeply constricted at the apex) is not altogether even,-it being widely, but lightly, impressed in the centre behind; and its third tarsal joint is more evidently dilated and bilobed, and the terminal one is shorter, than is the case in Oxydema.

95. Orthotemnus (nov. gen.).-As in the two preceding genera, the type of the present group (which appears to be extensively spread over the islands of the Malayan archipelago) is a comparatively large and elongate insect, and of a dark hue; but it recedes in many important particulars from the neighbouring forms,- particularly however in its flattened surface, and elongate, triangular prothorax, which is very straightly truncated at the base (where it is of the same width as the elytra- 
which are perfectly parallel, and are likewise very straightly truncated in front), and in its rostrum being rather long and robust, but of equal breadth throughout, in its eyes being very largely developed, in its elytra being separately recurved at their extreme apex, in its third tarsal joint being small and almost simple, and in its four anterior coxæ being very widely and subequally distant, whilst the posterior ones are, if anything, even less remote than the others,- a character which is most unusual amongst the Cossonids. The examples now before me (all of which seem to pertain to a single species) are from the collection of $\mathrm{Mr}$. Pascoe, and were captured by $\mathrm{Mr}$. Wallace at Dorey in New Guinea, as well as in Batchian, Makian, and Ceram.

96. Macrorhyncolus (Wollaston, Trans. Ent. Soc. Lond. 33. 1873).-The present genus, which I established a short time ago to receive a Cossonid which was obtained by Mr. G. Lewis in Japan, and of which a second species (from Ceylon) is now before me, communicated by $\mathrm{Mr}$. Fry, is somewhat intermediate between the preceding groups and Rhyncolus; nevertheless I believe that it is, in reality, far more nearly allied to the former than to the latter. From Rhyncolus it differs, principally, in the body being relatively longer, narrower, and more parallel, - it being less convex, and without any tendency to be ovate (or expanded behind the middle); and its surface is more shining, and of an intenser black. Its rostrum is more strictly parallel,-being indeed, if anything, rather contracted, perhaps, than otherwise, towards the base (instead of, as in the Rhyncoli, somewhat thickened); its eyes are larger and more prominent; its prothorax and metasternum are more elongated; its club (although small) is both less narrowed and less acuminate; and its four anterior coxæ are a little more remote.

97. Héterarthus (Wollaston, Trans. Ent. Soc. Lond. 29. 1873).- - It was for two very closely related species which were captured by Mr. G. Lewis in Japan that I lately established the genus Heterarthrus; and a third is now before me, from the collections of $\mathrm{Mr}$. Pascoe and Mr. Janson, from the same region, - it having been taken near Nagasaki, in the island of Kushiu. They may be known from the members of the neighbouring groups by their convex and fusiform bodies having the 
elytra either altogether pale, or else (which would seem to be the normal condition) ornamented with suffused blackish markings. The head is narrow, with the eyes consequently less wide apart than what is the case in most of these immediately-allied types; and the rostrum is somewhat short and robust, though by no means very broad, and gently, but appreciably, dilated towards the tip-which is, itself, rather straightly truncate. The prothorax (which is finely and densely punctulated) is a good deal narrowed, and much constricted, in front; and the antennæ and legs (the former of which have their club shortish, and tolerably abrupt) are comparatively slender. The intermediate coxæ are remotely separated (occasioning the four hinder ones to be equidistant); the femora are unusually thin towards their base; and the tarsi (which have the terminal joint ordinary and clavate in the males, but subconical in the females) are very conspicuously lengthened.

98. Conarthrus (nov. gen.).-In the conical but not abbreviated last joint of its feet (which may, or may not, be indicated in both sexes, - for I have only a single example of each species from which to judge), no less than in the densely punctured anterior portion of its surface, and its short, unacuminated club, the present genus (which is founded on two species whieh were captured by Mr. Wallace in the islands of the Malayan archipelago, and a third, from Cochin China, which has been communicated by Mr. Fry) is more related, I think, to Heterarthrus and Eutornus than it is to the groups around Exonotus and Phacegaster-with the latter of which, nevertheless, in the proportions of its broad head and rostrum, as well as its large size and parallel, cylindric body, it almost entirely agrees. It may be known from the forms amongst which it seems to me most natural to associate it by its elongate, linear outline, black hue, sloping (or sub-perpendicular) scutellum (- a character, however, which is less distinctly indicated in the C. vicinus from Cochin China), its exceedingly flexuose anterior tibiæ, and its wide head and rostrum,- the former of which is also much exserted, whilst the latter varies in the two Malayan examples now before (but which I nevertheless believe are both of them females), being in one instance perfectly parallel, and in the other not only a little longer but appreciably dilated anteriorly. It is possible however that I may be mistaken in regarding these two Malayan 
individuals as pertaining to the same sex, in which case the outline of the rostrum may perhaps be only sexual. But, be this as it may, I suspect that they are specifically distinct from each other.

99. Eutornus (nov. gen.).-The two insects which I have described as members of the present genus are from Ceylon and the Malayan archipelago,- - the one from the former having been communicated by Mr. Janson (to whom I have dedicated the species), whilst the other is from the collection of $\mathrm{Mr}$. Pascoe and was captured by Mr. Wallace.* Indeed, judging from the many examples now before me, the Malayan representative would appear to be widely spread over those particular islands, and also to be remarkably constant, or free from variation,- the types of it which I have examined having been obtained in New Guinea, Morty, Tondano, Gilolo, and Makian.

The characters of the genus are very similar to those of Conarthrus, and yet I feel satisfied that the two groups are essentially distinct,-Eutornus receding from the latter not only in the less parallel (or more fusiform) outline, and more lightly sculptured surface, of the insects for which it is established, and in the peculiarity of their colour, which (instead of a uniform black) is rufo-ferruginous, with the anterior and posterior portions more or less suffused, or obscured; but likewise in their rostrum being apparently always linear, in their prothorax being less straightly truncated (or more subsinuated) at its base, in their scutellum not being tilted (or sub-perpendicular), in their elytra being (as in Heterarthrus) obscurely, and minutely, rounded-off, separately, at the extreme apex, and in the last joint of their feet being less conspicuously conical. Their first and second abdominal segments, too, are more convex,- -having scarcely any tendency to be longitudinally hollowed-out, or concave.

100. Coptus (nov. gen.).-The two curious and closelyallied little species on which the present genus is established have been communicated by $\mathrm{Mr}$. Pascoe, and were taken by Mr. Wallace in the islands of New Guinea and Sula, of the Malayan archipelago. Apart from their rather small size, parallel outline, subdepressed surface, and their rufo-piceous, or piceo-ferruginous hue, they may be

- The $E$. dubius, from New Zealand, is less typical, and may perhaps be found eventually to pertain to a new but cognate genus. 
known readily from the neighbouring forms by their eyes being enormously developed and very prominent, by their antennæ (which have the second funiculus-joint much abbreviated, and the club abrupt) being inserted towards the base of their rostrum, and by the latter being exceedingly broad (indeed scarcely narrower than the head), but nevertheless parallel, much arcuated, and straightly truncate, or lopped-off, in front. The third articulation of their feet is simple, and their coxæ (even the anterior pair) are widely and subequally separated.

101. Pachyops (nov. gen.).-Two examples of the species for which the present genus has been established (which have been communicated by $\mathrm{Mr}$. Pascoe), were obtained by Mr. Wallace at Sarawak in Borneo. They may be known from the allied forms by their narrow, parallel, cylindric, and rather deeply, closely sculptured bodies; by their broad, thick, convex, greatly exserted head; by their short and wide rostrum; by their long, subconical prothorax, which is but lightly constricted in front; by their elongate scape, and roundish, abrupt, compressed, largely-developed club; and by their coxæ being somewhat less separated than is the case in the neighbouring groups,-the anterior pair being scarcely, if at all, more remote than in the Rhyncoli.

102. Pentamimus (nov. gen.).- Several examples of a Cossonid which I have received from Mr. Pascoe as coming from King George's Sound in southern Australia, and a closely allied species (likewise Australian) which has been communicated by Mr. Fry, have so much the prima facie aspect of large Rhyncoli that they might be almost supposed to pertain to that genus. Yet their 5 -jointed funiculus, and rounder and more developed club, show them to be altogether distinct; though their affinities are so unmistakeably with the Rhyncoliform groups that it would be absurd to suppose (on account of the structure of their funiculus) that they have anything whatever to do with the subfamily Pentarthrides. In other respects Pentamimus is remarkable for its shining, deeply sculptured and cylindrical body; for its thickened head, and short, broad (though parallel) rostrum; for its somewhat incrassated antennæ (which are implanted a-little behind the middle of the latter) having their scape a good deal lengthened and backwardly curved; and for its legs being rather long and thick, with the third tarsal joint simple. 
103. Tetracoptus (nov.gen.).-The present genus, the type of which (although very much smaller, and more lightly punctured) at first sight closely resembles Pentamimus, is remarkable for its quadriarticulate funiculus,it being the only instance amongst the entire Cossonida, outside the subfamily Dryophthorides, so far at least as I have hitherto observed, in which that organ is composed of but four joints; yet so unmistakeably is it a member, as regards the whole of its other details, of the Rhyncoliform groups that it would be as absurd to remove it on account of the structure of its funiculus into the Dryophthorides (with which in everything else it totally disagrees) as it would be to regard Pentamimus and Tomolips as Pentarthrids, or to include Hexarthrum amongst the Onycholipides. In point of fact there can be no question, despite its 4-jointed funiculus, about its affinities; and it is a significant fact that the only exponents of the subfamily Cossonides in which the funiculus is made-up (so far as I am aware) of less than seven articulations should pertain to genera which appear, in a natural system of arrangement, to be at no great distance from each other,- - namely Hexarthrum (in which the funiculus is composed of six joints), Tomolips and Pentamimus (in which there are but five), and Tetracoptus (where the number is reduced to four).

A part however from the primary peculiarity to which I have just called attention, Tetracoptus may be known by its cylindrical body and very lightly sculptured surface; by its exceedingly short and broad, but nevertheless parallel, rostrum (which has a wide, but shallow, channel in front); by its elongate, large, subconical prothorax (which is about the same width posteriorly as the elytra, and is more constricted in front than in Pentamimus); by the smallness of its scutellum; and by its abrupt, considerablydeveloped club. Its anterior coxæ are tolerably wide apart, and the four hinder ones are about equidistant; its legs (especially as regards the tibiæ) are somewhat short, its third tarsal joint is simple, and its claws are minute.

The single example of this genus from which my diagnosis is compiled has been communicated by Mr. Pascoe, and was captured by Mr. Wallace at Dorey in New Guinea.

104. Xestónerma (nov. gen.).-The present genus and the following one are a good deal allied to each other, 
and appear to be extensively spread over the Malayan archipelago-whence two species of each, now before me (which have been communicated by Mr. Pascoe), were obtained by Mr. Wallace in the islands of Ceram, Morty, Batchian, and Ternate. They belong to a type quite distinct from any of the preceding ones,-their very lightly sculptured, shining, deep-back, cylindrical bodies, in conjunction with their short, broad, and thick rostra (which are but very little narrower than the head), their excurved scape, their abrupt, compressed club, and the fact of their first and second abdominal segments being divided by a very conspicuous line, giving them a character which it is impossible to mistake. In Xestoderma the rostrum is free from an anterior channel, the capitulum is but moderately developed, the intermediate coxæ are very remotely separated, and the third tarsal joint is quite simple. The scutellum is either small and somewhat rounded, or else smaller still, short and transverse.

105. Xestosoma (nov. gen.).- As already implied, the members of this genus have much the appearance of those of the preceding one; nevertheless the body is relatively a little broader and thicker; and moreover, whilst one of the species is highly polished, the other is almost opake. The antennæ too have their scape longer and somewhat more robust, and their club dark and sericeous, and considerably more developed,-it being very large and rounded in the $X$.grandicollis, but oval in the subopacus. The scutellum is very minute, short, and transverse (rather more so perhaps than in even the Xestoderma atra); the intermediate coxæ are rather less widely separated; and the third tarsal joint is not quite simple,-it being appreciably (at any rate in the anterior pair), though very minutely, sub-bilobed, or cordate.

106. Lissopsis (nov. gen.).-Unfortunately the only example which is accessible to me in drawing out the characters of the present genus has lost its antennæ; yet its other details are so well defined, and I am so convinced that the insect cannot be referred to any other group enunciated in this paper, that I have no hesitation in treating it as a distinct type of the sub-Hylastideous Cossonids with exceedingly abbreviated rostra. It is at once remarkable for its rather wide, short, and parallel-oblong outline (which is somewhat obtuse both before and behind); for its ros- 
trum, although thus abbreviated, being nevertheless subparallel, rather than triangular, as well as slightly concave in the middle, and most curiously polished (and unsculptured) at the base; for its eyes being, as in Sphcrocorynes, extremely prominent; for its prothorax being large and convex, about equally rounded at the sides, and of the same breadth at its widest part as the elytra; for the latter being shortly-cylindric, very deeply and coarsely sulcate-punctate, and obtusely rounded and minutely asperated posteriorly; for its tibiæ (at any rate the front pair) being subflexuose; and for its coxæ, even the anterior ones, being widely separated. The specimen which has furnished the diagnosis is from the collection of $\mathrm{Mr}$. Pascoe, and was captured by $\mathrm{Mr}$. Wallace at Saylee on the north-west coast of New Guinea.

107. Sphærocorynes (Wollaston, Trans. Ent. Soc. Lond. 38. 1873).-Spharocorynes is one of the many genera the discovery of which is due to the researches of $\mathrm{Mr}$. G. Lewis in Japan; and it is conspicuous for its very short and channelled rostrum being nevertheless (as in Lissopsis) parallel, rather than triangular, and for its antennæ (which are thickened and considerably developed) having their scape elongate, their funiculus abbreviated, and their club large, rounded, and abrupt. Its eyes are extremely prominent; its body (which is subcylindrical, and comparatively lightly and delicately, though rather closely, sculptured) is convex, just appreciably sericeous on the elytra, and rather more evidently so beneath; and its legs are subequally separated at their base,- the anterior pair being a little more, and the hinder pair a little less, remote than is usual amongst the Cossonids. Its tibiæ (the front ones of which are slightly flexuose) are rather long; and its tarsi have their first joint considerably lengthened, and the third one, although scarcely widened, very minutely (but evidently) bilobed.

108. Xenotrupis (nov. gen.).-The affinities of this genus are somewhat difficult,--its longer and less thickened rostrum, which is gradually narrowed posteriorly, its less incrassated head, and fusiform (instead of parallel) outline tending to remove it from these immediate groups; yet at the same time it has so much in common with them in its convex, shining, deep-black, lightly sculptured surface, its abrupt and compressed club, its largely de- 
veloped prothorax and elongate feet, as also in the fact of its first and second abdominal segments being divided from each other by a conspicuous line, that I think it will be more natural to place it in the present position than elsewhere. Its coxæ are all of them very widely separated, though each successive pair is more remote than the one which precedes it; its eyes are exceedingly large and prominent; and its prothorax is slightly concave on the underside. The single species on which the genus is established is from the Malayan archipelago,-it having been captured by Mr. Wallace in the island of Batchian, as well as at Dorey in New Guinea.

109. Pachystylus (nov. gen.).-Two examples of the remarkable species for which the present genus is established have been communicated by Mr. Fry as having been received from Chili; and their position in a natural system of arrangement is not altogether very apparent,- - though, on the whole, I believe that it will be best to place them at no great distance from Rhyncolus. Nevertheless I must admit that in the minuteness of their scutellum they stand perfectly alone amongst those immediate groups, and make a far nearer approach to Phloeophagus and Caulotrupis. Still, the scutellum is not quite obsolete; and the other details of their structure (particularly as regards their incrassated limbs, and their short first tarsal and second funiculus joints) are so much more in accordance with the corresponding ones of the Rhyncoli that I cannot persuade myself to remove the genus into the Phloophagus neighbourhood; though, at the same time, I am far from thinking that the situation which I have selected for it is quite satisfactory. Be the position, however, of Pachystylus what it may, it is, as a genus, very distinct from everything else with which I am acquainted,- the smallness of its scutellum and its extremely prominent eyes (which in the male sex are abruptly terminated posteriorly, but gradually sloped-off in front), in conjunction with its somewhat lengthened rostrum (as compared with that of the Rhyncoli), which is very much broader in the males than in the females, and its elongate, thickened scape (which, on account of its robustness throughout, is but little clavated towards the apex), giving it a character which is essentially its own. Although not wider than the elytra, its prothorax (which is almost free from an anterior constriction) is very largely developed, and elongate; and there 
is a peculiarity about its surface,-which is subopake throughout the anterior half, whilst the elytra are slightly shining, and just appreciably even subænescent (calling faintly to mind certain of the Madeiran Caulotrupides). The underside, too, is rather singularly modified according to the sex, - the metasternum in the females being a little concave posteriorly, and furnished in the middle with a minute, isolated keel, abruptly terminated in front; whilst in the opposite sex the keel is absent, but the concavity is larger (extending through the first segment of the abdomen).

110. Xenommetes (Wollaston, Trans. Ent. Soc. Lond. 35. 1873).-Xenomimetes is a genus which was detected by Mr. G. Lewis in Japan,- - where indeed the only representative of it which I have hitherto seen would appear to be locally abundant, and (unless I am much mistaken) of pine-infesting habits. In this latter respect it consequently resembles Eremotes and Brachytemnus, with the former of which it has several points (though perhaps only superficial ones) in common. It may easily be recognized by its type being elongate, narrow, and parallel, as well as somewhat opake and very densely sculptured,-it being also (when viewed beneath a high magnifying power) minutely pubescent, and asperated, towards the hinder apex (where the elytra are separately, and conspicuously, rounded-off, causing them to appear almost divaricate). The rostrum is rather peculiar in its construction,-being very short, but nevertheless quite parallel, and suddenly much narrower than the head; the eyes are extremely prominent; the club (unlike that of Eremotes and of the Rhyncoli) is rounded and abrupt, the antennæ being comparatively slender; the legs (particularly as regards the tarsi) are a good deal elongated; the tibiæ (more especially however the anterior pair) are elongated and subflexuose; and the coxæ are but slightly separated,the front ones indeed being not more so than in Rhyncolus, whilst the two hinder pairs (which are about equidistant) are by no means very remote.

111. Eremotes (Wollaston, Trans. Ent. Soc. Lond.2nd Ser. v. 364. 1861).*-The genus Eremotes, which may be

* When compiling my 'Coleopt. Atlantidum,' in 1865, I changed the name of this genus, from Eremotes, into Syntomocerus, - feeling that the title was so near to Eretmotes, of De Marseul, that there might be a risk 
regarded as an offshoot of Rhyncolus, was established by myself in 1861 to receive the "Hylastes crassicornis" of Brullé,- a Hylastes-shaped Cossonid which infests the pine-trees of the Canarian archipelago ; and a recent examination of some of the discordant species of (so-called) Rhyncolus has convinced me that the European R. strangulatus is an undoubted member of the same group. Indeed a single example is now before me (described in the after-part of this paper) which is unquestionably a third representative of Eremotes, but I have unfortunately no information concerning its precise habitat. However I believe it to be European,-it having been purchased by John Gray, Esq. (in whose collection it now is), some years ago, from M. Tarnier of Dijon, as the " $R$. chloropus"-with which, I need hardly add, it has scarcely anything in common.

Judging therefore from the three members which have hitherto been brought to light, Eremotes may be said to differ from Rhyncolus in its species being not only larger, more cylindrical, and more coarsely sculptured, but likewise in their prothorax being longer, more cylindrical, and more constricted in front, in its rostrum being shorter, broader and thicker, in its eyès being more prominent, and (above all) in the structure of its antennæ,-which are extremely incrassated, their funiculus especially being thick and robust, and with the second joint so reduced in length as to be almost hidden within the apex of the greatly enlarged basal one. In all probability Eremotes will be found to be exclusively of pine-infesting habits; and it is far from impossible that the species which I have enunciated in the latter portion of this memoir, under the name of $E$. gravidicornis, may prove to have come from the region of the Pyrenees.

112. Rhyncolus (Germar, Ins. Spec. Nov. 307. 1824). -Like Phloophagus and Cossonus, the genus Rhyncolus has had many forms assigned to it, by various authors, which will be seen, when carefully examined, to be not strictly on the pattern of its acknowledged type-namely, the European $R$. ater, Linn. (or chloropus, Fab.). Thus, after removing Eremotes (for the reception of the R. strangulatus, Perris), Stereocorynes (for the truncorum, Germ.),

of possible confusion. Since however the Munich Catalogue, and others, have not accepted this alteration on my part, which would appear to be deemed by them to have been unnecessary, I have thought it better to revert to the original nomenclature. 
Hexarthrum (for the culinaris, Germ., and the submuricatus, Bohm.), and Brachytemnus (for the porcatus, Müll.), there still remains a residuum, even amongst its smaller members, which future monographers will in all probability further divide; yet, having reduced its heterogeneous material thus far, and since I am not professedly in this paper examining every described species (some of which would not be readily accessible), I am content to leave the group partially pruned, and to treat it as represented by those particular exponents which I have been able to inspect, and a list of which will be found in my general summary at the close of the present memoir. As thus curtailed, therefore, I believe that Rhyncolus will be found to possess by no means so universal a range as the different Catalogues would lead us to conclude,-none of its members being, apparently, of a large stature. At the same time, however, I would not wish to imply that its area of distribution is unnecessarily restricted; but merely to call attention to the fact that a vast proportion of the species which figure as Rhyncoli in various papers and local enumerations have in reality nothing in common with the universally-acknowledged generic type.

For the characters which separate this genus from Phloephagus, with which it has occasionally been confounded, the observations which I have given under the latter will suffice.

113. Caulophilus (Wollaston, Ins. Mad. 315. 1854). - The insect on which this genus was established in 1854, and which I captured twenty-six years ago in the island of Madeira, is still unique; and in its general appearance it somewhat resembles at first sight a small state of the European Rhyncolus cylindrirostris, Oliv. (= lignarius, Mshm.). Nevertheless when closely inspected it will be seen to be structurally dissimilar in many respects; and I doubt indeed if it can be actually associated with the Rhyncoli at all. Thus, in addition to its rostrum being obsoletely divided from the head by a very obscure frontal line, or depression, its antennæ are by no means on the true Rhyncolus pattern,- - their club being considerably larger and thicker, but nevertheless more acute at the apex, their funiculus less incrassated (the basal joint being very conspicuously smaller, and the terminal ones narrower and more transverse), and their scape more clavate. Its eyes also are very much more developed, as well as 
more approximate (or less widely separated); its scutellum is a trifle larger; and its elytra are somewhat more cylindric or parallel. As in the majority of the Rhyncoli, its third tarsal articulation is simple.

114. Xenocnema (nov. gen.).--It is for an insect from New Zealand, which has been communicated by Dr. Sharp, and which was captured by Mr. Lawson in Auckland, that I am compelled to establish this genus; and there is perhaps no member of the Cossonide which I have hitherto examined which is so difficult as regards its affinities,-for although (as I cannot but think) an undoubted member of the present family, in the construction of its tibiæ it is nevertheless completely Hylastideous. Moreover the first and second segments of its abdomen are less elongate, and far more divided, than is the case even in those genera which shew an unmistakeable affinity with the Hylastida, the latter of them being (somewhat after the fashion, however, that we observe in Calyciforus) in a different plane from the former; and yet in other particulars-as, for instance, in the increased length and diminished breadth of its rostrum, its posteriorly-unasperated elytra, and its unapproximated anterior coxæ-Xеnocnema is absolutely more on the normal Cossonideous pattern than such groups as Stenoscelis, Dendroctonomorphus, and Tomolips, in which the body is obtusely cylindrical, and more or less roughened behind, the rostrum exceedingly short and broad, and the anterior legs practically contiguous. Altogether therefore I am inclined to place it nearer than those forms to the Rhyncoli and typical Cossonides, whilst at the same time acknowledging its evident relationship with the Hylastids in the very significant structure of its tibiæ. These latter indeed are quite unprecedented in any of the Cossonids which have hitherto come beneath my notice,they not only having their tibial hook obsolete (an eccentricity which we perceive in a few exceptional genera, such as Thaumastophasis, Aorus, and Lipancylus), but (which is far more important) being expanded towards their outer apex (more particularly however as regards the four hinder ones) into a lamelliform spinose process; whilst the inner angle is armed with a small spur, which (after the manner so common amongst the Scolytidiens) is developed in the front pair into a comparatively lengthened sub-horizontal spine.

TRANS. ENT. SOC. 1873.-PART IV. (OCT.) 
Apart from these eccentricities of tibiæ and abdomen, Xenocnema is remarkable for its rather short and thick, but somewhat parallel and depressed, body,-which is densely and sharply sculptured, and of a piceo-ferruginous hue; for its rostrum (which is robust, but not particularly abbreviated) being divided by a distinct line (above and below) from the forehead; for its antennæ being almost medial as regards their insertion; for its eyes being prominent; for its prothorax being large, elongate, and subquadrangular; and for the very unusual sculpture of its elytra,- the interstices of which are costiform, each costa however being as it were divided into two by a densely punctulated central stria.

115. Stereocorynes (nov. gen.).- - It is the European Rhyncolus truncorum, Germ., which has afforded the details for the present genus; and it is surprising to me how that remarkably-constructed insect could ever have been associated with the $R$. ater, and the various other species on the true Rhyncolus-type. Thus, not only is it more strictly cylindrical and obtusely rounded behind, but its rostrum and antennæ are on a totally different pattern, - the former being short and subparallel in the males, but still shorter and subtriangular in the females; whilst the latter (which are inserted considerably behind the middle) are, as compared with those of the Rhyncoli, exceedingly abbreviated and glabrous, the scape particularly being reduced in length, the funiculus-joints closely compacted together, and the club solid, compressed, and ob-triangular (being straightly truncated at its apex). In other respects Stereocorynes is conspicuous for its eyes being extremely sunken or depressed (instead of prominent as in Rhyncolus); for its prothorax being very convex, and quite unconstricted in front; for its femora, particularly the front pair, being considerably thickened, and with a faint appearance beneath of an obtuse anguliform tooth; and for its four anterior coxæ being (as in Hexarthrum) so manifestly more approximated as to be well nigh contiguous.

116. Hexarthrum (Wollaston, Ann. Nat. Hist. v. 448. 1860). - The genus Hexarthrum was established by myself thirteen years ago for the reception of a Rhyncolus-like insect, with a 6-jointed funiculus and subasperated elytra, which had been captured in various houses, and outhouses, 
at Madeira, and the habits of which seem to be very similar to those of Pentarthrum and Amaurorrhinus; and it is only now that I have been enabled to identify it, through the examination of more extensive material, with the European Rhyncolus culinaris, of Germar,-a species which does not appear to be common in collections, or one which is very extensively known. Nevertheless I can detect no difference between the Madeiran insect and a type of the latter which has been communicated by Mr. Gray; and I do not hesitate therefore in regarding them as identical. Yet the generic characters of Hexarthrum remain clear and well defined, and afford another instance of the loose manner in which so many discordant forms have been associated with the Rhyncoli, and of the little care which appears to have been bestowed by certain Coleopterists on the structural features of their published species.

So far as I am aware, Hexarthrum is the only member of the Cossonida (outside the very anomalous subfamily Onycholipides) in which the funiculus is composed of only six articulations; and it is further remarkable for its rostrum being short and narrowly subtriangular, for its antennæ bring greatly abbreviated (even more so perhaps than in Stereocorynes), for its elytra being shortly cylindric, obtusely rounded behind, and subasperated (particularly as regards their posterior half), and for its four anterior coxæ being subcontiguous. As in Stereocorynes and Tomolips, its antennæ are not only much reduced in length (especially the scape), but are likewise glabrous, and with the funiculus-joints very closely compacted together; nevertheless the club is more rounded, or less apicallytruncate, than in those genera. Its prothorax also (which is unconstricted in front) is nearly unmargined at the base; its first and second abdominal segments are divided by an unusually distinct line; and its entire surface, although appearing quite bald, will be seen, when viewed beneath the microscope, to be very sparingly besprinkled (which is not the case in Stereocorynes and Tomolips) with a short and most minute pubescence.

I may state that a Hexarthrum has been detected lately by Mr. G. Lewis in Japan, closely allied to (but nevertheless unquestionably differing from) the European and Madeiran $H$. culinare; and also that the European Rhyncolus submuricatus, Bohm., appears, if I may trust an example now before me from the collection of John 
Gray, Esq., and which almost completely satisfies the published diagnosis of that insect, to be likewise a Hexarthrum.

117. Tomolips (nov. gen.).-With the exception of Pentamimus from Australia, the present genus offers the only exception (as far as I have hitherto observed), outside the subfamily Pentarthrides, in which the funiculus is composed of but five joints ; nevertheless it is so manifestly related to Hexarthrum (in which that organ is 6-articulate), and likewise to the sub-Hylastideous groups around $\mathrm{Bra}$ chytemnus, that it is as impossible to consider it a Pentarthrid as it would be to place Hexarthrum (on account of the number of its funiculus joints) amongst the anomalous types of the Onycholipides. And hence, so long as a natural arrangement (and not a purely artificial one) is to be aimed at, I have practically no choice left me but to treat it as an exception in the subfamily Cossonides. It is a significant fact however that its nearest known ally should be a genus in which the funiculus-articulations are likewise reduced in number,-in that instance however (from the normal seven) to six; and it would look therefore as if these immediate forms were subject par excellence (in that particular respect) to instability. Be this however as it may, I will merely repeat that the two genera in question (namely Hexarthrum and Tomolips) are, with the exception of Pentamimus and Tatracoptus, the only instances, so far as I am aware, in the present subfamily, in which the funiculus is otherwise than 7-jointed,-it being composed of six articulations in the one, and of five in the other.

But, apart from this primary peculiarity in the structure of its funiculus, Tomolips is somewhat osculant between Hexarthrum and the strictly sub-Hylastideous genera-in which the rostrum is extremely short and broad, the eyes are less widely separated, and the sculpture is remarkably coarse ; whilst in the obtriangular shape of its solid and compressed club it shews an equal affinity with the European Stereocorynes. However its posteriorly-asperated elytra is a character of considerable importance, and one which is likewise indicated (though to a less extent) in Hexarthrum. In its glabrous antennæ (the scape of which is much abbreviated, and the funiculus very compact), as well as in its four anterior coxæ being nearly contiguous, it is in perfect accordance with these imme- 
diate forms ; but in its elytra being more produced (or less obtusely-rounded) behind, in its shoulders being rather suddenly and acutely porrected, and in the front tibia of its type being armed at their inner angle with a compressed bifid spur, there is a singularity about it which is essentially its own. The two species of Tomolips which are now before me were taken in Mexico, and are from the collection of Mr. Fry.

118. Dendroctonomorphus (nov. gen.). - - It is for a Hylastes-, or Dendroctonus-like Cossonid from Ceylon, which (together with an allied species from Malabar, and a rather less typical one from Mexico) has been communicated by Mr. Fry, that I have been compelled to establish the present genus. In its structural peculiarities it is somewhat intermediate between Brachytemnus and Stenoscelis,-agreeing with the former in its conspicuous (though less largely developed) scutellum, comparatively elongate, almost unconstricted prothorax, the general character of its sculpture (which however is not quite so coarse), and in its perfectly simple third tarsal joint; but with the latter in its asperated elytra, greatly lengthened feet, more widely separated eyes, and less glabrous antennæ. In its thickened head, short, triangular rostrum, sunken eyes, and cylindrical body, it is in accordance with the whole of these sub-Hylastideous forms.

119. Brachytemnus (nov. gen.). - It is in order to receive the European Rhyncolus porcatus, Müll., and my nearly-allied $\boldsymbol{R}$. pinipotens from the Canarian archipelago, * that I have proposed the present genus; and it seems marvellous to me now how those curious insects could ever have been included amongst the Rhyncoli-from which they appear to differ in nearly every detail of their

* My B.pinipotens (= crassirostris, olim), which I captured in an old fir-tree in the island of Grand Canary, is most closely allied to the B. porcatus, Müll., of Southern Europe. Its rostrum and prothorax however (the former of which is free from an anterior channel, whilst the latter is less sinuated on either side behind the middle) are just appreciably less coarsely and more sparingly punctured; its elytra (which have the shoulders less porrect) are a trifle more parallel, there being apparently no tendency to be even obsoletely widened posteriorly, and have their apical region less obtusely-desilient (or suddenly bent-downwards); and the club of its antennæ is rather more truncated in front. The underside also is somewhat less grossly punctured, and the first abdominal segment, which is convexer, is likewise a little more remotely so. 
structure. Indeed in its thickened head, abbreviated, subtriangular rostrum, and depressed eyes, no less than in its greatly shortened antennæ and its long and slender feet, the genus has very much the sub-Hylastideous aspect of Stenoscelis: and it may be defined therefore to differ essentially from Rhyncolus in its much shorter and more triangular rostrum; in its larger and more sunken eyes, which are appreciably less lateral (or more sub-approximated above); in its prothorax being altogether more cylindrical and developed; in its very much more abbreviated antennæ (the scape of which is so reduced in length as to be even shorter than that of Stenoscelis,-indeed as short as in the European genera Stereocorynes and Hexarthrum, or as in Calyciforus and Eurycorynes from Brazil), the club of which, although compressed, is exceedingly rounded, solid, and abrupt; in its first and second abdominal segments being much more conspicuously divided from each other; in its legs and tarsi being slenderer (with the tibial hook more straightened, and the basal joint of the latter rather more elongate); and in its coxæ being more approximated, - the four hinder ones, in fact, being nearly contiguous. In its scutellum however being conspicuous, Brachytemnus recedes from Stenoscelis, and agrees better with the other immediately-allied forms.

120. Calyciforus (nov.gen.).-The very extraordinary insects, which have been communicated by Mr. Fry and Mr. Janson, for which the present genus is established, and which were captured in the provinces of Rio Janeiro and Bahia in Brazil, are amongst the most remarkable members of the Cossonide with which I am acquainted; and yet their affinities are, unquestionably, with such forms as the European Brachytemnus, Eurycorynes from Brazil, and Stenoscelis-from St. Helena, Southern Africa, and Japan. Indeed in its thickened head, short, subtriangular rostrum, and sunken, subapproximated eyes, as well as in its excessively abbreviated antennæ, its slender, filiform feet, and the fact of its four anterior coxæ being nearly contiguous, the genus has much marvellously in common with the first of those groups; nevertheless the comparatively large size of its members, and the deep and anomalous triangular excavation in the middle of their prothorax behind (immediately in front of the greatly developed scutellum), added to the extraordinary sculpture of their elytra (the sulci of which are wide, deep, opake, and 
transversely strigose, whilst the interstices are broad, costate, and shining, and studded with a single series of large subasperated punctures), and their short, transverse, abrupt, anteriorly-truncated, cup- (or somewhat calyx-) shaped capitulum, are all of them characters which are essentially their own. In its prothorax being comparatively unconstricted in front Calyciforus is, likewise, on the Brachytemnus-type; nevertheless it is impressed anteriorly in the centre (which is not the case in that genus); and both the prothorax and elytra are coarsely margined at their respective bases. Its four anterior tibiæ are armed at their inner angle with a robust spine; and the hooks of all of them are powerfully developed. Its feet are as slender as, and if anything even more elongated than, in Stenoscelis ; but their third joint is still narrower and more entire, being perfectly simple.

121. Eurycorynes (nov. gen.).- I am indebted to Mr. Janson and Mr. Fry for the remarkable Cossonid from which the details for the present genus have been drawn-out; and it has given me much pleasure in dedicating the species to the former of these eminent Coleopterists. Like Calyciforus it is South-American, having been received by Mr. Janson from the province of Minas Geraes in Brazil ; while Mr. Fry's example appears to have been taken by himself near Rio Janeiro; and it is at once conspicuous for the very unusual structure of. its greatly abbreviated antennæ,- the scape of which has the joints gradually more and more transverse and lamelliform, the last one of them being so thin as to be only just appreciable against the enormously enlarged club. This latter is most peculiar,--being exceedingly wide, transverse, and abrupt (more so indeed than in any member of the family with which I am acquainted). In its thickened head, and in the shortness of its triangular rostrum and antennæ, as well as in its sunken eyes and elongated slender feet, Eurycorynes has much in common with Brachytemnus, Calyciforus, and Stenoscelis; but it agrees best with the last of those three genera in the fact of its scutellum being nearly obsolete, and in its elytra being asperated (though less so, and in a different manner) both before and behind. Nevertheless, in reality, it is perhaps nearer to Calyciforus, - with which it agrees in its eyes being less widely separated on the forehead, in its prothorax being less shortened, in its elytra being broadly sulcated (though not quite 
so coarsely so as in that group), with their costate interstices branded with a row of conspicuous subasperated punctures, in its four anterior coxæ (although very closely approximated) not being quite contiguous, and in the third articulation of its feet not being in the slightest degree widened, and remarkably simple. The punctation of its head and prothorax is extremely dense and substrigulose; and the latter has a polished line, or faint keel, evanescent before and behind, down the centre.

122. Stenoscelis (Wollaston, Journ. of Ent. i. 141. 1861).- - Of all the Cossonids which have hitherto been described, perhaps Stenoscelis makes the nearest approach to the sub-Curculionideous forms of the Hylastida,-its shortly cylindric body, which is a little asperated (as well as just appreciably widened, and obtusely rounded) posteriorly, having much in common with such genera as Dendroctonus. In its thickened head, short, triangular rostrum, and sunken eyes, as well as in its exceedingly abbreviated antennæ and its elongated slender feet, it is on much the same pattern as the three preceding groups; nevertheless its prothorax is shorter, or more transverse, more constricted anteriorly, and subsinuate on either side in the middle, its four anterior coxæ are more completely approximated, and the third joint of its feet (although scarcely at all widened) is not quite simple,-being evidently, though minutely, bilobed. In the fact of its scutellum being nearly obsolete it has a greater affinity with Eurycorynes than with Calciforus or Brachytemnus; but its capitulum (which is oval, and on the ordinary type) is not in any degree anomalously developed, and agrees better therefore with the last of those three genera. The three exponents of it which have been hitherto detected are from the island of St. Helena, the Cape of Good Hope, and the Japanese archipelago.

\section{Species nove, in hôc Tractatu nunc Descripte.}

Genus 1 . Notiominetes.

Wollaston (vide, ante, p. 440).

Notiomimetes Pascoei, n. sp.

N. elliptico-fusiformis, depressiusculus, subnitidus, calvus, rufo-piceus; capite immerso, rostro parallelo, fere 
haud sculpturato; prothorace elongato-subquadrato, elytris paulo angustiore, ad latera leviter rotundato, longe pone apicem profunde constricto, parum grosse sed haud densissime punctato ; elytris ellipticis basi truncatis, dense substriato-punctatis; antennis pedibusque clare rufo-ferrugineis. Subtus grosse sed vix dense punctatus.

Long. corp. lin. vix 1.

Habitat Australiam meridionalem, a Dom. Masters juxta mare captus. Insectum inter Cossonidas anomalum, atque in memoriam Dom. F. P. Pascoe citatum.

\section{Genus 2. Psilodryophthorus.}

Wollaston (vide, ante, $p .441$ ).

Psilodryophthorus costatus, $\mathrm{n}$. sp.

P. fusiformi-ellipticus, niger, subnitidus, fere calvus; capite rostroque (parallelo, crasso, cylindrico) sat dense punctatis; prothorace (magno, cylindrico-subquadrato, fere æquali) multo profundius grossiusque punctato; elytris (ellipticis, basi late arcuatim emarginato-truncatis) profunde punctato-sulcatis, interstitiis alte et argute costatis, postice simplicibus (nec cariniformibus); antennis tarsisque piceo-ferrugineis. Subtus grosse et profunde punctatus.

Long. corp. lin. 2.

Habitat ins. New Guinea, ad Saylee a Dom. Wallace deprehensus.

\section{Genus 3. Stenommatus.}

Wollaston (vide, ante, $p$. 441).

Stenommatus Fryi, n. sp.

S. ellipticus, niger sed densissime subsericato-velutinus; rostro elongato, gracili, arcuato, antice polito esculpturato piceo, postice longitudinaliter strigoso ; fronte canaliculatâ; prothorace (elytris paulo angustiore) profunde et grosse punctato; elytris profunde punctato-sulcatis, interstitiis convexis, costiformibus; antennis tarsisque piceis, nudis, femoribus tibiisque subcinereo-velutinis. Subtus parum grosse (sed haud profunde et haud dense) punctatus.

Long. corp. lin. $1 \frac{1}{3}$.

Habitat Mexico, a Dom. A. Fry benigne communicatus, cujus in honorem nomen triviale proposui. 
Genus 6. Synommatus.

Wollaston (vide, ante, p. 443).

Synommatus confluens, n. sp.

S. ellipticus, opacus, niger sed inæqualiter subfulvescenti sericato-lutosus; rostro elongato, arcuato-cylindrico, vestito, ad apicem ipsissimum calve nitido piceo, inter antennas canaliculato; prothorace (elytris multo angustiore) subovali-cylindrico, postice subangustiore, antice leviter constricto, profunde et grossissime punctato; elytris antice latis et valde truncatis, postice attenuatis, profunde punctato-sulcatis (sulcis latissimis et punctis maximis), suturâ interstitiisque (præsertim alternis) convexis, costiformibus; antennis pedibusque piceis, opacis, nudis, capitulo nitido, clariore, et ad apicem internum (una cum femoribus tibiisque) dense vestito. Subtus subopacus, grossissime sed parce et haud valde profunde punctatus.

Long. corp. lin. $2 \frac{1}{2}$.

Habitat Borneo, ad Sarawak a Dom. Wallace repertus. Coll. Pascoe.

\section{Genus 9. Lyprodes. \\ Wollaston (vide, ante, $p .444$ ). \\ Lyprodes cylindricus, n. sp.}

L. angustus, cylindricus, piceo-niger, opacus, squamis subcinereis lutosis obtectus; rostro elongato, parallelo, oculis prominentibus; prothorace (elytrorum latitudine) valde profunde et grosse punctato, antice asperato; elytris profunde et grosse sulcato-punctatis, interstitiis paulo elevatis; antennis (subgracilibus) tarsisque (brevibus, latis) ferrugineis. Subtus parum grosse, sed parcissime et levissime subasperato-punctatus, necnon (oculo fortissime armato) setulis brevissimis cinereis remotis obsitus.

Long. corp. lin. vix $1 \frac{1}{4}$.

Habitat ins. Malayenses, in Sula a Dom. Wallace deprehensus.

\section{Genus 10. Phleophagomorphus.}

Wollaston (vide, ante, $p .445$ ).

Phloophagomorphus angusticollis, $\mathrm{n}$. sp.

P. elongate cylindrico-ovatus, convexiusculus, nitidissimus, subpellucide castaneus; rostro (brevi, lato, ad basin strangulato) capiteque (convexo) nigrescentioribus, illo sat 
distincte sed hôc parcius levissimeque punctulatis; prothorace (sub-parvo, elytris angustiore, cylindrico-ovato) multo profundius punctulato; scutello transversim impresso; elytris (elongate cylindrico-ovatis, basi sinuatim truncatis) profunde punctato-, aut subcrenato-striatis, interstitiis convexiusculis ac minutissime uniseriatim punctulatis; antennis, tibiis tarsisque piceo-ferrugineis, femoribus sensim obscurioribus. Subtus sat grosse, sed remote et leviter, punctatus.

Long. corp. lin. $1 \frac{2}{3}$.

Habitat Novam Granadam, a Dom. Fry communicatus.

\section{Genus 11. Pseudopentarthrum.}

Wollaston (vide, ante, p. 445).

Pseudopentarthrum phloophagoides, n. sp.

P. breviter cylindricum, subnitidum, calvum, nigrum; rostro (brevi, lato parallelo) minute punctulato; prothorace ovali, ad latera æequaliter rotundato, subconvexo, multo grossius profundiusque sed vix densissime punctato; elytris parallelis, cylindricis, profunde striato-punctatis, interstitiis convexiusculis ac minutissime (vix perspicue) uniseriatim punctulatis; antennis pedibusque breviusculis et (præsertim illis) rufescentioribus. Subtus in sternis remote sed grcsse punctatum; abdominis segm. ${ }^{\text {tis }} 1^{\mathrm{mo}}$ et $2^{\text {do }}$ fere impunctatis.

Long. corp. lin. $1 \frac{1}{4}$.

Habitat Mexico; in coll. Dom. Fry.

\section{Genus 12. Xenosomatium.}

Wollaston (vide, ante, $p .446$ ).

Xenosomatium tibiale, n. sp.

X. angustulum, parallelum, convexiusculum, nitidum, piceo-ferrugineum ; capite rostroque (arcuato, robusto, ad basin strangulatim contracto) parce, levissime et minute punctulatis; oculis maximis, prominentibus, prothorace elongato, triangulari-cylindrico (ante basin latitudine elytrorum), paulo distinctius tamen minute parceque punctulato, pone apicem leviter constricto; elytris tenuiter punctato-striatis, ad basin sensim rufescentioribus; antennis pedibusque fere concoloribus, scapo (robusto, valde excurvato) sub-clariore. Subtus alutaceum, minute et parce punctulatum.

Long. corp. lin. 1.

Habitat ins. Malayenses, a Dom. Wallace captum. Coll. Pascoe. 


\section{Genus 13. Pentarthrum.}

\section{Wollaston, Ann. Nat. Hist. xiv. 129 (1854).}

§ I. Funiculi art. ${ }^{u s} 2^{\text {dus }}$ sequentibus sensim longior.

\section{Pentarthrum zealandicum, n. sp.}

P. subfusiformi-cylindricum, subnitidum, piceum elytris plus minus pallidioribus; prothorace triangulari-ovato, convexo, dense sed haud grosse punctato, mox pone apicem sat profunde constricto; elytris vel piceo-ferrugineis vel clare rufo-piceis, sed per suturam et in limbo plus minus nebuloso-obscurioribus, striato-punctatis, interstitiis transversim rugulosis ac minutissime uniseriatim punctulatis; antennis pedibusque longiusculis, clare et pallide rufopiceis ; tarsorum art. ${ }^{\circ} 3^{\text {tio }}$ fere simplici. Subtus minute et leviter punctulatum.

Mas, rostro latiore, parallelo, depressiusculo, sat profunde punctato, necnon in medio canaliculato; antennis in medio ejus insertis.

Fœm., rostro graciliore, cylindrico, fere esculpturato, integro, ad basin paululum strangulato; antennis pone medium ejus insertis.

Long. corp. lin. 2.

Habitat Novam Zealandiam, a Dom. Janson communicatum.

(Obs.-Species P. Huttoni, europæo, simillimum; sed differt corpore paululum majore latiore ac minus fusiformi, prothorace sensim angustiore, pone medium magis rotundato, et minus grosse punctato, ely tris sublevius sculpturatis ac pallidioribus, sed tamen per suturam necnon in limbo plus minus obscuratis, scapo sublongiore graciliore, rostro masculo canaliculato, et fœemineo ad basin paulo evidentius strangulato.)

\section{Pentarthrum nitidum, n. sp.}

P. fusiformi-cylindricum, nitidum, nigro-piceum ; prothorace triangulari-ovali, convexo, subremote sed grosse punctato, mox pone apicem sat profunde constricto ; elytris subfusiformibus basi truncatis, striato-punctatis, interstitiis transversim rugulosis ac minutissime uniseriatim punctulatis, obsoletissime subæneo-tinctis; antennis pedibusque piceis ; tarsorum art. ${ }^{\circ} 3^{\text {tio }}$ simplici. Subtus dense et argute punctatum. 
Mas, rostro latiusculo, parallelo, sat dense minuteque punctulato; antennis in medio ejus insertis.

Fom. adhuc latet.

Long. corp. lin. $1 \frac{3}{4}$.

Habitat Chili, a Dom. Fry benigne communicatum.

(Obs.-Corpore subfusiformi P. Huttono simillimum; sed paulo minus, nitidius, ac nigro-piceum, nec rufocastaneum, prothorace convexiore et minus dense punctato, elytris minus rugulosis, capitulo minus abrupto, pedibusque subbrevioribus, tarsorum art. ${ }^{\circ} 3^{\text {tio }}$ simplici, nec sub-bilobo.)

\section{Pentarthrum affine, n. sp.}

P. præcedenti simillimum, sed vix subminus, prothorace paululum minus convexo minusque ad latera rotundato (sc. magis triangulari), sensim densius punctato, elytris subpicescentioribus, striis profundioribus subdensiusque punctatis, interstitiis subconvexioribus ac magis rugulosis.

Long. corp. lin. vix $1 \frac{3}{4}$.

Habitat Chili, a Dom. Fry communicatum.

\section{Pentarthrum longirostre, $\mathrm{n} . \mathrm{sp}$.}

P. fusiformi-cylindricum, nitidum, nigro-piceum ; rostro elongato, subparallelo (postice, præsertim in $\delta$, paululum angustiore), arcuato, minutissime leviter et sat dense punctulato, a fronte (fere impunctatâ) lineâ distincte diviso; oculis prominentibus; prothorace triangulari-ovali, convexo, subgrosse punctato, mox pone apicem profunde constricto; elytris subfusiformibus basi truncatis, subdilutioribus, punctato-striatis, interstitiis leviter transversim rugulosis ac minutissime uniseriatim punctulatis; antennis pedibusque longiusculis, rufo-piceis ; tarsorum art. ${ }^{\circ} 3^{\text {tio }}$ lato et valde profunde bilobo. Subtus grosse et sat profunde punctatum.

Long. corp. lin. $1 \frac{2}{3}-2$.

Habitat Novam Zealandiam; ab Auckland misit Dom. Lawson. Ad describendum communicavit Dom. Sharp.

(Obs.-Inter Pentarthra insigne rostro elongato, subgracili, postice, præsertim in $\delta$, sensim angustiore, a fronte lineâ conspicue diviso, necnon tarsorum art. ${ }^{0} 3^{\text {tio }}$ lato ac profunde bilobo.) 
§ II. Funiculi art. ${ }^{u s} 2^{\text {dus }}$ haud sequentibus longior.

Pentarthrum subsericatum, n. sp.

P. subcylindricum, subopacum, pallide rufo-ferrugineum, ac minutissime parcissimeque sericatum; prothorace ovatotriangulari, densissime sed vix grosse punctato, mox pone apicem profunde constricto; elytris dense et parum grosse striato-punctatis, interstitiis obsolete transversim rugulosis; antennis pedibusque breviusculis; tarsorum art. $^{\circ} 3^{\text {tio }}$ simplici. Subtus minute et leviter punctulatum.

Mas, rostro latiore, parallelo, depressiusculo, sat profunde denseque ruguloso-punctato; antennis in medio ejus insertis.

Fæm., rostro graciliore, cylindrico, multo minutius punctulato, ad basin paululum strangulato; antennis mox pone medium ejus insertis.

Long. corp. lin. vix $1 \frac{1}{2}$.

Habitat Novam Zealandiam, a Dom. Janson communicatum.

(Obs.-Species in hoc genere anomala corpore fere opaco et minutissime parceque sericato, nec omnino calvo).

\section{Pentarthrum rugosum, n. sp.}

P. cylindricum, dense, grosse, et rugose sculpturatum, subopacum, piceum; rostro breviusculo, crasso, parallelo, oculis prominentibus, densissime et grossissime punctatoruguloso; prothorace subtriangulari-ovato, densissime et grosse punctato, mox pone apicem profunde constricto; elytris dense striato-punctatis (punctis magnis), interstitiis densissime transversim rugulosis; antennis pedibusque breviusculis, crassiusculis, paulo clarioribus ; tarsorum art. $^{\circ} 3^{\text {tio }}$ evidenter sed minute bilobo. Subtus profunde et parum dense punctatum.

Long. corp. lin. $1 \frac{1}{3}$.

Habitat ins. New Guinea, ad Saylee a Dom. Wallace deprehensum.

\section{Pentarthrum sublavigatum, n. sp.}

P. angustum, fusiformi-cylindricum, leviter sculpturatum, subnitidum, clare pallido-castaneum ; rostro longiusculo, crassiusculo, subparallelo sed pone antennas paulo angustiore (aut substrangulato), oculis magnis, 
prominentibus, minute et leviter punctulato; prothorace triangulari-ovato, minute et leviter punctulato, mox pone apicem paululum constricto; elytris tenuiter leviterque substriato-punctatis (punctis parvis) ; antennis pedibusque breviusculis, illis paulo minus incrassatis ; tarsorum art. ${ }^{\circ}$ $3^{\text {tio }}$ simplici.

Long. corp. lin. $1 \frac{1}{4}$.

Habitat ins. Malayenses, a Dom. Wallace in Sula captum. Coll. Pascoe.

\section{Pentarthrum Grayii, n. sp.}

P. angustulum, cylindricum, subnitidum, piceum elytris paulo rufescentioribus; rostro crassiusculo, parallelo, oculis valde prominentibus, dense et profunde punctato ; prothorace elongato, subconico, grosse punctato (punctis versus latera longitudinaliter subconfluentibus), mox pone apicem profunde constricto; elytris striato-punctatis, interstitiis transversim rugulosis ac minutissime parcissimeque (juxta suturam dense) uniseriatim punctulatis ; antennis pedibusque crassiusculis, paulo clarioribus ; tarsorum art. ${ }^{\circ} 3^{\text {tio }}$ simplici, ult. ${ }^{\mathrm{mo}}$ gracili.

Long. corp. lin. $1 \frac{2}{3}$.

Habitat Braziliam, a Dom. J. Gray benigne donatum, cujus in honorem nomen triviale stabilivi.

(Obs.-Species corpore cylindrico, prothorace elongato subconico, tarsorumque art. $^{\circ} 3^{\text {tio }}$ simplici et ult. ${ }^{\text {mo }}$ gracili $P$. cylindrico, mihi, affinis; sed differt corpore paulo majore et obscuriore, rostro subbreviore, conspicue latiore atque densius grossiusque punctato, prothorace antice subprofundius constricto, punctis versus latera magis evidenter longitudinaliter subconfluentibus, necnon antennis pedibusque sensim crassioribus.)

\section{Pentarthrum nigrum, n. sp.}

P. elongatum, crassum, fusiformi-cylindricum, convexum, nitidum, nigrum ; rostro longiusculo, crassiusculo, parallelo, oculis valde prominentibus, parce sed profunde punctato; prothorace elongato, subconico, grossissime et profunde sed haud dense punctato, antice subintegro (vix constricto) ; elytris subfusiformi-parallelis basi undulatim truncatis, convexis, grosse punctato-sulcatis, interstitiis convexis ac minutissime parcissimeque uniseriatim punctulatis; antennis pedibusque crassiusculis, illis rufo- 
piceis, his piceis; tarsorum art. ${ }^{\circ} 3^{\text {tio }}$ simplici. Subtus profunde, parce, et grosse punctatum.

Long. corp. lin. 2.

Habitat in Tasmaniâ; communicavit Dom. Pascoe.

(Obs.-Inter Pentarthra distinctum corpore magno, tamen angustulo, convexo, nigro, et grosse sculpturato, prothorace antice vix constricto, elytrisque ad basin undulatim truncatis, interstitiis convexis subcostiformibus.)

\section{Genus 14. Sericotrogus.}

Wollaston (vide, ante, p. 446).

\section{Sericotrogus subanescens, n. sp.}

S. angustus, elongate subparallelo-fusiformis, subæneopiceus, nitidiusculus, pubeque grossâ demissâ subæneocinereâ parce vestitus; capite prothoraceque profunde punctatis, illo valde exserto (rostro longiusculo, arcuato, dense ruguloso-punctulato, oculis prominentibus), hôc subovali, convexo, ad latera subæqualiter rotundato, antice fere integro, necnon in lineâ_mediâ sublæviore; elytris longe fusiformibus basi truncatis (sc. antice sensim angustioribus), leviter punctato-striatis; antennis pedibusque rufo-piceis (illis tarsisque clarioribus), capitulo ferrugineo. Subtus subalutaceus, parcissime et minutius pubescens, antice vix punctatus, sed in meso- et meta-sternis abdominisque segm. ${ }^{\text {tls }} 1^{\mathrm{mo}}$ et $2^{\mathrm{do}}$ valde profunde grosseque punctatus.

Long. corp. lin. $1 \frac{1}{3}-1 \frac{1}{2}$.

Habitat Nov. Zealandiam, ab Auckland missus ; a D. Sharp amice donatus, necnon in coll. Dom. Lawson.

\section{Genus 15. Stenotrupis.}

\section{Wollaston (vide, ante, $p .447$ ).}

Stenotrupis crassifrons, n. sp.

S. angustissimus, parallelus, depressus, subnitidus, piceus; capite prothoraceque dense et argute punctulatis, illo elongato-ovali crasso valde exserto, hôc ovato-triangulari antice gradatim valde angustato et pone apicem vix constricto; elytris parallelis, ad apicem minute pubescentibus, tenuiter punctulato- (aut fere crenulato-) striatis, interstitiis transversim subreticulato-rugatis; antennis piceoferrugineis; pedibus rufo-piceis. 
Mas, rostro breviore, crassiore, apicem versus sensim magis dilatato.

Long. corp. lin. vix $1 \frac{3}{4}$.

Habitat ins. Malayenses, in Makian a Dom. Wallace deprehensus.

Stenotrupis acicula, n. sp.

S. præcedenti similis sed multo minor, etiam angustior, ac omnino pallidus (oculis solis nigris); capite prothoraceque parcius et profundius punctatis, elytris densius et distinctius striato-punctatis, pedibusque brevioribus.

Long corp. lin. 1.

"Catolethrus palmeus, Schön." (in litt.), sec. coll. Pascoeano.

Habitat ins. Cuba, a Dom. Pascoe communicatus.

Genus 16. Microcossonus.

Wollaston (vide, ante, p. 447).

Microcossonus Wallacei, n. sp.

M. angustus, parallelus, depressus, nitidus, pallide rufoferrugineus; rostro brevi, crasso, antice paulatim dilatato, vix punctulato; capite elongato, crasso, exserto, obscuriore, et distinctius sed parce punctulato; prothorace magno, ovato-triangulari, multo argutius punctato; elytris parallelis, leviter substriato-punctatis, suturâ vix obscuriore. Subtus parce et levissime punctatus.

Long. corp. lin. vix 1.

Habitat Nov. Guinea; ad Saylee captus a Dom. Wallace, cujus in honorem nomen triviale dedi.

\section{Genus 17. Cossonideus. \\ Wollaston (vide, ante, p. 448). \\ Cossonideus Pascoei, n. sp.}

C. fusiformi-parallelus, depressus, subnitidus, piceoferrugineus; capite profunde punctato, punctis in rostro (breviusculo, crasso, parallelo) obsoletioribus ; oculis maximis, valde prominentibus; prothorace triangulari-ovato, subalutaceo necnon grosse profundeque punctato, in medio late longitudinaliter impresso; elytris clarioribus, rufotestaceis sed in limbo (præsertim postice) necnon minus evidenter per suturam obscurioribus, grosse et profunde

TRANS. ENT. SOC. 1873.-PART IV. (OCT. ) U U 
sulcato-punctatis; antennis pedibusque (elongatis, robustis) piceis. Subtus valde profunde, sed vix dense, punctatus.

Long. corp. lin. vix $2 \frac{1}{2}$.

Habitat Australiam occidentalem, a DD. Pascoe et Fry communicatus.

\section{Genus 19. Tүсніоsoma.}

Wollaston (vide, ante, $p .449$ ).

\section{Tychiosoma gracilirostre, n. sp.}

T. elliptico-oblongum, latiusculum, depressum, nitidum, pallide rufo-castaneum; capite parvo, inter oculos parce punctafo et ibidem minute foveolato; rostro longissimo, gracillimo, parallelo, cylindrico, impunctato, et, una cum prothorace (parvo, subtriangulari), politissimo, hôc parce et minutissime punctulato, æquali; elytris suboblongis basi truncatis, grosse punctato- (aut fere crenato-) sulcatis, interstitiis postice et versus latera convexis, postice gradatim suffuse obscurioribus; antennis pedibusque elongatis, illis gracilibus, his crassis. Subtus testaceo-castaneum, nitidissimum, fere impunctatum, prosterno inter coxas anticas fulvo-pubescenti.

Long. corp. lin. 3.

Habitat ins. Philippine, a Dom. Pascoe communicatum.

\section{Genus 20. Leptominus. \\ Wollaston (vide, ante, p. 449). \\ Leptomimus fragilis, n. sp.}

L. angustissimus, subdepressus, opacus, rufo-brunneus ; capite parvo, rostro prothoraceque longissimis, densissime et rugose punctatis, illo gracillimo, hôc subovato-triangulari; elytris (prothorace vix angustioribus) parallelis, densissime et rugose striato-punctatis; antennis elongatis, gracilibus; pedibus posterioribus brevibus. Subtus densissime et profunde ruguloso-punctatus.

Long. corp. lin. vix 2.

Habitat ins. Malayenses, in Gilolo a Dom. Wallace repertus.

\section{Leptomimus delicatulus, n. sp.}

L. præcedenti similis, sed subminor et etiam angustior, paululum magis cylindricus minusque depressus; rostro etiam graciliore et minus rugose sculpturato; prothorace pone medium sensim minus rotundato-ampliato; antennis 
paulo brevioribus; necnon corpore toto dense sed breviter setuloso-pubescente.

Long. corp. lin. $1 \frac{2}{3}$.

Habitat ins. Malayenses, inter bambusas a Dom. Wallace in Gilolo deprehensus.

\section{Genus 24. Microtribus.}

Wollaston (vide, ante, p. 451).

Microtribus Huttoni, n. sp.

M. fusiformis, subnitidus, calvus (solum versus basin elytrorum, et ipsissimam prothoracis, pilis perpaucis fulvescentibus parce obsitus,) nigro-piceus ; capite convexo, fere haud punctulato ; rostro (longiusculo, graciliusculo, parallelo) distinctius sed parce punctulato; prothorace (ovali, convexo, utrinque æqualiter rotundato) sat grosse et profunde punctato ; elytris (fusiformibus basi truncatis) subalutaceis, paulo subtransversim malleato-rugulosis et obsolete remoteque subundulatim subpunctulato-lineatis; antennis pedibusque longiusculis, picescentioribus. Subtus alutaceus et parcissime punctatus (punctis in sternis maximis ac profundis, sed in abdomine gradatim multo levioribus ac minutioribus).

Long. corp. lin. $1 \frac{2}{3}$.

Habitat in Novâ Zealandiâ, a Dom. F. W. Hutton deprehensus, cujus in honorem nomen triviale proposui.

\section{Genus 2.5. Mesoxenomorphus.}

Wollaston (vide, ante, p. 451).

Mesoxenomorphus africanus, n. sp.

M. angustulus, fusiformis, nitidus, calvus, piceus ; rostro breviusculo, latiusculo, subparallelo, dense et minute punctulato, oculis minutissimis, prominentibus ; prothorace elongato, triangulari-ovato, convexiusculo, paulo distinctius parciusque punctato ; elytris cylindrico-fusiformibus, leviter substriato-punctatis, interstitiis depressis et minutissime uniseriatim punctulatis ; antennis pedibusque brevibus, crassiusculis, rufo-piceis. Subtus sat profunde et grosse (sed in abdominis segm. ${ }^{\text {tis }} 1^{\mathrm{mo}}$ et $2^{\mathrm{do}}$ parcius ac leviter) punctatus.

Long. corp. lin. $1 \frac{1}{2}$.

Habitat Africam australem (sc. Caffrariam), a Dom. E. W. Janson communicatus. 
Genus 26. Heteropsis.

Wollaston (vide, ante, p. 452).

Heteropsis Lawsoni, n. sp.

H. angustus, parallelus, depressiusculo-cylindricus, nitidus, piceo-castaneus ; rostro a capite (fere impunctato) lineâ distincte diviso, brevi et (præsertim in $\widehat{\jmath}$ ) latissimo, postice paulo angustiore, depressiusculo, subarcuato, dense et minute punctulato ; prothorace elongato, ovato-triangulari, antice leviter constricto, paululum profundius punctulato; elytris parallelis, leviter punctato-striatis, interstiliis minutissime et parce uniseriatim punctulatis; antennis pedibusque paulo clarioribus. Subtus paulo grossius sed vix profunde punctatus.

Long. corp. lin. $1-1 \frac{1}{4}$.

Habitat Novam Zealandiam ; ab Auckland misit Dom. Lawson, cujus in honorem nomen specificum dedi.

Genus 30. Halorhynchus.

Wollaston (vide, ante, p. 453).

\section{Halorhynchus cacus, $\mathrm{n}$. sp.}

H. ovato-fusiformis, nitidus, clare rufo-piceus, pilisque longissimis cinereis parce obsițus, rostro breviusculo, crasso, parallelo, parce punctato, versus apicem obscuriore; prothorace (elytris sensim angustiore) ovali, profunde et parce punctato; elytris subovalibus basi truncatis, inæqualibus (sc. remote longitudinaliter subcostatis,-costis regulariter interruptis, tuberculos elongatos postice acutiusculos efficientibus); pedibus vix obscurioribus. Subtus nitidissimus et fere haud punctatus, sed longe et parce pilosus.

Long. corp. lin. $1 \frac{1}{3}$.

Habitat Australiam occidentalem, ad Freemantle captus; a Dom. Pascoe benigne communicatus.

\section{Genus 44. Thaumastophasis. \\ Wollaston (vide, ante, p. 460).}

Thaumastophasis oculatus, n. sp.

T. breviter oblongus, crassus, convexiusculus, nitidiusculus, grosse sed parce pallidulo-sericatus; capite prothoraceque rufo-piceis, sed elytris clare rufo-testaceis; rostro (breviusculo, crassiusculo, parallelo) rugulose et confuse subpunctato; oculis maximis, sat prominentibus; capite prothoraceque dense et profunde punctatis, hôc 
(parvo, elytris multo angustiore) submalleato-inæquali sed tamen antice vix constricto; elytris (breviter cylindricis, basi undulatim truncatis) grosse substriato-punctatis, interstitiis minutissime parceque sub-uniseriatim punctulatis, in disco antico leviter bi-impresso; antennis pedibusque elongatis, illis gracilibus rufo-testaceis, his crassis rufoferrugineis. Subtus rufo-piceus, grosse sed leviter et parce punctatus, setulisque pallidioribus demissis irroratus.

Long. corp. lin. $1 \frac{2}{3}$.

Habitat Australiam meridionalem, ad Gawler deprehensus. A Dom: Pascoe amice communicatus.

\section{Genus 45. Himatium.}

Wollaston (vide, ante, p. 461).

\section{Himatium pubescens, n. sp.}

H. angustum, cylindricum, depressiusculum, nitidiusculum, rufo-piceum, longe sed parce fulvo-pubescens; capite convexo, esculpturato ; rostro angustulo, parallelo, sat profunde et inæqualiter ruguloso-punctato ; prothorace ovato-triangulari, antice conspicue constricto, valde profunde grosseque punctato; elytris (prothorace paulo latioribus) parallelis, cylindricis, dense, profunde et grosse striato-punctatis, interstitiis angustis depressis et minute uniseriatim punctulatis; antennis pedibusque clare rufoferrugineis, illarum capitulo fere testaceo. Subtus profunde et grosse punctatus.

Long. corp. lin. circa $1 \frac{1}{2}$.

Habitat Indiam australem (Malabar), a Dom. Fry communicatum.

\section{Genus 46. Pholimonotus.}

\section{Wollaston (vide, ante, $p$. 461).}

Pholidonotus squamosus, n. sp.

P. angustulus, subopacus, piceus sed squamis sublutosis setisque crassis suberectis, omnibus subcinereis, plus minus vestitus ; rostro angusto, elongato, subparallelo, recto, densissime punctulato-ruguloso; prothorace ovato-triangulari, subter squamis densissime grosseque punctato; elytris subparallelis, grosse denseque substriato-punctatis (punctis magnis, sed striis obsoletis); antennis tarsisque piceotestaceis; femoribus tibiisque crassis, rufo-piceis setososquamosis. Subtus grosse et densissime punctatus, sed 
setulis brevibus robustis subcinereis demissis parce adspersus.

Long. corp. lin. $1 \frac{1}{3}$.

Habitat Borneo; ad Sarawak collegit Dom. Wallace. Communicavit Dom. Pascoe.

\section{Genus 47. Coptorhamphus. \\ Wollaston (vide, ante, p. 462).}

Coptorhamphus subfasciatuş, n. sp.

C. parallelo-oblongus, subopacus, niger, setis crassis (in parte suberectis) aureo-fulvescentibus parce obsitus necnon in elytris subfasciatim decoratus; rostro (a capite profunde strangulatim diviso) elongato, gracili, parallelo, arcuato, argute longitudinaliter 3-costato, postice fulvo-setoso; capite usque ad oculos (magnos sed demissos ac subinferiores) immerso; prothorace (elytris multo angustiore) subovali basi truncato, antice leviter constricto, grossissime profunde et densissime punctato, et in disco (mox pone medium) foveâ rotundatâ magnâ impresso ; elytris grosse et profunde substriato-punctatis, striis antice obsoletis sed postice profundis, utrinque longe pone basin late impressis, obsolete sub-trifasciatim fulvo-setoso ornatis; antennis longiusculis, rufo-ferrugineis (scapo et capitulo clarioribus); pedibus valde robustis, piceis, squamosis; femoribus subtus longe denticulatis. Subtus grosse et valde profunde punctatus (punctis in regione centrali minoribus).

Long. corp. lin. $2 \frac{1}{4}$.

Habitat ins. Java; benigne communicavit Dom. Pascoe.

\section{Coptorhamphus strangulatus, n. sp.}

C. angustulus, subcylindricus, subopacus, piceo-niger, setulis brevissimis subdemissis cinereis parcissime irroratus; rostro (a capite profunde strangulatim diviso) elongato, gracili, parallelo, arcuato, sat grosse, sed parce leviter et confuse, sublongitudinaliter punctato ac obsoletissime costato; capite usque ad oculos (magnos sed demissos ac subinferiores) immerso, minute leviterque punctulato; prothorace (elytris vix angustiore) suboblongo basi truncato, antice fere integro, grosse punctato, et in disco (mox pone medium) foveâ rotundatâ valde profundâ argute impresso ; elytris grosse sed leviter substriato-punctatis, striis postice profundioribus; antennis rufo-piceis (scapo et capitulo multo clarioribus); pedibus robustis, piceis, minute 
cinereo-squamosis; femoribus subtus minute denticulatis. Subtus grosse sed parce punctatus.

Long. corp. lin. 2.

Habitat ins. Borneo, ad Sarawak a Dom. Wallace repertus. In coll. Dom. Pascoe.

\section{Genus 49. Brachyschapus.}

\section{Wollaston (vide, ante, $p$. 463). \\ - Brachyscapus crassirostris, n. sp.}

B. suboblongus, convexiusculus, nitidiusculus, calvus, ater ; rostro (brevi, crasso, triangulari) parce et leviter punctulato, et, una cum prothorace (ovali, convexo, utrinque subæqualiter rotundato), alutaceo; hôc elytris conspicue angustiore, multo grossius profundiusque punctato ; elytris profunde et grosse sulcato-punctatis, interstitiis convexiusculis ac minutissime parcissimeque punctulatis; antennis pedibusque piceis, illis tarsisque paulo clarioribus. Subtus parce sed grossissime, et parum profunde, punctatus.

Long. corp. lin. $1 \frac{3}{4}$.

Habitat Africam australem, a Natal missus. In coll. Dom. Fry.

\section{Genus 50. Phlqophagosoma.}

Wollaston, Trans. Ent. Soc. Lond. 23. (1873).

\section{(Subgenus Amorphorhynchus, Woll.)}

\section{Phloophagosoma sinuaticolle, $\mathrm{n}$. sp.}

P. subparallelo-fusiforme, depressum, nitidum, politum, atrum; rostro arcuato, supra in medio convexo aut subgibboso et ibidem gradatim subampliato (quare antice subattenuato), fere impunctato; capite parvo, angusto, oculis magnis sed subdemissis; prothorace (elytris angustiore) subquadrato, apice subito acuminato et ibidem profunde constricto, fere impunctato (punctulis solum minutissimis parce adsperso), ad basin ipsam bisinuato (nec recte terminato), quare in medio (ante scutellum) quasi acuminate producto ; elytris subparallelis (a basi paulatim vix subattenuatis), profunde subcrenato-lineatis, interstitiis latis ac impunctatis; antennis tarsisque piceo-ferrugineis, femoribus tibiisque nigro-piceis. Subtus ad latera ipsis- 
sima grosse punctatum, sed in regione mediâ (depressâ) fere impunctatum.

Long. corp. lin. 2.

Habitat ins. Malayenses, -in Nov. Guinea, Borneo, et Ceram a Dom. Wallace repertum. Coll. Pascoe.

\section{Phløophagosoma glaberrimum, n. sp.}

P. præcedenti simile, sed paululum majus, etiam depressius (sc. valde deplanatum), etiam magis politum, et fere omnino impunctatum; rostro paululum longiore; prothorace ad basin fere immarginato, necnon in medio obtusius producto; elytris magis parallelis, multo levius ac magis tenuiter subcrenulato-striatis; antennis pedibusque longioribus, scapo præcipue longiore, capituloque majore ac magis obscuro.

Long. corp. lin. 2.

Habitat ins. Java, a Dom. Wallace lectum. Communicatum a Dom. Pascoe.

\section{Phloophagosoma rotundicolle, $\mathrm{n}$. sp.}

P. subparallelo-fusiforme, minus depressum, nitidum, politum, atrum; rostro et capite ut in $P$. sinuaticolle sed paululum distinctius (tamen subtilissime) punctulatis ; prothorace convexiore, antice profundius constricto, et ubique paululum evidentius (tamen minutissime ac levissime) punctulato, ad latera magis et subæqualiter rotundato, postice recte truncato (nec sinuato); elytris longioribus, profunde substriato-punctatis; antennarum capitulo obscuriore, tarsorumque art. $^{\circ} 3^{\text {tio }}$ evidenter bilobo. Subtus dense et levissime punctulatum.

Long. corp. lin. $2 \frac{1}{3}$.

Habitat ins. Malayenses, in Amboyna a Dom. Wallace deprehensum. Coll. Pascoe.

\section{Phloophagosoma fusirostre, n. sp.}

P. fusiforme, depressiusculum, subnitidum, nigrum; rostro longiusculo, arcuato, supra in medio convexo aut gibboso et ibidem gradatim subampliato (quare antice subattenuato), dense punctato; capite parvo, angusto, etiam densius et grosse punctato, oculis magnis sed subdemissis; prothorace (elytris angustiore) ovato-triangulari, antice leviter constricto, dense et profunde punctato ; 
elytris subparallelis (a basi paulatim vix subattenuatis), profunde et grosse punctato-sulcatis, interstitiis convexis, transversim rugulosis ac minutissime parcissimeque punctulatis; antennis rufo-piceis, scapo elongato, capitulo magno et sub-obscuriore; pedibus longiusculis, crassis, piceis. Subtus dense, grossissime et profunde punctatum.

Long. corp. lin. $2 \frac{1}{3}$.

Habitat ins. New Guinea, ad Saylee a Dom. Wallace repertum.

\section{Phloeophagosoma vicinum, $\mathrm{n} . \mathrm{sp}$.}

P. fusiforme, depressiusculum, subnitidum, nigrum ; rostro elongato, gracili, arcuato, supra in medio vix subgibboso et vix subampliato, dense et minutissime punctulato; capite parvo, angusto; oculis demissis, haud latissime separatis ; prothorace ovato-triangulari, antice leviter constricto, dense et profunde punctato ; elytris subparallelis (a basi paulatim vix subattenuatis), profunde punctatostriatis, interstitiis transversim rugulosis ac minutissime parcissimeque sub-uniseriatim punctulatis; antennis clare rufo-ferrugineis, scapo elongato, capitulo magno; pedibus piceis, subtus profunde, dense, et grosse punctatum.

Long. corp. lin. $1 \frac{2}{3}$.

Habitat Borneo; ad Sarawak collegit Dom. Wallace. Ad describendum misit Dom. Pascoe.

(Obs.-P. fusirostri affine sed multo minus, ac multo minus grosse sculpturatum; rostro sublongiore, multo graciliore, necnon in medio minus gibboso minusque ampliato, antennis clarioribus, pedibusque, præsertim tarsis, brevioribus.)

\section{Phlocophagosoma angustulum, n. sp:}

P. parallelo-subfusiforme, angustulum, convexiusculum, nitidum, nigrum ; rostro breviusculo, arcuato, robusto, supra in medio obsolete subgibboso, subtilissime levissimeque punctulato ; capite angustulo, oculis magnis, prominulis; prothorace (elytris subangustiore) triangulari-ovato, antice leviter constricto, ad latera valde rotundato, distincte et argute (tamen sat minute) punctato; scutello magno; elytris subparallelis, profunde striato-punctatis; antennis pedibusque breviusculis, crassiusculis, rufo-piceis; tarsorum art. ${ }^{\circ} 3^{\text {tio }}$ evidenter sed minute bilobo. Subtus parce 
et profunde punctatum, punctis in regione centrali minoribus ac levioribus.

Long. eorp. lin. $1 \frac{2}{3}$.

Habitat ins. Malayenses, in Batchian a Dom. Wallace inventum. Coll. Pascoe.

\section{Phloeophagosoma opaculum, n. sp.}

P. fusiformi-parallelum, angustulum, elongatum, subdepressum, subopacum, piceo-nigrum ; rostro longiusculo, subarcuato, robusto, supra haud gibboso, minute sed argute punctulato; capite minus angusto, oculis prominulis; prothorace (pone medium latitudine elytrorum) elongato, subtriangulari, antice profunde et longe constricto, ad basin fere immarginato, distincte et argute sed haud dense punctulato; ely tris parallelis, vix picescentioribus, profunde punctato-striatis; antennis pedibusque breviusculis, crassiusculis, rufo-piceis; tarsorum art ${ }^{\circ} .3^{\text {tio }}$ sensim sed minute bilobo. Subtus alutaceum, in medio parce et levissime sed ad latera ipsissima declivia sat grosse punctulatum.

Long. corp. lin. 2.

Habitat ins. Malayenses, a Dom. Wallace in Batchian lectum. Coll. Pascoe.

\section{(Species hujus generis magis typica.)}

Phloophagosoma morio, n. sp.?

P. fusiforme, convexiusculum, nitidum, atrum; rostro elongato, arcuato, subparallelo, supra in medio obsolete convexo aut subgibboso, distincte punctulato; oculis subprominulis; prothorace (pone medium latitudine elytrorum) elongato, ovato-triangulari, antice leviter constricto, paulo profundius sed in disco vix dense punctulato; elytris fusiformibus basi truncatis (i. e. a basi gradatim sensim attenuatis), profunde et grosse punctato-sulcatis, interstitiis convexis ac minutissime parcissimeque punctulatis; antennis pedibusque piceis. Subtus argute sed parce punctatum.

Long. corp. lin. $2 \frac{1}{2}$.

cf. Phlœophagus cossonoides, Mots., Bull. Mosc. ii. 531 (1863).

Habitat ins. Ceylon, a Dom. Fry communicatum.

\section{Phloeophagosoma atratum, n. sp.?}

P. præcedenti simile, sed minus, vix magis cylindricum, paulo minus nitidum, et ubique subdensius sculpturatum; 
rostro sub-breviore, sensim minus arcuato, ac magis parallelo (nec in medio etiam obsolete subgibboso); fronte integrầ (vix foveolatâ); oculisque paulo magis prominentibus.

Long. corp. lin. 2.

cf. Phlœophagus linearis, Mots., Bull. Mosc. ii. 531 (1863). catum.

Habitat ins. Ceylon, a Dom. E. W. Janson communi-

\section{Phloeophagosoma corvinum, n. sp.}

P. parallelo-fusiforme, angustulum, subcylindricum, convexiusculum, nitidum, atrum ; rostro longiusculo, parallelo, minute et parce punctulato; oculis parvis, prominulis; prothorace (pone medium latitudine elytrorum) triangulariovato, antice leviter constricto, paulo profundius tamen leviter punctulato; elytris subcylindricis, punctato-, aut fere subcrenato-striatis, interstitiis subconvexis, subrugulosis ac minutissime (vix perspicue), parcissimeque punctulatis ; antennis subgracilibus, rufo-piceis, capitulo sub-obscuriore; pedibus subgracilibus, piceis. Subtus remote et leviter punctulatum.

$\operatorname{Var} \beta$ (affine). - Elytrorum interstitiis vix perspicue punctulatis, striis postice sublevius impressis.

Long. corp. lin. $2 \frac{1}{3}$.

Habitat Novam Zealandiam, a DD. Fry et Janson communicatum.

(Obs.-Species P. morio, in ins. Ceylon degenti, valde affinis, sed magis parallelum, aut minus fusiforme, prothorace paululum minus elongato minusque conico, sc. pone medium evidenter magis rotundato ; elytris magis parallelis, ad apicem ipsissimum magis integris, minus profunde, præsertim postice, striatis, interstitiis minus convexis minutiusque punctulatis; pedibusque sensim minus incrassatis.)

\section{Phlcophagosoma puncticolle, n. sp.}

P. fusiforme, angustulum, convexiusculum, subnitidum, nigrum ; rostro longiusculo, antice lato, postice paululum angustiore, dense et profunde punctato; oculis magnis, prominentibus; prothorace (elytris subangustiore) triangulari-ovato, antice sat profunde constricto, dense et grosse punctato; elytris (a basi usque ad apicem gradatim attenuatis) profunde striato-punctatis, interstitiis minutissime et parce punctulatis; antennis pedibusque elongatis, 
crassiusculis, paulo picescentioribus ; tarsis elongatis, art. ${ }^{\circ}$ $3^{\text {tio }}$ sensim (tamen minute) bilobo. Subtus profunde et parce punctatum.

Long. corp. lin. $2 \frac{1}{2}$.

Habitat peninsulam Malayensem, a Malacca a Dom. Fry communicatum.

(Obs.-Species corpore majore, fusiformi, profundius sculpturato, rostro postice obsolete angustato, oculis magnis prominentibus tarsorumque art. $^{\circ} 3^{\text {tio }}$ paulo evidentius subbilobo cum gen. Notiosomus aliquo modo congruens, et forsan, una cum $P$. proximo, ad hoc genus vix omnino pertinens.)

\section{Phløophagosoma proximum, n. sp.}

P. præcedenti valde affinis, sed subminus ac magis parallelum, capite rostroque subangustioribus et paulo minus profunde punctatis, prothorace sensim minore ac vix minus grosse punctato, elytris magis parallelis (sc. minus regulariter attenuatis), pedibusque subgracilioribus.

Long. corp. lin. $2 \frac{1}{3}$.

Habitat ins. Malayenses, in Makian a Dom. Wallace repertum. Coll. Pascoe.

\section{Genus 54. Melarhinus.}

Wollaston (vide, ante, p. 466).

Melarhinus nigritus, $\mathrm{n} . \mathrm{sp}$.

M. parallelo-fusiformis, opacus, niger sed hinc inde fusco-cinereo lutosus ; capite prothoraceque profunde densissimeque punctatis, hôc in medio obsolete carinulato, et pone apicem valde profunde constricto ; elytris sat grosse substriato-punctatis, interstitiis planiusculis et densissime punctulatis, (oculo fortissime armato) minutissime parce sericato-pubescentibus; antennis pedibusque crassis, his tarsisque piceis.

Long. corp. lin. $2 \frac{1}{2}$.

Habitat ins. Madagascar, a Dom. Pascoe communicatus.

\section{Genus 55. Psilosomus. \\ Wollaston (vide, ante, $p .466$ ). \\ Psilosomus opacus, n. sp.}

P. fusiformis, depressiusculus, opacus, niger, ubique densissime punctatus, sed calvus; prothorace magno, 
elongato, oblongo antice et præsertim postice truncato, profundius argutiusque punctato, ad basin anguste marginato; elytris grosse sulcato-lineatis (sulcis latis, necnon in fundo obsolete subpunctatis), interstitiis latis costiformibus ac minute denseque punctulatis; antennis longiusculis, picescentioribus, pedibus crassiusculis, validis. Subtus calvus, vix profunde et vix dense punctatus.

Long. corp. lin. $2 \frac{1}{3}-2 \frac{1}{2}$.

cf. Cossonus hebes, Walk., Ann. Nat. Hist. iv. 218 (1859).

Habitat ins. Ceylon, necnon peninsulam Malayensem (in Malacea et Paulo Penang),-a DD. E. W. Janson, G. Lewis et A. Fry benigne communicatus.

\section{Genus 58. Lipancylus.}

Wollaston (vide, ante, $p .468$ ).

Lipancylus inarmatus, n. sp.

A. angustulus, subcylindricus, depressiusculus, nitidiusculus, (nisi oculo fortissime armato) calvus ; capite prothoraceque minute, dense et argute punctulatis, rostro (elongato, gracillimo, cylindrico) paulo minutius punctulato et subpicescentiore, oculis magnis, demissis; prothorace elongato-subquadrato, antice haud constricto, ad basin sub-biarcuatim truncato; elytris parallelis, apice singulatim rotundatis, versus humeros subpicescentioribus, profunde crenulato-striatis, interstitiis latis et vix punctatis; antennis gracilibus, piceo-ferrugineis; pedibus crassis, tarsis latis et picescentibus. Subtus nitidus, grosse sed parce punctatus, punctis posticis minoribus.

Long. corp. lin. 4.

Habitat Americam australem, in regionibus juxta Amazon degens.

\section{Genus 60. Homaloxenus.}

Wollaston (vide, ante, p. 469).

Homaloxenus dentipes, n. sp.

H. parallelo-oblongus, latiusculus, valde depressus, subopacus, minute parceque subcinereo-sericatus, rufo-ferrugineus; capite parvo, minute et dense punctulato, oculis maximis sed demissis; rostro (longissimo, gracillimo, parallelo, recto) in medio carinulato sed utrinque grosse longitudinaliter strigoso; prothorace (elytris angustiore) 
quadrato-ovali, antice leviter constricto et ibidem in medio tenuiter carinulato, per totum discum latissime depresso, grosse sed vix profunde punctato punctulisque minoribus interjectis adsperso ; elytris parallelis, profunde subpunctatostriatis, interstitiis latis, dense transversim rugulosis ac minutissime et crebre punctulatis; antennis pedibusque elongatis, clarioribus, illis gracilibus, his crassis; femoribus subtus uni-denticulatis. Subtus subopacus, densissime minutissimeque pnnctulatus, et brevissime subtiliter fulvosericatus.

Long. corp. lin. $2 \frac{1}{4}$.

Habitat ins. Americæ centralis, in San Domingo captus. A Dom. J. Gray benigne donatus.

\section{Genus 62. Eucoptus. \\ Wollaston (vide, ante, p. 470). \\ Eucoptus depressus, n. sp.}

E. angustus, parallelus, depressus, subopacus, piceus, nisi oculo fortissime armato calvus (sed vere subtilissime parcissimeque sericatus); rostro rufo-ferrugineo, in $q$ elongato gracillimo et minute punctato, sed in $\delta$ breviore robustiore et subrugosius sculpturato; capite (nigrescente) prothoraceque multo profundius punctatis, hôc elongato, subovato-triangulari, in medio lineâ læviore instructo, mox pone apicem profunde constricto; elytris pallide rufocastaneis, tenuiter striatis, striis fere simplicibus (vix subpunctatis), interstitiis transversim reticulatis; antennis pedibusque pallide rufo-ferrugineis. Subtus subopacus, alutaceus, argute sed parce punctatus.

Long. corp. lin. $1-1 \frac{1}{2}$.

Habitat Americam australem (in regionibus juxta Amazon necnon in provinciâ Rio de Janeiro, Braziliæ, degens). Coll. Fry et Pascoe.

\section{Genus 67. Megalocorynus. \\ Wollaston (vide, ante, p. 473). \\ Megalocorynus capitatus, n. sp.}

M. parallelus, valde depressus, nitidus, niger; capite inter oculos rotundatos profunde et dense punctato; rostro (in $q$ breviusculo, angustulo, depresso) minutissime parceque punctulato; prothorace (brevi, ad latera subæqualiter rotundato) grossius ac parum dense subæqualiter punctato, in carinulâ mediâ obsoletâ (postice magis elevatâ) 
læviore, postice in medio leviter impresso, punctis in impressione (juxta carinulam) subdensioribus ac submajoribus; elytris grosse punctato-sulcatis, punctis maximis et interstitiis elevatis costiformibus; antennis tarsisque piceis, illarum capitulo longissimo nigrescentiore et densissime velutino. Subtus nitidissimus, profunde et parum dense punctatus.

Mas adhuc latet.

Long. corp. lin. circa 3.

Habitat Americam borealem, a Mexico missus. Coll. Janson.

(Obs. - Species Cossono conicirostri, Bohm., i. e. C. depressi $\&$, valde affinis, et forsan ejus status topographicus. Differt solum, ut mihi videtur, rostro paululum breviore et inter oculos subminus grosse punctato, prothoraceque ad latera sensim minus rotundato, postice in medio minus profunde longitudinaliter impresso, necnon punctis magnis juxta carinulam minoribus ac minus densis.)

\section{Genus 68. Catolethrus.}

Schönherr, Gen. et Spec. Curc. iv. 1077 (1838).

a. Metasternum valde elongatum.

Catolethrus laviusculus, n. sp.

C. angustus, parallelo-fusiformis, subdepressus, nitidus, piceus; rostro minutissime et leviter punctulato; prothorace ovato-triangulari, profundius (sed haud grosse) parceque punctato, in lineâ mediâ læviore; scutello magno, depresso; elytris sat leviter striato-punctatis, interstitiis latis depressis ac minutissime parceque punctulatis; antennis pedibusque rufescentioribus. Subtus minute, parce, et leviter punctulatus.

Long. corp. lin. $2 \frac{3}{4}$.

Habitat Americam australem (in provinciâ Rio de Janeiro, Braziliæ, a Dom. Fry deprehensus).

\section{Catolethrus Grayii, n. sp.}

C. angustus, parallelo-fusiformis, subdepressus, subnitidus, piceo-castaneus elytris sensim pallidioribus; rostro distinctius punctulato ; prothorace subovali, ad latera subæqualiter rotundato, profunde, rugose et parum dense punctato, postice in medio late longitudinaliter subimpresso ; elytris profunde, rugose et dense striato-punctatis, interstitiis convexis, transversim rugulosis ac mi- 
nutissime parceque punctulatis; antennis pedibusque subconcoloribus. Subtus alutaceus, parce sed argute et parum grosse punctatus.

Long. corp. lin. $2 \frac{2}{3}$.

Habitat Americam australem (ad Petropolis in provinciâ Rio de Janeiro Braziliæ), a Dom. J. Gray captus, cujus in honorem nomen triviale proposui.

\section{Catolethrus productus, n. sp.}

C. angustissimus, elongatus, parallelus, valde depressus, nitidus, piceus; rostro elongato, minute et parce punctulato; prothorace elongato, ovato-triangulari, profunde et grosse sed vix dense punctato, in lineâ (aut carinulâ) mediâ læviore; scutello magno, depresso; elytris (vix rufescentioribus) elongatis, parallelis, subtenuiter striatopunctatis, interstitiis latiusculis depressis ac minutissime parcissimeque punctulatis; antennis pedibusque breviusculis, clare rufo-piceis.

Long. corp. lin. $2 \frac{1}{2}$.

Habitat Americam australem (in provinciâ $\mathrm{S}^{\text {tæ }}$ Catharinæ, Braziliæ, a Dom. Fry lectus).

\section{b. Metasternum paulo minus elongatum.}

\section{Catolethrus parvus, n. sp.}

C. angustus, parallelo-fusiformis, depressus, nitidus, piceus sed in elytris rufo-castaneus; rostro minute punctulato; prothorace ovato-triangulari, profunde et grosse sed vix dense punctato, ante medium obsoletissime subcarinulato; elytris profunde striato-punctatis, interstitiis subdepressis, subrugulosis ac minutissime parcissimeque punctulatis; antennis pedibusque clare rufo-piceis. Subtus alutaceus, parce et sat grosse punctatus.

Long. corp. lin. $1 \frac{1}{3}$.

Habitat Americam australem (a provinciâ Bahia, Braziliæ, a Dom. Fry communicatus).

\section{Catolethrus basalis, n. sp.}

C. angustulus, parallelo-fusiformis, depressus, nitidus, piceo-niger; rostro (a capite etiam distinctius diviso, necnon ad basin evidentius incrassato) gracili, piceo, minute punctulato, postice tenuiter canaliculato; prothorace (elytris conspicue angustiore) profunde, rugose et parum dense punctato, in medio obsoletissime carinulato; elytris profunde et grosse striato-punctatis, interstitiis 
transversim rugulosis ac minutissime parceque punctulatis ; antennis pedibusque rufo-piceis, scapo et funiculi art. ${ }^{\circ} 1^{\text {mo }}$ clarioribus. Subtus profunde et parum dense punctatus.

Long. corp. lin. 2.

Habitat Americam australem (in provinciâ $\mathrm{S}^{\text {tæ }}$ Catharinæ, Braziliæ, a Dom. Fry deprehensus).

\section{Genus 69. Stenotribus. \\ Wollaston (vide, ante, $p .474$ ). \\ Stenotribus longicollis, $\mathrm{n}$. sp.}

S. angustissimus, elongatus, parallelus, nitidus, fere niger ; rostro (elongato, parallelo) minutissime parcissimeque punctulato; prothorace valde elongato, triangularicylindrico, subdepresso, profunde et grosse sed vix densissime punctato, æquali (nec carinulato, nec impresso); elytris parallelis, sat tenuiter punctato-striatis, versus humeros rufescentioribus, interstitiis transversim subrugulosis ac minutissime (vix perspicue) parcissimeque uniseriatim punctulatis; antennis rufo-piceis, pedibus piceis. Subtus parce sed argute punctulatus.

Long. corp. lin. $1 \frac{1}{2}$.

Habitat Americam australem (a Dom. Fry a provinciâ Bahia, Braziliæ, communicatus).

Genus 72. Gleodema.

Wollaston (vide, ante, p. 476).

Glœodema spatula, n. sp.

G. angustula, elongata, fusiformis, convexa, nitidissima, nigra sed in prothorace femoribusque rufa; capite rostroque elongatis, minute (in illo parce sed in hôc dense) punctulatis, illo elongato spatuliformi (sc. antice rotundatoampliato); prothorace (elytris paulo angustiore, et subtus concavo) postice subovali, convexo, antice subito et profunde constricto, æquali ac fere impunctato (punctulis solum minutissimis parce adsperso), rufo sed antice et postice nigro-marginato; elytris fusiformibus basi truncatis, obsolete striato-punctatis, striâ juxta suturam paulo distinctiore atque omnibus ad apicem profundis; antennis pedibusque elongatis, crassis, illis, tibiis tarsisque nigropiceis, femoribus (basi apiceque exceptis) rufis. Subtus politissimus, fere impunctatus, ac postice castaneus.

Long. corp. lin. 5.

TRANS. ENT. SOC. 1873.-PART IV. 
Habitat Nov. Guinea, ad Dorey a Dom. Wallace deprehensa. Coll. Pascoe.

\section{Gloodema ruficollis, n. sp.}

G. præcedenti similis, ac forsan ejus sexus alter. Differt corpore minore, rostro minus elongato et multo magis parallelo (sc. antice paululum solum latiore), prothorace subtus vix (aut obsolete solum) concavo, elytris paulo magis evidenter (tamen leviter) punctato-striatis.

Long. corp. lin. $3 \frac{1}{2}$.

Habitat Nov. Guinea, a Dom. Wallace ad Saylee reperta. Coll. Pascoe.

\section{Genus 73. Glemoxenus. \\ Wollaston (vide, ante, $p .477$ ). \\ Gloooxenus armatus, n. sp.}

G. angustulus, elongatus, fusiformis, convexus, nitidissimus, ater; capite prothoraceque minutissime parceque punctulatis (rostro breviusculo, lato, parallelo, depressiusculo), hôc elongato, cylindrico-ovato, antice sat profunde constricto; elytris (a basi usque ad apicem gradatim attenuatis) levissime substriato-punctatis, interstitiis minutissime (vix perspicue) sub-uniseriatim punctulatis; antennis pedibusque crassis, vix picescentioribus, illarum capitulo dense subfulvo-pubescenti. Subtus nitidus, et fere impunctatus.

Long. corp. lin. $2 \frac{1}{3}$.

Habitat Madagascar, a Dom. J. Gray benigne donatus.

\section{Genus 74. Exonotus. \\ Wollaston (vide, ante, $p .477$ ). \\ Exonotus basalis, n. sp.}

E. angustus, elongatus, fere parallelus, cylindricus, nitidus, niger sed elytris antice rufis; capite rostroque latis (latitudine subæqualibus), subconvexis, minute sed (præsertim in hôc) dense punctulatis; prothorace (elongato, triangulari-ovato, antice valde constricto) convexo, æquali, minute sed paulo parcius punctulato, ad basin distincte sed anguste marginato; elytris parallelis, sat profunde crenato-(vix punctato-) striatis, interstitiis minutissime parcissimeque punctulatis; antennis pedibusque incrassatis, subpicescentioribus. Subtus nitidus, castaneus, et fere impunctatus. 
Mas (?), paulo major, rostro sublatiore necnon antice sensim dilatato.

Fæem. (?), paulo minor, rostro subangustiore necnon omnino parallelo.

Long. corp. lin. $3 \frac{1}{2}-4$.

Habitat ins. Malayenses, in Tondano et Celebes, a Dom. Wallace captus. Coll. Pascoe.

\section{Genus 75. Pseudocossonus.}

\section{Wollaston, Trans. Ent. Soc. Lond. 27 (1873). \\ Pseudocossonus dimidiatus, n. sp.}

P. angustulus, elongatus, subfusiformi-parallelus, depressiusculus, nitidus, niger sed elytris in parte anticâ gradatim rufis; capite, rostro prothoraceque minutissime parceque punctulatis, rostro longiusculo, subgracili, arcuato et fere parallelo (solum ad antennarum insertionem obsolete facillimeque subampliato), oculis magnis, prominentibus; prothorace (elytris vix angustiore) sub-triangulariovali, antice subito et valde constricto, æquali; elytris fere parallelis, sat profunde punctato-striatis, interstitiis latis depressis et vix perspicue punctulatis; antennis pedibusque (brevibus) picescentioribus. Subtus læte rufocastaneus, nitidissimus, et fere impunctatus.

Long. corp. lin. 3.

Habitat Nov. Guinea, ad Dorey a Dom. Wallace captus. Coll. Pascoe.

\section{Genus 76. Catolethromorphus. \\ Wollaston (vide, ante, $p$. 479). \\ Catolethromorphus nigripes, n. sp.}

C. angustus, parallelus, subdepressus, nitidus, brunneopiceus elytris pallidioribus (sc. rufo-castaneis); capite et rostro (longiusculo, robusto, parallelo) minutissime punctulatis, oculis magnis rotundatis et sat prominentibus; prothorace breviusculo, subovali-quadrato, antice et postice truncato, mox intra apicem constricto, æquali (nec carinulato, nec impresso); elytris sat leviter striato-punctatis, interstitiis latis depressis ac minutissime parcissimeque uniseriatim punctulatis, ad apicem ipsissimum subrecte truncatis; antennis pedibusque nigrescentibus, scapo (longiusculo) rufescentiore. Subtus nitidissimus, parce et minute punctulatus.

Long. corp. lin. vix $2 \frac{2}{3}$.

Habitat Indiam orientalem, a Dom. Fry communicatus. 


\section{Genus 77. Brachychenus.}

Wollaston (vide, ante, p. 479).

\section{Brachychœnus pallidulus, n. sp.}

B. angustulus, parallelus, depressiusculus, nitidus, clare rufo-ferrugineus; capite nigrescentiore, parce punctato, rostro (parallelo, robusto) minutissime parce punctulato; prothorace (triangulari-ovato, antice leviter constricto) æquali, sat grosse sed haud dense punctato ; elytris parallelis, profunde punctato-striatis, interstiis minutissime (vix perspicue) parcissimeque uniseriatim punctulatis; antennis pedibusque crassiusculis, concoloribus, funiculo vix obscuriore. Subtus sat profunde sed haud dense punctatus.

Long. corp. lin. $1 \frac{1}{2}$.

Habitat ins. Borneo, prope Sarawak a Dom. Wallace lectus.

\section{Genus 78. Stenomimus.}

\section{Wollaston (vide, ante, p. 480).}

\section{Stenomimus Fryi, n. sp.}

S. angustus, fusiformi-parallelus, convexiusculus, nitidulus, rufo-testaceus; rostro (longiusculo, subgracili, parallelo) cylindrico, distincte sed parce punctato, oculis magnis, subrotundatis, valde prominentibus; prothorace elongato, ovato-triangulari, antice profunde constricto, parum profunde et parum dense punctato, postice in medio obsolete longitudinaliter impresso; elytris parallelis, minutissime parcissimeque sericatis, ad apicem ipsissimum obsolete obscurioribus, tenuiter subcrenulato-striatis, interstitiis depressiusculis ac minutissime (vix perspicue) parcissimeque uniseriatim punctulatis; antennis pedibusque brevibus, concoloribus. Subtus parcissime et levissime punctatus.

Long. corp. lin. $1-1 \frac{1}{4}$.

Habitat Americam australem,-in provinciâ Rio de Janeiro, Braziliæ, repertus a Dom. Fry, cujus in honorem, ob gratias mihi amicissime oblatas, nomen triviale stabilivi.

\section{Genus 79. Microminus.}

Wollaston (vide, ante, p. 480).

Micromimus Batesii, n. sp.

M. angustulus, parallelo-fusiformis, depressiusculus, nitidus, subpicescenti-rufotestaceus; rostro (brevi, lato, 
subparallelo) supra depressiusculo, distincte sed parce punctato, oculis maximis sed demissis; prothorace elongato, triangulari-ovato, antice leviter constricto, profunde et grosse sed parce punctato, in medio obsolete longitudinaliter impresso; elytris parallelis, profunde punctato(aut fere subcrenato-) striatis, interstitiis convexis subcostiformibus ac minutissime (vix perspicue) parcissimeque uniseriatim punctulatis; antennis pedibusque brevibus, concoloribus. Subtus grosse et profunde sed haud dense punctatus.

Long. corp. lin. $1 \frac{1}{3}$.

Habitat Americam australem,-in regionibus circa Amazon lectus a Dom. Bates, cujus in honorem nomen specificum proposui.

\section{Micromimus pumilio, n. sp.}

M. præcedenti similis sed paulo minor, subpallidior, et vix minus grosse sculpturatus; oculis minoribus (tamen magnis); elytrisque sensim minus parallelis, interstitiis paulo minus costiformibus aut convexis. Subtus depressiusculus, nitidus, parcissime et levissime punctatus.

Long. corp. lin. $1-1 \frac{1}{4}$.

Habitat in ins. Americæ centralis, in Trinidad repertus. (Coll. Fry.)

\section{Micromimus nigrescens, $\mathrm{n}$. sp.}

M. parallelo-fusiformis, depressiusculus, nitidus, piceoniger aut nigro-piceus; rostro (brevi, lato, subparallelo) minutissime parceque punctulato, præsertim antice rufescentiore, oculis maximis sed demissis; prothorace triangulari-ovato, antice leviter constricto, profunde et grossissime sed parce punctato, in medio late et distincte longitudinaliter impresso; elytris parallelis, profunde punctato- (aut fere crenato-) striatis, interstitiis convexis et conspicue costiformibus sed vix perspicue uniseriatim punctulatis; antennis pedibusque brevibus, piceo-ferrugineis. Subtus grosse, sed leviter et parce, punctatus.

Long. corp. lin. $1 \frac{1}{2}$.

Habitat Americam borealem, in Mexico degens. (Coll. Fry.)

Genus 80. Glagotrogus.

Wollaston (vide, ante, $p .481$ ).

Glootrogus politissimus, n. sp.

G. angustulus, parallelus, valde deplanatus, politissimus ; 
capite prothoraceque fere impunctatis (punctulis solum subtilissimis levissimis parce adspersis), illo elongatoquadrato, angustulo, valde exserto, depresso, nigro, rostro (brevi, lato, subparallelo) picescentiore; prothorace triangulari-quadrato, basi subrecte truncato, apice haud constricto, æquali, rufo-piceo; elytris subpellucide testaceis, sed in limbo et versus scutellum gradatim suffuse picescentioribus, versus latera obsoletissime, levissime et tenuiter sublineato-punctulatis, sed versus suturam fere omnino esculpturatis; antennarum scapo clare et pallide rufo-ferrugineo, funiculo piceo, capitulo paulo nigrescentiore; pedibus brevibus, politissimis, piceis. Subtus deplanatus, politissimus, haud sculpturatus.

Long. corp. lin. $1 \frac{1}{2}$.

Habitat ins. Malayenses, in Morty et Gilolo a Dom. Wallace detectus. (Coll. Pascoe et Janson.)

\section{Genus 81. Homalotrogus.}

Wollaston (vide, ante, p. 482).

\section{Homalotrogus angustifrons, n. sp.}

H. angustulus, parallelus, valde deplanatus, nitidus ; capite elongato, angusto, ovali, valde exserto, fere nigro, rostro picescentiore et una cum illo minute parceque punctulato; prothorace subquadrato, basi subrecte truncato, apice breviter constricto, æquali, piceo, subalutaceo punctulisque minutissimis levissimis parcissime adsperso ; elytris subpellucide testaceis, sed in limbo gradatim suffuse subpicescentioribus, levissime lineato-punctatis; antennarum scapo clare rufo-ferrugineo, funiculo piceo, capitulo paulo nigrescentiore; pedibus rufo-piceis. Subtus depressus, politus, fere esculpturatus (punctulis solum minutissimis levissimis parcissime irroratus).

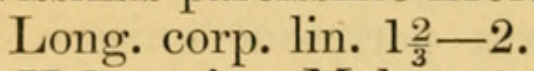

Habitat ins. Malayenses, a Dom. Wallace in Ceram et Batchian deprehensus. (Coll. Pascoe.)

\section{Genus 82. Isotrogus. \\ Wollaston (vide, ante, p. 483). \\ Isotrogus tabellatus, n. sp.}

S. angustulus, parallelus, valde deplanatus, nitidus; capite elongato, ovali, valde exserto, nigro, rostro (subparallelo) ad apicem picescentiore et una cum illo minutissime parcissimeque punctulato; prothorace elongato, 
triangulari-oblongo, basi sensim trisinuato, apice breviter constricto, postice in medio obsoletissime subcarinulato, punctis perpaucis maximis notato; elytris (interdum obsolete) subpellucide testaceis, sed in limbo et suturâ conspicue suffuse nigrescentibus, distincte striatopunctatis; antennarum scapo rufo-ferrugineo, funiculo capituloque paulo obscurioribus; pedibus piceis. Subtus politus, fere esculpturatus (punctulis solum minutissimis levissimis parcissime irroratus).

Long. corp. lin. $1 \frac{2}{3}-2$.

Habitat ins. Malayenses, a Dom. Wallace in Batchian captus.

\section{Isotrogus maurus, n. sp.}

S. angustulus, parallelus, minus depressus, nitidus, niger; capite paulo crassiore, paulo minus exserto, minute foveolato, et una cum rostro (subparallelo) minutissime parcissimeque punctulato; prothorace elongato, triangularioblongo, basi conspicue trisinuato, apice constricto, postice in medio leviter depresso, punctis perpaucis maximis ubique (in fundo impressionis densius bilineatim) notato; elytris vel concoloribus vel interdum in disco singuli obsoletissime subtestaceo-tinctis, profunde punctato-striatis; antennis picescentioribus.

Long. corp. lin. $2 \frac{1}{2}$.

Habitat ins. Malayenses, in Batchian a Dom. Wallace lectus.

\section{Genus 83. Heterophasis.}

Wollaston (vide, ante, $p$. 483).

\section{Heterophasis ruficollis, $\mathrm{n} . \mathrm{sp}$.}

H. parallelo-fusiformis, valde depressus, nitidus; capite fere nigro, profunde foveolato, rostro gradatim rufo-ferrugineo et, una cum illo, minutissime parcissimeque punctulato; prothorace (elytris distincte angustiore) ovali-subquadrato, basi evidenter trisinuato, apice profunde constricto, clare testaceo-rufo, æquali, fere impunctato,solum punctis perpancis magnis, in seriebus duabus dorsalibus necnon in fundo stricturæ positis, notato; elytris subfusiformibus basi truncatis, sat grosse substriato-punctatis (sc. striis obsoletis, sed punctis magnis); antennis pedibusque longiusculis, illis rufo-ferrugineis, capitulo obscuriore, his clare testaceo-rufis. Subtus in medio late 
deplanatus, politus, impunctatus, tamen ad latera declivia ipsissima grosse sed subleviter punctatus.

Long. corp. lin. 2-2 $\frac{1}{2}$.

Habitat Nov. Guinea, ad Dorey a Dom. Wallace deprehensus.

\section{Heterophasis concolor, n. sp.}

H. parallelo-fusiformis, valde depressus, nitidus, ater; capite obsolete foveolato, rostro apicem versus minus dilatato et, una cum illo, minutissime parcissimeque punctulato; prothorace (elytris vix angustiore) ovali-subquadrato, basi evidenter trisinuato, apice sat profunde constricto, æquali, parce et levissime punctulato et punctis perpaucis vix majoribus, in seriebus duabus dorsalibus necnon in fundo stricturæ positis, notato; elytris subfusiformibus basi truncatis, punctulato-striatis (striis sat profundis, sed punctis parvis); antennis (elongatis) tarsisque rufo-ferrugineis, capitulo obscuriore, femoribus tibiisque nigro-piceis.

Long. corp. lin. 2.

Habitat ins. Nov. Guinea, ad Dorey a Dom. Wallace captus. Coll. Pascoe.

(Obs.-A H. ruficolli præcipue differt corpore nigro et etiam magis depresso, rostro apice multo minus dilatato, prothorace punctulis minutissimis distinctioribus adsperso sed tamen punctis in duplici serie discali multo minoribus, sc. vix majoribus quam reliquis, necnon punctis in elytrorum striis multo minoribus.)

\section{Genus 85. Hyponotus. \\ Wollaston (vide, ante, p. 484). \\ Hyponotus subpubescens, n. sp.}

H. angustulus, elongatus, parallelus, vix depressus, opacus, niger, minutissime, brevissime et parce fulvosetuloso-pubescens; capite latiusculo, et una cum rostro (lato, brevi, subparallelo, postice solum paululum contracto, necnon in medio carinulato) densissime et rugose punctato; prothorace breviter subovali (ad latera æqualiter rotundato), densissime, grossissime et æqualiter punctato, postice in medio obscure carinulato (sed haud impresso); scutello nitidiusculo; elytris (elongatis, valde parallelis) grosse substriato-punctatis, interstitiis valde distincte uniseriatim punctulatis; antennis tarsisque piceis. Subtus 
nitidiusculus, densissime, profunde, et grosse æqualiter punctatus.

Long. corp. lin. circa 4.

Habitat peninsulam Malayensem, in Singapore a Dom. Wallace repertus. (Coll. Pascoe.)

\section{Genus 86. Borophlaeus.}

Wollaston (vide, ante, $p .484$ ).

Borophløus puncticollis, n. sp.

B. angustulus, parallelus, depressiusculus, nitidus, ater ; rostro (breviusculo, latiusculo, fere parallelo, sc. postice paululum angustiore) profunde et rugose punctato, fronte (inter oculos magnos, prominentes) foveâ subrotundatâ profundâ notatâ; prothorace subtriangulari-quadrato, antice paulo constricto, postice leviter trisinuato, profunde, grosse, parum dense et subæqualiter punctato (punctis utrinque in disco paulo minoribus), postice evidenter carinulato sed haud longitudinaliter impresso; elytris grosse punctato-sulcatis, interstitiis convexis; antennis tarsisque paulo dilutioribus. Subtus parum grosse sed in medio haud profunde punctatus.

Long. corp. lin. $2 \frac{1}{3}-2 \frac{1}{2}$.

Habitat Mexico, in coll. Dom. Fry.

\section{Borophlous minor, n. sp.}

B. præcedenti similis, sed minor; rostro subbreviore, omnino parallelo (nec postice subangustiore), et paulo densius punctato; prothorace subdensius et vix grossius punctato; scutello minore; elytrorum interstitiis angustioribus ac evidentius (tamen minutissime) uniseriatim punctulatis; necnon antennis pedibusque subbrevioribus, magis pubescentibus, illarum capitulo minus incrassato.

Long. corp. lin. circa 2.

Habitat Americam borealem, in coll. Dom. Janson.

Genus 87. Pachytrogus.

Wollaston (vide, ante, p. 484).

Pachytrogus crassirostris, $\mathrm{n}$. $\mathrm{sp}$.

P. crassus, parallelus, convexus, cylindricus, nitidus, ater; capite rostroque latis, crassis, minute et parce punctulatis, hôc brevi, subtriangulari-parallelo, supra obsolete subgibboso, oculis demissis; prothorace elongato, cylin- 
drico-oblongo, postice subrecte truncato, antice integro, grossissime et subæqualiter sed parce punctato, in lineâ postmediâ læviore, æquali; elytris (prothorace vix latioribus) grosse sulcato-punctatis, interstitiis fere impunctatis; antennis tarsisque picescentioribus. Subtus subalutaceus, parce et grosse sed (saltem postice) vix profunde punctatus.

Long. corp. lin. $3 \frac{1}{2}$.

Habitat Americam australem, in Chili degens. Coll. Janson.

\section{Genus 88. Stereoborus. \\ Wollaston (vide, ante, p. 485). \\ Stereoborus robustus, $\mathrm{n}$. sp.}

S. angustulus, subfusiformi-parallelus, nitidus, ater; capite lato et, una cum rostro (brevi, subquadrato), alutaceo, minus nitido, necnon parce minuteque punctulato, canaliculâ e foveâ minutâ profundâ frontali oblongâ surgente (interdum etiam pone hanc levius currente) et fere usque ad apicem continuatâ; oculis sat prominentibus; prothorace elongato, cylindrico-ovato, antice profunde constricto, postice trisinuato, in medio carinulato et utrinque juxta carinulam punctis maximis in lineâ valde confusâ sitis notato, ubique parcissime minute punctulato punctisque magnis versus latera atque in fundo stricturæ ac per basin ipsissimam adsperso; elytris grosse punctato-striatis; antennis pedibusque robustis, paulo picescentioribus.

Long. corp. lin. $3 \frac{2}{3}-4$.

Habitat ins. Nov. Guinea, ad Dorey a Dom. Wallace (teste coll. Pascoeano) deprehensus.

\section{Stereoborus affinis, n. sp.}

S. præcedenti similis, sed minor, capite rostroque vix grossius ac vix densius punctulatis, hôc sensim minus lato, canaliculâ antice breviore (sc. longe pone apicem evanescente) atque e foveâ frontali magis rotundatâ (minus oblongâ) surgente, prothorace subminore et subgrossius punctato.

Long. corp. lin. $3-3 \frac{1}{4}$.

Habitat ins. Malayenses, a Dom. Wallace in Gilolo et Matabello repertus. Coll. Pascoe.

\section{Stereoborus punctirostris.}

S. magnitudine formâque generali S. affini simillimum, sed differt rostro sensim angustiore atque nitido (nec alu- 
taceo), necnon densius (præsertim antice) et paulo distinctius punctato, canaliculâ subbreviore ac postice paululum magis profundâ; prothorace sensim densius grossiusque punctato.

Var. $\beta$ (obliteratus).-Rostrum vix parcius leviusque punctatum, canaliculâ centrali levius impresso ; prothorace vix minus grosse punctato.

Long. corp. lin. $3 \frac{1}{4}$.

Habitat ins. Malayenses, in coll. Dom. Janson. "Var. $\beta$ " (obliteratus), in Nov. Guinea et in Ké degentem, communicavit Dom. Pascoe.

\section{Genus 89. Stereotribus.}

Wollaston (vide, ante, p. 486).

a. Rostrum breve, subquadratum.

Stereotribus scabrifrons, n. sp.

S. angustulus, parallelus, convexiusculus, nitidus, ater ; capite valde malleato-inæquali, aut quasi scabroso, parce punctato necnon antice tuberculo minuto centrali instructo; rostro (brevi, subquadrato, subtus ad apicem dense et longe fulvo-barbato) minutius densiusque punctato, necnon postice grosse et profunde sed breviter longitudinaliter fisso (lateribus fissuræ postice subelevatis, et ibidem subtuberculiformibus), oculis prominentibus; prothorace elongato, cylindrico-ovato, antice profunde constricto postice leviter trisinuato, in medio carinulato impunctato, ubique parce et profunde punctato, punctis utrinque juxta carinulam necnon ad latera, per basin, et in fundo stricturæ majoribus ac parum grossis; elytris grosse punctato-striatis ; antennis pedibusque robustis, paulo picescentioribus..

Long. corp. lin. $2 \frac{2}{3}$-vix 3.

Habitat ins. Malayenses, in Batchian et Banda a Dom. Wallace repertus. Coll. Pascoe.

\section{Stereotribus fissifrons, n. sp.}

S. præcedenti similis, sed paulo minor; capite æquali (nec malleato-scabroso), fissurâ centrali longiore (sc. antice magis versus apicem rostri, et postice in frontem, currente); rostro subtus ad apicem fere calvo (nec dense fulvo-barbato); prothorace paulo minore atque densius, multo grossius magisque æqualiter punctato (punctis solum utrinque in disco paulo minoribus); pedibusque sensim 
minus incrassatis, tibiis anticis intus minus late lamellatoampliatis.

Long. corp. lin. $2 \frac{1}{3}-2 \frac{2}{3}$.

Habitat ins. Malayenses, a Dom. Wallace in Tondano captus. Coll. Pascoe.

b. Rostrum paulo longius, ac basin versus sensim angustatum. Capitulum majus ac longius. (Subg. Stereotrogus, Woll.)

Stereotribus incisus, n. sp.

S. fissifronti parum similis, sed major, rostro (subtus ad apicem fere calvo) longiore ac postice sensim angustato, fissurâ centrali valde profundâ subtrianguliformi, postice haud in frontem currente, oculis magis (sc. valde) prominentibus; prothorace longiore, paulo magis triangulari ac profundius (sc. grossissime) punctato (punctis magnis et fere æqualibus), carinulâ mediâ (ut in illo) lævi ; tibiis anticis (ut in S. scabrifronti) intus late lamellato-ampliatis.

Long. corp. lin. circa 3.

Habitat Ceylon, in collectione Dom. Fry.

Stereotribus tuberculifrons, $\mathrm{n} . \mathrm{sp}$.

S. scabrifronti primâ facie affinis, sed multo major et rostro (ut in S. inciso) longiore ac postice angustato, necnon capitulo majore; capite convexo, valde malleatoinæquali, aut quasi subscabroso, dense et profunde punctato, necnon antice tuberculis tribus (centrali subcarinuliformi) instructo; rostro (subtus ad apicem dense et longe fulvo-barbato) minutius punctulato, postice grosse et profunde, sed breviter, longitudinaliter fisso (lateribus fissuræ postice elevatis, et ibidem gradatim nodiformibus), oculis valde prominentibus; prothorace elongato, cylindricoovato, punctato ut in $S$. scabrifronte sed paulo grossius; elytris grosse punctato-striatis.

Long. corp. lin. $3 \frac{2}{3}-4$.

Habitat Ceylon, in collectionibus DD. Fry et Janson.

Genus 90. Stereominetes.

Wollaston (vide, ante, p. 486).

Stereomimetes crassicornis, $\mathrm{n} . \mathrm{sp}$.

S. angustulus, parallelus, convexiusculus, nitidus, subpiceus sed in elytris niger; capite rostroque dense punctatis (punctis in hujus medio longitudinaliter confluenti- 
bus), hôc antice rotundato-ampliato, basi angustato, postice profunde et aperte canaliculato (canaliculâ a foveâ frontali rotundatâ profundâ surgente) ; prothorace elongato, suboblongo, antice profunde constricto, postice subrecte truncato, in medio carinulato impunctato, ubique profunde et sat dense punctato, punctis utrinque in disco subminoribus; elytris grosse punctato-striatis, interstitiis minutissime sed evidenter punctulatis, ad basin subrecte truncatis; antennis (crassissimis) pedibusque rufo-piceis. Subtus subtestaceo-piceus, argute et sat dense, sed vix valde profunde et vix grosse, punctatus.

Long. corp. lin. $3 \frac{2}{3}$.

Habitat Australiam occidentalem, a "Champion Bay" missus. Ad describendum benigne communicavit Dom. Pascoe.

\section{Genus 91. Stereoderus.}

Wollaston (vide, ante, p. 486).

a. Rostrum emarginatione apicali (pro labri receptione) lobo magno, in medio fisso, fere repletâ; ergo rostrum ad apicem ipsissimum in medio quasi trifissum.

Stereoderus barbatus, n. sp.

S. angustulus, parallelus, cylindricus, convexus, nitidus, ater; capite lato, crasso, antice tuberculo parvo centrali instructo, et una cum rostro (brevissimo, latissimo, capite vix angustiore, et subtus ad apicem dense ac longe fulvobarbato) minute et parce punctulato; oculis magnis, valde anterioribus, prominentibus; prothorace valde elongato, cylindrico-conico, antice leviter constricto, postice subrecte truncato, aquali, minute et parce punctato ; elytris breviter cylindricis obsolete substriato-punctatis, striis punctisque postice evanescentibus, interstitiis latis depressis ac subtilissime parcissimeque punctulatis; antennis rufo-piceis, scapo clariore; pedibus piceis.

Long. corp. lin. 3.

Habitat ins. Malayenses, in Ceram a Dom. Wallace detectus. Communicavit Dom. Pascoe.

Stereoderus simplex, $\mathrm{n}$. sp.

S. præcedenti similis, sed minor, fronte in medio foveâ punctiformi notatâ (nec tuberculatâ), prothorace multo 
profundius grossiusque punctato necnon antice levius constricto, elytris paulo profundius substriato-punctatis.

Long. corp. lin. 2.

Habitat ins. Malayenses, a Dom. Wallace in Batchian captus. Coll. Pascoe.

\section{b. Rostrum emarginatione apicali fere simplici,-sc. lobo centrali brevi, integro, obsoleto.}

Stereoderus pacificus, n. sp.

S. barbato affinis sed subangustior, valde cylindricus; tuberculo frontali magis in rostro (depressiore, alutaceo) sito, et fronte (pone illum) canaliculâ brevissimâ minutissimâ notatâ, lateribus canaliculæ obsoletissime subelevatis (quasi tuberculos duos minutissimos obsoletissimos efficientibus); emarginatione rostrali apicali fere simplici ; prothorace (longissimo, subtriangulari-cylindrico) etiam minutius leviusque punctulato; necnon elytris sublongioribus et etiam obsoletius substriato-punctatis.

Long. corp. lin. vix 3 .

Habitat ins. Pacificas "Fiji" dictas, a Dom. Pascoe amice communicatus.

\section{Genus 92. Oxydena. \\ Wollaston (vide, ante, $p .487$ ). \\ Oxydema fusiformis, n. sp.}

O. angustula, elongata, fusiformis (antice et postice attenuata), nitida, nigra; capite rostroque (elongato) dense punctatis, punctis in illo sat magnis sed in hôc gradatim minutioribus, illo inter oculos prominentes foveâ profundâ punctiformi impresso; prothorace elongato, subovali, antice valde constricto, æquali, sat dense sed parum minute punctato; elytris a basi paulatim attenuatis, ad apicem ipsissimum obsolete singulatim subrotundatis, profunde punctatostriatis, interstitiis subconvexis et transversim rugulosis ac minutissime sub-uniseriatim punctulatis; antennis pedibusque paulo picescentioribus.

Long. corp. lin. $3-3 \frac{1}{3}$.

Habitat Ceylon; benigne communicavit Dom. Janson.

$$
\text { Oxydema attenuata, n. sp. }
$$

O. præcedenti valde similis, et forsan ejus varietas geographica; differt corpore paulo minore, subangustiore, subdepressiore, punctis in prothoracis disco antico minori- 
bus ac sensim magis remotis, elytrorumque interstitiis vix perspicue punctulatis.

Long. corp. lin. vix 3.

Habitat ins. Malayenses, a Dom. Wallace ad Dorey in Nov. Guinea detecta. Communicavit Dom. Pascoe.

\section{Oxydema puncticollis, n. sp.}

O. præcedentibus paulo minor ac magis atra; capite rostroque minus nitidis ac densius grossiusque punctatis ; prothorace paulo densius ac multo grossius punctato; elytris apicem versus sensim magis attenuatis, striis minus profundis (sc. sub-obsoletis) sed punctis majoribus, interstitiis magis depressis ac punctulis (minutissimis, vix perspicuis) remotioribus notatis.

Long. corp. lin. $2 \frac{2}{3}$.

Habitat ins. Malayenses, in Batchian a Dom. Wallace capta. Coll. Pascoe.

\section{Genus 93. Notiosomus.}

Wollaston (vide, ante, $p .488$ ).

Notiosomus major, n. sp.

N. elongatus, angustus, fusiformis, nitidiusculus, niger ; capite rostroque (longiusculo) sat profunde et dense punctatis, punctis in illo sat magno sed in hôc gradatim minutioribus, illo inter oculos prominulos foveâ punctiformi impresso; prothorace (elytris paululum angustiore) elongato, subovali, convexiusculo, antice profunde constricto, æquali, profunde et dense punctato ; elytris elongate fusiformibus basi truncatis, convexiusculis, profunde striatopunctatis, interstitiis minutissime (vix perspicue) subuniseriatim punctulatis ; antennis tarsisque paulo picescentioribus, horum $\operatorname{art}^{\circ} .3^{\text {tio }}$ conspicue bilobo. Subtus profunde et sat grosse punctatus.

Long. corp. lin. 3.

Habitat Australiam meridionalem, ad Rockhampton lectus. Communicavit Dom. Pascoe.

\section{Notiosomus australis, n. sp.}

N. elongatus, fusiformis, nitidiusculus, piceo-niger ; capite rostroque profunde punctatis, punctis in illo magnis sed in hôc gradatim minutioribus, illo inter oculos valde prominentes foveâ punctiformi impresso; prothorace(elytris conspicue angustiore) minus elongato, subovato basi truncato, convexiusculo, antice leviter constricto, æquali, pro- 
funde et grosse punctato, lineâ obsoletissimâ in medio sublæviore; elytris fusiformibus basi truncatis, convexiusculis, profunde striato-punctatis, interstitiis transversim subrugulosis ac minutissime (tamen conspicue) sub-uniseriatim punctulatis; antennis pedibusque paulo picescentioribus. Subtus profunde et grosse punctatus.

Long. corp. lin. $2 \frac{2}{3}$.

Habitat Australiam, in collectione Dom. Fry.

\section{Notiosomus congener, n. sp.}

N. præcedenti similis, et forsan ejus status topographicus. Differt solum (ut mihi videtur) capite prothoraceque (et forsan elytrorum striis) subremotius grossiusque punctatis, hôc lineâ centrali læviore distinctius instructo.

Long. corp. lin. $2 \frac{2}{3}$.

Habitat Australiam occidentalem; communicavit Dom. Pascoe.

\section{Genus 94. Aphanocorynes. \\ Wollaston (vide, ante, p. 488). \\ Aphanocorynes depressus, n. sp.}

A. angustus, elongatus, parallelo-fusiformis, depressus, niger; capite rostroque (parallelo) minute sed densissime punctulatis, alutaceis, subopacis, oculis parum prominentibus; prothorace elongato, triangulari-ovato, alutaceo, subopaco, paulo profundius ac paulo minus dense punctulato, antice profunde constricto, postice in medio late et leviter longitudinaliter impresso; elytris parallelo-fusiformibus basi truncatis, tenuiter punctulato-lineatis, interstitiis depressis transversim rugulosis ac minute parceque (tamen conspicue) punctulatis ; antennis tarsisque piceis ; femoribus tibiisque minus picescentibus. Subtus subalutaceus, subopacus, grosse sed vix profunde punctatus.

Long. corp. lin. $2 \frac{2}{3}$.

Habitat Australiam meridionalem, a Dom. Masters ad "King George's Sound" captus. Coll. Pascoe.

\section{Genus 95. Orthotemnus.}

Wollaston (vide, ante, $p$. 489).

Orthotemnus reflexus, n. sp.

O. angustulus, elongatus, parallelus, depressus, nitidus, niger; capite rostroque (parallelo) minute, dense, et leviter punctulatis, oculis magnis prominentibus; prothorace 
elongato, triangulari, basi recte truncato et ibidem elytrorum latitudine, antice leviter constricto, aquali, vix profundius parciusque punctulato; elytris parallelis, utrinque ad apicem ipsissimum singulatim reflexis, basi rectissime truncatis, tenuiter punctato-striatis, interstitiis depressis ac minute parceque (tamen conspicue) sub-uniseriatim punctulatis; antennis pedibusque plus minus picescentibus. Subtus dense, minute et leviter punctulatus.

Long. corp. lin. $2 \frac{1}{2}-3$.

Habitat ins. Malayenses, longe lateque diffusus; in Nov. Guinea, Batchian, Makian, et Ceram a Dom. Wallace deprehensus. Communicavit Dom. Pascoe.

\section{Genus 96. Macrorhyncolus.}

Wollaston, Trans. Ent. Soc. Lond. 33 (1873).

Macrorhyncolus crassitarsis, $\mathrm{n}$. sp.

M. cylindrico-fusiformis, angustus, nitidus, ater; rostro longiusculo, latiusculo, subparallelo sed ad basin paulo contracto, minute et parce punctulato, oculis magnis et valde prominentibus; prothorace elongato, triangularicylindrico, antice valde constricto, paulo profundius (sed parum minute) punctulato; elytris (prothoracis basi vix latioribus) fusiformibus basi truncatis, profunde et grosse striato-punctatis, interstitiis minutissime (vix perspicue) sub-uniseriatim punctulatis; antennis pedibusque breviusculis, crassiusculis, nigro-piceis, illarum capitulo angusto, ferrugineo; tarsis brevibus, crassis. Subtus parce et leviter punctulatus.

Long. corp. lin. $1 \frac{3}{4}$.

ef. Rhyncolus ater, Mots. [nec Linn.], Bull. Mosc. ii. 446 (1866).

Habitat Ceylon, a Dom. Fry benevole communicatus.

(Obs. - Species M. crassiusculum, insularum Japonicarum, aliquo modo simulans; sed minor, angustior, minus parallelus, subconvexior, ac minus profunde sculpturatus, rostro paulo graciliore, oculis minoribus, prothorace angustiore et magis cylindrico, antennis in medio, nec pone medium, ejus insertis, scapo breviore, tarsorumque art. $^{\circ} 3^{\text {tio }}$ magis simplici.)

TRANS. ENT. SOC. 1873.-PART IV. (OCT.) Y Y 


\section{Genus 97. Heterarthrus.}

Wollaston, Trans. Ent. Soc. Lond. 29 (1873).

\section{Heterarthrus pictus, n. sp.}

H. fusiformis, convexus, subnitidus, niger vel piceoniger; capite rostroque minute et parce punctulatis, hôc breviusculo, ad basin evidenter substrangulatim constricto; prothorace elongato, cylindrico-triangulari, antice valde constricto, vix profundius punctulato; elytris fusiformicylindricis, obscure rufo-testaceis, in limbo necnon in plagâ postmediâ suffusâ (per suturam antice versus scutellum angustius currente) nigrescentibus, striato-punctatis (striis versus suturam profundioribus), interstitiis depressis et minutissime parcissimeque uniseriatim punctulatis; antennis clare piceo-ferrugineis, pedibus piceis.

Variat prothorace plus minus, sed præsertim utrinque postice, suffuse pallidiore.

Long. corp. lin. $1 \frac{1}{2}$.

Habitat ins. Japonicas, prope Nagasaki captus. Coll. DD. Pascoe, Lewis, et Janson.

(Obs.-H. Lewisii et pallidipenni, Woll., colore formâque generali simillimus, sed subnitidior, necnon in rostro prothoracisque disco parcius minutiusque punctulatus, punctulis in elytrorum interstitiis subminoribus, prothorace antice profundius constricto, rostro ad basin paululum magis strangulatim contracto, necnon antennis vix omnino in medio, sc. forsan mox pone medium, ejus insertis.)

\section{Genus 98. Conarthrus.}

Wollaston (vide, ante, p. 491).

\section{Conarthrus tarsalis, n. sp.}

C. angustus, elongatus, cylindricus, subnitidus, niger; capite prothoraceque dense et parum minute punctulatis, illo lato subconvexo crasso valde exserto et antice foveâ punctiformi notato, rostro (vix capite angustiore) subdepresso et apicem versus gradatim paulo latiore, hôc elongato, triangulari-cylindrico, antice valde constricto, in disco postico obsoletissime late impresso; elytris parallelis, profunde subcrenulato-striatis, interstitiis subconvexis et conspicue uniseriatim punctulatis; antennis pedibusque elongatis, crassis, illis tarsisque paulo picescentioribus, 
tarsorum art. ${ }^{\circ}$ ult. $^{\mathrm{mo}}$ valde conico (ad basin lato). Subtus minute, leviter, et parum dense punctatus.

Long. corp. lin. $3 \frac{1}{3}$.

Habitat ins. Malayenses, in Makian a Dom. Wallace repertus. Communicavit Dom. Pascoe.

\section{Conarthrus cylindricus, $\mathrm{n}$. $\mathrm{sp}$.}

C. præcedenti similis, sed minor, rostro breviore ac omnino parallelo, fronte minus evidenter foveolatâ, prothorace paulo magis triangulari et subdistinctius punctato necnon in medio lineâ obsoletâ læviore instructo (in disco postico haud, etiam obsolete, impresso), elytris vix minus parallelis, striis sensim minus profundis, antennis pedibusque paulo brevioribus ac vix picescentioribus, tarsorum art. ${ }^{\circ}$ ult. $^{\mathrm{mo}}$ minus incrassato.

Long. corp. lin. $2 \frac{1}{2}$.

Habitat ins. Malayenses, a Dom. Wallace in Batchian lectus. In collectione Dom. Pascoe.

\section{Conarthrus vicinus, $\mathrm{n}$. $\mathrm{sp}$.}

C. cylindrico simillimus, sed vix ejus status geographicus. Differt tamen solum prothorace paulo minus conico, sc. ad latera (pone medium) sensim magis rotundato; elytris vix magis transversim rugulosis, ad basin distinctius marginatis; scutelloque majore et magis horizontali (vix declivi).

Long. corp. lin. $2 \frac{1}{2}$.

Habitat Cochin China, in collectione Dom. Fry.

Genus 99. Eutornus.

Wollaston (vide, ante, $p$. 491).

Eutornus Jansoni, n. sp.

E. elongatus, fusiformis, nitidiusculus, niger sed in elytris (præsertim antice) sensim rufescentior, aut rufoferrugineus; capite rostroque crassiusculis et gradatim versus apicem densius punctulatis, illo antice foveâ profundâ punctiformi notato, hôc lato parallelo breviusculo; prothorace elongato, cylindrico-ovato, antice profunde constricto, profundius argutiusque dense punctato; elytris fusiformi-cylindricis, postice gradatim subattenuatis, striatopunctatis (striis versus suturam profundioribus), interstitiis depressis ac minutissime uniseriatim punctulatis ; an- 
tennis pedibusque crassiusculis, piceis. Subtus vix dense et in medio leviter punctatus.

Long. corp. lin. $2 \frac{2}{3}$.

Habitat Ceylon, sec. coll. E. W. Janson,-cujus in honorem nomen triviale dedi.

\section{Eutornus ferrugineus, n. sp.}

E. elongatus, fusiformis, nitidiusculus, rufo-ferrugineus sed antice et postice plus minus evidenter obscurior; capite rostroque minute punctulatis et plus minus nigrescentioribus (rarius rufo-ferrugineis); prothorace elongato, cylindrico-ovato, antice profunde constricto, vix argutius punctulato; elytris fusiformi-cylindricis, postice gradatim subattenuatis, striato-punctatis (striis versus suturam profundioribus), interstitiis depressis ac minutissime uniseriatim punctulatis, postice sæpius gradatim paulo obscurioribus; antennis pedibusque crassiusculis, fere concoloribus. Subtus parcissime et levissime punctulatus.

Long. corp. lin. 2-2 $\frac{1}{2}$.

Habitat ins. Malayenses,-in Nov. Guinea, Morty, Tondano, Gilolo, et Makian a Dom. Wallace lectus. Communicavit Dom. Pascoe.

(Obs.-E. Jansoni affinis, sed discedens corpore minore et sensim clarius ferrugineo, antice et postice paulo minus obscurato, necnon subtus parcius leviusque punctulato; rostro prothoraceque minutius leviusque punctulatis, foveâ frontali obsoletâ, hôc antice sensim minus profunde constricto; scutello magis horizontali; pedibusque clarioribus.)

\section{Eutornus dubius, n. sp.}

E. elongatus, fusiformis, nitidus, piceo-niger sed in elytris ferrugineus, capite rostroque profunde et parce punctulatis; prothorace elongato, ovato-cylindrico, antice sat profunde constricto, paulo grossius sed parce punctato; elytris subfusiformi-cylindricis basi recte truncatis, striatopunctatis (striis postice levioribus), interstitiis minutissime parcissimeque uniseriatim punctulatis; antennis pedibusque piceo-ferrugineis. Subtus subalutaceus, grosse sed parce punctatus.

Long. corp. lin. $1 \frac{2}{3}$.

Habitat Novam Zealandiam, a Dom. Lawson repertus. Benigne communicavit D. Sharp.

(Obs.-Species ad hoc genus forsan vix omnino pertinens. Ab E. Jansoni et ferrugineo differt corpore mi- 
nore nitidiore et paulo grossius sculpturato, rostro subangustiore, prothorace elytrisque ad basin rectius truncatis, his ad apicem haud singulatim rotundatis, scapo minus curvato, tarsisque subgracilioribus, art. $^{\circ} 3^{\text {tio }}$ magis simplici.)

\section{Genus 100. Coptus. \\ Wollaston (vide, ante, p. 492). \\ Coptus oculatus, n. sp.}

C. angustus, parallelus, subdepressus, nitidus, rufopiceus aut fere piceo-ferrugineus; rostro (brevi, lato, parallelo, arcuato) minute punctulato, oculis maximis, valde prominentibus; prothorace ovali-cylindrico, antice - leviter constricto, æquali, profundius punctato; elytris parallelis, subrufescentioribus, sat profunde punctatostriatis, interstitiis minutissime parcissimeque uniseriatim punctulatis; antennis pedibusque clarioribus. Subtus parce et parum leviter punctatus.

Long corp. lin. $1 \frac{1}{3}$.

Habitat ins. Malayenses, a Dom. Wallace in Sula repertus. In collectione Dom. Pascoe.

Coptus minor, $\mathrm{n} . \mathrm{sp}$.

C. præcedenti similis, et forsan ejus varietas insularis. Differt solum corpore subminore, subpallidiore, necnon rostro prothoraceque subdensius ac sensim minus grosse punctatis.

Long. corp. lin. $1 \frac{1}{4}$.

Habitat Nov. Guinea, ad Dorey et Saylee a Dom. Wallace deprehensus.

\section{Genus 101. PaChyops.}

Wollaston (vide, ante, p. 492).

Pachyops cylindricus, n. sp.

P. angustus, parallelus, convexiusculus, cylindricus, subnitidus, niger aut subpiceo-niger; capite (magno, lato, crasso, convexo, valde exserto) rostroque (brevi, lato) dense sed parum minute punctulatis, fronte obsoletissime et tenuiter canaliculatâ; prothorace (elongato, conicocylindrico) dense et profundius punctato, æquali sed in lineâ mediâ obsoletâ læviore; elytris elongatis, parallelis, grosse punctato-sulcatis, interstitiis convexis, costiformibus ac minutissime uniseriatim punctulatis; antennis pedibus- 
que piceis, illarum capitulo ferrugineo. Subtus sat grosse et dense, sed vix profunde, punctatus.

Long. corp. lin. 2-21 .

Habitat Borneo; ad Sarawak collegit Dom. Wallace. In coll. Dom. Pascoe. .

\section{Genus 102. Pentaminus.}

Wollaston (vide, ante, p. 493).

Pentamimus rhyncoliformis, n. sp.

P. cylindricus, convexus, nitidus, niger ; capite prothoraceque (præsertim hôc) sat profunde punctatis, illo crasso, rostro brevissimo lato crasso, hôc elongato triangulari-cylindrico; elytris (prothorace vix latioribus) cylindricis, profunde et grosse sulcato-punctatis, interstitiis convexiusculis ac remote minuteque uniseriatim punctulatis, vix minus (saltem versus humeros) nigris; antennis pedibusque crassis, piceis, illarum capitulo ferrugineo. Subtus grosse et profunde punctatus.

Long. corp. lin. 2.

Habitat Australiam meridionalem, a Dom. Masters ad "King George's Sound " captus. Communicavit Dom. Pascoe.

\section{Pentamimus suffusus, n. sp.}

P. præcedenti fere similis, sed (ut mihi videtur) vix ejus varietas; differt sculpturâ, præsertim in elytris, paulo minus profundâ et minus grossâ, elytris, præcipue antice, sensim suffuse rufescentioribus, striis minus profundis ac postice vix punctatis (punctis sc. ibidem obsoletis), interstitiis paulo magis convexis, fronte distinctius canaliculatâ.

Long. corp. lin. 2.

Habitat Australiam, a Dom. Fry amice communicatus.

\section{Pentamimus canaliculatus, n. sp.}

P. rhyncoliformi similis, sed minor, rostro paululum minus convexo et antice late canaliculato; prothorace præsertim in medio densius ac subgrossius punctato (nec in lineâ mediâ, etiam obsoletâ, læviore); elytrorum interstitiis paulo minus convexis, punctisque in sulcis sensim inter se magis remotis.

Long. corp. lin. 2.

Habitat in Tasmania; ad describendum communicavit Dom. Pascoe. 


\section{Genus 103. Tetracoptus.}

Wollaston (vide, ante, p. 493).

Tetracoptus reductus, n. sp.

T. cylindricus, convexus, nitidus, niger; capite prothoraceque minutissime et levissime punctulatis, illo crasso, rostro brevissimo lato crasso antice late canaliculato, hôc magno, elongato, triangulari-cylindrico, antice parum distincte constricto; elytris (latitudine prothoracis versus basin) cylindricis, paulo minus nitidis, tenuiter punctatostriatis, interstitiis depressis ac minutissime uniseriatim punctulatis, ad humeros sub-plagiatim rufescentioribus; antennis pedibusque breviusculis, piceis. Subtus alutaceus, subopacus, minute parce et levissime punctulatus.

Long. corp. lin. $1 \frac{1}{3}$.

Habitat ins. Nov. Guinea, ad Dorey a Dom. Wallace detectus. A Dom. Pascoe ad describendum missus.

\section{Genus 104. Xestoderma.}

Wollaston (vide, ante, $p$. 494).

a. Scutellam (prcesertim in ôे) sat magnum, subrotundatum.

Xestoderma Wallacei, n. sp.

X. angustula, cylindrica, convexa, nitidissima, atra ; capite rostroque (brevi) latis, crassis, minutissime punctulatis; prothorace (elongato, cylindrico-ovato, antice leviter constricto) etiam subtilius, sc. subtilissime, punctulato, æquali; elytris cylindricis, leviter striato-punctatis, striis versus suturam profundioribus, interstitiis depressis ac subtilissime parcissimeque punctulatis; antennis pedibusque vix picescentioribus, capitulo ferrugineo. Subtus alutacea, parcissime et levissime punctulata.

Mas, rostro paulo longiore et omnino parallelo ; scutello submajore, aut magis rotundato.

Long. corp. lin. $2 \frac{1}{4}-3$.

Habitat ins. Malayenses, in Ceram et Ternate a Dom. Wallace lecta. Communicavit Dom. Pascoe.

b. Scutellum minus, et breve, transversum.

Xestoderma atra, n. sp.

X. præcedenti paulo minor ac subdistinctius punctulata ; rostro inter antennas late et obsolete impresso; scutello 
minore, breviore, magis transverso; elytrorumque interstitiis convexioribus.

Long. corp. lin. circa 2.

Habitat ins. Malayenses, a Dom. Wallace in Batchian et Morty deprehensa. Coll. Pascoe.

\section{Genus 105. Xestosoma.}

Wollaston (vide, ante, p. 494).

a. Prothorax basi recte truncatus. Scutellum minutum, brevissimum, transversum.

Xestosoma grandicolle, n. sp.

$\mathrm{X}$. crassum, cylindricum, convexum, nitidissimum, atrum ; capite rostroque (brevi) latis, crassis, fere impunctatis, hôc antice in medio profunde et late canaliculato; prothorace (magno, cylindrico-ovato, antice profunde constricto) fere impunctato, æquali; elytris cylindricis, striatopunctatis (striis levibus, sed punctis sat magnis), interstitiis depressis ac fere impunctatis; antennis pedibusque crassis, vix picescentioribus, capitulo magno, subrotundato, nigrescente, dense velutino.

Long. corp. lin. $2 \frac{2}{3}$.

Habitat ins. Malayenses; in Batchian collegit Dom. Wallace. A Dom. Pascoe communicatum.

\section{Xestosoma subopacum, n. sp.}

$\mathrm{X}$. crassum, breviter cylindricum, subconvexum, nigrum, antice subnitidum sed postice subopacum; capite rostroque (brevi) crassiusculis, minute sed distincte et parum dense punctulatis, hôc antice in medio profunde et late canaliculato; prothorace minus elongato, subovali basi truncato, utrinque subæqualiter rotundato, antice profunde constricto, dense, grossius profundiusque punctulato, æquali sed lineâ mediâ obsoletissimâ sublæviore; elytris breviter cylindricis, subopacis, punctato-striatis, interstitiis subtilissime parceque punctulatis; scapo tarsisque piceo-ferrugineis, his gracilibus, capitulo magno, ovali, nigrescente, dense velutino.

Long. corp. lin. 2.

Habitat ins. Malayenses, a Dom. Wallace in Batchian detectum. Coll. Pascoe.

b. Prothorax basi obsolete subsinuatus. Scutellum majus, ac magis rotundatum. (Subg. Xestomorphus, Woll.)

Xestosoma costipenne, n. sp.

X. elongato-crassiusculum, cylindricum, subconvexum, 
subnitidum, nigrum; capite rostroque (brevi) latis, valde incrassatis, distincte et parum dense punctulatis, hôc in medio latissime sed leviter impresso-canaliculato; prothorace (elongato, conico-cylindrico, antice levissime constricto) densissime et profunde punctato, æquali sed in lineâ mediâ tenui obsoletâ sublæviore; elytris elongatis, cylindricis, profunde punctato-sulcatis, interstitiis convexis costiformibus ac minutissime uniseriatim punctulatis; antennis tarsisque piceis.

Long. corp. lin. vix 3.

Habitat ins. Malayenses, a Dom. Wallace (nisi fallor in Sula) detectum. Communicavit Dom. Pascoe.

\section{Genus 106. Lissopsis.}

Wollaston (vide, ante, p. 495).

Lissopsis speculifrons, $\mathrm{n} . \mathrm{sp}$.

L. oblongo-cylindricus, latiusculus, calvus, niger, subnitidus sed in elytris paulo obscurior; capite rostroque dense punctatis, hôc in medio subconcavo et postice transversim politissimo esculpturato; prothorace magno, convexo, subovali, ad latera æqualiter rotundato, paulo profundius sed minus dense punctato; elytris parallelis, breviter cylindricis, profunde et grosse sulcato-punctatis, interstitiis latiusculis ac minutissime uniseriatim punctulatis, postice parce asperatis; pedibus crassiusculis, vix picescentioribus. Subtus subopacus, subalutaceus, parum grosse, sed vix profunde et haud dense, punctatus.

Long. corp. lin. $1 \frac{2}{3}$.

Habitat Nov. Guinea, ad Saylee a Dom. Wallace repertus. A Dom. Pascoe ad describendum missus.

\section{Genus 108. Xenotrupis.}

Wollaston (vide, ante, $p .496$ ).

Xenotrupis fusiformis, $\mathrm{n} . \mathrm{sp}$.

$\mathrm{X}$. fusiformis, convexus, nitidus, ater ; fronte rostroque (longiusculo, postice angustiore) minute sed distincte et sat dense punctulatis; prothorace magno, elongato, triangulari-ovali, antice levissime (saltem in $q$ ) constricto, æquali, subtilissime levissimeque punctulato (etiam minutius quam in rostro); elytris levissime substriato-punctatis, interstitiis latis depressis ac subtilissime parcissimeque punctulatis; antennis pedibusque longiusculis, crassiusculis, vix pices- 
centioribus, illarum capitulo ferrugineo. Subtus alutaceus, subtilissime parcissimeque punctulatus.

Long. corp. lin. $2-2 \frac{1}{2}$.

Habitat ins. Malayenses; in Batchian, necnon ad Dorey in Nov. Guinea, cepit Dom. Wallace. In collectione Dom. Pascoe.

Genus 109. PAChystrlus.

Wollaston (vide, ante, p. 496).

Pachystylus dimidiatus, n. sp.

P. cylindrico-fusiformis, convexus, niger; capite prothoraceque (præsertim in $q$ ) subopacis, et sat grosse (saltem in hôc) punctatis, hôc in lineâ mediâ obsoletâ paulo minus punctato, rostro elongato et (præsertim in $\hat{\delta}$ ) robusto, oculis valde exstantibus; prothorace magno, elongato, antice vix constricto; scutello minuto, punctiformi; elytris (subfusiformibus basi truncatis) nitidioribus et obsoletissime etiam subæneo-tinctis, striato-punctatis, interstitiis convexiusculis ac minutissime (vix perspicue) remoteque subuniseriatim punctulatis; antennis pedibusque elongatis, crassis, piceis. Subtus alutaceus, grosse sed parce et leviter punctatus.

Long. corp. lin. $2 \frac{1}{3}-2 \frac{1}{2}$.

Habitat Americam australem, in Chili degens. Benigne communicavit Dom. Fry.

\section{Genus 111. ERemotes.}

Wollaston, Trans. Ent. Soc. Lond. 2nd Ser. v. 364 (1861). Eremotes gravidicornis, n. sp.

E. cylindricus, calvus, subnitidus, niger ; rostro brevissimo, lato, crasso, tamen parallelo, apice in medio triangulariter impresso, dense et argute punctulato; oculis valde prominentibus ; prothorace elongato, ovato-cylindrico, valde profunde, grosse et dense (in medio sensim remotius) punctato; elytris cylindricis, valde profunde punctatosulcatis, interstitiis angustis costiformibus ac minutissime uniseriatim punctulatis; antennis pedibusque (saltem illis) crassissimis, picescentioribus, capitulo ferrugineo, tarsis clare rufo-piceis.

Long. corp. lin. 2.

Habitat Europam australem?, a Dom. J. Gray ad describendum benigne missus.

(Obs.-Species strangulato, Perris, valde affinis, sed 
differt rostro subargutius punctulato necnon ad apicem in medio triangulariter impresso, prothorace elytrorumque sulcis paulo grossius punctatis, his multo angustioribus ac magis profundis, sed tamen interstitiis latioribus ac obtusius costiformibus, necnon seriebus punctulorum minutorum in alto, nec in fundo, sitis. $\boldsymbol{E}$. strangulatus et gravidicornis a crassicorni, Canariensi, discedunt corpore minore, rostro et prothorace in medio paulo densius punctatis, oculis sensim minus prominentibus, scutello subminore atque elytrorum interstitiis angustioribus et convexioribus, aut magis costatis.)

\section{Genus 112. Rhyncolus.}

\section{Germar, Ins. Spec. Nov. 307 (1824).}

Rhyncolus cylindricollis, n. sp.

R. cylindricus, calvus, subnitidus, niger; rostro brevissimo, lato, crasso, subtriangulari, apice in medio late et obsolete impresso, dense punctulato; oculis valde prominentibus; prothorace elongato, subcylindrico, antice integro (nec constricto), profunde et densissime punctato ; elytris (prothorace sensim latioribus) cylindricis, ad basin undulatim truncatis, valde profunde punctato-sulcatis, interstiis costatis ac minute uniseriatim punctulatis; antennis (in medio rostri insertis) pedibusque crassiusculis, picescentioribus, capitulo ferrugineo; tarsorum art. ${ }^{\circ}{ }^{\text {tio }}$ simplici.

Long. corp. lin. 2.

Habitat Californiam, in collectione Dom. Fry.

(Obs.-Species corpore magno cylindrico et grosse sculpturato, rostroque brevissimo lato cum gen. Eremotes melius congruens; sed tamen funiculi art. ${ }^{\circ} 2^{\mathrm{do}}$ haud valde abbreviato, prothoraceque antice integro nec constricto.)

\section{Rhyncolus californicus, n. sp.}

R. fusiformi-cylindricus, nigro-piceus, subnitidus; rostro brevi, lato, parallelo, dense et profunde punctato, oculis valde prominentibus; prothorace elongato, ovato-triangulari, antice leviter constricto, densissime profundeque punctato, lineâ mediâ læviore ; elytris profunde punctato(aut fere subcrenato-) sulcatis, interstitiis convexis ac minutissime parcissimeque sub-uniseriatim punctulatis; antennis pedibusque crassis, vix rufescentioribus, capitulo 
ferrugineo ; tarsorum art. ${ }^{\circ} 3^{\text {tio }}$ fere simplici. Subtus grosse et profunde punctatus.

Long. corp. lin. 2.

Habitat Californiam, a Dom. Fry communicatus.

(Obs.-R. atro, Europæ, magnitudine, colore, formâque generali simillimus, sed tamen certe distinctus. Differt elytris sensim magis parallelis, cylindricis, interstitiis convexioribus, corpore omnino magis nitido et paulo grossius densiusque sculpturato, rostro magis parallelo, nec etiam obsolete subtriangulari, prothorace in lineâ mediâ læviore, tarsisque subminus incrassatis.

\section{Rhyncolus punctatus, n. sp.}

R. cylindrico-fusiformis, angustulus, rufo-piceus, subnitidus ; rostro brevi, lato, parallelo sed ad basin paululum contracto, dense, profunde et rugose punctato, oculis valde prominentibus; prothorace elongato, ovato-triangulari, antice profunde constricto, profunde et grosse punctato; elytris (ad apicem obscure singulatim subrotundatis) profunde punctato- (aut subcrenato-) striatis, interstitiis convexis et distincte uniseriatim punctulatis; antennis pedibusque crassis, rufescentioribus; tarsorum art. ${ }^{\circ} 3^{\text {tio }}$ minute sed evidenter bilobo. Subtus profunde, dense et grosse punctatus.

Long. corp. lin. $1 \frac{1}{2}$.

Habitat Braziliam; in provinciâ Rio de Janeiro cepit Dom. Fry.

\section{Rhyncolus similis, n. sp.}

R. præcedenti similis, sed subminor, rostro angustiore, prothorace subminore, antice minus constricto, et, una cum elytrorum interstitiis, sensim minus profunde punctato, antennis vix gracilioribus.

Long. corp. lin. $1 \frac{1}{3}$.

Habitat Braziliam; a Dom. Fry in Rio de Janeiro lectus.

\section{Rhyncolus laviusculus, n. sp.}

R. cylindrico-fusiformis, angustulus, clare rufo-piceus (aut fere castaneus), subnitidus; rostro brevi, latiusculo, parallelo, minute et subremote punctulato, oculis prominentibus; prothorace elongato, cylindrico-triangulari, antice leviter constricto, alutaceo parum minute et subremote 
punctulato; elytris (ad apicem singulatim subrotundatis) leviter punctato- (aut subcrenato-) striatis, interstitiis subdepressis ac minutissime uniseriatim punctulatis ; antennis pedibusque crassiusculis, paulo rufescentioribus; tarsorum art. $^{\circ} 3^{\text {tio }}$ minute sed evidenter bilobo. Subtus alutaceus, levissime et parce punctatus.

Long. corp. lin. $1 \frac{2}{3}$. Fry.

Habitat Braziliam; repertus in Rio de Janeiro a Dom.

\section{Rhyncolus fusiformis, n. sp.}

R. cylindrico-fusiformis, angustus, nigro-piceus (interdum obsoletissime etiam subcyaneo-tinctus), subnitidus; rostro brevi, latiusculo, parallelo, sat profunde sed subremote punctato, piceo, oculis prominentibus; prothorace elongato, cylindrico-triangulari, antice leviter constricto, subalutaceo, parum minute sed vix dense punctulato; elytris (ad apicem singulatim subrotundatis). leviter striato-punctatis, interstitiis depressis ac minutissime uniseriatim punctulatis; antennis pedibusque breviusculis, clare rufo-piceis ; tarsorum art. ${ }^{0} 3^{\text {tio }}$ fere simplici. Subtus subalutaceus, sat grosse sed vix profunde punctatus.

Var. $\beta$. elytrorum interstitiis paulo convexioribus ac vix minus distincte uniseriatim punctulatis. (Bahia.)

Long. corp. lin. $1 \frac{1}{4}-1 \frac{1}{3}$.

Habitat Braziliam, in provinciis Rio de Janeiro et Bahia degens. Collegit Dom. Fry.

\section{Rhyncolus protensus, n. sp.}

R. fusiformi-cylindricus, nitidus, niger; rostro longiusculo, minus lato (tamen robusto), parallelo, arcuato-subcylindrico, dense et profunde punctato, postice in medio tenuiter canaliculato, oculis sat prominulis; prothorace longissimo, subconico, antice subintegro, profundius et parum dense punctato; elytris (latitudine prothoracis pone medium) subcylindricis, vix picescentioribus, profunde punctato-striatis, interstitiis minutissime sub-uniseriatim punctulatis; antennis (in medio, aut mox pone medium, rostri insertis) pedibusque breviusculis, crassiusculis, piceis, capitulo ferrugineo; tarsorum art. ${ }^{\circ} 3^{\text {tio }}$ angusto, integerrimo.

Long. corp. lin. 2.

Habitat Californiam; in collectionibus DD. J. Gray et Janson. 


\section{Genus 114. Xenocnema. \\ Wollaston (vide, ante, p. 499). \\ Xenocnema spinipes, n. sp.}

X. parallelo-oblonga, crassa, depressiuscula, subnitida, piceo-ferruginea; rostro breviusculo, robusto, parallelo, densissime rugoseque punctulato, a capite (nitidiore et fere impunctato) lineâ distinctâ diviso; oculis prominentibus; prothorace magno, elongato, subquadrangulari, ad latera subrecto, antice profunde constricto, densissime et argute punctato sed in lineâ mediâ posticâ læviore; elytris subparallelis, basi recte truncatis, postice minute fulvopubescentibus, profunde et grosse punctato- (fere crenato-) sulcatis, interstitiis subdepressis ac obtuse costiformibus, costis in medio lineâ dense punctulatâ divisis (quasi e costis duâbus efformantibus); antennis pedibusque breviusculis fere concoloribus. Subtus sat grosse sed haud valde profunde punctata.

Long. corp. lin. $1 \frac{2}{3}$.

Habitat Novam Zealandiam; in Auckland collegit Dom. Lawson. A Dom. Sharp ad describendum amice communicata.

\section{Genus 117. Tomolips. \\ Wollaston (vide, ante, p. 501).}

§ I. Metasternum breve, et densissime rugoseque punctatum. Pedes, presertim antici, paulo magis incrassati; tibiis anticis ad angulum internum calcari compresso bifido armatis.

Tomolips bicalcaratus, n. sp.

T. subfusiformi-cylindricus, subnitidus, niger; rostro subangustulo-triangulari, dense et argute punctulato, oculis demissis, haud late separatis ; prothorace magno, subovatocylindrico, antice fere integro, valde profunde et grosse punctato (punctis maximis); elytris subfusiformi-cylindricis, ad basin undulatim truncatis, ad humeros acute porrectis, profunde et grosse punctato-sulcatis, interstitiis convexis ac minute parceque uniseriatim punctulatis, postice grosse asperatis, ad apicem ipsissimum minute singulatim rotundatis; antennis pedibusque crassis, picescentioribus. Subtus valde profunde, grosse, et dense rugoso-punctatus.

Long. corp. lin. $2-2 \frac{1}{4}$.

Habitat Mexico; a Dom. Fry benigne communicatus. 
§ II. Metasternum paulo longius, convexius, et minus dense punctatum. Pedes, prasertim antici, paululum minus incrassati; tibiis anticis calcari parvo simplici armatis.

\section{Tomolips asperatus, n. sp.}

T. præcedenti similis, sed paulo minor, subangustior, ac magis cylindricus (elytris sc. evidentius omnino parallelis); rostro paululum breviore et latiore; prothorace elytrisque vix minus grosse sculpturatis, his ad humeros sensim minus acute porrectis, ac ad apicem integris (nec minute divaricatis). Subtus nitidior, et (præsertim in metasterno abdoninisque segmento primo) minus dense ac minus rugose punctatus.

Long. corp. lin. circa 2.

Habitat Mexico; una cum præcedente communicavit Dom. Fry.

\section{Genus 118. Dendroctonomorphus. Wollaston (vide, ante, $p .501$ ). \\ Dendroctonomorphus muricatus, n. sp.}

D. ovato-cylindricus, calvus, nitidus, niger; capite rostroque crassis, illo punctulato, hôc densius punctulato et longitudinaliter striguloso; prothorace magno, ovatocylindrico, multo profundius grossiusque sed minus dense punctato; antice subintegro, utrinque pone medium sinuato; elytris ovato-cylindricis, ad apicem obtuse truncatodesilientibus, profunde punctato-sulcatis, interstitiis obtuse costatis ac minute confusim punctulatis, postice mucronibus magnis asperatis; antennis (brevissimis) ad apicem tarsisque (longissimis, gracilibus) clare piceo-ferrugineis. Subtus parce et grosse, sed leviter, punctatus.

Long. corp. lin. 2-2 $\frac{1}{3}$.

Habitat Ceylon; a Dom. Fry ad describendum missus.

\section{Dendroctonomorphus parallelus, $\mathrm{n}$. sp.}

D. cylindricus, angustulus, (nisi oculo fortissime armato calvus, sed vere) antice et postice necnon subtus minutissime parcissimeque sericatus, subnitidus, niger; capite rostroque crassis, illo punctulato, hôc densius punctulato et longitudinaliter substriguloso; prothorace ovato-cylindrico, profundius grossiusque dense punctato, antice leviter constricto, utrinque pone medium subsinuato; elytris 
parallelis, cylindricis, ad apicem obtuse truncato-desilientibus, punctato-sulcatis, interstitiis convexis ac minutissime uniseriatim punctulatis, postice mucronibus parvis dense asperatis; antennis (brevissimis) ad apicem tarsisque (longissimis, gracilibus) clare piceo-ferrugineis. Subtus parce, grosse, et profunde punctatus.

Long. corp. lin. $1 \frac{3}{4}$.

Habitat Mexico; in collectione Dom. Fry.

\section{Genus 120. Calyciforus.}

Wollaston (vide, ante, p. 502).

Calyciforus excavatus, n. sp.

C. cylindricus, calvus, nitidus, niger; capite rostroque crassis, subalutaceis, illo punctulato, hôc dense longitudinaliter substriguloso; prothorace magno, subovato-cylindrico, profundius grossiusque punctato et utrinque longitudinaliter strigoso, antice subintegro sed in medio transversim impresso, basi marginato, necnon in medio (ante scutellum, magnum) valde profunde arguteque triangulariter exciso; elytris cylindricis sed ad apicem sublatioribus et ibidem obtuse truncato-desilientibus, basi grosse marginatis, latissime et profunde sulcatis (sulcis opacis ac dense transversim strigosis), interstitiis latis costatis nitidis et subgrosse uniseriatim subasperato-punctatis; antennis (brevissimis) pedibusque (robustis) piceis, tarsis (longissimis, gracilibus) clarioribus. Subtus subalutaceus, subopacus, grosse sed leviter punctatus.

Long. corp. lin. $2 \frac{2}{3}-3 \frac{1}{4}$.

Habitat Braziliam, in provinciis $\mathrm{S}^{\text {ta }}$ Catharina et Bahia repertus. Communicaverunt DD. Fry et Janson.

\section{Calyciforus erosus, n. sp.}

C. præcedenti affinis, sed vix (nisi fallor) ejus sexus alter; minor; capite rostroque paulo minus incrassatis, subnitidioribus (sc. haud alutaceis), et minus dense punctatis, hôc sensim angustiore; prothorace paulo angustiore minusque ovato (aut magis cylindrico), grossius punctato (punctis magis longitudinaliter subconfluentibus), postice in medio sub-longius excavato; elytris postice haud sublatioribus, sulcis minus latis, minus opacis ac minus dense transversim strigulosis (sc. strigis magis evidenter regulariter interruptis, quasi punctos transversos efficientibus), punctis in interstitiis subminoribus, interstitiis $1^{\mathrm{mo}}$ et $2^{\mathrm{do}}$ ad 
basin (juxta scutellum) minus incrassato-confluentibus; antennarum capitulo vix subminore.

Long. corp. lin. vix $2 \frac{1}{2}$.

Habitat Braziliam; in provinciâ Rio de Janeiro collegit Dom. Fry.

\section{Genus 121. Eurycorynes.}

\section{Wollaston (vide, ante, p. 503).}

\section{Eurycorynes Jansonianus, n. sp.}

E. cylindricus, calvus, subnitidus, niger; capite rostroque crassis, densissime longitudinaliter subtrianguloso-punctatis ; prothorace subovato-cylindrico, densissime et grossius strigoso-punctato, in medio carinulâ lævi (antice et postice evanescente) instructo ; elytris cylindricis, late et parum profunde sulcatis (sulcis in fundo leviter punctatis), interstitiis latiusculis costatis ac uniseriatim subasperatopunctatis, antice in medio densius subtransversim rugulosis et in parte posticâ minutissime subserratulo-asperatis ; pedibus piceis ; antennis (brevibus) tarsisque (longissimis, gracilibus) piceo-ferrugineis. Subtus subalutaceus, parum grosse sed vix profunde punctatus,-punctis versus apicem decrescentibus.

Long. corp. lin. 2.

Habitat Braziliam, in Rio de Janeiro a Dom. Fry repertus. A provinciâ Minas Geraes communicavit Dom. Janson, cujus in honorem nomen specificum stabilivi.

\section{Genus 122. Stenoscelis.}

\section{Wollaston, Journ. of Ent. i. 141 (1861).}

Stenoscelis crassifrons, $\mathrm{n}$. sp.

S. breviter cylindricus, subnitidus, niger, postice et subtus minute et parce fulvo-pubescens; capite magno, globoso, crassissimo, et, una cum rostro, densissime et sat grosse punctato, hôc brevissimo latissimo crasso; prothorace (ante basin latitudine elytrorum) magno, subcylindrico-ovato, antice constricto, necnon ad latera pone medium subsinuato, grossius et vix minus dense punctato; elytris cylindricis, ad apicem obtuse rotundatis, late et parum profunde sulcato-punctatis, interstitiis convexis subuniseriatim punctulatis et postice parce sed distincte muricato-asperatis, antice versus scutellum transversim 
subplicato-rugosis: antennis tarsisque clare piceo-ferrugineis. Subtus convexus, alutaceus, dense sed haud profunde punctatus.

Long. corp. lin. $1 \frac{2}{3}$.

Habitat Africam australem (Caput Bonæ Spei), in collectione Dom. Fry.

(Obs.-S. hylastoides, Woll., affinis, sed profundius grossiusque sculpturatus, necnon postice et subtus minute sed parce fulvo-pubescens; capite majore, crassiore, sc. globoso, permagno; rostro etiam breviore, latiore, sc. brevissimo ; oculis sensim minus, tamen valde, depressis ; prothorace majore, longiore, postice latiore, antice minus constricto, ad latera paulo minus sinuato ; elytrisque pone basin obsolete transversim impressis.) 


\section{$2 \mathrm{BHL}$ Biodiversity Heritage Library}

Wollaston, Thomas Vernon. 1873. "XVIII. On the Genera of the Cossonidæ." Transactions of the Entomological Society of London 21, 427-652. https://doi.org/10.1111/j.1365-2311.1873.tb00645.x.

View This Item Online: $\underline{\text { https://www.biodiversitylibrary.org/item/51216 }}$

DOI: https://doi.org/10.1111/j.1365-2311.1873.tb00645.x

Permalink: https://www.biodiversitylibrary.org/partpdf/33392

\section{Holding Institution}

Smithsonian Libraries

\section{Sponsored by}

Smithsonian

\section{Copyright \& Reuse}

Copyright Status: Public domain. The BHL considers that this work is no longer under copyright protection.

This document was created from content at the Biodiversity Heritage Library, the world's largest open access digital library for biodiversity literature and archives. Visit BHL at https://www.biodiversitylibrary.org. 